

$$
13797 / \mathrm{A} \quad 2.31
$$




$$
\because 58 \cdot 4 \cdot 8-8 \quad 252434
$$


Digitized by the Internet Archive in 2015

https://archive.org/details/b22018645_0001 





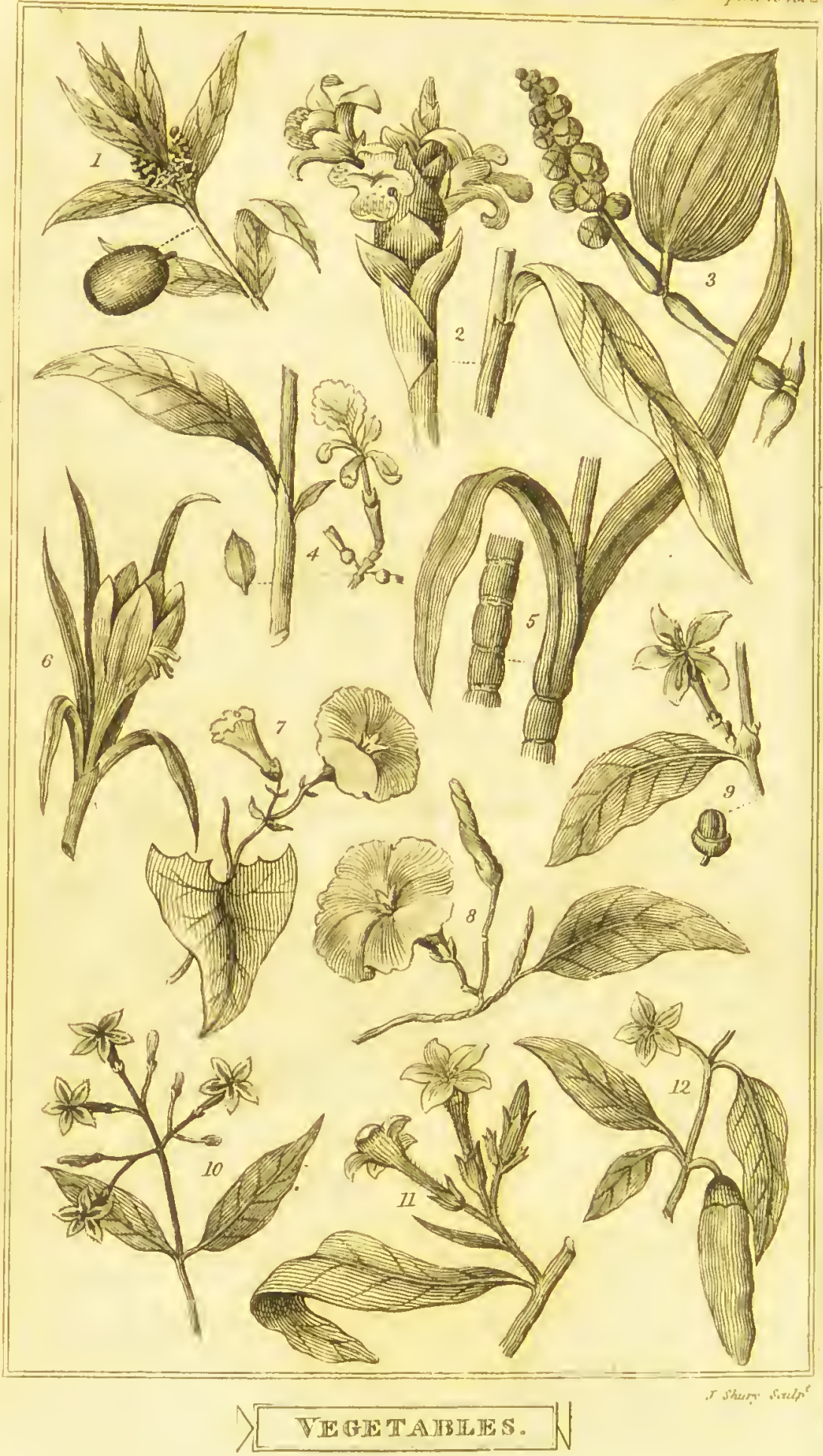




\section{USEFUL KNOWLEDGE:}

OR

A FAAMILIAR ACCOUNT

or the

VARIOUS PRODUCTIONS

OP

海ature,

MNELAL, VEGETABLE, AND ANIMAL,

WHICR AIE CHEFLY EMTLOYED FOR THE USE OP DIAN.

Illustraled with numerous Figures, and intended as a Work both of Instruction and Reference.

BY THE

REv. WILLIAM BINGIEY, AM. FIS.

3.ATE OF PETERHOUSE, CAMBRIDGE, AND AUTIIOR OF

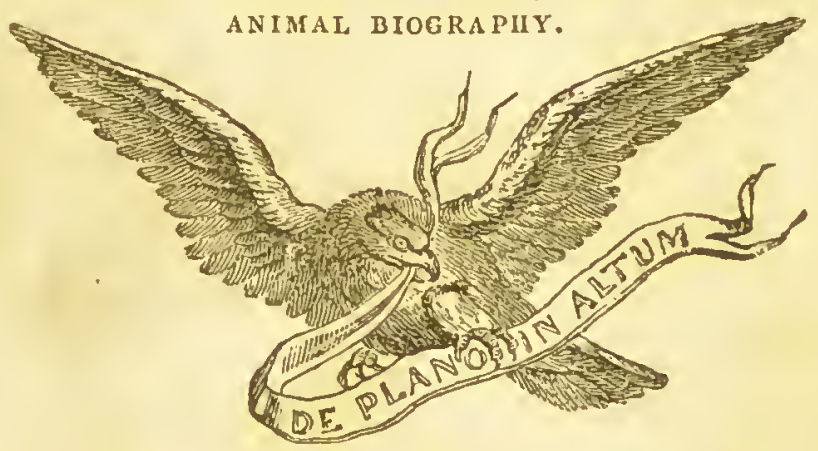

IN THREE VOLUMES.

VOL. II. VEGETABLES.

TITIRD EDITION.

1.ONDON : PRINTED FOR BALDWIN, CRADOCK, AND JOY; HARVEY AND DARTON;

A.TD F. C. AND J. RIUINGTUN.

1821. 
25434

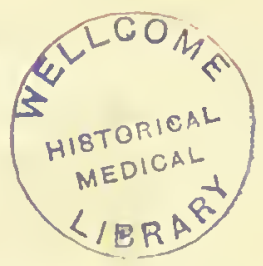

C. Baldwiu. Printr,

New BriclgreStrent. Loudon. 


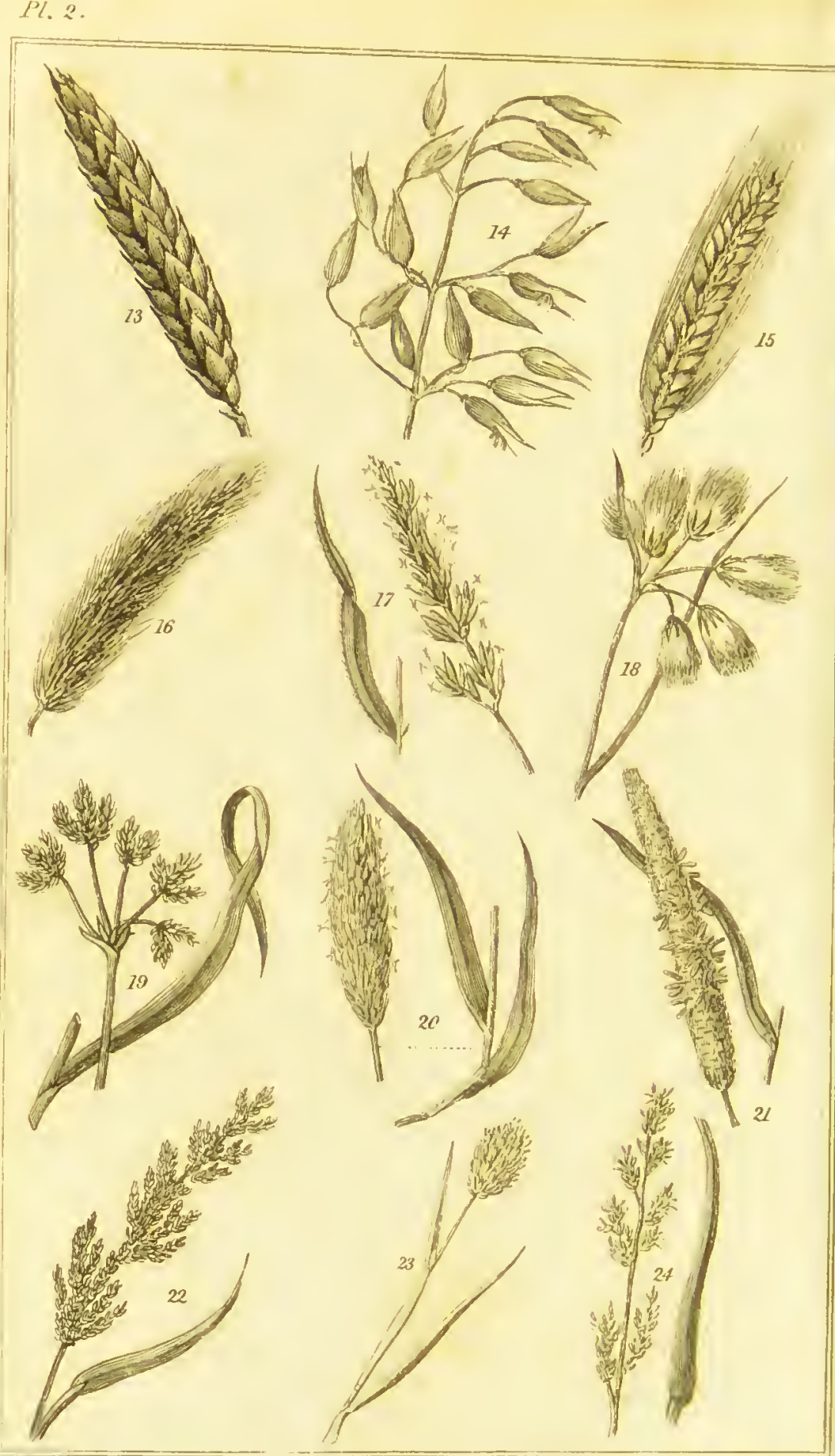

NTESFTABIIAS。 


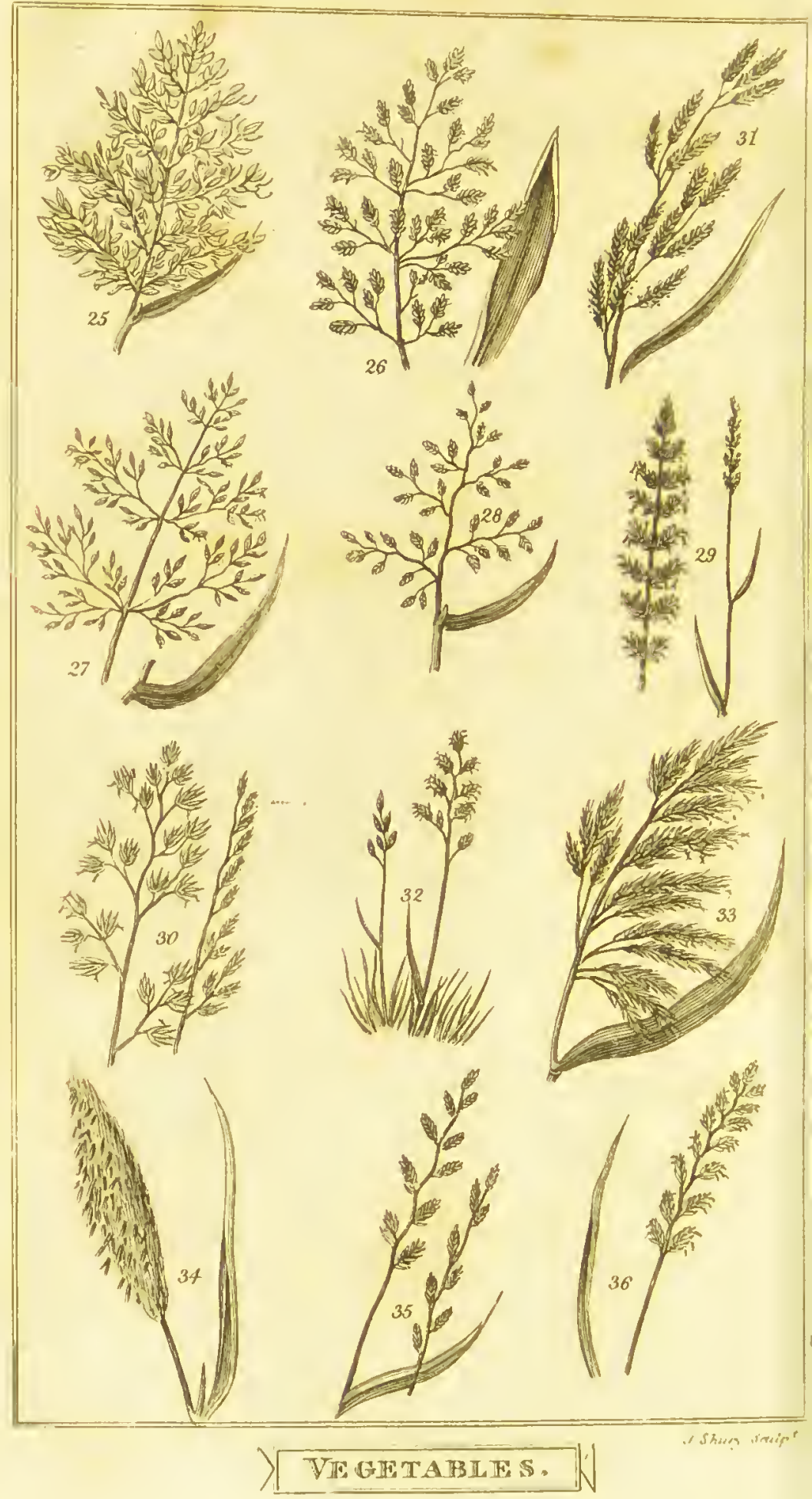




$$
\text { . }
$$




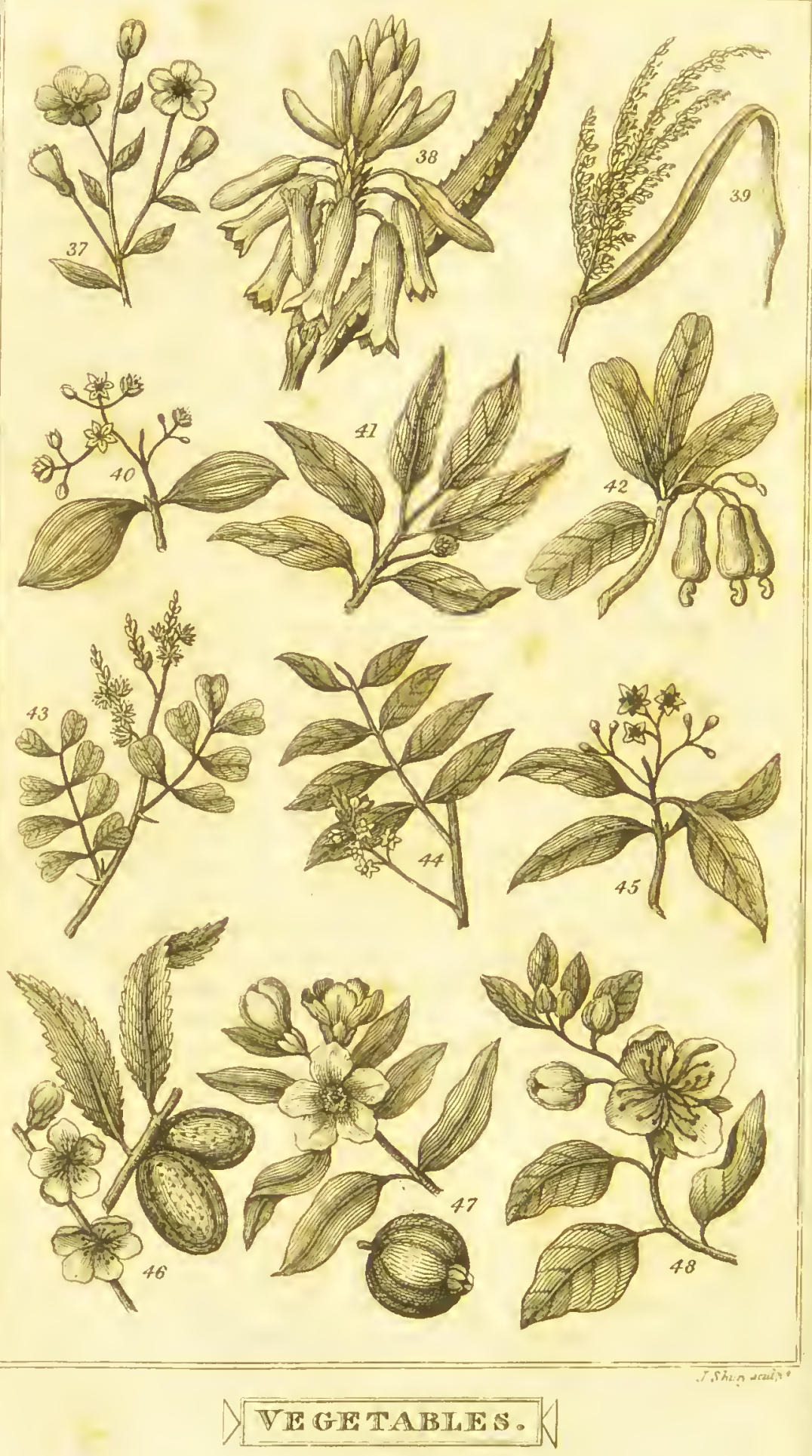




\title{
EXPLANATION OF THE PLATES
}

\author{
OF THE \\ SECOND VOLUME.
}

Fig.

1. Olive.

2. Ginger plant.

3. Black pepper.

4. Cardanom plant.

5. Sugar cane.

6. Saffron.

FRONTISPIECE: PLATEI.

Fig.

7. Scanmony plant.

8. Jalap plant.

9. Coftee-tree.

10. Peruvian bark tree.

11. Tobacco plant.

12. Annual Capsicun.

PLATE II.

Fig.

13. Wheat.

14. Oats.

15. Barley.

16. Rye.

17. Vernal grass.

18. Cotton grass.

19. Bull-rush.

Fig.

20. Meadow fox-tail grass.

21. Cat's tail grass.

22. Fiorin, or Orcheston long grass.

23. Camany grass.

24. Puiple melic grass.

\section{PLATE III.}

Fig.

25. Meadow soft grass.

26. Reed meadow grass.

Fig.

31. Flote fescus grass.

32. Sheep's fescus grass.

2T. Smooth.stalked meadow 33. Common reed. grass.

28. Arnual meadow grass.

23. Crested dog's-tail grass.

30. IIard fescue grass.

34. Sea matweed.

35. Riye, ol Ray grass.

36. Cuuch, or Squitcls grass.

PLATE IV.

Fig.

97. Flax.

98. Socotrine Aloe.

30. Rice.

40. Cinnamon-tree.

41. Camphor-tree.

42. Casliew Nut uree.

Fig.

43. Logwood-tree.

44. Mahogany-tree.

45. All-spice, or Pimento tree.

46. Almond-tree.

17. Pomegranate.

18. Cisper plant. 
Fig.

49. Tea-tree.

50. Clove tree.

51. Tamarind-tree.

52. Cotton plant.

53. Cowhage plant.

54. Chocolate-tree.

Fig.

61. Common elin 62. Broad-leaved elm. 63. Alder.

64. Beech-tree.

65. Sweet chesnut. 66. Horse chesurt.

Fig.

73. Ilorubeam. 74. White poplar. 75. Black poplar. 76. Flowering ash. 77. Lignum-vita tree. 78. Quassia-tree.
PLATE V.

Fig.

55. Orange-tree.

56. Lemon-tree.

57. Bread-firut tree.

58. Maize, or Indian corn.

59. Cucumber.

60. Indian rubler tree.

\section{PLATE VI.}

Fig.

67. Hasel.

68. Oak.

69. Walnut-tree.

70. Sycanore.

71. Plane-tree.

72. Mulberry-tree.

\section{PLATE VII.}

Fig.

70. Ash-tree.

80. Nutmey-tree.

81. Hop plint.

82. Hemp.

83. Fig-tree.

84. Morell. 



\section{USEFUL KNOWLEDGE.}

\section{VEGETABLE PRODUCTIONS.}

\section{INTRODUCTION.}

1. EGETABLES or Plants are natural bodies endowed with organization and life, but destitute of voluntary motion and sense; and BoTANy is that branch of natural science which treats of their structure and functions, the systematical arrangement and denomination of their several kinds, and their peculiar properties and uses.

2. The principal parts of plants are the root; the herb or plant itself; and the fructification, or flower and fruit.

3. As it is the sole object of this introduction to describe, in a concise manner, the Linnæan arrangement of plants, for the purpose of explaining tlie classification adopted in the present volume, the parts of fructification only will be mentioned. These are the calyx, corolla, stamens, pistil, seed-vessel, sceds, and receptacle.

4. The CALYx, or flower cup, is the green part which is situated immediately ben eath the blossom. In some

VOL. II. 
plants this consists of one, in others of several leaves; and it is frequently tubular, as in the polyanthus, and cowslip.

5. The conolla, or blossom, is that coloured part of every flower on which its beauty principally depends. The leaves that compose it are denominated petals. Some flowers, as the convolvolus and campanula, have only a single petal; and others, as the rose and peony, have several petals.

6 . In the centre of the flower there are two kinds of organs on which the fructification and reproduction of the species more particularly depend. These are the stamens, and the pistil. The stamens are slender, thread-like, substances, which surround the pistil. They each consist of a filament or thread, and an anther or summit: the latter contains, when ripe, a fine dust or powder called pollen. This, though, to the naked eye, it appears a fine powder, is so curiously formed, and is so various in different plants, as to be an interesting object for the microscope. Each grain of it is, commonly, a membranous bag, round or angular, rough or smooth, which remains entire till it meets with any moisture; it then bursts and discharges a most subtile vapour.

7. The pistil is a prominent part, immediately in the centre of each flower, which adheres to the fruit, and is destined for the reception of the pollen. Some fluwers have only one pistil; others have two, three, four, \&c. and others more than can be easily counted.

8. At the foot of the pistil is situated the germen. 'This, when grown to maturity, has the name of peri- 
Carp ol SEED-VESSEL, and is that part of the fructification which contains the seeds; whether it be a capsule as in the poppy, a nut as the filbert, a drupe as the plum, a berry as the gooseberry, a pome as the apple, a pod as in the pea, or a cone as of the fir-tree.

9. That part of every vegetable, which, at a certain state of maturity, is separated from it, and contains the rudiments of a new plant, is called the SEED.

10. The RECEPTACLE is the base which connects all the parts of fructification together, and on which they are seated. In some plants this is very conspicuous; and in none more so than the artichoke, of which it forms the eatable part, called the bottom.

11. The Linnæan system of classification of plants is founded upon a supposition that the stamens represent the male, and the pistils the female parts of fructification. The whole vegetable creation has been distributed, by Linnæus, into twenty-four classes. These are divided into orders, which are subdivided into genera or tribes; and these genera are further divided into species or individuals.

12. Of the CLASSEs the discriminating characters are taken from the number, connexion, length, or situation of the stamens. In each of the first twenty classes there are stamens and pistils in the same flower; in the twenty-first class, the stamens and pistils are in distinct flowers on the same plant; in the twenty-second, in distinct flowers on different plants; in the twenty-third, in the same flower and also in distinct flowers; and in the twenty-fourth class they are not at all discernible. Thus: 


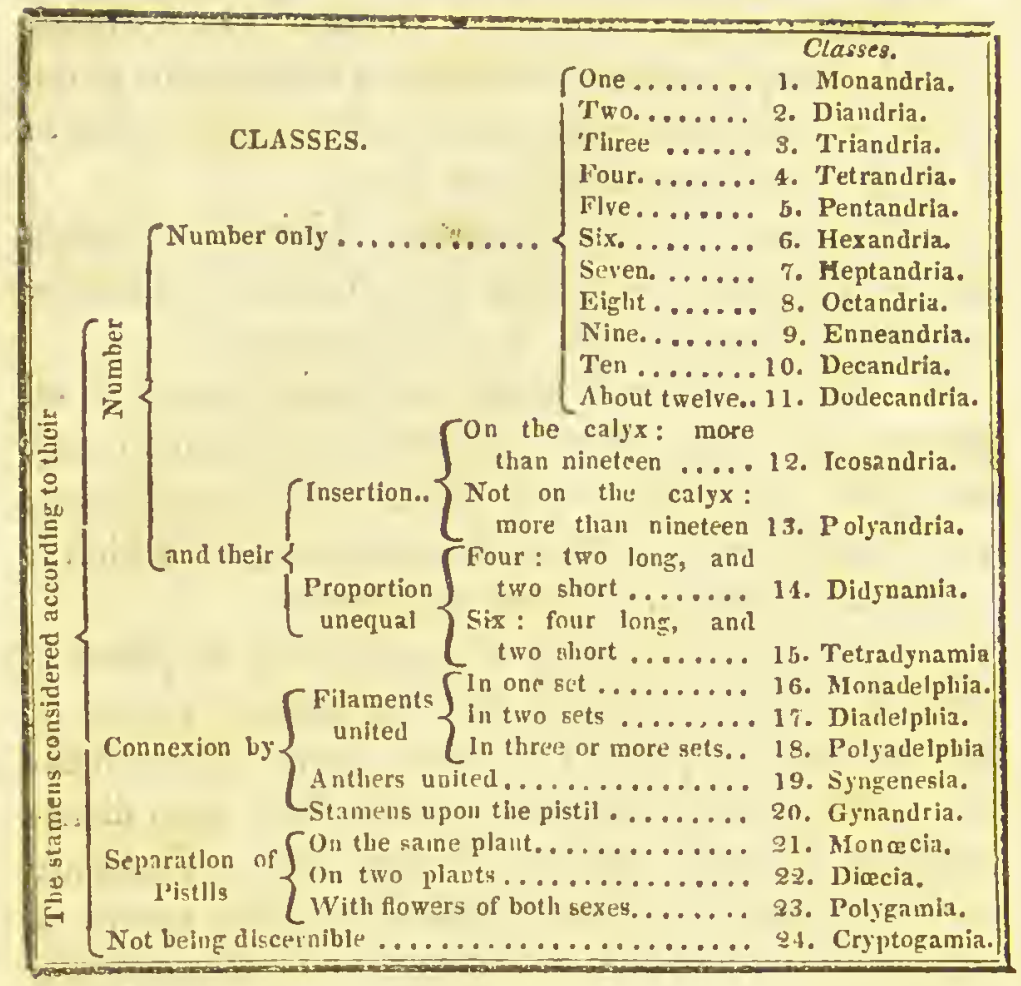

13. The characters of the orDers are most commonly taken from the number of the pistils; but sometimes from circumstances relative to the stamens, pistils, or seed. Those of the first thirteen classes are taken from the number of pistils, thus :

Monogynia ..... 1 pistil. Heptagynia ...... 7 pistils. Digynia.......... 2 pistils. Octagy'nia ......... 8 pistils. Trigynia ....... 3 pistils. Enmeagynia ....... 9 pistils. Tetragynia ..... 4 pistils. Decagynia......... 10 pistils. Pentagynia ...... 5 pistils, Dodecagynia.. about 12 pistils. Hexagynia ..... 6 pistils. Polygynia ..... many pistils. 
The order of the fourteenth class, Didynamia, are taken from the situation of the seeds; and are

Gymnospernia... naked sceds.

Angiospermia ... seeds in a capsule.

The orders of the fifteenth adass, Tetradynamin, are formed from a difference in the shape of the seedressel :

$$
\begin{aligned}
& \text { Siliculosa ........ a broad pod. } \\
& \text { Siliquosa ......... long pod. }
\end{aligned}
$$

In the classes Monadelphia, Diadelphia, Polyadelphia, and Gynandria, the orders are taken from the number of stamens :

Pentandria........5 stamens.

Hexandria, \&c....6 6 stamens, \&c.

In the nineteenth class, Syngenesia, the orders are taken from the structure of the flower:

Polygamia æqualis,-alt the florets alikc.

Polygamia superflua, 一the florets of the centre perfect or united; those of the margin with pistils onty, but all producing perfect seeds.

Polygamia frustranea, - the florets of the centre perfect or united; those of the margin, in general, without either stamins or pistils.

Polygamia necessaria, - the florets of the centre with stamens only; those of the margin with pistits only.

The classes Moncecia and Dicecia take their orders from the number and other peculiarities of the stamens:

Monaudria ........ 1 stamen.

Diandria, \&c.......2 2 stamens, \&c.

Polyand ria .......7 stamens.

Monadelphia .......stamens united into one set

Polyadelphia ....... stamens united into several sets.

Gynandria .........stamens upon the pistit.

In the class Polygramia there are three orders:
Monoocia.
Diœcia.
Triocia. 
The twenty-fourth class, Cryptogamia, has five orders:
1. Ferns.
4. Flags.
2. Mosses.
5. Mushrooms,
3. Liverworts.

The Linnæan system is professedly artificial. Its sole aim (observes Sir J. E. Smith) is to help any one to learn the name and history of an unknown plant in the most easy and certain manner. This is done by first determining its class and order; after which its genus is to be made out, by comparing the parts of fructification with all the generic characters of that order; and, finally, its species, by examining all the specific definitions of the genus. 


\section{CLASS I.-MONANDRIA.}

\section{MONOGYNIA.}

14. GINGER is the dried root of a somewhat reed-lihe plant (A momum zingiber, Pl. 1. Fig. 2.) which grows wild in several parts of Asia; and is much cultivated both in the East and. West Indies.

The flowers of the ginger plant issue from stalks distinct from those which support the leaves, and form a kind of ear or spike, of beautiful colours and very fragrant smell.

The cultivation of ginger is nearly similar to that of potatoes. The lanu is first well cleansed from weeds: it is then dug into trenches similar to those which our gardeners make for celery; and the plants are set in these trenches in March or April. They flower about September; and, in January or February, when the stalks are withered, the roots are in a proper state to be dug up.

These are prepared for use in two ways. When intended for what is called ruhite ginger they are picked, scraped, separately washed, and afterwards dried with great care, by exposure to the sun. For black ginger they are picked, cleansed, immersed in boiling water, and dried. This process is much less laborious and expensive than the last, consequently the price of the article is not so great. By boiling, the ginger loses a portion of its essential oil ; and its black colour is owing to this.

The uses of ginger, both in medicine, and as a spice, are numerous and well known. In the West Indies this root is frequently eaten fresh in salads, and with other 
food: and the roots when dug up young, namely, at the end of three or four months after they have been planted, are preserved in syrup, and exported as a sweet-meat to nearly all parts of the world. The ginger which is brought into this country from the East Indies is much stronger than any we have from Jamaica.

15. CARDAMOMS are the seeds of an East Indian plant (Fig. 4,) which has shining reed-like stalks and spear-shaped glossy leaves. They are brought into Europe in their pods, zulich are small, oblong, triangular, and each dividea' into three cells.

The roots are thick, fleshy, and knotted. The stalks grow from seven to twelve feet high; and the flower's are of irregular shape, and, in colour, are green, pink, and white.

In those woody parts of India where cardamom plants spontaneously grow, the inhabitants form plantations of them by a very simple process. They clear, from particular spots, the greater number of the trees; and, towards the close of the fourth rainy season afterwards, they look for the first crop of cardamoms (raised from the scattered seeds which have lain dormant in the ground), and they are seldom disappointed.

The cardamom harvest usually commences in October, and lasts till December. Women or children pluck the fruit-stalks from the roots, carry them into the houses, and there spread them upon mats to dry. The pods are then separated fiom the stalks by stripping them with the fingers: they undergo some further processes of drying; after which they are packed for exportation, in large chests, which are well pitched at the joints and seams, to prevent them from being injured by moisture. It is estimated that about 15,000 pounds weight of these seeds are annually vended at the East India Company's sales.

Cardamoms have a pleasant aromatic smell; and, when chewed, impart to the mouth a warmth and pun-

* Ammomum cardanomum, Linn.-Eletteric cardamemam, Maton in Linn. Tran. x. p. 254. 
gency which, to most persons, are extremely grateful. The Indians use them, in considerable quantity, in their food; and also mix them with betel (22), and chew them, under a belief that they tend to facilitate digestion. They are sometimes used with us in medicine, but more frequently for the purpose of concealing the nauseous taste of other medicines.

16. TURMERIC is a thick, fleshy, and solid East Indian root, which is usually seen in pieces from half an inch to two inches and upwards in length; has a yellowish and rugged surface, and is of a shining saffron brown colour within.

The flowers of the turmeric plant (Curcuma longa) are white, and form an ear or spike, which issues immediately from the root. The leaves arc spear-shnped, and each eight or nine inclues long.

This root, which has an aromatic smell somewhat resembling that of ginger, is much cultivated in the East Indies, where it is in common use as a seasoning for ragouts and other dishes. It constitutes a principal ingredient in curry porvder; and, under this form, is used, in great quantities both in India and Europe. Some years ago it had considerable repute as a medicine for the removal of jaundice, diseases of the liver, and other complaints : but the chief purpose for which it is now esteemed is its imparting a rich yellow dye to silks, linen, or woollen ; and for heightening and rendering brighter the red colours dyed with cochineal and vermilion. It is much in request hy glovers, for dyeing yellow gloves. Some of the Indian tribes use it in painting their bodies.

17. ARROW ROOT, in the state that we see it, is a kind of starch, manufactured from the root of a plant which is cultivated both in the East and West Indies.

This plant (Maranta arundinacea) is about two feet high, has broad, pointed, and somewhat hairy leanes; small white flowers in clusters, and a nearly globular fruit about the size of a currant.

The arrow-root plant has its name from the Indians B 5 
așing its juice as a remedy for wounds inflicted by poisoned alrows, They likewise consider it efficacious against the stings of those venomous insects with which the countries of nearly all liot climates abound.

The starch or powder of arrow root is obtained by the following process. The roots, when a year old, are dug up, washed, and beaten to a milky pulp, in deep wooden mortars. This pulp is afterwards well washed in clean water, and the fibrous parts, that are found amongst it, are carefully separated and thrown away. It is next passed through a sieve or coarse cloth, and suffered to stand for some time to settle. The water that remains is subsequently drawn off, and the white mass at the bottom is again washed. After this the water is entirely cleared away, and the pulp, when dried in the sun, is an extremely pure kind of starch; which requires only to be reduced to powder to attain the state in which we import it.

There is no European vegetable, if we except the salep or orchis root (219), which yields so large a proportion of nutritive mucilage as this. Consequently, as an article of diet for children, and persons recovering from illness, it has of late years been found extremely valuable. Care, however, should be taken to obtain it genuine, as the high price for which it is sold is frequently the cause of its being adulterated. It is even said that the article usually sold in London under the name of arrow-root, consists chiefly of starch made from potatoes. 


\section{CLASS II.--DIANDRIA.}

\section{MONOGYNIA.}

18. The OLIVE (Olea Europea) is a low eyergreen tree, which, in its gcneral form and appearance, somewhat re. sembles a willow. It is cultivaled in several parts of the continent, and has spear-shaped leaves, and clusters of small white flowers, that arise at the junction of the leaves and branches (Fig. 1.)

The fruit of this tree has the name of olives. These are usually about the size of a damson plum, and each contains a hard, rough stone. When first gathered they have an acrid, bitter, and unpleasant taste ; and it is not until they have been steeped, for several days, in a ley of wood ashes, and then pickled in salt and water, that they are in the state to be introduced at table after dinner, in desserts. Lucca olives, being smaller than any others, have the weakest taste. The larger ones are imported from Spain, and are the strongest; but those most esteemed are the olives of Provence, which are of middle size. If olives be eaten by persons of delicate habits, especially after a solid or heavy dinner, they are considered injurious, on account of the great quantity of oil they contain.

It is to this fiuit that we are indebted for the salad or olive oil, which is so much in use throughout every part of Europe. The preparation of it is as follows :The olives, when sufficiently ripe, are carefully picked, by hand, off the trees, and those that are bad are taken out and thrown aside. After having been left a little while to wither, they are first bruised, and then more completely crushed, by an upright millstone rolling upon an horizontal plane. The paste thus formed is submitted to the operation of the press. The finest oil How first: whien no more is found to flow, the pulp is 
moistened with boiling water, and the mass is again pressed. This done, the remaining oil is drawn from the surface of the water, but it contains some impurities from which it cannot, without difficulty, be cleared. What remains of the pulp is squeezed into lumps or balls, and dried for fuel. If the olives be indiscriminately gathered and leaped together, sound and unsound, without selection, the oil is always bad. The wild trees yield a very small kind of fruit, which furnishes, though in less quantity, a peculiarly excellent oil.

The olive tree has ever' been considered the symbol of peace; and the ancient poets have asserted that $\mathrm{Mi}$ nerva well merited the honour of giving her name to the city of Athens for having planted it in Attica. As a wood, this tree is in considerable request by cabinet makers, from its being beautifully veined, and taking an excellent polish. In some parts of Spain, ormamental boxes are made of the roots of the olive tree.

Olive oil is employed in various branches of culinary and domestic economy. When united with soda, it is manufactured into soap. Il is likewise used in medicine ; is adopted as a softening ingredient in almost all kinds of ointments and plasters, and is supposed to be efficacious as a remedy against the poison of the viper. Persons copiously anointed with oil are said to have escaped the infection of the plague and yellow fever.

\section{TRIGYNIA.}

19. THE COMMON JASMINE (Jasminum officinale) is a well known shrub, with white, salver-shaped flowers, and opposite, winged leaves, the leafteis somewhat pointed; and is a native of Malabar and other parts of the East.

As an ornamental shrub, jasmine has long been cultivated in Europe. It is chiefly trained against walls and trellis-work, and is interesting, not only from the elegance of its foliage, but also from the number of beautiful white flowers with which it is adomed throughout the summer and autumn. Thẹse expale a sweet 
and penetrating odour, particularly after rain, and in the night.

The Italians, by a very simple operation, prepare from the flowers of jarmine a grateful perfume. They soak cotton-wool in some kind of scentless vegetable oil, and then place, in glass vessels, alternate layers of this and of the flowers. After having been lcft in this state some days, the flowers are found to have given the whole of their fragrance to the oil in thic cotton: they are then separated, and the oil is pressed out and removed into small glass bottles for use.

20. BLACK PEPPER is the dried berry of a climbing or trailing plant (Piper nigrum, Fig. 3) wohich grows in the East Indies, and in most of the islands of the Indiun Sea.

Its stem has numerous joints, and throws out roots at every joint. The leaves, which are somewhat egg-shaped, and pointed, are of a browonish colour, and have each seven very strong nerves. The flowers are small and white.

In the cultivation of pepper, it is customary to mark out the grounds into regular squares of about six feet each, which is the usual distance allowed for the plants. And, as these have not sufficient strength to support themselves in an upright growth, they are gencrally placed near a thorny kind of shrub, among the branches of which they creep like ivy. When they havc run to a considerable height, the twigs, on which the berries hang, bend down, and the fruit appears in long slender clusters of from twenty to fifty grains, somewhat resembling, but much more compact, than bunches of currants. The berries are green when young, but change to a bright red colour when ripe. As soon as they begin to redden, they arc in a fit state to be gathered. When gathered, they are sprcad upon mats in the sun, where they are suffered to remain till they becomc dry, black, and shrivelled, as wc see them. In this statc they have the denomination of black pepper.

White pepper is nothing more than the best and soundest of the berries, gathered when they are fully 
ripe, and stripped of their external coat or skin. To effect this they are steeped, for about a week, in salt water, by the end of which time the skins burst. They are then dried in the sun, rubbed between the hands, and winnowed. Thus cleared from their skins they are rendered smaller and more smooth than black pepper.

As the acridity of pepper lies principally in the skin, this kind becomes, of course, much less pungent than the other; but it has one recommendation, that it can be made only of the best and soundest grains, taken at their most perfect state of maturity.

Pepper is an article of considerable traffic betwixt this country and the East Indies. That which is imported from Malabar is considered better than any other. The quantity of pepper vended at the East India Company's sales has, in some years, exceeded six millions of pounds' weight, of which seven or eight hundred thousand pounds have been retained for home consumption.

Both black and white pepper are in daily use, not only as a spice, but also in cookery. When coarsely ground, pepper is eaten with peas, cabbages, cucumbers, and other flatulent and cold vegetables; and occasionally also with fish. It is sometimes employed in medicine as a stinulant.

A singular imposition respecting pepper is occasionally practised in retail shops in London: artificial pepper-corns, both black and white, are mixed and sold with real pepper. 'The detection of this fraudulent mixture, however, is easy. If a handful of the suspected pepper be thrown into water, the artificial corns will fall to powder, or be partially dissolved, while the true pepper-corns will remain whole. The fraudulent grains are said to be made of peas-meal.

21.' LONG PEPPER is the fruit of a slender climbing shrub (Piper longum) which grows in the East Indies.

It is of cylindrical shape, about an inch and half in length, and a quarter of an inch in thickness; and is formed by the 
union of a great number af small roundrd grains. The shrub that produces it has dark green and heurt-shaped leaves, each with seven strong nerves.

A considerable quantity of long pepper is annually imported in this country from Bengal and other parts of the East, for use, both in domestic economy and in medicine.

The inhabitants of India drink water in which long pepper has been infused, and esteem it a valuable remedy for some disorders of the stomach. They also distil an ardent spirit from it; and they pickle this fruit in vinegar, for use at table.

The fruit that is collected for exportation is gathered before it is quite ripe.

22. BETEL is the leaf of a climbing East Indian plant (Piper betel) which belongs to the same trile as pepper; and, in shape and appearance, is not much unlike that of ity, but is more tender, and full of juice.

There is an almost incredible consumption of betel over the whole continent of India. The inhabitants chew it almost incessantly, and in such quantity that their lips become quite red, and their teeth black, a colour greatly preferred by them to the whiteness which Europeans so much affect. They carry it, in little white boxes, about their persons, and present it to each other, by way of compliment and civility, in the same manner as the Europeans do snuff. This is done by women as well as by men; and it would be considered an offence if those to whom it was offered should refuse to accept of, and chew it. The leaves are sometimes used alone, but much more commonly covered with a kind of lime made of sea shells, and wrapped round slices of the areca nut (245). 


\section{CLASS III.TRIANDRIA.}

\section{MONOGYNIA.}

23. SAFFRON is the orange-coloured pistil, or centre part, of a purple species of crocus (Crocus sativus) which flowers in the autumn, and is chiefly distinguished by having the three cxtremities of the pistil so long as to hang out of the flower (Fig. 6.)

In Cambridgeshire there is a town called Saffron Walden, that has its name from the quantity of saffron which is anuually produced in its neighbourhood.

The roots of the saffron crocuses are planted at the distance of about five inches from each other, and tivo inches deep in the ground. As soon as the flowers appear, they are gathered by hand every morning, just before they open; and, as they continue to open in succession for several weeks, the saffron harvest of course continues so long. When the flowers are gathered, they are spread on a table: the upper part of the pistil only is picked out, and the rest of the flower is thrown away. As soon as a sufficient quantity of the pistils have been collected, they are dried in a kind of portable kiln; over this a hair cloth is stretched, and upon it a few sheets of white paper. The saffron is scattered upon these to the thickness of two or three inches, and is then covered with several sheets of paper, over which is laid a coarse blanket five or six times doubled, or a canvas bag filled with staw. As soon as the fire has heated the kiln, a board, on which a weight is put, is placed upon the blanket to press the saffion into a cake. By the end of the first hour, a strong fire being employed, the cake is formed. 'This is then turned, and, for another hour, is subjected to an equal degree of heat. It is then turned a second time, and a more gentle heat is employed, till the cake becomes dry, during which time it is turned every half hour. 
A field of saffron will continue in perfection for three or four years, yielding progressively, during this period, more numerous and larger flowers, as well as an increase of the bulbous roots; after which the offsets may be advantageously transplanted to other situations.

The saffron which is grown in England is considered superior to any that is imported from other countries. The best saffron may be known by the breadth of the blades. It ought not to be of too deep a red or orange colour, and should be fiesh and tough, and have a strong but pleasant aromatic odour. Saffron should not be kept more than twelve months.

Saffion was much used by the ancients as a perfume, but, in this respect, their taste was very different from ours. Not only were the halls, theatres, and courts, through which they wished to diffuse an agreeable smell, strewed with this substance, but it was used by them for a scent, in vinous extracts. From saffron, with the addition of wax, the Greeks, as well as the Romans, prepared scented salves. In our own country it was formerly much used in medicine; having been esteemed an excellent remedy in hysterical and other complaints. When taken in small doses, it tends to exhilarate the spirits; but it ought to be used with great moderation. It is sometimes used by bakers, to colour and flavour different kinds of cakes and biscuits. With water or spirits it gives out a beautiful yellow colour; but this is not useful as a dye, as, on exposure to the air, it soon fades; and no means have hitherto been discovered by which it can be fixed and rendered permanent.

24. ORRIS ROOT is the root of a white flowered kind of iris, called Florentine Iris (Iris Florentina), which is a native of Italy, and is distinguished by having two flowers on each stalk, the petals bearded, and the leaves sword-shaped.

In a dried state this root is well known on account of its grateful odour, which somewhat approaches that of the violet. It is consequently much used in the manu- 
facture of hair-powder, and other articles for which an agreeable scent is required. It is sometimes employed in medicine as a pectoral or expectorant, and sometimes in dropsies. In a recent state the root is extremely acrid; and, when chewed, it excites in the mouth a pungent taste, which continues for several hours; but this acrimony is almost wholly dissipated by drying.

Orris-root is chiefly imported from Leghorn.

25. The YELLOW WATER-FLAG, or COMMON IRIS (Iris pseudacorus) is a very conspicuous plant in most of our marches. It has sword-shaped leaves, and, about the middle of July, bears large and beautiful yellow flowers.

The roots of this plant possess qualities which render then capable of being applied to many useful purposes. Their astringency is such that it is supposed they might be employed with great advantage in the tanning of leather. In the island of Jura, one of the Hebrides, they are used for dyeing a black colour; and the inhabitants of some parts of Scotland adopt them instead of galls in the making of ink. For this purpose they are cut into thin slices, and boiled, or infused in water, till the liquid is deeply tinged with blue. This is poured clear off, and the blade of a knife, or some other piece of iron, is put into it, and rubbed hard with a rough white pebble, by which process, after a little while, the liquor becomes perfectly black.

A slice of the fresh root, if held between the teeth, will, it is said, almost instantly remove the sensibility, and thus alleviate the pain, of tooth-ache. The leaves of this plant are considered poisonous to all cattle except sheep.

26. The PAPYRUS is a sedge-like plant (Cyperus papyrus), which grows in watery places in Egypt, Syria, Sicily, and Madagascar.

It has a three-sided stem, many feet in heisht, which is terminated by a bushy head, consisting of a large and compound cluster of flowers.

From this plant the ancients made their paper; and 
the process of manufacturing it is described by Pliny, the Roman naturalist, to have been very simple. The inner rind of the stem was merely cut into strips, and laid in parallel and transverse rows; and these, on being heavily pressed with weights, adhered together. The substance thus formed, though of rude texture, was capable of being written upon; and there are many manuscripts still extant on paper of this description. The ancients also sometimes employed the sword-shaped leaves of this plant for writing upon. With the former a kind of ink was used; but on the latter the letters were formed by a metallic pointed instrument, called by the Romans a stylus.

But the papyrus plant was not merely useful for writing upon. The inhabitants of the countries where it is found manufacture it, even to this day, into sailcloth, mattresses, ropes, and sometimes even into wearing apparel. When the stems are compactly woven together, and plastered, externally, with a kind of resinous substance, so as to prevent the admission of water, they are made into boats. These, though they resemble great baskets in appearance, are of considerable use to the inhabitants. "The "ark of bulrushes daubed with slime and pitch," in which the infant Moses was placed, is supposed, by the best commentators, to have been a boat made of this plant.

The floral thyrsus which was used to adorn the temples and statues of the gods, was a representation of the tuft of the papyrus.

\section{DIGYNIA.}

27. SUGAR is the concrete or crystallized juice of the sugar cane (Saccharum officinarum, Fig. 5), a plant, much cultivated both in the East and West Indies, wohich has a jointed stem eight or nine feet high, long and flat leaves of greenish yellow colour, and flowers in bunches.

The cultivation of the sugar-cane is pursued to great extent in the islands of the West Indies, where, about 
three centuries ago, it was first introduced from China, or soine other parts of the East, and where it flourishes with great luxuriance, particularly in moist and rich ground.

The season for planting it commences about the beginning of August. This operation is performed by laying the canes in rows, in trenches formed for the purpose. Roots issue from each joint; and, in the course of nine or ten months, the stems which rise from these respective roots, and constitute the sugar crop, attain their perfect state. The saccharine juice is contained in a spongy pith with which the interior of the plant is filled.

When cut down, the leaves are thrown aside as of no use in the manufacture of sugar, and the stems or canes are divided into pieces, each about a yard in length. These are tied together in bundles, and conveyed to the sugar-mill; where they are bruised betwixt three upright wooden rollers covered with iron. The juice, which flows from them, is conducted, by canals, into a large vessel formed for receiving it. The quantity of juice prepared by some of these mills is upwards of ten thousand gallons in a day:

The next operation is called clarifying. For this purpose the juice is conducted, along a wooden gutter lined with lead, to a place called the boiling house, where it is received into copper pans, or caldrons, each placed over a separate fire. A certain proportion of powdered lime is now added to it, for the purpose of taking up any acid which the juice may happen to contain. The heat is then increased until the liquor is nearly in a boiling state. By this process the greatest part of the impurities that were contained in the juice rise to the surface in a scum. The purified liquor is then carefully drawn off, either by a syphon or a cock, leaving the scum at the bottom of the pan.

From these pans it is conveyed, by another gutter, or channel, to the grand copper, or evaporating boiler, where the scum, which rises to the surface, is skimmed 
off as the liquor boils. After undergoing a similar process in smaller boilers, with a further mixture of lime, until it has attained a certain degree of thickness, it is transferred into a large shallow wooden vessel, where, as it cools, it granulates or runs into an imperfect crystallization, by which it is in some degree separated from the molasses or treacle, an impure part of the juice, which is incapable of being crystallized, and which, in large casks, is exported, for various useful purposes, to the different countries of Europe.

From the cooler the sugar is lemoved to the curinghouse. This is a large, airy building, furnished with a capacious cistern, for the reception of the molasses. Over the cistern is an open frame of strong joist-work; upon which are placed several enpty hogsheads, each open at the head, and having a few holes at the bottom, closed by stalks of the plantain tree thrust through them. The mass of saccharine matter is now put into these hogsheads; the molasses are separated from the sugar, by draining, into the cistern, through the spongy stalks of the plantain; and the remainder, thus entirely crystallized, has the name of muscovado or ratu sugar.

The article denominated clayed sugar undergoes a process somewhat different. For the preparation of this, the sugar, when taken from the coolers, is put into conical vessels of earthen-ware, each having, at its bottom, a loole, about half an inch in diameter, which, at the commencement of the process, is stopped with a plug. This plug, after the sugar has become perfectly cool, is removed, and the molasses drain through the hole. When these have ceased to run, the surface of the sugar, in the vessel, is covered with fine clay, to a certain thickness, and water is poured upon the clay. This, oozing through it pervades the whole mass of sugar, redissolves the molasses still remaining in it, with some parts of the sugar itself, carries these off through the hole at the bottom, and renders the 
sugar, that is left, much purer than that which is made the other way.

The further refining of sugar, or forming it into the white conical loaves which are so much used in this country, is the business of the European sugar-bakers. This is done by dissolving the raw sugar in water, boiling the solution in lime water; and then clarifying it with bullock's blood, or the white of eggs, and straining it through woollen bags. After due evaporation it is suffered to cool to a certain degree. It is then poured into conical moulds of unglazed earthen-ware, the summits of which are perforated. Here it concretes into a hard white mass, leaving that part of the syrup, which will not crystallize, to run off through the hole in the point of the cone. The broad end of the cone is then covered with moist clay, the water from which penetrates into the sugar, and displaces and carries off the impurities which, otherwise, would be retained in and discolour it. It is then carefully dried, and receives the name of loaf, or lump sugar.

Sugar-candy is formed by boiling down a solution of sugar till it becomes thick; and then removing it into a very hot room, to crystallize upon sticks or strings, placed across small tubs, or other vessels. It is denominated brown or white sugar-candy, according to the quality of the sugar of which it is made.

Barley sugar is sugar boiled in barley water, but now more frequently in common water, till it is brittle. It is then rolled on a stone anoited with oil of sweet almonds, and formed into twisted sticks. To give it a colour, a small quantity of saffron is sometimes mixed with it.

When sugar was first introduced into this country, it was employed only as a medicine; but it has now become an essential article both of luxury and use. It is the basis of syrups; and is used in cooking, and in confections, preserves, sweetmeats, and liqueurs of every description. Sugar is also sometimes employed in medicine. 
The juice of the sugar-cane is so palatable, and at the same time so nutritive, that, during the sugar harvest, every creature which partakes freely of it, whether man or animal, appears to derive lsealth and vigour from its use. The meagre and sickly negroes exhibit, at this season, a surprising alteration; they now become fat and healthy. The labouring horses, oxen, and mules, being allowed, almost without restraint, to eat of the refuse plants, and of the scummings from the boiling-house, improve now infinitely more than they do at any other season of the year.

$R u m$ is a spirituous liquor distilled from molasses, scummings of the hot cane juice from the boiling house, or law cane liquor from canes expressed for that purpose, lees (or, as it is called in Jamaica, dunder), and water. The dunder answers the purpose of yeast for the fermentation.

Sugar-canes, as large and juicy as those of the West Indies, are cultivated in several parts of Spain, but particularly in the country betwixt Malaga and Gibraltar. They were originally introduced, by the Moors, several centuries ago; and the sugar made from them is of excellent quality. There are sugar mills, in more than twelve different places, on the coast of Grenada, all of which are fully employed: in one village there are four, which cost at least 5,000l. sterling each.

28. OATS are the seeds or grain of an annual plant tion.

The country from zollich they were originally imported is not known.

The principal use of oats in this country is for the feeding of horses. In the northern parts of England, and in Scotland, they are applied also to the nutriment of man. When simply freed from their husks they are called groats o1 grits; and, in this state, are much used in broths, and other kinds of nutriment for sick and in. 
firm persons. More frequently, however, they are ground into oatmeal, which is made into cakes, biscuits, \&c. The husks, infused in water, and allowed to remain till the water becomes somewhat acid, are boiled to a jelly called sowins. A grateful and nutritive kind of jelly, which has the name of flummery, is also made of oatmeal, boiled with water, and flavoured with a little orange-flower water, and sugar.

Oats will thrive in almost any soil, but they are chiefly productive on land that has been newly brokeniup. They are usually sown in February or March, and the harvest commences about August. Several kinds or varieties are cultivated in different parts of England, such as rohite oats, black outs, brown or red oats, Tartarian or reed oats, Friezeland oats, Poland oats, and some others, but, of these, the first are considered the most valuable.

39. WHEAT' is a rell known kind of corn (Triticum hybernum, Fig. 13) which is cultivated in most of the civilized countries of ihe world, and is supposed to have been originally introduced, into Europe, from some part of Asia.

No grain is so valuable to the inhabitants of nearly all climates as this; and, by a wonderful ordination of Proviclence, it is rendered capable of sustaining, without injury, almost the two extremes of heat and cold. Not only does it ripen in Egypt and Barbary, but it ripens equally well in Scotland, Denmark, and Sweden.

It constitutes the chief food of the British nation; and its abundance or scarcity regulates, in a great degree, the welfare and prosperity of the inlabitants. The whole annual consumption of grain, in this island, anıounts to nearly 25,000,000 quarters; and in London alone, to more than $1,162,100$ quarters. Of this by far the greatest pruportion is wheat.

For the cultivation of this important grain the best lands are rich clays and heavy loam; and, although light soils will produce wheat of excellent quality, yet tlie crops on the other soils are by far the most abund- 
ant. The best season for committing the seed to the ground is September, and the earlier in the nonth the better. Some farmers consider it necessary to steep the seed in brine or other pickle before it is used, to prevent it from being devoured by vermin, and render the corn less liable to disease than it would be without this process. In a good season the wheat harvest commences in August, and is finished in the course of the ensuing month. This species of corn is usually cut with instruments called reaping-hooks, but in some parts it is mown with scythes.

'The different kinds or varieties of wheat that are cultivated in this country are too numerous to be particularized.

Wheat is liable to injury, not cnly from the attack of insects, but from several linds of disease, the principal of which are blight, milderw, and smut. In the former the fibres and leaves of the plants are contracted and enfeebled, and the grain is ultimately deprived of sufficient nourishment: by mildew the straw and ear are affected: and by smut the grains, instead of containing their proper substance, become filled with a black or dark brown powder.

Wheat flour consists of four distinct principles, gluten, starch, albumen, and a sweet kind of mucilage. And it is a remarkable circumstance that the gluten, if not similar, has a very near alliance to animal substances.

To enumerate the various ways in which preparations from wheat serve for nutriment would be unnecessary, as they are known to every one.

Starch is a substance frequently prepared from wheat, and is obtained by the following process. The wheat is put into tubs of water, and exposed, for some days, to the heat of the sun, in order to bring on a proper degree of fermentation, the water being clianged twice a day. Having now become sufficiently soft, it is poured into large canvass bags, which are worked or beaten, on a board over an empty vessel, to extract the farinaceous

VOL. II. 
particles. Fresh water is put to it, and after being considerably agitated, it is allowed to subside. As the sediment increases, the water is gradually drained off, and, at length, the starch is formed into small pieces, and dried for use.

During the late war, when the intercourse betwixt France and the West Indian islands was entirely cut off, several attempts were made in that country to obtain sugar from starch. The process was a long and intricate one; and the success with which it was attended was not such as to render it either practically or permanently useful.

Bran is the husk of wheat, separated in grinding. Infusions of bran are, not unfrequently, employed both externally and internally in medicine. They are also sometimes used to cleanse the hands instead of soap. And, in times of scarcity, bran has been advantageously employed in the making of household bread.

Wheat straw, when chopped or cut small, forms a wholesome provender for horses and oxen, especially when mixed with green food. It is also used as litter for liorses, and is employed as thatch for cottages, houses, and barns. When cut into certain lengths, bleached by means of sulphur, and split, it is plaited, and formed into hats and bonnets.

A nutritive substance called Semolina is formed from wheat flour, granulated by a particular process. A patent was granted in the year 1780 to Mr. Jacob Levy, for a method of making it. Previously to this, semolina had been imported from Poland, under the name of Cracow groats. It constitutes a light and. wholesome food for invalids, being considered, in this respect, preferable to sago ; it may also be made into excellent puddings.

Macaroni is a preparation from the finest wheat flour, mixed with eggs, or other glutinous substance. It is chiefly imported from Italy, Sicily, and Germany. Its name implies cut paste, and it is eaten in various ways; on the continent with milk, and with us in soups and 
puddings, or served up in a dish with grated cheese, milk, and other ingredients.

Vermicelli is made by a mixture of flour, cheese, the yolks of eggs, sugar and saffron. This, being reduced to a proper consistency, is formed into long slender pieces or threads, like worms, by being forced, with a piston, through a number of little holes, in the end of a pipe made for the purpose. Vermicelli was first brought from Italy, and it is chiefly used in soups and other culinary preparations.

30. BARLEY is a well known kind of corn (Hordeum distichon, Fig. 15.) which grows wild in the island of Sicily, and some other parts of the south of Europe.

Next to wheat, this is, in Europe, the most valuable of all the species of grain, especially for growth on light and sharp soils. The seed-time for barley usually commences about the end of March or the beginning of April, and sometimes lasts until the first week in June; and, for the produce, four quarters per acre are considered a fair average crop, and eight quarters a very extraordinary one.

Few instances of fecundity in corll are more remarkable than what has been related of two grains of sixROWED BARLEY (Hordeum hexastichon) which were planted in a garden: they produced 113 stalks, nearly all of which yielded ears; and these contained, in the whole, more than 2,500 grains.

The principal use to which barley is applied in this country is for the making of malt, from which beer and ale are brewed. For this purpose it is first steeped in water for three or four days. It is thell taken out, and suffered to lie, until it begins to sprout or germinate. As soon as the germination has approached a certain state its further progress is prevented by drying the barley in a kiln, heated with coke, charcoal, or straw. The grain lias now become mellow and sweet; and, after having been crushed in a kind of mill contrived for the purpose, its saccharine qualities are easily extracted by the boil-

c 2 
ing water, in brewing. The liqune that is thus produced lias the name of rort; and this, after having undergone the process of fermentation, and having re. ceived a bitter flavour by a mixture of hops, becomes ale or beer. Hence has originated the general appellation of malt liquor. What remains of the malt after brewing is called grains. These, in London, are employed for the feeding of horses, cows, and swine.

Besides the use of barley in brewing, there is in some countries, especially in Scotland and Germany, a great consumption of this grain, for broths, soups, and other foud. For this purpose it is freed from its husks and formed into round granules, about the size of small shot, and of a pearly whiteness, which thence have the name of pearl-barley. All except the heart or best part of the grain is thus taken away. The barley, in this state, when boiled, forms a nutritive food; and a decoction of it, properly flavoured with acid, is said to be one of the best beverages than can be adopted in pcute diseases. The making of pearl harley is a German invention. In Scotland the lower classes make it by means of hand-mills; and many persons are satisfied with merely ridding the grain of its husks by stamping it in mortars.

Barley-meal is occasionally made into bread by the poor; and it is likewise used for the fattening of poultry and swine. From barley-straw a yellowish coloured paper has been manufactured; the maling of which was, some years ago, attempted in this country upon a large scale, but without success.

31. RYE (Secale cereale, Fig. 16.) is a kind of grain supposed to have been first introduced into the northern parts of Europe, from the island of Crete.

As bread corn, sometimes alone, hut more commonly mixed with wheat, rye was formerly in great request, particularly in the northern counties of England. This mixture, which is denominated blend-corn, or mastin, is at present partially used, in certain districts, not only 
from motives of economy, but also because the rye is supposed to render the bread more moist and palatable than it would otherwise be. In some parts of the country rye is much used by ginger-bread bakers, for the dark colour of its flour is not perceptible, when mixed with treacle. This species of grain is frequently used for the distillation of spirits.

It has been remarked, in some districts of France, that rye, from bad seasons, or from other causes, has proved noxious and even poisonous. The grains of the corn, thus degenerated, are black on the outside and tolerably white within; and, when dry, are harder and closer than good grain. Bread that is made of rye which contains even a great quantity of this bad corn, is not distinguishable by the taste, from other rye bread; and it seldom produces its ill effects till some time afterit has been eaten. It is then said to occasion gangrenes in the legs and other parts of the body, and dangerous fevers. The poorer people, however, are those chiefly who are subject to these diseases, as many of them have little other substantial food to subsist upon than bread made of this species of corn.

In several parts of England rye is sown either by itself, or mixed with tares to be cut whilst green, for the feeding of sheep, cows, and horses. Rye straw is used by brick-makers, and collar-manufacturers; and is considered an excellent material for the thatching of cottages and barns.

32. GRASSES.-By grasses we are to understand such plants as have a round, jointed, and hollow stem, surrounded at each joint with a single leaf, long, narrow, and pointed: and the fowers of which are a kind- of chaffy husk. According to this definition, wheat, larley, oats, and rye, properly belong to the grasses, although they are known by the peculiar appellation of corn or grain.*

* The grasses are so numerous, and the describing of them in such manner as to be understood by an inexperienced person would be attended with so much difficulty, that it has been 
To the grasses it is that the face of nature is indebted for a great portion of its cheerful appearance, and its beauty. They constitute the general herbage of every country, covering to an immense extent the whoie surface of the ground. They are very various in their kinds, the British species alone being nearly a hundred and twenty in number. To many species of animals their leaves afford an indispensable article of sustenance; and their seed supply food to birds.

\section{SWEET SCENTED VERNAL GRASS} (Anthoxanthum odoratum, Fig. 17).*-This species is usually considered (though it perhaps ought not exclusively to be so) as that to which the hay fields are indebted for their well known and delightful fragrance. When partially dried it is very odorous; and, if chewed in a recent state, its stalks are highly aromatic, tasting not unlike those of fresh lavender. The root has an odour somewhat resembling that of musk. A distilled water, which serves as a vehicle for some perfumes, is occasionally prepared from the leaves and flowers of the vernal grass. The dried flowers are employed in some parts of the Continent for imparting an agreeable flavour to snuff and tobacco.

- The vernal grass is not very productive, and by some farmers it is considered not palatable for cattle. Others, however, esteem it an useful addition in their meadows; and, from its being generally found in great abundance on such pastures as sheep are fond of, and afford exceljent mutton, it is at least thought to be a good grass for them.

considered more advantageous to the reader, to admit, in this place, only some of the most important kinds; and merely to speak of their uses, referring to the figures for their further illustration.

* This grass has only two stamens, and consequently belongs to the class Diandria, but it is placed here for the salse of general uniformity. 
34. COTTON GRASS (Eriophorum angustifolium, Fig. 18). - The seeds of this grass are encompassed with long cottony, or wool-like hairs; and so abundant are the plants in many tracts of marshy land, particularly in the northern parts of England, that the ground appears almost as if covered with snow.

Poor people sometimes stuff their pillows with the down of the cotton grass; but there is a prevailing opinion that it is not wholesome to sleep on. This down is probably too brittle to be manufactured by itself into thread, yet, in combination either with wool or cotton, it may be spun into a strong and uniform yarn, from which gloves, stockings, and cloth, in small quantity, have been made. Its brittleness has been much corrected by a simple chemical process. Wicks for candles have sometimes been made of it.

35. BULL-RUSH (Scirpus lacustris, Fig. 19).-Of the stems of this plant the rush bottoms of chairs are made. Being of soft and pliant texture, totally destitute of roughness, the bull-rush is also sometimes used. for the stuffing of pack-saddles, making of mats, and thatching of cottages.

36. MEADOW FOX-TAIL GRASS (Aiopecumus pratensis, Fig. 20) is a very common but valuable kind, which grows freely in moist and fertile pastures and meadows. It possesses, in a superior degree to any other grass, the three great requisites of quantity, quality, and early growth. The best hay which is brought to London is said to be from meadows where this grass abounds; and, in many parts adjacent to the metropolis, it is extremely abundant.

37. TIMOTHY GRASS, or NIEADOW CAT'STAIL (Phleum pratense, Fig. 21), is a grass much cultivated in several parts of North America, and particularly in wet, loamy grounds, where, though coarse and hard, it is found extiemely productive and useful. Such 
has been the celebrity of timothy grass, that a gentleman (William Strickland, Esq.) was requested by the Board of Agriculture to make inquiries concerning it; and, from his remarks, it appears that this grass is the chief support of cattle wherever the meadows of it abound. He saw extraordinary crops of Timothy grass growing, as thickly as it could stand upon the ground, three or four feet high, and, in some instances, as coarse as wheat straw. It is cut before it arrives at maturity; and horses are said to prefer the hay that is made of it to every other kind, and to thrive peculiarly well upon it.

Though a native and very common grass in our own country, it is doubtful whether our climate be sufficiently warm to bring it to the same perfection in which it is found in America. It has, however, been cultivated, in England, with considerable success ; and, when used for green food, for which it is particularly calculated, it may be cut two or three times in one season; but, when intended for hay, it should be cut at least a week before it flowers.

\section{FIORIN, or ORCHESTON LONG GRASS} (Agrostis stolonifera, Fig.22), is known as a troublesome weed in moist meadows and pastures, and also in coldand stiff arable land, by name of Blacle Squitch or Bentgrass. It grows with such luxuriance, lying upon the ground, and taking root at the different joints, that the stems are somttimes several feet in length; and, when cultivated as a crop, it has been known to produce, at two cuttings, betwixt seven and eight tors per acre. This grass was first brought into notice as a grass for hay, by a small tract of meadow ground, in which it was cultivated several years ago, at a village called Orcheston, in Wiltshire. Horses, sheep, and cattle are said to be extremely partial to it, and to prefer the hay which is made from it to any other. To be in perfection, it requires a moist climate, or a wet soil; and it will grow on cold clays, that are unfitted for other grasses. 
In Ireland it is called fiorin grass, and, under this appellation, it was first introduced to the public notice in that country, in the year 1810, by the Rev. Dr. Richardson, of Clonfecle, in the county of Antrim.

39. The MEADOW SOFT GRASS, or YORKSHIRE WHITE GRASS (Holcus lanatus, Fig. 25), though it vegetates late in the season, produces an abundant crop, and flourishes well in any moist situation. Both its foliage and flowers are soft and woolly. It is chiefly calculated for the feeding of sheep, and has answered extremely well, when close fed. The hay that is made from it is said to be very injurious to horses, and it is not much relished by cattle.

40. CANARY GRASS (Phalaris Canariensis, Fig. 23). This grass grows wild in Worcestershire, and some other parts of England. It is, however, often cultivated for the sake of its seeds, which are extensively used as food for small birds.

\subsection{PURPLE MELIC GRASS (Melica cerulea,} Fig. 24) is found in great luxuriance on the turf moors, near Glastonbury, in Somersetshire. The people of that neighbourhood make of its stalks a neat kind of besoths; which are used as a cheap and tolerably good substitute for hail brooms. This grass occurs in the most barren sandy, and boggy situations; but, more especially, about pools upon mountainous heaths.

42. REED MEADOW GRASS (Poa aquatica, Fig. 26) is one of the most useful of the British grasses particularly if grown in wet meadows, or upon the: banks of rivers or brooks. In the fenny lands of Cam-. bridgeshire and Lincolnshire it not only affords a rich pasturage for cattle in summer, but forms also the chief part of their winter sustenance. In situations favourable to its growth it sometimes attains the height of five or six feet. When cut for hay, it is first dried, then bound 
up into sheaves, and formed into ricks, in which it undergoes a slight fermentation that much improves it. Cows and sheep are both partial to this grass. As hay, it is a valuable food for cattle, and particularly for milch cows.

\section{SMOOTH-STALKED MEADOW GRASS} (Poa pratensis, Fig. 27) is a favourite grass for cattle; and flourishes even on the driest soils, growing wild in meadows, on dry banks, and even on walls. In rich meadows of Somersetshire it forms a considerable part of the herbage; and, in such as have been flooded during the winter, it flourishes with such luxuriance as nearly to exclude every other grass. Notwithstanding this, it possesses the valuable property of resisting excessive drought, and is frequently green in high gravelly pastures, after almost every other grass has been withered. It flowers early, and makes an extremely valuable hay.

44. ANNUAL MEADOW GRASS (Poa anmu, Fig. 28.)-No grass is more common than this, and none makes a finer turf. 'It occurs in almost every situation, by the sides of roads, on open and extensive commons; and in many parts of England there are whole meadows of it, without any mixture of other grasses. In those districts of Suffolk which produce the best butter, the annual meadow grass is found in great abundance.

It is a remarkable circumstance respecting this grass, that it does not suffer injury, but that, on the contrary, it is improved. by persons frequently walking over it. Mr. Stillingfleet states that, on the hill near Malvern, in Worcestershire, a walk which had been made for the convenience of the water drinkers, was, in less than a year, nearly covered with it, though no plant of it could be found about any part of the hill. This was attributed, in a great measure, to the constant treading upon it, by persons passing to and from the well. 
45: CRESTED DOG'S-TAIL GRASS (Cynosurus cristatus, Fig. 29) is extremely common in meadows and pastures, and constitutes a principal part of the turf, on high gravelly or chalky soils, in parks, lawns, and sheep-walks : and, from the close and thick turf which it makes, it affords good nourishment to cattle and deer. Parks that are famous for excellent venison contain a great proportion of this grass. In the summer time its seeds afford sustenance to pigeons and small birds.

46. SHEEP'S FESCUE GRASS (Festuca ovina, Fig. 32) has great celebrity as food for horses and cattle, and, in particular, for sheep, which are said to prefer it to all other grasses, and to become fat upon it sooner than upon any other. 'Though of short growth, its leaves are numerous and succulent. The Tartars are said generally to fix their habitations, during the summer, in places where there is the greatest plenty of this grass, from its yielding an abundant supply of excellent food for their cattle. And it has been remarked that the sepulchral monuments of the ancient Tartars are chiefly observed in situations where Sheep's Fescue Grass abounds; this has been considered a test of the great value which that people set upon it.

47. HARD FESCUE GRASS (Festuca diuruscula, Fig. 90) is common in pastures, meadows, and waste grounds. It springs early, affords excellent food for all kinds of cattle; and, in good ground, yields a plentiful crop.

48. FLOTE FESCUE GRASS (Festuca Auitans, Fig. 31). - This plant, which grows almost exclusively in wet ditches, and in ponds, is so favourite a food of horses and swine, that they will sometimes even endanger their lives to obtain it. A farmer, who resided some years ago at Ruscomb, in Berkshire, assured Mr. Stillingfleet that he had known a field of four acres 
(which was nearly always covered with water) afford sufficient nutriment to maintain five farm horses, in good condition, from April to the end of harvest, without any other food; and that it yielded even more than they could eat. The Cottenham and Chedder cheeses are said, in a great measure, to derive their celebrity from the cows feeding on this grass.

Its seeds are small, and are remarkable for their sweet flavour and nutritious qualities. They are annually collected in Poland, and are exported thence, into Germany, and other parts of the continent, under the name of manna seeds. These are used in soups, gruel, and puddings, even by persons of the first rank and consequence. When ground into flour, they are convertible into bread, which is little inferior to that made of wheat. The bran of these seeds is stated by Linnæus to be useful as a medicine for horses that are troubled with worms. Geese are fond of the seeds, and well know where to find them. It is remarkable that these seeds have hitherto been entirely neglected in England; though without difficulty they might be obtained in sufficient quantity to prove beneficial.

49. The COMMON REED (Arundo phragmites, Fig. 33) grows in ditches, ponds, and by the sides of rivers, attaining the height of six or seven feet, and flowering about the month of July.

Reeds are frequently made into screens or fences for gardens, and they are considered particularly eligible for sheltering tender plants from injury by cold, or blighting winds. They likewise make excellent weavers' combs; and, when nailed across a frame of wood-work, are frequently employed as a foundation for plaster floors. They are sometimes made into chair bottoms; and into thatch for cottages and out-building's.

From the flowers of the reed the country people of Sweden extract a green dye, which they occasionally use for woollen cloth; and we are informed that, from 
the dried roots, a flour may be made, which is capable of being converted into a wholesome and nutritive bread.

50. SEA MATWEED (Arundo arenaria, Fig. 34) is an useful and common plant on most of our sandy sea shores. Its cultivation has, at various times, been much encouraged, and even acts of parliament have been passed for its preservation, in consequence of its spreading roots giving stability to the loose, blowing sand, and thus raising a bulwark against the encroachments of the waves. The Dutch are said to have availed themselves of the advantage of these plants in securing and rendering firm several parts of their coasts, which would otherwise have suffered much injury.

At Newborough, a town on the south coast of the island of Anglesea, the inhabitants manufacture this plant into mats and ropes; and the Danes employ the fibrous roots for making whisk brushes.

The common people of Iceland collect the seeds of the sea matweed for making bread.

51. RYE GRASS, or RAY GRASS (Lolium perenne, Fig. 35), has, of late years, been cultivated in some countries, to considerable extent, as fodder for cattle. Its agricultural merits were first discovered in Norfolk, and, thellce, the seeds have been distributed througl the greater part of the kingdom; those who purcliased then little suspecting that the plant was a weed in their own fields. In dry pastures, and by road sides, this kind of grass is extrenely common.

When sown in high or sandy lands, either alone or mixed with clover, it yields an earlier crop than most other grasses; and thus affords food at a season when it is sometimes difficult otherwise to be obtained. The ray-grass that grows wild is stated to be much superior to that which is obtained by cultivation; and we are informed that, if sown in a rich and fertile soil, it will dwindle in a few years to a poor and insignificans grass. 
52. COUCH, or SQUITCH GRASS (Triticum repens, Fig. 36), is, in general, considered a troublesome and pernicious weed. The roots strike so deeply into the ground, and extend so widely, that the eradicating of them is frequently attended with difficulty. As the plant lies upon the ground it strikes out fibres from every joint; and so luxuriant is it sometimes seen, that a single joint, when transplanted, has, in the course of twelve months, covered a square jard of land.

The roots of couch grass are collected in large quantities at Naples, and sold in the market as food for horses. They have a sweetish taste, somewhat resembling that of liquorice; and, in times of scarcity, when dried and ground into meal, they have been converted into bread. A decoction of the roots is sometimes used in medicine.

\section{CLASS IV.-TETRANDRIA.}

\section{MONOGYNIA.}

53. TEASEL (Dipsacus fullonum) is a plant, with a somewhat egg-shaped head of flowers, and hard reflected scales, which is cultivated in several parts of England, to be used in the carding of woollen cloth.

The Fuller's Teasel is distinguished from other plants of the same tribe by having its leaves connected at the lase, the flowcr. scales hooked, and the general calyx reflected or bent back.

The seeds of this plant are usually sown in strong, rich land, about the commencement of spring. Thie flowers appear in July, and the blossoms begin to decay in the following month. Shortly after this the heads are cut off, and exposed daily to the sun until they are perfectly dried. 
In the clothing counties of England the fuller's teasel is an article of considerable inportance. The crooked scales accompanying the flowers are so hard and rough that the heads are employed for raising the knap of woollen cloths. For this purpose they are either set into flat boards like cards, or are fixed round the circumference of a large and broad wheel. The former are used with the hand; and the latter is turned round whilst the cloth is held against it.

54. MADDER (Rubia tinctorum) is a rough, trailing plant, that grows wild in several parts of the South of Europe, and is much cultivated in England and Holland on account of its roots, which are used by dyers and calicoprinters.

The land best adapted for the cultivation of madder is a soft, sandy loam. When the roots have attained sufficient growth, they are taken up, carefully peeled, and dried in an airy shed. After this they are conveyed to a kiln, where they undergo a lind of management somewhat similar to that adopted in the drying of hops.(260). The next process is to pulverize them, which is done by pounding or grinding; a secret that was long exclusively possessed by the Dutch.

Madder is extensively used in dyeing, not only on account of its yielding a fine red colour, but also as forming a first tint for several other shades. The madder used for dyeing cottons in the East Indies, is, in some respects, different from that cultivated in Europe. And, in the neighbourhood of Smyrna, and in the island of Cyprus, a kind of madder is grown which affords a peculiarly bright and beautiful colour.

This root is sometimes employed in medicine, in obstructions of the bowels, rickets, and a few other complaints. It tinges water a dull red colour, and spirit of wine a deep bright red. When eaten by animals, it stains even their most solid bones.

Cows are remarkably fond of the madder plant; and 
when they freely eat of it their milk becomes red, yet the cream which it affords makes a yellow butter.

55. SANDAL WOOD, or YELLOW SAUNDERS, is a ycllowish, odoriferous wood, which is imported from the East Indies in logs or short picces, chiefly as a perfume, or for the manufacture of ornamental articles.

The tree that produces it (Santalum album) grows principally on the coast of Malabar, and in the island of Timor. It has somewhat the appearance of a large myrtle, with sliff branches, and smooth, shining, spcar-shaped leavcs, each about two inches long. The finwers grow in clusters, small and red, and are succeeded by berries about the size of peas.

When the sandal wood trees are cut down they are stripped of their bark; after which the wood is usually chopped into billets or small pieces, and buried in a dry place for about two months. During this time the ants eat the outer part of it, without penetrating to the heart, which is the sandal. The billets are then taken up, smoothed, and sorted; and the deeper the colour the higher is found the perfume.

In China this elegant wood, when cut into large planks, is sometimes made into coffins for the principal persons; and such coffins are said to resist the effects of air and moisture for many years. The Chinese also reduce the wood to powder, and, with the addition of water, convert it into a paste, which they apply to their bodies, their furniture, and about their louses, as a perfume. The powder of sandal wood is likewise employed as an incense in their idolatrous temples. Hence it is that a consideraible trade in this wood exists between the East Indies and China.

Besides the logs, the chips and cuttings of the roots of sandal wood are an article of commerce. From these chips, and from the waste wood, an odoriferous oil is sometimes prepared, which is considered nearly equal in fragrance to oil of roses.

Sandal wood is at present seldon used in medicine : though, from its powerful qualities, it might probably bo applied to many medicinal purposes with success. 
It has a bitterish aromatic taste, accompanied by a degree of pungency which is by no means unpleasant.

\section{TETRAGYNIA.}

56. HOLLY (Ilex aquifolium) is a small evcrgrecn trec, with shining, irregular, and spinous lcaves, and white flowers which grow in chusters round lic brunches, and are succeeded by small red berries.

In those parts of the countiy where hollies are very abundant they afford a cheerfulness to the scenery in winter which is extremely pleasing. It is on this account principally that they are planted in gardens and shrubberies. The baŕbarous taste of our ancestors was such that they frequently clipped them into the shape of birds, quadrupeds, and other fantastic representations of nature.

As a fence, holly is eminently serviceable. When formed into hedges, it admits of being cropped, and retains its verdure and beauty, without injury, even through the severest winters. Its growth is slow, and its duration longer than that of most other trees. The roood, which is hard and close grained, is much used in veneering, and is frequently stained black, to imitate ebony. It is likewise advantageously used in making handles for knives, cogs for mill-wheels, and other articles. The leaves in winter afford a grateful food to sheep and deer; and the berries yield a subsistence, during this inclement season, to the feathered tribes. In some places, particularly in the island of Corsica, the inhabitants employ the seeds of holly for making a beverage somewhat similar, but much inferior, to coffee.

The bark of the holly is smooth, and replete with a strong mucilaginous substance, from which the article called birl-lime is made. For this purpose it is boiled ten or twelve hours; and, when the green rind is separated, it is covered up in a moist place, to stand for a fortnight. It is afterwards reduced to a tough paste, and washed in a running stream until no impurities are 
left. The next part of the process is to suffer it to ferment for four or five days; after which it is mixed, over the fire, with a third part of nut-oil (24.1), or sume other vily fluid, and is thus rendered fit for use.

Bird-lime has a remarkably adhesive quality, particularly to feathers and other dry substances. It is, on this account, employed for the smearing of twigs to ensnare birds. In its elasticity and inflammable nature it has much resemblance to Indian rubber; and, if any means could be adopted to harden it, there is little doubi but it might be substituted for that article.

Holly deserves to be much more extensively cultivated than it is. Some years ago a person who purchased a holly wood in Yorkshire, sold the bird-lime prepared from the bark to a Dutch merchant, for nearly the whole sum of his original purchase.

Among the ancient Romans it was customary to send branches of holly, to their friends, with new years' gifts, as emblematical of good wishes. We decorate our houses and churches with it at Christmas, to give, as it has been observed, an air of spring in the depth of winter.

\section{CLASS V.-PENTANDRIA.}

\section{MONOGYNIA.}

57. ALKANET is a dyeing drug, the bark of a root which produces a rough plant (Auchusa tinctoria), with downy and spear-shaped leaves, and clusters of small purple or reddish flowers, the stamens of which are shorter than the corolla.

Though this plant is sometimes cultivated in England, by far the greater portion of the allanet which we use is imported either from the Levant, or from the neighbourhond of Montpelier in France. 
Alkanet imparts a fine deep red colour to all unctuous substances, and to spirits of wine; but it tinges water with a dull, brownish hue. Its chief use is for the colouring of oils, plasters, lip-salve, and other similar articles. It is likewise employed in compositions for rubbing, and giving colour to mahogany furniture. Wax tinged with alkanet, and applied to the surface of warm marble, stains it flesh colour, and sinks deep into the stone.

58. The COWSLIP is a plant (Primula veris) which grows in most meadows and pastures, and is too well known to require any description.

The flowers of the cowslip, when picked and dried, are sometimes used as a balsamic tea. When boiled, with a certain proportion of water and sugar; and afterwards properly fermented, they may be made into a peculiarly pleasant wine.

The roots have a fine odoul ; and, when immersed in ale or beer, are said to add considerably to the strength of the liquor. The leaves are sometimes eaten as a pot-herb, and in salads; and both the leaves and flowers are an excellent food for silk-worms.

59. $B U C K-B E A N$, or $B O G-B E A N$ (Menyanthes trifoliata), is a common plant in shallow ponds; and is distinguishable by its leaves growing in threes, and its pink and white flowers treing shaggy on their inner surface.

There is no British plant the flowers of which are more beautiful than those of buck-bean; and nothing but the difficulty of propagating it in dry ground could prevent its having a place in every garden. The leaves are intensely bitter, and are occasionally used in the Highlands of Scotland as a tea, to strengthen the stomach. The inhabitants of some parts of Sweden employ them in place of hops, to impart a bitter taste to ale; two ounces of them being considered equal in strength to a pound of hops. By some persons the leaves of buck-bean are smoked instead of tobacco; and different preparations of this plant have been found 
efficacious as a remedy against agues, and in scorbutic and scrofulous diseases, rheumatisms, and dropsy. There is an opinion that sheep, when compelled to eat of buck-bean, are cured of the rot. In Lapland it is said that the pounded roots, though very unpalatable, are sometimes converted into bread.

60. SCAMMONY is a concrete or dried juice oltained from the roots of a climbing plant of the convolvulus tribe (Conrolvulus scammonia, Fig. 7), which is cultivated in Asialic Turkey, Syria, and Persia.

This plant is known by kaving arrow-shaped leavcs, notched in a particular manner at the base, and each flower-stalk bearing two or three large and somewhat purplish white flowers.

The roots of the scammony plant are thick, black on the surface, white within, and full of an acrid milky juice, which, in a concrete state, is frequently used in medicine. To obtain it, the earth, at a certain season of the year, is removed from the upper part of the roots whilst they are growing, and the tops are cut obliquely. The juice flows from the wound into a small vessel sunk into the earth, at the lower end of the gash, to receive it. But, as each root furnishes only a very small quantity, the produce of several roots is usually mixed together for the greater convenience of being exposed to the sun and dried. Still, however, the quantity, thus obtained, is sometimes insufficient to supply the demand. In this case an addition is made to it by the pressure of juice from the leaves and stalks.

The best scammony is imported from Aleppo, in light, spongy, friable pieces, of shining blackish grey colour, which have a faint, unpleasant smell, and a bitterish, pungent taste. It is sometimes adulterated with flour, and sometimes even with sand or earth.

In its medical effects, scammony, when administered alone, is an efficacious, though violent purgative. But if triturated or ground down with sugar, almonds, or gum-arabic, its operation becomes sufficiently mild and safe, 
61. JALAP is a dark-coloured root, which is usually inported, in transverse stices, from South America.

The plant that produces it (Comolvulus jalapa, Fig. 8) belongs to the convolvulus tribe, and has generally somewhat heart-shaped leaves, and flowers that are reddish on the outside, and dark purplo or yellowish within.

The name of jalap is derived from Xalapa, a town in South America, situated betwixt Vera Cruz and Mexico, where the plant, of which it is the root, was originally discovered, and whence it lias been imported, in great quantities, into Europe. The jalap plant is now cultivated in the botanical garden at Cliarlestown, and in several other parts of America. When recent, the root is large, whitish, and full of juice; but, when dried, the best pieces are compact, hard, weighty, and of dark colour, with black circular marks. Both in smell and taste it is very nauseous. It is frequently mixed with slices of bryony root; but these are easily distinguished by their paler colour and porous texture.

The oniy mode in whicl this root is of use is as a medicine; and it is administered in substance, in a tincture, and an extract. It has been advantageously employed in several disorders ; but, as it is very powerful in its effects, great caution is necessary in the use of it, particularly with children.

62. PERUVIAN BARK is the produce of a tree which grou's in South America, and chicfly in Peru, whence its name has been derived.

This tree (Cinchona officinalis), in size and gcneral appearance, somewhat rcscmbles our cherry-tree. Its leaves are in pairs, oval, pointed, nerved, and smooth on the upper side; and the flowers hang in loosc clusters, are firinged at the edges, and red in the inside (Fig. 10.)

Formerly this valuable medicine had the name of Jesuit's bark, from its having been first introduced into Europe by some persons of the religious order called 
Jesuits, that were settled in South America. They had been instructed in the use of it by the inhabitants of Peru, to whom it had long been known; and it continued, for many years, to be a lucrative article of commerce to them. For its officinal name of cinchona it was indebted to the lady of a Spanish Viceroy, the Countess del Cinchon, who, about 170 years ago, derived great benefit from taking it.

The tree from which it is obtained grows spontaneously, and in great abundance, in several of the mountainous forests of Quito and Peru. The proper time for cutting it is from September to November, the only season during which there is any considerable intermission from rain. The Indians, as soon as they have discovered a spot where the trees are in sufficient number, build a few huts for themselves, and one large hut for containing the bark, to preserve it from wet. 'They then go forth, each furnished with a large knife, and a bag which will hold about fifty pounds' weight of bark. Each tree occupies two men. They first cut or slice down the bark as far from the ground as they can reach. They then tie to the tree several sticks a little distance apart, and each about half a yard in length, to serve as a ladder by which they can ascend to the upper part, always slicing off the bark as far as they can reach, before they fix a new step. In this manner one of the two mounts to the top, whilst the man below collects what his companion cuts. To relieve each other, they ascend the different trees by turns; and they are generally able to fill their bags once in the course of the day. When they return to their huts, they spread out the bark to dry, and they are very careful to preserve it from wet, which would greatly injure it.

There are three sorts of hark in use: the pale, the red, and the yellow. Of these the two last have recently been discovered. The red is now very scarce, and is seldom brought intn Europe. The pale bark is 
imported, fiom the Spanish Main, in large bundles, closely packed in goat or other skins. The yellow is in much larger pieces, and flatter and thicker than those of the pale bark.

We are informed, by some writers, that the Peruvians first learned the use of this bark from observing certain animals, affected with intermittent fevers, instinctively led to it. Others say that one of the inhabitants of Peru, having an ague, was cured by drinking the water of a pool into which some trees of this kind had accidentally fallen. On its first introduction into Europe, its use was opposed by many eminent physicians; and, for a long time afterwards, it was believed to be a very dangerous remedy. Its character, however, in process of time, became perfectly established, and it is now considered one of the most valuable medicines we possess.

Peruvian bark is used as a remedy in intermittent fevers or agues; and, by some persons, is prescribed in other kinds of fevers, in confluent small-pox, in gangrenous sore throat, and indeed in every species of gangrene. It is given in powder, as an extract, a spirituous tincture, and a decoction; but the most efficacious form is that of powder. In taste it is bitter and astringent, leaving an impression upon the palate which continues for some time afterwards; but its smell is rather agreeable than otherwise.

63. COFFEE is the seed of an evergreen shrut which is cultivated in hot climates, and is chiefly imported from Arabia and the East and West Indies.

This shrub (Coflea Arabica, Fig. 9) is from ffftecn to twenty feet in height. The leaves are four or five inchcs long, and two inchcs broad, smooth, green, and glossy on the upper surface; and the flowers, which grow in lunches at the base of the leaves, are white and sweet-scented. The berries or fruit are of a somewhat oval shape, about thc size of a cherry, and of dark red colour, when ripe. Each of these contains two cells, and each cell has a single seed, which is the coffee as we see it before it undergoes the process of roasting. 
Coffee is an artiele of only late introduetion. To the Greeks and Romans it was wholly unknown. Its use appears to have originated in Ethiopia; and, in 15.54, it is stated to have been first introduced into Constantinople, whence it was gradually adopted in the western parts of Europe. In $1652 \mathrm{Mr}$. Daniel Edwards, a Turkey merehant, brought with him to England a Greek servant, whose name was Pasqua, and who understood the methods of roasting coffee, and making it into a beverage. This man was the first who publiely sold coffee in this eountry; and he kept a house for that purpose in George Yard, Lombard Street. At Paris, coffee was nearly unknown until the arrival of the 'Turkish anıbassador, Solomon Aga, in 1669; about three years after which the first eoffee-house is said to have been established in that city. The coffee shrub was originally planted in Jamaica in 1732.

Great attention is paid to the culture of eoffee in Arabia. The trees are raised from seed sown in nurseries, and afterwards planted out, in moist and shady situations, on sloping grounds, or at the foot of mountains. Care is taken to eonduet little rills of water to the roots of the trees, which at certain seasons require to be constantly surrounded with moisture. As soon as the fruit is nearly ripe, the water is turned off, lest the fruit should be rendered too succulent. In places much exposed to the south, the trees are planted in rows, and are shaded, from the otherwise too intense heat of the sun, by a branching kind of poplar tree. When the fruit has attained its maturity, eloths are placed under the trees, and, upon these, the labourer's shake it down. They afterwards spread the berries on mats, and expose them to the sun to dry. The husk is then broken off by large and heavy rollers of wood or iron. When the coffee has been thus eleared of its husk, it is again dried in the sun, and lastly winnowed with a large fan, for the purpose of clearing it from the piees of husks with which it is intermingled. A pound of coffee is generally more than the produce of one 
tree; but a tree in great vigour will produce three or four pounds.

'The best coffee is imported from Mocha, a town on the eastern bank of the Red Sea. This, which in Europe is called Mocha and 'L'urkey coffee, bears a higher. price than any which our colonists are able to raise; owing, as it is supposed, to the difference of climate and soil in which it is grown. It is packed in large bales, each containing a number of smaller bales; and, when good, it appears fresh, and of a greenish olive colour. The coffee next in esteem to this is grown in Java and the East Indies, and that of lowest price in the West Indies. When stowed in ships with rum, pepper, or other articles, it is said that coffee contracts a rank and unpleasant flavour, and this has been assigned as a reason of the inferiority of such as is imported from our own plantations.

The quantity of coffee annually supplied by Arabia is supposed to be upwards of fourteen millions of pounds. Before the commencement of the French Revolution the island of St. Domingo alone exported more than seventy millions of pounds per annum.

Almost all the Mahometans drink coffee at least twice a day, very hot, and without sugar. The excellence of coffee depends, in a great measure, on the skill and attention that are exercised in the roasting of it. If it be too little roasted, it is devoid of flavour ; and if too much, it becomes acrid, and has a disagreeable burnt taste. In England the operation of roasting is usually performed in a cylindrical tin box, perforated with numerous holes, and fixed upon a spit which runs lengthwise through the centre, and is turned by a jack.

In a medical view, coffee is said to be of use in assisting digestion, promoting the natural secretions, and preventing or removing a disposition to drowsiness. It has been found lighly beneficial in relieving some cases of severe head-acl.

The outer pulpy part of the berry, and the inner membrane, which immediately invests the seeds, are VOL. II. 
used by the Arabians; and of these the former is much esteemed, and constitutes what is called coffec it la sultane.

64. STRAMONIUM, or THORN-APPLE (Datura stramonium), is an annual plant, with thick round stalks, somewhat triangular lcaves, jagged or toothed at the edges, large white and funnel-shuped flowers, and seed vessels large and beset with spines.

Although originally a native of America, stramonium is now a fiequent weed on dunghills, and in cultivated ground of our own country; and, when once introduced into a garden, it is difficult to be eradicated. Its snell is exceedingly unpleasant, and its qualities are so pernicious, when taken internally, as to occasion giddiness, torpor, and sometimes cven deatl. The seeds are particularly injurious. Notwithstanding this the inspissated or dried juice of the leaves has been considered a valuable remedy in epileptic and other convulsive disorders. An ointment prepared fiom them afiords relief in external inflammations; and smoking the dried leaves has latcly been recommended in asthmatic complaints.

The soporiferous and intoxicating qualities of stramonium are well known in eastern countries, and liave often occasioned the plant to be cmployed for very improper uses.

65. TOBACCO, in the state that we see it, is a narcotic drug formed from the dried leaves of an annual plant (Nico. tiand Labacum, Fig. 11) that is principally cultivuted in North America.

The stalli of the tobacco plant is erect, strong, round, and hardy. The leaves are large, oblong, pointed, clammy, and of pale green colour. The flowers, which terminate the stem and branches in loose clusters, are of reddish colour, and funnel-shaped, roith a long hairy tube; and the seed vessel is oval, and divided into two cells, that contain many rounded seeds.

The cultivation of tobacco is carried on to great cxtent in several parts of North America. 'Ihe seed, mixed with ashes on account of its smallness, is sown 
a little before the beginning of the rainy season; and, in order the better to cover it, the beds are raked over or trampled upon. In about a fortnight the young plants begin to appear, and, as soon as they have four leaves, they are drawn up and transplanted in lines, and about three feet asunder, into the tobacco field. Here they are kept clear of weeds; and, as soon as they have eight or nine leaves each, the tops are nipped off to make the leaves grow thicker and longer. When the plants are full grown, and the leaves are become somewhat brittle, they are cut with a knife close to the ground. They are suffered to lie upon the ground for a little while, after which they are carried to the drying shed, where they are hung by pairs upon lines or ropes. When perfectly dry, the leaves are stripped from the stalks, and made into small bundles tied round with another leaf. These bundles are laid in heaps, and covered with blankets for about seven days to heat; after which they are closely stowed in casks for exportation.

The name of tobacco was given to this article from its having been originally brought into Europe from Tobago, or 'Tabago, an island in the Bay of Panama, near the coast of America.

'To the American Indians the use of tobacco has been known for many centuries; and the practice of smoling it is common to almost all the tribes. Tobacco forms a part of every entertainment; and, in the intervals of hunting, sleeping, and eating, it occupies no small portion of their time. In many of their religious ceremonies tobacco is used; and instances have occurred in which they have taken it in such quantity that death has ensued.

"The custom of smoking is understood to have been first introduced into England, by Sir Walter Raleigh, during the reign of Queen Elizabeth, and a ludicrous story has often been told respecting it : that Sir Walter having directed a servant to bring him a jug of water, the man, at his return into the room, found lim smok- 
ing, and, alarmed at seeing his master apparently on fire, threw the whole contents of the jug into his face to quench it.

So extensive has this nauseous practice now become, especially in Holland and Germany, that it constitutes a daily luxury with nearly all the peasantry of those countries, as well as with the more indolent and wealthy classes of the inhabitants. To many constitutions it is very injurious. When first begun, it occasions vomiting, intoxication, and other unpleasant effects. These however, by repetition, are discontinued, though its stupifying qualities are never entirely overcome.

Allother form under which tobacco is used, is that of snuff. The basis of snuff is tobacco powdered; but many other matters are added, to give it a peculiar smell, or to impart pungency to it. When first applied to the nose, snuff excites sneezing, but, by repetition, this entirely ceases. The practice of taking snuff has, in some instances, been found injurious to the smell and the voice; it has been attended with loss of memory, and by symptoms of a weakened or debilitated state of the nervous system.

But there is no mode of using tobacco so disgusting, to persons unaccustomed to it, as chewing. By the labouring classes, and particularly by mariners, this practice is chiefly followed, from a notion, though apparently a very erroneous one, that it will prevent the return of hunger, and, in some degree, supply a lack of food.

Though all these are disgusting as practices, there is no doubt, but, medicinally, they may be attended with good effects. By smoking and chewing, tooth-ach has often been relieved; and some persons consider the former a means of guarding against contagion. The occasional and moderate use of snuff has, in several cases, been found beneficial, particularly in head-achs, and in diseases of the eyes and ears. Infusions of tobacco are sometimes administered in medicine, but this drug is principally given in the form of a vinous or watery infusion. 
Tobacco is a powerful medicine, and requires to be used with great caution. The smoke of this herb, when blown against noxious insects, destroys them, and is tle means which gardeners adopt for ridding hot houses and green houses of such as infest their plants.

The tobacco plant is sufficiently hardy to sustain the rigour of an European climate, and is cullivated in several parts of Spain and Portugal. As however, on importation, it pays a heavy tax to government, the culture of it in this country is restricted, by the legislature, to half a rod of ground in physic gardens; and if this be exceeded, the cultivator is liable to a penalty of ten pounds for every rod.

The different kinds of tobacco and snuff are attributable rather to the difference of climate and soil in which the plants have been grown, and to the different modes of managernent and manufacture, than to any essential distinction in the plants from which they are manufactured.

66. DEADLY NIGHTSHADE (Atropa belladonna) is an extremely poisonous plant, which grows in hedges and waste grounds, in several parts of England, and has somewhat oval lenves of dull green colour, purple bell-shaped flowers, and shining black berries, each alout the size of a small cherry.

There is no British plant so injurious in its effects on the human frame as this; and the alluring appearance and sweetish taste of the berries have, in many instances, particularly with children, been succeeded by the most fatal consequences. It is true that some persons have been known to eat three or four of them without injury; but in othcrs a single berry, and even the half of one, has occasioned death. The leaves are more powerful than the berries. The usual symptoms of this poison are a deep and deadly stupor, giddiness, delirium, great thirst, retching, and convulsions. A draught of vinegar, and keeping the patient constantly in motion, are said to be the best means of cure. 
Some writers have supposed it was the deadly nightshade which produced those strange and dreadful effects that are described by Plutarch to have been experienced by the Roman soldiers, under the command of Antony, during their retreat from the Parthians : "Their distress for provisions was so grcat that they "were compelled to eat of plants unknown to then. "Among others, they found an herb, of which many " ate; these, shortly afterwards, lost their memory and " their senses, and wholly employed themselves in " turning over all the stones they could find; then, " being seized with vomiting, they fell down dead."

The leaves of the deadly nightshade have sometimes been used externally, and with good effcct, in cases of cancer; and in ulcers and tumours of different kinds. They are likewise given, internally, in infusion; but the sufferings of the patient, however small the dose may be, are so dreadful that few practitioner's like to resort to them.

67. POTATOE (Solanum tuberosum) is a well known edible root, which was originally imported into this country from America.

No root with which we are acquainted is so valuable to mankind in temperate climates, as the potatoe. In some countries, particularly in Ireland, it forms a most important article of food to the lower classes of inhabitants. By the English peasantly the potatoe is by no means esteemed as it deserves. In addition to its value for culinary uses, it might, in a very essential degree, be made to serve as a substitute for bread. If duly prepared, and mixed with a nearly equal portion of wheat flour, it may even be made into loaves. A kind of cheese may be made, by reducing potatoes to the consistence of paste, adding an equal quantity of the curd from which cheese is made, with a little salt and some other ingredients, mixing the whole together, and forming them in moulds. The Germans prepare a favourite dish by slicing boiled potatoes and pouring 
over them the same kind of sauce which is used for salads, and mixing anchovies with them.

These roots afford an excellent food for horses and cattle; and it is said that bullocks will fatten on them more speedily than on cabbages or turnips. Potatoes are likewise servicuable for the fattening of hogs ; but, for a little while before these are killed, it is requisite to use barley meal in addition, as otherwise the fat of the bacon is liable to boil away in the cooking. In the use of potatoes as food, it is requisite to prepare them in some manner by heat, as otherwise they are both unpalatable and poisonous.

$A$ kind of brandy was formerly distilled from potatoes; but this has been forbidden by the legislature. Starch may be made from potatoes, by the simple process of scraping them in water, and well washing the pulp : the starch settles to the bottom of the vessel, in a heavy and closely connected sediment. This starcli is of use for the same purposes as starch prepared from wheat: it is also valuable as a size; which, unlike the size produced from animal substances, does not easily putrefy, and has no disagreeable smell. Bakers in Germany, by the addition of calcined oyster shells and burrt hartshorn, convert the pulp of potatoes into yeast. The stalls or haulm of potatoes are capable of being made into paper. They are also of considerable utility as manure. The apples, or seed-vessels, may be usefully employed as a pickle: and, if properly prepared, they are said to be even more palatable than cucumbers.

There are numerous varietics of the potatoe. Of these the most remarkable are the different linds of kidney polatoes, the Aylesbury white, and Altringham early rohite, which are chiefly grown for the table: the ox noble, Irish purple, and red potaloes, which are adapted for fodder.

This valuable root was originally imported from America, about the beginning of the seventeenth century. The inhabitants of Ireland assert that it was first 
introduced into that country, by the accidental wreck, upon their coast, of a vessel which was laden with potatoes and fieighted for England.

The usual mode of planting potatoes is by cutting the roots into pieces, reserving one eye or bud to each division, and setting these in the earth. They will succeed in any tolerable soil; but they flourisl most luxuriantly in light sandy loams. The proper time for when the leaves and stems begin to decay. When cultivated on a small scale, they are usually dug with a three pronged fork; but when raised in fields, where this process would be too tedious, they are turned up by a plough.

68. CAPSICUMS are South American and Indian plants easily known by their hollow pods, of shining red or yellow colour, which contain many small, flat, and kidney-shaped
seeds.

The principal species are, Heart or Bell pepper (Capsicum grossum), Guinea pepper (Capsicum annum, Fig. 12), and Bird pepper (Capsicum baccutum).

All the species of capsicum possess the same general qualities. In hot climates, but particularly in the East and West Indies, and some parts of Spanish America, the fruit of these plants is much used for culinary purposes. It is eaten in large quantities, both with animal and vegetable food; and is mixed, in greater or less proportion, with almost all kinds of satices.

Cayenne pepper is made from the fruit of different species of capsicum. This fruit, when ripe, is gathered, dried in the sun, and then pounded; and the powder is mixed with a certain portion of salt, and kept, for use, in closely stopped bottles. Of late years Cayenne pepper has been introduced into most of the countries of Europe; and it is now very generally used as a poignant ingredient in soups and highly seasoned dishes. Its taste is extremely acrid, and it leaves a 
durable sensation of heat on the palate, which is best removed by butter or oil. When taken in small quantity, cayenne pepper is a grateful stimulant; and, in medicine it is used, both externally and internally, to promote the action of the bodily organs when languid or torpid; and it is said to be found efficacious in many gouty and paralytic cases.

69. The GUINEA PEPPER, or ANNUAL CAPSICUM (Fig. 12) is a slender herbaccous plunt, with smooth leaves, while flowers, single flower stalks, and smoolh, shining fruit of oblong shape and usually of red and yellow colour.

This plant is a native both of the East and West Indies, and is considered the most hardy of the whole tribe of capsicum. In many parts of the South of Europe, its fruit is eaten green by the peasants at their breakfasts, and is preferred by them to onions or garlic. The fruit of all the species may be rendered useful in domestic economy, either as a pickle, or as cayenne pepper. For the latter, it may be dried before a fire, and ground to powder in a common pepper-mill.

70. The BUCK-THORN (Rhamnus catharticus) is a spinous shrub, which grows in thickets and hedges, and has clusters of small green flowers, globular black berries, and somewhat oval leaves, serrated at the edge.

About the month of September the berries of the buck-thorn begin to ripen; and, if these are bruised when perfectly ripe, they yield a green tint. They are made into the sap-green which is used by painters in water-colours, by evaporating their juice to the consistence of a gum. From the juice of the unripe berries, mixed with allum, a yellow dye is obtained, which is employed by dyers, and also for staining maps or paper. If the fruit be gathered late in the autumn the juice is purple. The syrup of buck-thorn berries is sometimes used in dropsies and other complaints, though there are objections to it from its occasioning sickness and griping. The berries have a faint disagreeable smell, and a nauseous bitter taste. It is not 
usual to mix with, or substitute for them, the fruit of the berry-bearing alder, and of the dog-berry tree. The fraud is, however, easily detected on examination; for the buck-thorn berries have each four seeds, which the others have not.

The inner bark of the buck-thorn is said to yield a medicine preferable to that afforded by the berries, but it is an extremely powerful one.

71. NUX VOMICA, or VOMIC NUT, is a round, fat seed, about an inch in diameter, of greyish brown colour, and horny consistence, the produce of a tree (Sirychnos nux vomica) which grows in the East Indies.

The tree is of large size, and hus somewhat oval leavrs, in pairs, each marked with three or five strong rils. The young branches have swelled joints. The flowers are in a hind of umbels at the extremity of the branches.

The fruit which produces the vomic nut is a species of berry, about the size of a small apple, and covered with a hard substance somewhat resembling that of the pomegranate $(154)$, and of beautiful orange colour when ripe. This fruit is filled with a pulp which contains the seeds.

There is so great a consunption of nux vomica, that the quantity vended at the East India Company's sales, in 1808, was about five tons' weight, and its price about nineteen shillings per hundred weight, exclusive of the duty. It is imagined that public brewers sometimes use this drug in the adulteration of ale and porter, for the purpose of rendering it more intoxicating than it otherwise would be.

It is employed for the destruction of vermin; and is said to be quickly fatal to dogs, foxes, wolves, and most jother quadrupeds. When pounded and mixed with oatmeal, it is used for the killing of rats. Yet deleterious as this drug is, it has lately been employed on the Continent, as a medicine of great efficacy, in spasmodic affections of the bowels, and some other complaints; but its administration ought only to be attempted by medical men. 
An extract of nux vomica has lately been imported from India; but it is not generally known for what purpose.

72. The TEAK-TREE (Tectonia grandis) is a valuable species of timber, which grows in the forests of the East Indies.

This tree attains the height of. fifty fcet and upwards. Its leaves are somewhat oval, slightly scalloped, rough on the uppor side, and clad with a white down leneath; and its flowers arc in bunches, small, white, and fiagrant.

For the building of ships, teak-wood is estccmed superior to every kind of timber except oak. It is said to be alnost incorruptible in water; and its bitterness preserves it from the attack of worms. For all the purposes of carpentry, teak is the most useful timber that is produced in Asia. It is easily wrought, and is peculiarly strong and durable. That which grows on the coast of Malabar is considered the best; but the greatest quantity is obtained from Pegu. The former is nearly all hill timber, whereas the latter is the produce of a low and flat country. In India much of the furniture is made of teak wood.

The attention of goverument has of late been called to the cultivation of this timber ; and great encouragement is now given to an extensive propagation of it. In the present scarcity of oak timber in England, the increase of teak in the East is become an object of importance to the prosperity of our navy. Its culture has also been reconmended in our West Indian islands, the climate and soil of which are considered nearly similar to those of its native country.

73. MANGOS, as they are imported into this country, are the unripe fruit of an East Indian tree (Mangifura Indica) prickled in vinegar.

The mango tree grows to a grcut size, and has spear shaped leaves, each eight or nine inches long, and two inches wide. The flowers spring, in a loose lind of funch, from the cartremity of the stems. 
The fruit of this tree, when ripe, is as large as a goose's egg, and is much estecmed in India, on account of its invigorating odour; whieh, it is imagined, will restore health to persons in a declining state. Beneath its rough shell there is a kernel, similar to that of the almond, which may be eaten either fresh or preserved. From the expressed juice of this fruit the Indians prepare a kind of wine. When intended for pickling, the fruit is gathered in an unripe state. An imitation of mangos is made in our own country with a particular sort of melon. A small square piece is cut from the side of the melon, through which the seeds are taken out. It is then filled with mustard seeds and shred garlic, and afterwards pickled with vinegal and spices. Large cucumbers arc sometimes prepared as mangos.

74. RED CURRANT'S are the fruit of a well known shrub (Ribes rubum), which is cultivated in gardens; and which also grows wild in woods or thichets of some of the northern parts of England. Its bunches are smooth and pendant; and its flowers are fluttish.

The utility of this fruit in domestic economy has long been established. Its juice, if boiled with an. equal weight of loaf sugar, forms an agrecable substance, called currant jelly, which is much employed in sauces and for other culinary purposes; and also in the cure of sore throats and colds. The French frequently mix currant jelly with sugar and water, as a beverage; and, by many persons, this nixture is preferred to orgeat or lemonade. The juice of currants is a valuable remedy in obstructions of the bowels; and, in febrile complaints, it is useful on accuunt of its readily quenching thirst, and for its cooling effect on the stomach. 'This juice, fermented with a proper quantity of sugar, becomes a palatable wine, which is much improved by keeping; and which, with care, may be kept tor twenty years and upwards. Modes of making this, as well as other British wines, are to be found in all the domestic receipt books. 
The inner bark, boiled with water, is a popular remedy in jaundice; and, by some medical men, it has been administered in dropsical complaints.

White and flesh-coloured currants have, in every respect, the same qualities as the red species.

75. BLACK CURRANTS are the fruit of a garden shrub (Ribes nigrum) which is distinguished by having its bunches hairy and its flower's oblong.

The berries of the black currant shrub are larger than those of the red; and, in some parts of Siberia, are said to attain the size of a hazel nut. They are occasionally made into wine, jelly, and rob or syrup. The two latter are frequently employed in the cure of sore throats; and, from the great use of black currants in quinsies, they have sometimes been denominated squinancy or quincy berries.

The leaves are fragrant, and have been recommended for their medicinal virtues. An infusion of them, in the manner of tea, is very grateful, and, by many persons, is preferred to tea. The tender leaves tinge common spirits so as to resemble brandy; and an infusion of the young roots is useful in fevers of the eruptive lsind.

Black currant trees grow wild in wet hedges, and near the banks of rivers, in several parts of Norfolk. The dried currants of the shops do not belong to this family, but are a small kind of grape (79).

76. GOOSEBERRIES are the fruit of a prickly shrub (Ribes grossularia) which grows wild in Cheshire, Lancashire, and several parts of Yorkshire.

Few of the garden fruits are more esteemed for the table than gooseberries. For culinary purposes, gooseberries are generally employed before they are ripe; but this is founded on erroneous notions of their chemical properties, since, either for sauces orivine, though they are more cool and refreshing, they do not possess the delicate flavour and rich saccharine qualities which are inherent in the ripe fruit. Wine made of goose- 
berries has great resemblance to Champaigne. In the making of wine, after the juice has been cxpressed, it is customary to throw away the skins of the fruit. These, however, may with advantage be employed in distillation, as they afford an agreeable spirit somewhat resembling brandy. When kept a few months, this spirit is said to be little inferior, either in strength or flavour, to the best Cogniac brandy. Vinegar may be made from gooseberries. Some of the kinds are bottled while green, and kept for winter use; and others are, for the sarne purpose, preserved with sugar.

Gooseberries vary much in colour, size, and quality. Some are smooth, and others hairy. Some are red, others green, and others yellow or amber coloured. Wild gooseberries are greatly inferior, in size, to those which are cultivated in gardens.

77. IPECACUANHA (Viola ipecacuanha) is a medicinal root, small, wrinkled, bent, and contorted into a great variety of shapes; which is imported from the West Indies and Sonth America, and is given as an enetic.

Therc are three kinds of ipecacuanha: ash-coloured or grey, brown, and white. Of these, the asli-coloured is usually preferred for medicinal use, from its being more efficacious than the white, and less violent than the brown. Ipecacuanha was first brought into Europe towards the middlc of the seventeenth century; but it was not admitted into general use until about the year 1686, when it was introduced into practice under the patronage of Louis the Fourteentl of France. Its taste is bitterish and somewhat acrid; and it seems to cover the tongue with a kind of mucilage. It is one of the mildest and safest emetics with which we are acquainted; and is administered in powder, as a wine, and as a tincture. It has this peculiar advantage, that, if it do not operate as an emetic, it passes off without injury by the skin or bowels. In very small doses it is efficacious in obstinate coughs, and in several other complaints. 
The roots of a kind of dog's bane (Apocynum) are not unfrequently substituted for those of ipecacuanha; but, in some instances, this substitution has been attended with fatal consequences.

78. VINES are a very important tribe of shrubs, to the fruit of which we are indelted for all our foreign wines, for raisins of every description, and for the dried currants of the shops.

Several species of vine are cultivated; but by far the most important of the whole is the common vine (Vitis vinifera of Linnceus).

The earliest introduction of the vine into the western parts of Europe is stated to have been about the year 280, under the sanction of Probus, the Roman Emperor, who, throughout his whole dominions, was a zealous encourager of agricultural pursuits. There can be no doubt that vines were anciently propagated in our own island for the purpose of wine, and that there were vineyards of considerable extent in Gloucestershire, Hampshire, and some other counties; but, as vines are principally found to flourish in inland countries, lying betwixt the thirtieth and fifty-first degrees of latitude, it is evident that there can be no part of Great Britain sufficiently adapted to their successful cultivation.

Any person who has seen a hop garden, may ensily form an idea of the appearance of a vineyard. Vines are usually propapated by slips, cuttings, or offsets from the roots. These, when they have attained a sufficiency of roots, are transplanted from the nursury ground into the vineyard, the soil of which ought to be liglit and rich. They are placed, in this ground, in rows, and at regular intervals, leaving space sufficient for the vine dressers and the reapers to pass betwixt them; and as soon as the rooted plants are three years old, they begin to bear fruit. The season for pruning and diessing them is the early part of the year, before the sap begins to rise; and about the time when the flowers appear, the plants are fastened to poles, for the 
purposes of supporting them, of preventing them from growing entangled with each other, admitting a free circulation of air amongst them, and affording greater convenience for gathering the fruit.

The vintage, which is a season of mirth and delight to the whole country, commences in the early part of autumn. The villagers assemble in the respective vineyards under the direction of ovcrseers. The reaping of the grapes is, in general, performed in three distinct gatherings. The first of these comprehends all the finest and ripest bunches, carefully clearing away from them every grape that appears green or decayed : the second is confined to the large and thick clusters which are not so ripe as the others; and those which are nearly green, withered, or decayed, are gathered last.

To obtain the juice from the grapes, they are subjected to the operation of large presses of somewhat similar construction to the cyder presses of our own country (the separate gatherings being still kept apart). and the juice is received into vessels fixed for that purpose. Afterwards it undergoes the necessary fermentation to convert it into wine. By the ancients the juice was obtained by treading the grapes. This practice is alluded to in various parts of Scripture, but perhaps in none are the characteristics of the ancient vintage expressed more strongly than in the predictions of Isaiah concerning Moab: "And gladness is taken " away, and joy out of the plentiful field; and in the "vineyards there shall be no singing, neither shall there "be any shouting: the treaders shall tread out no "wine in their presses; I have made their vintage " shouting to cease." The treading of grapes is still practised in several parts of the world. The ancients frequently kept their wine in skins, or leathern bags, well secured at the seams: hence the passage in the gospels; " neither do men put new wine into old bottles ; " else the bottles break, and the wine runneth out, and " the bottles perish : but they put new wine into new "bottles, and both are preserved." 
The kinds of wine are extremely various. The difference which exists betwixt them is not, however, so much owing to a distinction in the species of grapes, as in the quality of the fiuit, produced by the varieties of soil, cultivation, and climate to which they are subject. This difference likewise depends, in some instances, on the peculiar mode of fermentation, and the state of the grapes from which the wine is produced.

(a) Pontuguese Wines. - Of all the kinds of wine that are consumed in England, none are so much in request as red port. This has its name from the city of Oporto, in the neighbourhood of which the vines that produce it are chiefly cultivated. A great proportion, however, of the port that is consumed in England, is said to be mixed with a Spanish red wine of inferior quality, or to be otherwise adulterated. Red port is brought over in casks called pipes, which measure 138 gallons each, and ought to fill fifty-two dozen bottles of legal measure.

'The difference in colour betwixt red wines and white does not so much depend upon the quality of the grape, as upon the mode in which the wines are prepared. The juice of red grapes, if carefully pressed, and fermented separately from the skins, forms a white wine. If the skins be pressed so as to discharge the colouring matter they contain, or, if they be allowed to remain in the juicc during the fermentation, the wine assumes a red tinge.

White port, and Lisbon, are two kinds of white wine which we receive from Portugal. Of these, the former was much in demand some years ago, but it is now seldom called for ; the latter is still in use.

(b) French Wrines.-Many excellent wires are produced in France. That usually considered the best is Burgundly, a red wine of very delicate flavour, which has its name from the province where it is made. The wines of the neighbourhood of Orleans, however, 
after having been matured by age, are much like Burgundy. Claret is the only French red wine for which there is any great demand in England. It is thin and highly flavoured, and is chiefly supplied from the neighbourhood of Bourdeaux. Some of the red wines of Champaigne are highly prized for their excellence and delicacy, though they, occasionally, have a pungent and sourish taste. Hermitage is produced from vineyards, at a place so called, near the village of Thein, on the eastern bank of the Rhone; and Cote Rotie, from vineyards on the opposite side of the river.

No French white wine has so nuch celebrity as Champaigne. This is of two kinds; one of which, called still or quiet Champaigne, has gone through the whole process of fermentation; the other, which has the name of sparkling Champaigne, has been bottled before the fermentation was,complete: this, consequently, proceeds slowly in the bottle, and causes the wine, on the drawing of the cork, to sparkle in the glass. Vin de Grave is produced in the vicinity of Bourdeaux, and the lower parts of Gascoigne: Pontac is made in Guienne; and Frontignac and Muscadel are white wines, the delicious productions of Languedoc.

(c) Spanisir Wine.-The country about Xeres, in Andalusia, is celebrated for a grape which produces an excellent wine called Sherry. There are several French and English houses at Xeres and Seville which trade, to great extent, in this wine. It is very strong and full bodied, owing, in a great degree, to the quantity of brandy with which it is mixed. In the province of $\mathrm{Va}$ lencia, some of the proprietors liave wines of different kinds, sixty, eighty, and even a hundred years old, the prices of which differ according to their age. Rota, in Seville, produces a rich and sweet white wine; and the country around Malaga, near Gibraltar, is celebrated for white wine which is known by that name; and so assiduously is the cultivation of the vine there pursued, that the export of the produce of the vinejards yields 
to the inhabitants an annual revenue of more than 200,000l. sterling per annum. We import from Spain a harsh and inferior kind of red roine, whieh, duty free, sells for only $10 l$. or $15 \%$. per pipe of 126 gallons; but the territory of Alieant produces a very rich and excellent kind of red wine. The sweet red wine which we eall tent is a Spanish produetion; chiefly imported from Cadiz, and in hogsheads of about sixty gallons each. It is made from the juice of a partieular kind of grapes, which are not used for this purpose until some time after they have been perfeetly ripe.

(d) Italian Wines.-Notwithstanding the ancient celebrity of many of the wines of Italy, by far the greater part of what are now manufactured in that eountry are thin and bad. Certain vineyards on mount Vesuvius, however, still have great celebrity for a luscious red wine called Lachryma Christi.

(e) German Wines.-Germany produces many excellent wines, of which Tokay, Hoek, Rhenish, and Moselle, are the most celebrated. Tokay has its name from a town in Hungary, near which it is chiefly made. The quantity of this wine is so small that, even on the spot where it is manufactured, ${ }^{r}$ it is sold at a very high priee. It is made by mixing with the eommon grapes a portion of luseious, half-dried, and shrivelled grapes; the latter being absclutely neeessary to eonstitute the peeuliar quality of the wine. The two linds of grapes are pressed separately, and the juice is afterwards mixed, fermented, and strained through a eloth or sieve into the barrels in which it is to eontinue. The best Tokay does not long remain in the plaee where it is made, a great portion of it being sent into the cellars of the nobility in other parts of Hungary. Tokay is certainly a fine wine, but is no way adequate to the price for which it is sold. Several years ago it could not be purchased, even in Hungary, for much less than half a guinea of English money per bottle; and yet there are few Englishmen, who, except on account of its 
scarceness, would prefer it to good Claret or Burgundy. Of all the German wines, that which is in greatest demand in England is Hock. This has its name from the town of Huckstadt in Suabia, celebrated for a great battle which was fought in its neighbourhood by the French and the allies in 1704. Rhenish and Moselle are produced chiefly on the banks of the rivers Rhine and Moselle, and have a cool sharp taste, and considerable strength. Anterior to the late wars in Germany, there were wines in the cellars of many of the noble and wealthy inhabitants of tlat country which were more than a hundred years old, and of such body, as to be uninjured even by so great an age.

$(f)$ Madeira and Teneriffe Wines.-To the Madeira and Canary Islands we are indebted for some excellent white wines. Of these Madeira roine is considered by far the most valuable, particularly after it has been ripened by conveyance into' a hot climate. The number of pipes of Madeira annually made is about 30,000 . The grapes, when gathered, are put into wooden vessels, and the juice is extracted by persons treading upon them.

The Canary Islands gave name to a rich white wine, which was formerly in great esteem under the name of Canary sack, and is now usually called Malmsey Madeira. The genuine Malmsey wine, which is of sweet and luscious tlavour, and rich golden yellow colour, is the produce of Malvesia, one of the Greek islands, and thence had originally its name, the French merchants denominating it Vin de Malvesia : but so little is now made that few persons can possess it. Teneriffe avine, when two or three years old, has much the flavour of Madeira, but, after this age, it becomes so sweet and mellow, as somewhat to resemble Malaga.

(g) Cape Wrnes. - There are produced, at the Cape of Good Hope, two kinds of peculiarly rich, sweet, and delicate wine, called red and rohite Constantia. The 
farm from which they have their name is situated about eight miles from Cape Town. The grapes of this farm, owing, as it is supposed, to some peculiarity in the soil, are superior to any other in the whole country. The vintage commences about March or April; and great care is taken in the manufacture of the wine, no fruit being used but such as is fully ripe and in the highest perfection. The annual produce is considered to be about sixty pipes of the red, and 100 pipes of the white wine. Constantia is in perfection when about two years old; but, when kept six or seven years, it sparkles in the glass somewhat like wine which has not undergone a perfect fermentation. What is denominated Cape Madeira is a light kind of white wine, the produce of the Cape of Good Hope. Considerable quantities of this wine are now consumed in England, in consequence of the lowness of its price. 'This is owing to its paying to government only one third part of the duty which is imposed on most other wines.

The juice of unripe grapes has a harsh, sour, and rough taste. This, under the name of verjuice, was formerly much esteemed for culinary and other purposes. The young truigs of the vine, when dried, cut into small pieces, and moistened with water, afford a wholesome food for cattle and horses. The leaves and tendrils have an astringent taste, which it is probable they would impart to British made wines, and thus render them somewhat similar to foreign wines. The roood of the vine, reduced to charcoal, is used by painter's for drawing outlines; and, from the seeds ur stones, a kind of oil is sometimes made, which can scarcely be distinguished from olive oil. These stones, when purified, moderately roasted, and ground to a coarse powder, form a tolerable substitute for chocolate.

Brandy is a spirituous liquor, produced by the distillation of wine; and prepared in most of the wine countries of Europe. The principal manufactories of this spirit are in France, particularly in Languedoc, and Anjou, whence comes the well-known Cogniac brandy. 
The distilleries of brandy in Catalonia, in Spain, are so extensive as to yield more than 35,000 pipes per annum. When brandy first issues from the still, it is colourless as water; and the colour, which is given to it by the merchants, is produced partly by the oaken casks in which it is kept, but chiefly by the addition of red saunders wood, burnt sugar, and, other colouring matters. These, however, do not in the least affect the quality of the spirit.

In addition to the preceding uses of the vine, we have to add those of its fruit in a recent state, called grapes, as a delicious addition to our desserts; and of this fruit, in a dried state, under tlie appellation of raisins and currants.

Raisins are grapes which have been suffered to remain on the trees until they are perfectly ripe, and have been dried. They are occasionally dried in ovens. Sometimes the clusters, being tied several together, are dipped in a ley of the ashes of rosemary and vine branches, with a certain portion of slaked lime, and are then dried by. exposure to the sun. 'The best fiuit of this description are the sun and jar-raisins; both of which are dried in the sun, without any preparation. These are imported from the southern countries of Europe; and also from the Asiatic provinces of Turkey. They are principally used for desserts, whilst Malaga raisins, and some other linds, are employed for culinary purposes and the making of wine.

79. 'The CURRANT'S of commerce are a small kind of raisins, or dried grapes, whish are produced in the Grecian Arclipelago, and particularly in the islands of Zante and Cephalonia.

The chief plantation of these grapes was anciently in the isthmus of Corinth, whence they obtained the name of Corinths, since corrupted to currants, Few, however, are now produced there, the vineyards having been neglected in consequence of the jealousy of the Turks not allowing large vessels to enter the gulf for their 
exportation. These grapes have no stones, are usually either of a red or black colour, and, when recently gathered, are an extremely delicious fruit.

The harvest commences in the month of August, and, as soon as the grapes are plucked from the trees, they are spread to dry, upon a floor prepared for the purpose by stamping the earth quite hard. This floor is formed with a gentle rising in the middle, that the rain, in case any should fall, may run off, and not injure the fruit: When sufficiently dry, the currants are cleaned, and laid up in magazines, being poured into them through a hole, and stowed so closely that it is necessary to dig them out with an iron instrument. They are packed for cxportation in large caslis, and by persons who have their feet greased in order to tread then close.

The principal consumption of currants is in England; but the inhabitants of the islands whence they are brought know little of the use we make of them. They i:magine that we employ them only in the dyeing of cloth, and are entircly ignorant of our luxury of Christmas pies, and plun puddings. A small but inferior kind of currants are grown in some parts of Spain.

\section{DIGYNIA.}

80. BEET (Beta vulgaris) is a well hnown fleshy or succulent root, which is cultivatcd in our hitchen gardcus, and grows wild in scucral countries of the south of Europe.

There are two principal varietics of beet, one of which is of deep red or purple colour, and the othcr is white, crossed with bands of red.

Red beet is principally used at table boiled and sut in slices : it is, however, sometimes pickled, and sometimes stewed with onions; but, if eaten in great quantity, it is sairl to be injurious to the stomach. The roots may be taken out of the ground for use about the end of August, but they do not attain their full size and perfection till the month of October. When good they are 
large, and of deep red colour; and, when boiled, they are tender, sweet, and palatable.

It has lately been ascertained that beet roots may be substituted for malt, if deprived of the greater part of their juice by pressure, then dried, and treated in the same manner as the grain intended for brewing. The beer, made from beet, has been found perfectly wholesome and palatable, and little inferior to that prepared from malt.

From rolite beet the French, during the late war, endeavoured to prepare sugar; that article, as a British colonial produce, having been prohibited in France. For this purpose, the roots were boiled as soon as possible after they were taken from the earth. When cold, they were sliced, and afterwards the juice was pressed out, and evaporated to the consistence of syrup. The sugar was obtained, from this syrup, by crystallization. From 110 pounds' weight of the roots, $41 \frac{1}{2}$ pounds of juice were obtained, which, on further evaporation, yielded somewhat more than $4: \frac{1}{4}$ pounds of brown sugar; and these, by a subsequent operation, produced four pounds of well grained white powder sugar. The residuun, together with the syrup or molasses which remained, produced after distillation, $3 \frac{1}{2}$ quarts of rectified spirit, somewhat similar to rum.

81. MANGEL.WVURZEL or ROOT OF SCARCITY, is a plant of the beet trilie (a variely of Beta cicla) with large and red reined leaves; those arising from the root being on footstalks, and those of the stem leing withoul stalks, and the flowers grouing in threes.

The farmers, in some parts of Germany, cultivate this plant as food for cattle, and they are said to prefer it, for that use, to potatoes, turnips, carrots, and indeed to most other vegetables. It was introduced to the public nuice in England, by the late Dr. Lettsom; and it has been strongly reconmended, not only for the feeding of cattle, but also for the use of man. Both the leaves and root grow to very large size; and the former, which 
may be eaten as spinach, continue in season long after that plant is withered. The root is insipid and unpalatable; but the stalks, and the stronger middle part of the leaves, may be stewed, or eaten plain-boiled, as asparagus.

82. BARILLA is the Spaniste name of a plant (Salsola soda) from the ashes of which is produced the salt called liali or sodil.

Sude is also procured from the ashes of PRICKLY SALTWORT (Salsola kali), SHrubir Saltwort (Suloola fructicosa), and numerous plants of olher trilies.

On the shores of the Mediterranean, where the preparation of soda is pursued to considerable extent, the seeds of the plants from which it is obtained are regularly sown in places near the sea. When at a sufficient state of maturity, the plants are pulled up by the roots, dried, and afterwards tied in bundles to be burnt. In some places, this is done in ovens constructed for the purpose; and in others, in trenches dug near the sea. The ashes, whilst they are hot, are contiuually stirred with long poles: and the saline matter they contain forms, when cold, a solid mass almost as hard as stone. This mass is afterwards broken into pieces of convenient size for exportation. The best sort of Spanish soda is in dark-coloured masses of biuish tinge, very heavy, sonorous, dry to the touch, and it externally abounds in small cavities. Its taste is sharp, corrosive, and strongly saline.

Soda is chiefly employed in glass and soap manufactories. See the uses of minerals, Vol. i. No. 200.

83. ELMS are forest trees weliknown in alnost cvery part of England. There are scueral species, of which, however, only three, the COMMON ELM (Ulmus cainpestris, Fig. 61,), WYCH HAZEL, or BROAD-LEAVED ELM (Ulmus montana, Fig. (j2,) and Dutch EI, (Ulusus suberosa), grow in this country without cultivation. They are easily distinguishable, from most other forest-trees, ly their leaves being rough, and doubly serrated at the edge.

of these trees the flowers of the first are four-cleft, and hav TOI, II. 
each four stamens, and the fruit is oblong: those of the second are five or six cleft, and have euch five or six stamens, the fiuit is roundish, and the leaves are broad; those of the third are four-cleft, and have four stamens, and the lark of the branches has a corky appearance.

The Dutcli elm is grown in most parts of England. The common elm, though plentiful in Worcestershire, Middlesex, and some other southern counties, is said to be rare further north than Granthan or Stamford. The wych hazel is common in woods and hedges throughout the whole of South Britain.

The use of the elm as timber is chiefly confined to rough and inferior work. Implements of husbandry are almost wholly made of it; and it is employed for waggons, carts, inill-wheels, water-pipes, low-priced chairs, blocks for hatmakers, and various other purposes; and among the lower and middling classes, almost exclusively, for coffins. The preference which it has obtained for the latter purpose, is supposed to have originated in its peculiar durability in moist situations.

Some of the northern writers state that, from the inner bark of the elm, if stripped off in the spring, and boiled in water, a) very palatable kind of beer may be brewell; and that this bark, dried and ground to powder, has, in times of scarcity, been mixed with meal to make bread. It is occasionally administered as a decoction for obstinate cutaneous complaints; and it has been proposed for use in rheumatism, dropsy, and other diseases. The young leaves may be used for the feed. ing of silk-worms.

Few trees are better adapterl than the elın; for planting in hedge rows, along the sides of roads, and along shady walks; but in the latter case the numerous suckers which grow up from its roots give niuch trouble to keep the ground clear.

84. GENTIAN is a bitter drug, the llied root of a plant (Gentianal lutea) which grows will unongst the Alps, and in other mountainous parts of the Continent. 
The Alower-stem of the gentian is two or three feet high, strong, smooth, and erect. The leaves which grow upon its lower part are spear-shaped, and ribbed, and those on the npper part are concare, smoolh, and egrg-shuped. The fluwers, which ure large and yellow, grow round the upper part of the stem on strong foot-stalks, and are divided at the edge into five or more segments. The calyx is a hivd of sheath.

Gentian is one of the principal bitters that are now used in medicine; and is of considerable service in fevers, and in such complaints as arise from weakness of the stomach. It is externally of a brown colour, and internally yellowish or bright red. Its taste is at first sweetish, but immediately afterwards bitter and pungent. As a simple bitter, it is rendered more grateful to the stomach by the addition of some warm aromatic; and, for this purpose, orange-peel is commonly employed. An extract of gentian root, boiled with water till it has nearly the consistence of honey, is kept in the shops.

85. GARDEN CARROT (Daucus carota) is a plant too well known to need any description.

In few vegetable productions are the effects of cultivation more conspicuous than in the carrot. The wild plants, which are common in most parts of England, have a root so small and woody, that no one could suppose they had any alliance whatever to the large and succulent root of ihe garden carrot.

The various uses of the carrot in crokery are well known. But, although it contains much nutriment, this root is difficult of digestion; particularly if eaten raw, or imperfectly boiled. Carrots are an excellent fodder for cattle and horses, either alone or mixed with hay; and, if given to cows, in winter or the early part of spring, they are said to cause a great increase of milk. If carrots be boiled with their wash, hogs will thrive well upon them. In some parts of Lingland this vegetable has been cultivated as a winter food for deer; and the leaves have sometimes been made ז 2 
made into hay. Carrots contain a large proportion of saccharine matter, and various but unsuccessful experiments have been made to estract sugar from them. They have, however, been more advantageously em. ployed in distillation. Ten pounds' weight of carrots will yield about half a pint of very strong, ardent spirit; and the carrots (twenty tons in weight) pro. duced by an acre of ground, have been known to produce 240 gallons of spirit. A syrup made of these roots, and clarified with the white of eggs, has been found useful for many purposes. An infusion of the seeds, and the expressed juice of the roots, are said to afford relief in fits of the gravel. A marnalade of carrots has been used with success in sea-scurvy, and a poultice prepared from them is sometimes employed in cancerous ulcers. Crickets are so fond of these roots that they may easily be destroyed by making a paste of flour, powdered arsenic, and scraped carrots, and placing this near their habitations.

86. ROCK SA.HPHIRE (Crihlmum marilimun) is an umbellife:ous plent, with fleshy spear-shined leuftets, and small but regular shaped white flucers.

The cliffs of Dover have long been celebrated for the production of this vegetable. which has received an additional interest from the notice that Shakspeare has taken of the gathering of it:

"Half-way down

"Hangs nne that gathers samplire; dreadful trade !"

It is also found on cliffs of other parts of the south of England, as well as in Italy, France, and spain; and generally in inaccessible situations.

In some parts of England the leaves of samphire: pickled in vinegar are in use for the table: they are. a'so used in salads, and for other culinary purposes. 13ut their place is frequently supplied by a nicich more. common plant, which grows in salt mar'shes, and has the name of marsh samphire (Salicornia). This, how- 
ever, is a very inferior substitute, and entirely destitute of the fine aromatic: finvour of the former species.

87. ASAFCETIDA is a resinons gun, procured from the ront of " large unbelifferous plant (Ferula asafoctida) uhich grous in the monutains of sone purts of Persia.

The leares of this plunt are nearly two feet long, doully winged, and hare the leaflets alternate. The fluners are small, und the seeds orul, flat, und euch marked with three longitulinal lines.

Nn one who has ever smelt the peculialy powerful, and garlic-like odour of asafœtida, can well forget it. If exposed to the air, but particularly when heated, it will pervade every apartment of a house. Notwithstanding this, it constitutes a favourite seasoning, for food, with the inhabitants of many of the eastern countries of the world. The Banian Indians, who never eat animal food, use it in almost all their dishes; and, before their meals, they even rub their mouths with it. to stimulate their appetite. It is sometimes used by our own cooks, but in very small quantity, in place of garlic. In maliy parts of Arabia and Persia, asafoetida is much esteened as a remedy for internal diseases, and even as an exter.ual application to wounds; and, with us, it is considered a powerful medicine in several disorder's. It has been applied, with success, in the cure of hooping-cough and worms; and in flatulent colics, it has, in many cases, afforded great relief. It is imported in masses of various sizes and form, and of yellow, brown, or bluish colour, sometimes interspersed with roundish white pieces.

The plant from the root of which asafotida is produced grows in the mountains which surround the small town of Disgnun, in Persia; and, at the season when it is collected, the whole place smells of it. The upper part of the roots, whicli are sometimes as thick as a man's leg, rises somewhat above the surfice of the ground. The harvest cominences when the leaves begin to decay; and the whole gathering is performed by the inhabitants of the place, in four different journeys to the mountains. The demand for the article in 
foreign countries being first ascertained to be sufficient for the trouble of collecting, the persons employed proceed to the mountains in companies of four or five each. The juice is obtained by cutting the roots across, at the same time sheltering them by the leaves (which have been previously twisted off) from the intense heat of the sun. Each party takes into its care about 2000 plants. After the first incision has been made, the roots are suffered to remain untouched for about a month, when they are agrain visited, and the gum which has exuded is taken off. This operation is repeated three times, a few days betwixt each; after which the plants are exhausted and left to die. At the respective gatherings each party generally brings away about fifty pounds' weight of asafortida. It is stated that a single ship is exclusively devoted to transporting the bulk of this commodity to the ports in the Persian Gulf; and that, when smaller parcels are carried, it is usual to tie them to the top of the mast.

In the year 1784, the asafoetida plant was introduced into the botanic garden at Edinburgh, from seeds which had been sent by Dr. Guthrie of Petersburgh to Dr. Hope.

The ferula tribe consists of nine or ten known species of plants, and it is supposed that asafotida is yielded by several of them.

. In some parts of the Levant the sailors are said to use the stallss of a species of ferula to transport fire from one island to another. This custom is of great antiquity, and explains a passage of Hesiod, who, speaking of the fire stolen from heaven by Prometheus, says that he carried it in a ferula. The foundation of this "fable is undoubtedly owing to what Diodorus Siculus informs us of Prometheus, that he was the inventor' of the steel with which fire is struck from flint; and in all probability that prince made use of the pith of the ferula instead of tinder, to convey it from ons place to another. 
88. CORIANDER is a small globular seed, produced by an anmul umbelliferous plant (Coriandrum sativum), with leaves in sleuder segments, and smull whitish fluwers, that grows wild in Suffolle and Essex, and is culticated in screral parts of England.

In several farms in Essex and Kent the cultivation of coriander is pursued to considerable extent. 'This is done soiely for the seed, which is used by distillers, druggists, and confectioners. In some parts of the North of Europe it is ground and mixed with dough, to give an aromatic flavour to bread.

Coriander is usually grown with teasel (53) and carraway (91); but, as neither of the latter come to perfection until the second year after they have been sown. the coriander is liarvested without interfering with the other crops. In this labour, which usually commences about the begirning of July, women and children are principally employed; and, to prevent the seeds of the largest and best plants from being shed and lost, each stem is cut separately. The stems are then carried in to some convenient part of the field, and threshed all together upon a sail cloth.

So luxuriantly, and, at the same time, so abundantly does this plant grow in a wild state, in some of the southern parts of Europe, as almost to choke the growth of wheat and other grain. Every part of it, except the seed, has a fetid and disagreeable smell. 'The seeds, when taken in large quantities, have been considered injurious; but Dr. Withering states, that he has known six drams of them taken without any remarkable effect.

89. PAKSNIP is the root of an umbelliferous plant (Pastinaca sativa), with winged and serrated leaves, and small yellow floicer's, which is cultivated in kitchen gardens, und which also grous wild on the borders of ploughed fields in severul purts of Englund.

The wild and cultivated parsnips differ much from each otlier, but particularly in the roots of the latter being large and succulent, and those of the former being slender and woody. 
Parsnips are propagated by seed sown in February or March, and the roots are in perfection about October. These, besides their use as a vegetable for the table, are of great value for the feeding of cattle, horses, sheep, and hogs. Land in Guernsey, which lets for $7 l$. an acre, is suwn with parsnips to feed cattle; and the milk of the cows so fed is not only richer than it would otherwlse be, but yields butter of tine saffron colour and excellent taste.

If parsnips be washed clean, and sliced among bran, horses will eat them. Thcy will fatten sheep and oxen in a short time; and for: the feeding of loogs they are at least cqual if not superior to carrots. As food for mankind they are considered extremely nutritive; and may, with great advantage, be kept on board ships that are destined for long voyages. It is, however, said that they should not be dug up for use in the spring, because, at that season, the nutritive juices rising upward to produce the seed, they are then unwholesome.

Parsnips abound in saccharine juice; and various experiments have, in vain, been made with a view to extract sugar from them. In several parts of Ireland they are used instead of malt in brewing ; and, when properly fermented, they afford an agreeable bevernge. The seeds are considered by some practitioners as an efficacious remedy in intermittent fevers.

90. FENNEL (Anethum freniculum) is a well known pollunt, which is cultivated in gurdens, und grouts wild in sereral purts of Englund.

The leaves of fennel, both boiled and raw, are used in sauce for several kinds of fish. The tender buds are eaten in salads; and, in Italy, the stalks are sometimes blanched as winter salad. A distilled water, prepared from the seeds, is occasionally administered as a medicine; and there was formerly a notion that the roots were peculiarly valuable, as a remedy in several diseases, but they are now almost wholly disregarded. 
91. CARAWAY is a small well linown sect, produced by an umbelliferous plunt (Curum carui), witli smooth and double winged lemes, narrow l'nflets, and smull urhite, or pulte flesle-coloured fowers, of which the petuls are bent incurd, so as to bicome herirtshaped.

The seeds of caraway have a pleasant spicy smell, and a warm aroniatic taste. They are much used by pastry-cooks and confectioners in cakes, and for other purposes. Incrusted with sugar, they are called caraway comfits. They are also distilled will spirituous liquors, to inprove their flavour; and are reconmended as a medicine in several disorder's. An essential oil and a spirit are also prepared from them. In the spring of the year the leaves are sometimes used in soups, or boiled with pot herbs. Tie roots may be converted into an agreeable pickle; and, if simply boiled, they are said by Palkinson to be better than parsnips.

This plant grows wild in several parts of England, but particularly in meadows and pastures near Bury St. Edmunds, in Suffolk. It is much cultivated in Essex and Kent. sometimes alone, and sometimes mixed with teasel (;:3) and coriander (\$8). 'The season for' cutting it is about the beginning of July; and it is threshed in the field on a cloth, in the same manner as rapeseed $(187)$.

92. ANISE-SEEDS are the production of an unbelliferous unnual plaut (Pimpinella anesum), which grows uill in Egypt, Syria, and other Eustern countries. They ure roundish and strialed, flatted on one side, und pointed at one end; and of pule colour, inciiving to green.

Attempts were made more than two hundred years ago to cultivate anise in this country, but the summers of our climate are seldom warm enougl to bring the plant to perfection. It has consequently been found necessary to import the seed from Malta and Spain, where it is cultivated to considerable extent.

Anise-seeds have an aronatic smell, and a pleasant warm taste, accumpanied with some degree of sweet-

$$
5
$$


ness. They have long been employed in medicine, and lave been considered useful in disenses of the lungs and complaints of the stomach. They give out all their virtue to rectified spirit; and a spirituous water prepared from a mixture of equal parts of aniseseed and angelica, is kept in the shops as a cordial.

93. PARSLEY (Apium petroselinum) is an annual unbelliferous plant, too common to need any description.

The uses of parsley, in our kitchiens, both for sauce and garnish, are numerous and well known. It is, however, poisonous to several kinds of birds; and, although so commonly used at table, facts have been adduced fiom which it would appear that, with some persons, it occasions epilepsy, or at least aggravates the fits in those who are subject to that disease. Inflammation. in the eyes has also been attributed to the use of it. Parsley is eaten with great avidity by sheep, and has been recommended for use in several diseases of those animals, as well as in some diseases of horses. Both the roots and seed are employed in medicine. The former have a sweetish taste, accompanied with a slight warmth, and a flavour somewhat resembling that of the carrot : the latter are warm and aromatic.

Parsley is a native of Sardinia, and propagated by seed, which is usually sown about the month of March.

94. CELERY (Apium graveolens) is a well knoun plant, belonging to the sume tribe as parsley.

In a wild state celery is found in ditches and marshes of several parts of England, and is a small, acrid, and noxious plant, called smallage: but, when cultivated, it entirely loses these properties.

It is grown in trenches, and is earthed up for the purpose of blanching or whitening the lower parts. The seeds are sown in spring, and the plants may be taken out for uss, horpards the end of the autumn. 
Celery is eaten raw in salads, boiled in soup, or stewed. The seeds are used, particularly at sea, for the flavouring of soup, to which they give the same taste as the plant itself.

95. COPAL is a somewhat resinous sulstance, oblained from a tree (Rhus copallinum) the proalucc of Americu, which has winged and very entire laves, the fool-stalks membranaceous and jointed.

We annually import considerable quantities of copal from the Spanish colonies in America, in irregular masses, some of which are transparent, of yellowish or brown colour, and others are whitish and semi-transparent. When copal is dissolved in any volatile liquid, and thinly spread upon wood, metal, or any other firm substance, so that the liquid may evaporate, the copal remains perfectly transparent; and forms one of the most beautiful and perfect varnishes that can be imagined. The varnish thus formed has the name of copnl varnish, and is said to have been first discovered in France. One mode of preparing it is by melting the copal with an equal quantity of linseed oil (97); another, by mixture with vil of turpentine; and a third, by mixture with alcohol or spirit of wine. 'I'he particular processes are described in the fourth volume of Dr. Thomson's System of Chemistry, fifth edition; but they are too long and intricate for insertion here.

Copal is the varnish which is chiefly used in the japanning of snuff-boxes, tea-boards, and other similar articles.

\section{TRIGYNIA.}

96. The COMMON ELDER (Sambucus nigra) is a wild English shrul, distinunishalie by i!s winged lcaves, with serrated and somewhal ova! leuflels, ils clustcrs of small white flowers dirided inlo five principal lranchcs, and the snall, black or purple leerries by which these are succeded.

The uses of the elder are more numerous than those of most other shrubs. There is scurcely any part of this 
shrub which has not been advantageously employed in some way or other. The wnod is yellow, and, in old trees, becomes so hard that it will take a polish almost as bright as that of box (232); and, indeed, it is often used as a substitute for box-wood. Its toughness also is such that it is made into strewers for butchers, tops for fishing rods, and reedles for the weaving of nets. It is liken ise employed by turners.

Sir J. E. Snirh has remarked that this tree is, as it were, a whole magazine of physic to rustic practitioners, and that it is not quite neglected even by professional men. Ointments have been nade of the green inner bark, and of the lraves. The dried flowers, infused in water, are used in fomentations, or as tea: and, mixed with butter-milk, they are sometimes employed as a wash for the face; and the clusters of flowers, before they open, may be made into a delicious pickle, to cat with boiled mutton. The berries are boiled into a rob, which is useful in sore throats, colds, and hoarsenesses. In addition to their medicinal services, the leavcs are sometimes thrown irito the subterraneuus paths of moles, under an impression that their smell will drive away those noxious animals. If turnips, cabbages, fruit trees, or corn, all of which are subject to blight from various kinds of insects, be strongly whipped with the green leaves and branches of elder, insects will not attack them; and an infusion of the leaves is sometimes sprinkled by gardeners over the bucls of such flowers as they wish to preserve from the devastation of caterpillars. Elder flowers have an agreeable flavour, which they impart, in distillation, to water; they are likewise used to give a flavour to vinegar. The berries are poisonous to poultry, lut their juice properly fermented, makes a pleasant and wholesome wine; and, in Germany, a very pure and strong spirit is distilled from them. The juice of elder berries is sometimes employed to give a red colour to raisin or other sweet wine. The young shoots of this shrub are filled with an exceedingly light jith, which is cut into balls for elec- 
trical experiments; and is also made into toys for the. amusenient of children.

'The elder will grow and thrive in almost any soil and situation; but, as every part of this shrub has an unpleasant narcotic sniell, people ought to be cautious not to sleep under its shade, as, in such case, it might prove of serious injury to them.

\section{TEYRAGYNIA.}

97. FLAX is the produce of an anmual piant (Linum usibulissinum, Fig. 37), wilh sprar-shaped laves, and line flowers, which is cultiruted in several parts of Great Brilain, and grous wild in corn-fields and sundy pastures of some of the southern countie's.

The stems of' these plants rise to the height of about two fert. The sead vessels and la aves of the calyov are sharp poinled, and the flowers have each fice scolloped petals.

It is supposed that we were originally indebted for this plant to those parts of Egypt which are annually inundated by the Nile; but the time of its introduction into this country is unknown. It utility is incalculable. To it we are indebted for the linen we wear, for our sheets, tablencloths, and numerous other indispensable articles of clothing and domestic economy; and although cotton might, in some degree, supply its place, those persons who have been accustomed to the comforts of linen would be little desirous of the exchange.

The cultivation of flax is pursued to considerable extent in some prarts of the British dominions. The seed imported from Riga and Holland is generally, though perhaps erroneously, esteemed the best. It is sown in March or April ; and the plants, when nearly ripe, are pulled up by the roots. 'I hese, if flax and not seed be the object of the crop, are either placed in snall parceis upon the surface of the land, for exposure to the sun, to dry; or they are immediately conveyed to the place where they are to undergo the pro cess called watering. For this purpose they are loosely tied in small bundles, placed in pools or pouds of sot. 
and stagnant water, and allowed to continue there several days. By the fermentation which takes place, the bark or flaxy substance becomes separated. They are then taken our, and thinly spread upori the grass, in regular rows. Here they are occasionally turned until they have become so brittle, that, on being rubbud between the hands, the flax easily and freely separates from the stalks. They are taken up, anil bound in sheaves, to be either sent to a mill, or to be broken and scuttled, as it is called, by a machine contrived for that purpose.

The flax, by the above process, having been separated from the stalks, it subsequently undergoes various dressings, according to the purposes for which it is to be used.

When the plants have been grown for seed, they are pulled as before, and then laid together by handsful upon the ground, with the seed ends towards the south, that they may be the better exposed to the sun. The next operation is to force off the seed vessels. For this purpose a large cloth is usually spread on some adjacent and convenient spot of ground, and an instrument, called a ripple, is placed in the nicldle of it. This is a sort of comb, consisting of six, eight, or ten, long, triangular, upright teeth. The seed ends of the flax are pulled repeatedly through the teeth of the conib, by which the parts containing the seed are removed from the stalks. After this the pods and seeds, which have the name of line-seeds, are spread upon a cloth in the sun to dry, and subsequently are threshed, sifted, winnowed, and cleansed. The best seed is generally preserved for sowing, and the second sort yields considerable profit in the oil which is obtained from it by pressure This, which is called linseed oil, is equally useful in the arts and in medicine. It is occasionally employed for making the soap called green soap. If lieat be applied during the pressure of the seeds, the oil attains a yellowish colour and a peculiar smell, and, in this state, it is used by painters and varnishers. An infusion of the 
seed, in the manner of tea, is recommended in coughs; and from the seed is also made an useful kind of poultice for external inflammations.

After the oil has been expressed, the remaining farinaceous part of the seeds is squeezed together into large masses, called oil-cake, which is given as food to oxen.

lt must be remarked that the water in which flax has been macerated becomes thereby poisonous to cattle; and, on this account, the practice of steeping it in any running stream or common pond was prohibited by an act of Parliament, passed in the reign of Henry the Eighth.

\section{CLASS VI. HEXANDRIA.}

\section{MONOGYNIA.}

98. The PINE (Bromelia ananas) is a rich and highly fragrant fruit, of lurge size, and yellow colour, with protuberances on its surface; and crowned by a tuft of strong and pointed leaves, edged with sharp spines.

This, the best and finest flavoured of all known fivuits, was originally imported into England from South America, about the year 1690. In that country and the West Indies it has long been cultivated in the open ground; and, from free access to a congenial atmosphere, it attains there a much fine flavour than is possible in a forced state, in the hot-houses of Great Britain.

Pines are planted in earth; and the pots which contain them are immersed in beds of bark, after it has been used by the tanners. About the month of April the young fruit begins to advance, but the usual season for. ripening does not commence till July, and the fruit 
is in greatest perfection from the middle of August to the end of september. The ripening of pines is dis. coverable by the fragrant odour which they emit, and by their protuberances yielding to pressure with the hand; and their favour speedily dissipates if left uncut longer than three or four days after they are fully ripe. When brought to table, their leafy crowns should be reserved for planting. These, if placed in pots, and plunged in the bark-bed, or in a hot-bed, and covered, for some time, with glass, will in two years bear fruit.

There are several varieties of pine, of which the following are among the principal.

(a) While Pine.-1his has a whitish and fibrous flesh, and the rind as yellow as that of an orange. Its smell is highly fragrant, and it excels most other kinds in size and beauty, though its flavour is inferior to that of many. Its juice edges the teeth, and sometimes makes the lips smart.

(b) The yellow pine edres the teeth less : but both this and the preceding variety are exceeded by

(c) The sugar-lonf pine; which is distinguished by the purple stripes on the outside of the leaves, and by its straw-coloured fruit.

(d) The Montserrat pine is now rare in Europe, though in America it is estecmed in preference to most others. It is principally kuown by the protuberances of the fruit being longer and fatter than those of the common sort.

In the West Indies an excellent liquid sweetmeat or confection is made from pines. 'This fruit also is sometimes preserved whole, and, when taken out of the syrup, is iced over with sugar. Sweetmeats of this kind were formerly sent into Europe, in great quantity, from the Antilles. Wine made from piries is almost equal to Malmsey: at the end of about three weeks it becomes so ewhat acid, but it recovers by longer keeping. P'ines in the West Indies, are frequently put into rum to communicate to that liquor their peculiar aromatic flavour. 
99. GARLIC (allium sativum) is a plant with bullous ront, of irregalar form, composed of many smullei bulls, called cloves, which are all included within a white slin.

The st.pm leaves are flut and narrow ; the upper part of the stern bears small bulls, and the stamens are three pointed.

In warm clinates, where garlic is produced with considerably less acrimony than in this country, it is much used, both as a seasoning and as food. 'The lower classes of French, Spaniards, and Portuguese, consume great quantities of it. The Jews also eat of it to excess. With us it is in considerable estimation for culinary and other domestic purposes. It has an acrid taste, and an highly offensive smell: and it differs from the onion only by being more powerful in its effects. When bruised and applied to the skin, it causes inflammation, and raises blisters.

The medical properties of garlic are various. In dropsical complaints, asthmas, and igues, it is said to have been successfully used. Some instances have occurred, in deafiress, of the beneficial effects of wrapping a clove of grarlic in muslin and putting it into the ear. As a medicine internally taken, garlic is administered as a bolus, $01^{\circ}$ made into pills. Its smell is considered an infallible remedy against vapours: and to be useful in nearly all the nervous disorders to which females are. subject. An oil is sometimes prepared from garlic, which is so heavy as to sink in water. But the virtues of this pungent vegetable are more perfectly and more readily extracted by spirit of wine than in any other way. A syrup is also made from it.

'The juice of garlic is saill to be the best and strongest cement that can be adopted for broken glass and china, leaving little or no mark, if used with care. snails, worms, and the grubs, or larvæ of insects, as well as moles, and other vermin, may all be driven away by placing preprations of garlic in or 11 ear their haunts.

'This plant grows wild in the island of Sicily.

100. LEEKS (Allium porrum) belong to the onion or garlic tribe, and are known by their leaves growing out on each 
In some countries leeks are much esteemed for culinary uses, in soups, broth, and for boiling as greens with meat.

They are considered the badge of the Welsh nation, and representations of them are fiequent'y worn by persons of that country on the day of their patron saint, St. J)avid. The origin of this custom was an occurrence, during the Welsh wars, in which a party of Welshmen, wanting a mark of distinction, and shortly afterwards passing through a field or garden of Jeeks, seized and stuck the plants in their caps, and under this signal were victorious.

Leeks are natives of Switzerland.

101. SHALOT (Allium ascalonicum) is a lind of gurlic, the bull's or roots of which are oblong, irregular, und seldom of large size.

The stem is naked and round; the leaves are somewhat awlshaped; the head of flowers is globular; and the stumens are threc-pointed.

The uses of shalot, or echalote, as it is denominated by the French, are alinost wholly confined to cookery. It has a strong, but rather pleasant smell, on which account it is renerally preferred to onions. It is employed for the seasoning of soups, gravy, hashes, pickles, and for numerous other purposes.

This plant grows wild in several parts of the Continent.

102. The CANADIAN or TREE ONION (Allium Canadense) is remurkatle for producing a bull or onion at the top of the stalk.

The stem is naked and round; and the leaves nre flat and narrow.

These onions are well deserving of attention both as objects of curiosity, from producing their bulb at the upper extremity of the stalk, and also for their use. When pickled, they are generally thought superior in Havour to the common onion.

They were originally imported from Canada; are 
perennial, and are propagated by planting the bulbs in the spring or autumn. Either the bulbs of the root or those on the stalk will grow.

103. CHIVES (Allium schænoprasum) are the smallest of the garlic tribe, seldon rising morc than a few inches above the ground, and the bulls not leing larger than peas.

The slem is nuked, as long as the leaves; and the lewes are round, and somewhiat awl-shaped.

Chives are natives of Italy, Switzerland, and several other parts of Europe; and are so hardy, and at the same time so useful, that they merit a place in every garden: yet, in the nurthern counties of England and in Scotland, they are very rarely to be seen. The leaves, which are small and are the principal parts that are . used, appear early in the spring. They are employed in salads, and for numerous culinary purposes; and often at a season when other plants of the same tribe cannot be procured.

104. The COMMON ONION (Allium cepa) is known by its round and hollow leaves, and its swelling pipy stalk, which is considerally thicker in the middle than either at the top or lottom.

The name of onion is derived from the Latin word unio, which, properly, signifies a bulb that does not throw out offsets. Onions are propagated by seed which are sown in spring; and the bulbs or roots arrive at perfection in the autumn. The whole plant, when young, is eaten as salad. Onions generally cease to grow towards the middle of August, the stalks and leaves at that time shrinking and turning brown. Shortly after this they must be drawn out of the earth; the tops and blades must be cut off; and the routs dried, either in a warm place, or by exposure to the sun.

Spanish onions are of large size, and flattened shape ; and Portugal onions are large, handsome bulbs, of
roundish form.

By the common people onions are frequently eaten 
raw with their food. This has particularly been the case, and from time immemorial, with the inhabitants of Egypt. By stimulating the stomach, they are supposed to favour ciigestion. Some persons have imagined that they possess a large portion of alimentary matter ; but others say that they afford little or no $n$ urishment, and that, when eaten fieely, they produce flatulencies, occasion thirst, liearl-achs, and turbulent dreams. (Inions have so, much acrimony as generally to affect the breath for many hours; but, when boiled or roasted, this is, in a great measure, dissipated, and they then exhibit some sweetness, with a considerable portion of mucilaginous matter. Onions are of great use in several culinary preparations, but particularly in soup and pickles. They are employed in medicine chiefly as poultices for swellings; and have been recommended by some persons, to be rubbed on bald parts of tbe head, to promote the growth of the hair.

105. ASPARAGU.S (Asparagus officinali is is a well hnown planl, the young shools of which are a faturtite culinary vegelalle.

Few circumstances in the phenomena of vegetation are more remarkable than the gradual enlargement of size, and improvement of quality, which have taken place in the cultivation of asparagus. It grows wild on the pebbly beach nerir. Weymouth, and in the island of Anglesea: but its sten, in these situations, is not usually thicker than a gonse's quill, and its whole height does not exced a few inches: whereas in gar-
dens its stem is sometimes near three quarters of an inch thick, and its height, when at maturity, is four or five feet.

Asparagus is one of the greatest delicacies which our kitchen gardens afford, and it is particularly estimable from the early season at which it is p:oduced. Even in the open ground, it is in perfection for the table about the end of April; and when forced, by being planted in hot-beds under glass, it may be cut much earlier. 
Asparagus continues in season till about the end of June.

It is usually raised from seed, in beds formed for the purpose: and the plants shuuld remin three years in the ground before they are cut: after which, for several years, they will continue to afford a regular annual supply. During the winter, they are secured from the effects of frost by the beds being covered some inches thick with straw or litter.

In the cutting of asparagus, the knife is passed three or four inches beneath the ground. The plints are cut by sloping the blade upward; and the white part that we see, is that which had not previously been exposed to the air. The smallest plants are suffered to grow for the purpose of producing berries to restock the beds, and keep them continually in a state of supply.

106. ALOES are an extensive tribe of plants, some of which ure not more thun a few inches, whilst others are thirly feet and upwards, in height. All the leaves are fleshy, thick, and more or less spinous at the edges or extremity.

These plants, which are chiefly inhalitants of hat climates, have flowers of a single petal, lise mouth expanded, the lase necturiferous, and the filaments of the stamens inserted into the receptucle.

Some of the larger kinds of aloes are of great importance to the inhabitants of countries in which they grow. Beset as the leaves are with strong spines, they form an impenetrable fence. The negroes of the western coast of Africa make ropes and weave nets of the fibrous part of these leaves. 'l'he Hottentots hollow out the stems of one of the kinds into quivers for their arrows. In Jamaica, there is a species of aloe which supplies the inhabitants with bow-strings, fishing lines, and materials from which they are able to weave stockings and hammocks. An aloe which grows in the kingdom of Mexico is applied br the inhabitants to alınost every purpose of life. It serves as hedges for enclosures: its trunk supplies the place of timber for 
the roofs of houses, and its leaves the place of tiles. From this plant the Mexicans make thread, needles, and various articles of clothing and cordage: whilst from its juices they manufacture wine, sugar, and vinegar. Some parts of it they eat, and others they apply in medicine.

The juice of aloes was formerly used in Eastern countries in embalming, to preserve dead bodies from putrefaction; and, as the resinous part of this juice is not soluble in water, it is sometimes adopted in hot climates as a preservative to ships' bottoms against the attack of marine worms. One ounce of it mixed with turpentine, tallow, and white led, is considered to be sufficient for covering about two superficial feet of plank; and about twelve pounds are sufficient for a vessel of fifty tons' burthen. In proof of the efficacy of this method, two planks of equal thickness, and cut from the same tree, were placed under water, one of them in its natural state, and the other smeared with the composition above described. They were suffered to continue in the water eight months, and when, at the end of that time, they were taken out, the former was perforated in ever'y part, and in a state of absolute decay ; whilst the latter was as perfect as at firot. In the East Indies, the juice of these plants is used as a varnish, to prescrve wood from the attacks of destructive insects : and skins, and even living animals, are sometimes smeared with it for the same purpose.

There is a tract of mountains, about fifty miles north of the Cape of Good Hope, which is wholly covered with aloes. Among the Mahometans, and particularly in Egypt, the aloe is a kind of symbolic plant: it is dedicated to the offices of religion; and pilgrims, on their return from $\mathrm{Mecca}$, suspend it over their doors, as a declaration that they have performed that holy journey.

107. SOCOTRINE ALOES are the dried juice of a large species of aloe (Aloe perfoliala, $\mathrm{F}_{1} \mathrm{~g} 38$ ) which grows in treat abundance in the island of Zocotra, near the moulh of the Red Sea. 
The leaves are sword-shaped, fleshy, smooth, full of juice, of bluish-green colour; and beset at the edges with strong spines. The flower-stems rise to the height of three or Sour feet, are smoolh, erect, and have at the top a spitie of flowers of purple or reddish colour, the stamens of which have oblong orange-coloured anthers.

The true Socotrine aloes are imported into this country wrapped in skins; and when pure have a bright surface, and are in some degree pellucid. In the lump they have a yellowish red colour, with a purplish cast; and when reduced to powder, are of a golden yellow. Their taste is bitter and disagreeable, but somewhat aromatic; and their smell is not unpleasant.

Barbadoes aloes, common aloes, or hepatic aloes, are the dried juice of a variety of the Socotrine aloes, which is cultivated in Barbadoes and Jamaica. Of this we import three kinds : one in gourd shells; an inferior kind, in pots; and another, still worse, in casks.

In the cultivation of aloes it is requisite that the plants should grow for two or three years before the juice is procured from them. The operation of collecting the juice is performed in different ways. Dr. Browne tells us that labourers go into the field with knives and tubs; and that cutting off the largest and most succulent leaves close to the stalk, they inmediately put them into the tubs in an upright position, that the liquor may drain from the wounds. When this is nearly all discharged, they take the leaves out singly, and clear them of any juice that may adhere to them; and the liquor is then put into shallow flat-bottomed vessels, and dried gradually in the sun, until it acquire:s a proper thickness to be poured out or ladled into the gourd shells which are to contain it. What is thus obtained is called Srocotrine aloes, and is the clearest and most valuable of any. An additionsl quantity of juice is obtained by pressing the leaves.

- In some places the plants are pulled up by the roots, and, after having been carefully cleansed from earth or other impurities, they are sliced and cut in pieces, into 
small hand-baskets or nets. In these the pieces are boiled. for a little while, in water, by which the juice is extracted; and successive baskets full are boiled in the same liquor, until it becomes thick and of dark colour. The fluid part is subsequently evaporated, and what remains is put into gourd shells for sale.

Other methods of inspissating or drying the juice are to pour it into bladders left open at the top, and suspended in the sun; or to place it in broad shallow trays of wood, pewter or tin, exposed to the sun every dry day, until the fluicl parts are exhaled, and a perfect resin is formed, which is then packed up for sale

There is a kind called Cabnlline or horse aloes, which has a rark and unpleasant smell, but in taste is not much more disagrceable than either of the others. In its properties it agrees nearly with hepatic aloes, but it is chiefly employed by farriers in horse medicines.

The medical properties of aloes lave long been known and established: and their extensive application in medicine is, perhaps, the best proof that can be adsluced of their utility. In the arts aloes are, in several respects, useful. But, particularly, the leaves of the Socotrine aloes afford il beautiful violet colour which does not require the ild of any mordant to fix it; the same also is capable of being formed into a fine transparent colour for painting in miniature.

108. The GRFAT, or AMERICAN ALOE (Agave Americani), is a large plant, the leaves of which are thick, fleshy, and spinous ai the edge, and the stem branched and of grenï height.

The fiouers of this plant are distinguished by haring the tule of ihe corolla narrowed in the middle, the stamens longer than the corolla, and the style longer than the stamens.

This magnificent native of North America is by no means an uncommon plunt in our gardens, but, with us, it is seldom seen in flower. There is indeed a notion, but it is an erroneous one, that the American 
aloe does not bloom until it is a hundred years old. The fact is, that the flowering depends alnost wholly on its growch. In hot countries it will flower in a few years; but in colder climates, the growth being slower, it is necessarily longer in arriving at maturity. The stem which bears the blossoms rises fiom the centre of the leaves, and, when the plant is in a vigorous state, it fiequently exceeds the height of twenty feet. An American alse in the garden of the ling of Prussia was forty feet high. Branches issue fiom every side, and in such manner as to form a kind of pyramid, composed of greenish yellow flowers, which stand erect, and are seen in thick clusters at every joint. When in full flower, the appearance of this aloe is extremely splendid; and if the scason be favourable, and the plant be sheltered from the cold in autumn, a succession of blossoms will sometimes be produced for near three months.

In the warmer parts of Europe, Anerican aloes are cultivated as objects of cunsiderable utility. They are frequeltly grown in rows, as fences, for enclosures, particularly in Spain, Portugal, and Italy. In Algarvia the leaves are employed for scouring pewter and other kitchen utensils, and floors; and, cut into slices, are used for the feeding of cattle.

By a certain preparation, the juice of the leares is made into cakes, which are employed for washing, and which will lather with salt water as well as with fresh. The fibres of the leaves, when properly prepared, may be separated into threads that are useful in various ways. This separation is sometimes effected by bruising ard steeping them in water, and afterwards beating them. The process, in some parts of Portugal, is, after plucking the largest and best leaves, to place them on a square board, which a person presses obliquely between lis breast and the ground, and then scrapes with a square iron bar held in bothl hands. By this operation all the juices are pressed out, and only the fibres and some of the membranous parts of the leaves remain, which are then easily detached. The fibres are employed for

VoL. 21. 
all the purposes to which tliread can be applied, but they are neither strong nor durable; and if exposed to moisture, they soon decay.

109. The FAN PALM is a very remarkable tree (Corypha umbriculifera) that grows in the East Indies, but particularly in Malabar, and the island of Ceylon; its leaves, eight or ten in numler, rise out of the summit of the trunk, are zoinged and somewhat fan-shaped, and have their segments connected by a thread or filte.

The stem of the fan palm is straight, cylindrical, smooth, and as tall as a ship's mast. Its leaves are upwards of six yards in length, and four yards wide; and form altngether a head of twelve or thirteen yards in diameter. These leaves, which, when dry, fold up somewhat like a fan, are used for the covering of liuts and coitages; and not untrequently by soldiers, instead of canvas, for the construction of tents. One of them is sufficiently large to shelter twenty persons from the rays of the sun. 'They are also a kind of natural paper on which the inliabitants write, by means of a starp-pointed iron instrument, which leaves indelible marks upon them. Many of the books which are shown in Europe for thuse of Egyptian papyrus (26) are said to be formed of parts of these leaves. - The rith of the trunk, beaten into a kind of paste and mixed with water, is formed into cakes, and constitutes a species of bread, very serviceable to the inhabitants in times of scarcity. The juice of some parts of the tree is used as an enetic.

'The fan palms are said not to bear fruit until they are near forty years old; but after this period, when in perfection, they produce annually more than twenty thousand berries each. These are each about $1 \div$ inch diameter, of globular shape, smooth, green, and fleshy; but are not known to be of any use.

110. The ROTANG or DRAGON'S BLOOD TREE, is a sperites of eane (Calamus rntang) which grows to the length of more than a hundred feet, is abont as thick as a man's arm, and is closely lieset with erect prickles. 
This cane has at the top a tuft of lenves which are several feet in length, and allernalely winged, and of which the leaflets are sword-shaped, and armed with sharp spincs.

In consequence of its great length and slender form, the rotang tree (which is usually found in woods near rivers, and in morassy places) does not grow entirely upright; but, after having attained the height of five or six yards, it depends, for support, upon other trees, which it sometimes overruns, in nearly an horizontal direction, to the extent of sixty or eighty feet. The flowers are produced in upright spikes that separate into long spreading branches, and are succeeded by a red and somewhat egg-sliaped fruit, which to the taste is pleasantly acid.

The drug called Dragon's Blood* is obtained from this fruit, in Japan, and several other countries of the East. The Japanese expose the fruit of the Rotang tree to the steam of boiling water, by which the external shell is softened, and a resinous fluid is forced out, that is afterwards enclosed in leaves and suspended in the air to dry. In Sumatra the external surface of the fruit is observed to be covered with the resin: this is rubbed off, melted in the sun, and formed into grains or globules, which are folded in leaves, and are considered the purest kind of dragon's blood. In some countries the fruit is boiled in water, and the resin, which floats upon the surface, is skimmed off and subsequently purified, and formed into the requisite sliape for sale. An inferior kind of dragon's blood is made up into large masses, which contain the membranous parts of the fruit and other impurities. When this substance is tolerably pure, it breaks smooth, and appears internally of a dark red colour; melts readily, and easily catches fire. Its principal use is in medicine.

The stem of the rotang furnishes the inhabitants of the countries where it grows with shafts for pikes or

* Several other trees besides this produce the red kind of resin called Dragon's Blood.

$$
\text { F. } 2
$$


spears; and the inner part of the young shoots is boiled or roasted for food.

111. The COMMON WALKING CANES (Calamus scipionum) have a smooth and glossy stem, usually marked with dark spots: and the knots or joints are sometimes three or four f'cet asunder.

These canes grow, very abundantly, in Sumatra and other Eastern islands, as well as on the continent of India, whence they appear to have been originally exported to Europe by the Dutch. There is a consiclerable trade in them to China. The long spaces between the knots, their shining surface, and Jightness, have renclered them preferable to most other articles for walking canes.

112. The RATTAN, or TRUE CANE (Cillamus verus), is remarkalle for growing to the great length of a hundred feet and upwards, and, at the same time, not leing thicker than a n'an's finger.

A trade in rattans to considerable extent is carried on from several of the islands of the east to China, which is the principal market for them. These canes are extremely tough and fle ible, of yellowish brown colour, and, when cut into thongs, are sonetimes used to make cables and other ropes. Our caue-bottomed chairs are male of split rattans, the outer or smooth surface of which is always kept uppermost. For this work the canes are chosen by their great length, pale yellow colour, and bright gloss. They are purchased in bundles, each of which contains a hundred canes, neatly tied in the midcle, and the ends bent together. When perfectly dry, they are so hard as to yield sparks of fire when struck against each other. 'The word rattan, in the Malay language, signities a staff or walking stick.

113. The BAMBOO CANE (Bambusa arundinacea) has a hollow, round, straight, and shining stem; and sometimes grow's to the length of furty feet and upwards: it has knots at the distance of ten or twelve inches from each other, with 
thick, rough, and hairy sheaths, alternate branches, and inull, entire, and spear-shaped leaves.

There is scarcely any plant so common in hot climates as this, and few are more extensively usetul. It occurs within the tropical regions both of the eastern and western hemispheres, throughout the Eirst Indies and the greater part of China, in the West Indies, and America. In Englanol, it can only be cultivated in a hot-house; and its growth is so rapid, even there, that a strong shoot has been known to spring from the ground and attain the height of twenty feet in six weeks.

The inhabitants of many parts of India build their houses almost wholly of bamboo; and make nearly every description of furniture with it, in a very ingenious manner. They likewise form with it several kinds of utensils, for their kitchens and tables; and, from two pieces of bamboo rubbed hard together, they produce fire. The masts of boats, boxes, baskets, and innumerable other articles, are made of bamboo. A fter having been bruised, steeped in water, and formed into a pulp, the sheaths and leaves may be manufactured into paper. The stems are froquently bored, and used as pipes for conveying water ; and the strungest stems serve to make the poles with which the slaves or servants carry those kind of litters so common in the East, called palanquins. The stems of the bambou serve also as the usual fence for gardens and other enclosures: and the leaves are gencrally put round the tea which is sent in chests from China to Europe. The Chinese make, of the external bark of the lamboo, a kind of cordage, which has the acivantage of united lightness and durability. For this purpose the bark is cleft in strips several feet in length; and these are twisted together according to the thickness that is required. For the tow lines of their vessels, eight or nine bands or strips are sufficient; bur, for cables, a much greater number is requisite. Some of the Malays preserve the small and lender shoots of bamboo in vinegar 
and pepper to be eaten with their food. Many of the walking canes which we see in Europe are formed of the young shoots of this plant.

The Chinese make a kind of frame-work of bamboo, by which they are enabled to float in water; and the Chinese merchants, when going on a voyage, always provide themselves with this simple apparatus to save their lives in case of shipwreck. It is formed by placing four bambons horizontally across each other, so as to leave, in the middle, a square place for the body; and, when used, this firme is slipped over the head, and secured by being tied to the waist.

114. The COMMON RUSH (Juncus effusus) is known by its green, smooth, stiff, upright, leafless and pointed stem; huving a loose bunch of small flowers at the side, and the sced-vessels blunt at the extremily.

Although the rush is generally considered by farmers a noxious weed in wet meadows and pastures, it is applicable to a variety of useful purposes; but particularly for making the wicks of rushlights. For this purpose it is usually cut a little after Midsummer ; and is immediately afterwards thrown into water, and kept there, that it may not become dry, and that it may be the more easily peeled.

At first a person would find it no easy matter to divest a rush of its rind, so as to leave on each side, from top to bottom, one regular, narrow, and even rib, that may support the pith. But this, by practice, soon becomes familiar even to children.

When rushes are thus far prepared, they are spread on the grass to be bleached; and, afterwards, they are dried in the sun for use.

If only one r'sb of peel be left, instead of two, rushes will supply the place of cutton wicks for candles. In some parts of Hampshire the labouring people form wicks of this description; they dip them into scalding fat or grease, and use them in place of candles. 
Rushes are sometimes manufactured into a sligh: kind of baskets. In the vicinity of Farnliam, in Surry, they are cut about Midsummer, and dried in the same manner as hay. After this they are formed into a kin.l of rick, and sheltered till the succeeding spring. Ther are then usefully employed, for bands or ties, in fastening hop-binds to the poles. In a fresh state they are sometimes made into brooms or besoms for black smiths, and other artisans working in metals.

115. BARBERRIES are a beautiful red and ollongshaped fruit, produced, in small bunches, by a slirub (Berbelris vulgaris) which grows wild in many parts of Englann. This shrub has somewhat oval, serrated, and pointed leaves: thorns growing three together upon the branches; and pen. dent clusters of yellow flowers.

So great is the acidity of this beautiful fruit that even birds refuse to eat it. In this respect it nearly approaches the tamarind. When boiled with sugar, however, it makes an agreeable preserve, rob, or jelly, according to the different modes of preparing it. Barberries are also used as a dry sweetmeat, and in sugarplums or comfits; are pickled with vinegar, and are used for the garnishing of dishes. They are likewise well calculated to allay heat and thirst in persons afflicted with fevers. The bark of the barberry shrub is said to have been administered with effect in cases of jaundice, and in some other complaints; and the inner bark, with the assistance of alum, dyes linen a fine yellow colour. The roots, but particularly their bark, are employed, in Poland, in the dyeing of leather.

A very singular circumstance has been stated respecting the barberry shrub; that corn, sown near it, proves ahortive, the ears being in general destitute of gain : and that this influence is sometimes extended to a distance of three or four hundred yards across a field. A similar opinion, on this subject, prevails in France, as well as in England, but there is reason to suppose it is without foundation. 


\section{DIGYNIA.}

116. RICE (Orvza saliva, lïg. 39) is a well-known hind of grain, which is much cullivated in the I:ust Indics, America, und some jurls of Spain; and whirh, preziously $10 \mathrm{its}$ leing sold for use, is freed from a lvownish husk that corers it.

The rice l, lant has an erect, simple, round, and joinled stem. Its leates are narrow and pointed; and ils flucers appear in a hind of bunch, at the cutromily, somewhint resemliting, but more compact than, an ear of orits.

We, are at present, chiefly supplied witl rice from America; and it is said that the Americans were indebted fur this grain to a small bag of it which was formerly given as a present from a Mr. Dubois, trea. surer of the East India Complany, to a Carolina mercliant.

A wet and morassy soil, appears in general necessary to the cultivation of rice. The parts of the farms or plantations in which it is grown are usually so situated as to admit of being flooded; and, in many places, reservoirs of water are formed for this purpose. These reservoirs have sluices, by which the rice fields may be inundated at pleasure. In reaping the crop, the labourers generally work knee deep in water and mud. As the rice is cut, the sheaves are put on drays, and carried out to be spread on dry ground. The rice thus produced has the name of marsh rice, and is that which is chiefly imported into Europe.

In some of the mountainous parts of the East Indies rice is cultivated on the sides of hills, where it can only be watered by rain. It is sown, lowever, at the beginring of the rainy, and reaped in the beginning of the dry season; so that, in fact, it has nearly all the advartages of being watered, which the marsh rice possusses. The general appellation of rice, in the East Indies, is paddy; but the kinal just mentioned is denominated paddy gunung, or mountoin rice, and is littlo 
known in Europe, though of late years it has been cultivated with success in Tuscany. Its grains are whiter, finer, and more palatable than those of the marsh rice.

After the liarvesting of rice, the next process is to free the grains from the husk in which they are enveloped. 'There are several ways of doing this. In some places they are pounded in large mortars, and afterwards winnowed. In others large cylindrical pestles are lifted by a wheel worked by oxen; ard between these one person sits and pushes forward the rice to be beaten, whilst another carries it off to be winnowed, and supplies firesh parcels. 'The inhabitants of several parts of the East throw it into hot water, by which the grains are slightly swelled, and thus burst through the husk. In the island of Ceylon, and in some parts of America, a hollow place, about a foot in depth, and nine or ten yards in diameter, is dug in the ground. This is filled with corn, which is trodden by oxen driven round it until the grain is cleared. The Sacred and other writings inform us that this was the mode which the ancients adopted with other species of grain.

In Spain, when the rice is ripe, it is gathered in sheaves, and put into a mill, where the lower grinding stone is covered with cork; and, by this means, the grain is separated from the husk, without being bruised.

Rice is said to have been lately cultivated, with success, in some parts of Scotland; and it is not improbable, that, by degrees, this species of grain may be naturalized to our climate.

No kind of grain is so generally adopted for foud in hot climates as this. The inhabitants of many parts of the East subsist almost wholly upon it; and large quantities are annually imported into Europe, where it is highly esteemed for puddings and numerous culinary preparations. It is considered very nutritive, but it should not be eaten in too large quantities by languid or debilitated persons. In a scarcity of other 
grain, rice may be used with considerable advantage as an ingredient in bread. Indeed, on account of its excellence and its cheapness, it claims attention as a general article of sustenance for the poorer classes of society; as it is well krown that a quarter of a pound of rice, slowly boiled, will yield more than a pound of solid and nutritive food. For the fattening of poultry, boiled rice has been adopted with success, and it would be more generally adopted than it is, were it not for an unfounded and very extraordinary notion that it tends to make them blind.

The inhabitants of the East obtain from rice a vinous liquor, which is more intoxicating than the strongest wine; and an ardent spirit, called arrack, is also partly made from it. 'The latter is chiefly manufactured at Battavia and at Goa on the coast of Malabar ; and is said to be distilled from a mixture of the wort or infusion of rice, and of toddy, or the juice of the cocoanut tree (233), to which other ingredients, and particularly spices, are added.

There is only one species of rice; but the varieties of it, according to the soil, climate, and culture, are very numerous.

\section{.CIASS VII-DHEPTANDRIA.}

\section{MONOGYNIA.}

117. The HORSE-CHESNUT (Esculus hippocasta. num, Fig. 60) is a very common tree in parlis and pleusnre grounds, bearing leaves cuch composed of sercn large lobes; und huring large and elegrent chusters of light-coloured flower's.

Each flouer consists of fice prtuls of white colon, irregrelarly spotted with red und yellow; and ronendish, but undulated or nuted at the edges. The finit, which is of litter and mpleasant tnste, is enclosed in a rondish capsule or seed tessel, besct uith spines, and divided into threc cells. 
There is no tree of British growth more admired, or more deserving of admiration on account of its brilliant appearance at a very early season of the year than the chesnut. Its benutiful flowers, in upright conical spikes, terminate the branches on all sides, in such manner that sometimes almost the whole tree appears as if it were covered by them.

The fruit of the horse-chesnut has been found of considerable use in the fattening of cattle, the tallow of which it is said to render peculiarly firm. For this purpose, however, as well as for the feeding of sheep, it has been considered advantageous to macerate the nuts in lime water, or in caustic alkali, to deprive them of their bitterness; and, afterwards, to wash them in water, and boil them into a paste. Goats and deer are partial to these nuts; but they are said to be unwholesome for swine. In Turkey they are ground and mixed with provender for horses; and, if they could be wholly divested of their bitterness and acrimony, it is supposed they might be converted into bread. A patent was granted, in the year 1796, to Lord W. Murray for his discovery of a method of extracting starch from horsechesnuts; and a paste or size has been made from them, which is preferred by book-binders, shoe-makers, and paper-hangers, to that made from wheaten flour. They contain a soapy quality, and are used, in some parts of France and Switzerland, for cleaning woollens, and for the washing and bleaching of linen; and, if ground and made into cakes or balls, it is supposed they might answer the purpose of soap, both in washing and fulling. If a small portion of horse-chesnut, il a state of powder, be snuffed up the nostrils, it excites sneezing; and even an infusion or decoction of it has been said to produce a similar efftict. These have consequently been administered in some complaints of the head and eyes, and have been productive of considerable benefit. The prickly husks may be advantageously cmployed in the tanning of leather. 
The rood of the horse-chesnut tree is white, soft, and of little value. It however serves occasionally for water pipes, for mill-timber, and turners' ware. If it be dipped into scalding oil, and well pitched, it however becomes extremely durable. In some parts of the Continent the bark of this tree is used in the cure of intermittent and other fevers; and some writers have been of opinion that it might, with arlvantage, be substituted in several complaints for Peruvian bark.

This tree was first brought into Europe, from the northern parts of Asia, about the year 1.550; and its growth is so rapid, that trees, raised fiom nuts, have, in twelve or fourteen years, attained nearly their full dimensions. It is further remarkable, in the growth of the horse-chesnut tree, that the whole of the spring shoots are said to be completed in little more than tliree weeks from the first opening of the buds.

\section{CLASS VIII.-OCTANDRIA. \\ MONOGYNIA.}

118. B.ALSAM, n. BALM of GILEAD, is the dried juice of a lou tree ar shmb (Autris gileadensis), which grous in sexerul muts of Alyssimin and sylin.

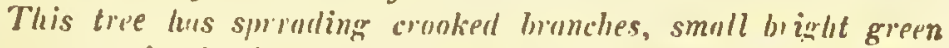
learrs, gimeing in threes, and small while fours s am sepurate fout. stalks. The petuls are, font in nusnher, and the fivit is a smull egg. shupeel berry, contuining a smooth nut.

I3y the inhabitants of Syria and Egypt, this balsam, as it appears firm the authority of the scriptures, was in great esteem in the highest periods of antiquity. We are informed by Josephus, the Jewish historian, that the balsam of Gilead was one of the trees which was given by the Queen of Saba to King Solomon. 
Those Ishmaelitish merchants, who were the purchasers of Joseph, are said to lave been travelling from Gilead, on the eastern side of Canaan, to Egypt, having their camels laden with "spicery. balm, and myrrh." It was then, and it still is, considered one of the most valuable medicines that the inhabitants of those countries possessed. 'The virtues, however, which have been ascribed to it, exceed all rational bounds of credibility.

The mode in which it is obtained is described by $\mathrm{Mr}$. Bruce. He says that the bark of the trees is cut, for this purpose, with an axe, at a time when the juices are in their strongest circulation. 'These, as they noze through the wound, are received into small earthen bottles; and every day's produce is gathered, and poured into a larger bottle, which is closely corked. When the juice first issues from the wound, it is of light yellow colour, and somewhat turbid appearance; but, as it settles, it becomes clear, has the colour of honey, and appears more fixed and heavy than at first. Its smell, when fresh, is exquisitely fragrant, and strongly pungent, not much unlike that of volatile salts; but, if the bottle be left uncorked, it soon loses this quality. Its taste is bitter, acrid, aromatic, and astringent.

The quantity of balsam yielded by one tree never exceeds sixty drops in a day. Hence its scarcity is such that the genuine balsam is seldom exported as an article of commerce. Even at Constantinople, the centre of trade of those countries, it cannot, without great difficulty, be procured. In Turkey it is in high esteem as a medicine, an odoriferous unguent, and a cosmetic. But its stimulating properties upon the skin arc such that the face of a person unaccustomed to use it becomes red and swollen, and continues so for some days afterward. The lurks also take it in small quantities, in water, to fortify the stomach, and excite the animal faculties. 


\section{$\int 10$ ROSE-WOOD.-COMMON AND SUGAR MAFLES.}

119. ROSE-WOOD (Amyris balsamifera) is an odoriferous tree, with smooth oval leaves, which grous in the island of Jumaica.

The wood of this tree is nuch used by cabinet-makers in this country for the covering or veneering of tables and other furniture. Its grain is of dark colour, and very beautiful. This tree yields an odoriferous balsam, which is much esteemed, both as an external applica. tion for the cure of wounds, and an internal medicine in various diseases.

120. The COMMON MAPLE (Acer campestre) is a lowo kind of tree, common in woods and hedges, which has its leaves in lobes, blunt, and notched, and green flowers in upright clusters.

By the Rornans the maple rood, when knotty and veined, was often highly prized for furniture. The poet Virgil speaks of Lvander sitting on a maple throne. The knots of this wood were considered to resemble the figure of birds, beasts, and other animals : and when boards, large enough for tables, were found of this curious part of it, the extravagance of purchasers is said to have been incredible. Indeed its value, in that madly luxurious age, is stated to have been such, that, when, at any time, the Romans reproached their wives for their extravagance in pearls, jewels, or other rich trifles, the latter were accustomed to retort, and turn the tables upon their husbands. Hence our expression of "turning the tables" upon any person is said to have been derived.

With us the maple tree is used by turners, particularly for making cups, which may be rendered so thin as to be almost transparent. 'This wood, where it is devoid of knots, is remarkably white, and is sometimes used for domestic furniture. On account of its lightness, it is frequently employed for musical instruments, and particularly for those of the violin kind.

121. SUGAR MAPLE (Acer saccharinum) is a North Anericun tree, which grows to the height of foty or sixty feet, and 
has somewhat hand-shaped lenves, in five divisions, notched at the edges, and downy undernealh.

This large and beautiful tree is much cultivated in America on account chietiy of the juice which it yields, and which is made into sugar. The process of obtaining the juice is, in the spring of the year, to bore holes about two inches deep into the tree, and to put into each of these holes a projecting spout, by which it may be conveyed into troughs placed to receive it. Each tree will afford from twenty to thirty gallons of juice, from which may be obtained five or six pounds of sugar. The juice is clear, of pleasant flavour ; and, in its simple state, is sonetimes drunk as a remedy against the scurvy. The sugar, which is obtained from it by evaporation, is clean to the eye, and very sweet, but it has a peculiar, though not umpleasant taste. It may be clarified and refined in the same manner as the common sugars. The juice of the maple furnishes also a pleasant wine, and a very excellent vinegar.

The roood of this tree is valuable as timber, and is also well adapted for turnery and cabinet ware, nore particularly as it is said not to be liable to suffer by the depredations of insects.

Possessing these properties, and being sufficiently hardy to sustain the rigours even of a cold climate, its culture, in our own country, would be attended with great advantage, and cannot be too strongly recomnended.

122. The SYCAMORE (Acer pseudoplatanus, Fig. 70) is a handsome tree of British grouth, which has leaves in five lobes unequally serralod; and green flowers in pendunt chusters.

It is peculiarly deserving of remark concerning this tree, that it grows better near the sea than in any other situation, and that plantations of sycamores may be so made as even to defend the herbage of the adjacent country from the spray, and consequently from the injurious effects of the sea. Its growth is quick, yet it will increase in size until it is two hundred years old. 
The soil in which it best flourishes is a loose black earth. The only inconveniences attending it in plantations is the early shedding of its leaves.

In the spring of the year the inhabitants of some parts of Scotland bore holes through the bark of the sycamore, at the distarce of about twelve inches from the root, and suffer the juice to drain into vessels, to the amount of eight or nine quarts a day from each tree. This liquor they convert into a kind of wine; and,-if the watery part were evaporated, an useful sugar might be obtained from it.

The roood of the sycanore is soft and white, and was fornerly mucl in request by turners, for making trenchers, dishes, bowls, and other articles; but, since the general introduction of earthen ware for all these purposes, its value has greatly decreased.

123. CRANBERRIES ure a smull red fruit with purple dnts, produced hy a slender wiry plant (Vaccinium oxicoccos), which gromes in the peat!y bogs of sereral parts of the north of England, and also in Norfolle, Lincolnshire, and Cambrilgeshire.

The leares are small, somenthot ocoll, and rolled back at the edges, and the slem is thread-shuped and traiting. The blossoms are smoll, lint benutifil, ench ronsisting of four distinct petals rolled back to the base, und of deep flich colout.

The collecting of cranberries is a tiresome and disagreealble employment, as each berry, which seldom exceeds the size of a pea, grows on a separate stalk, and the morasses in which they grow are frequently very deep. Cranberries are niuch used in the northern counties, and great quantities of them are bottled and sent to London. So considerable a traffic in this fiuit is carried on, that, at Longtown in Cumberland, the amount of a inarket day's sale, during the senson for gathering it, is stated by Dr. Withering to be from $20 l$. to $: 0 l$. Cranberries begin to ripen about the month of August, and continue in perfection for some weeks.

They are much used in confectionary, but particularly in tarts; their rich flavour being very ge- 
nerally esteemed. The usual mode of preserving them is in dry bottles, corked so closely as to exclude all access of the external air: soine persons, however, fill up the bottles with spring water. Others prepare this fruit with sugar. From the juice of cranberries, mixed witl a certain portion of sugar, and properly fermented, a grateful and wholesone wine may be made. The inhabitants of Sweden use this fruit onily for the cleaning of silver plate.

A considerable quantity of cranberries is annually imported, into this country, from North America and Russia. These are larger than our uwn, of a different species, and by no means of so pleasant flavour.

124. There are three other species of fruit belong. ing to the cranberry tribe, whicl grow wild in this country, on heaths or in woods. These are BILBERRIES, or BLEA-BERRIES (Vaccinium myrtillus), which are occasionally eaten in milk, and in tarts, and which afford a violet-coloured dye: GREAT BILBERRIES ( $V$. uliginosum), whiclr, in France, are sometimes employed to tinge white wines red; and RED WHORTLE-BERRIES ( $V$. vitis idaca), which, though not of very grateful flavour, are occasionally used in tarts, rob, and jelly.

125. The COMUON HEATI, or LING (Erica vulgaris,) is " well-known hlant, with mumerons smult rose-coloure'd fluter's, which grou's will on heuths and mountuinous ustes, in neurly every part of Englund.

The principal use to which the heath is applied is for making brooms or besoms. It is likewise bound into fagots, and employed as fuel, particularly for ovens; and is, not unfrequently, employed in the filling up of drains, and the morassy parts of roads, previously to their being covered with earth, stones, and other durable materials. In the Highlands of Scotland, the poorer inhabitants make walls, for their cottages, with alternate layers of heath and a kind of mortar made of black earth and straw : they likewise thatch their cabins with it, and make their beds of it. The inhabitants of Islay, 
one of the western islands of Scotland, are said to brew a wholesome kind of beer from one part of malt, and two parts of the young tops of heath. The stalks and tops may be rendered of considerable service in the tanning of leather; and in dyeing woollen cloth an orange colour. Bees are partial to the flowers; but the honey which they form, after having fed upon these flowers, acquires a reddish tint. The leaves and seeds of heath afford a grateful food to grouse, and other animals.

\section{TRIGYNIA.}

126. BUCKWHEAT, or BRANK, is a black and triangular grain, moduced by a plant of the persicaria tribe (Polygonum fagnpyrum), with somewhat arrou-shaped leaves, and purplish white flowers.

Although buckwheat may now be considered as in some degree, naturalized in this count "y, and as growing wild near our fields and dunghills, it was originally introduced from the northern parts of Asia, and was first cultivated here about the year 1600. The flowers appear about July, and the seeds ripen in October; and so tender are the plants, that a single night's sharp frost will destroy a whole crop.

As a grain, buckwheat has been principally cultivated for oxen, swine, and poultry; and althougl some farmers state that a single bushel of it is equal in quality to two bushels of oats, others assert that it is a very unprofitable food. Mixed with bran, chaff, or grains, it is sometimes given to horses. The flower of buckwheat is occasionally used for bread, but more frequently for the thin cakes called crumpets. In Germany it serves as an ingredient in pottage, puddings, and other food. Beer may be brewed from it; and, by distillation, it yields an excellent spirit.

The best mode of harvesting this grain is said to be by pulling it out of the ground like flax, stripping off the seeds by the hand, and collecting these into aprons, or cloths tied round the waist. 
Buckwheat is much cultivated in the domains of noblemen and gentlemen possessed of landéd property, as a food for pheasants. With some farmers it is the practice to sow buckwheat for the purpose only of ploughing it into the ground, as a manure for the land. Whilst green, it serves as food for sheep 'and oxen; and, mixed with other provender, it may also be given with advantage to horses. The blossoms may be used for dyeing a brown colour.

The principal advantage of buckwheat is, that it is capable of being cultivated upon land which will produce scarcely any thing else, and that its culture, comparatively with that of other grain, is attended with little expense.

\section{CLASS IX.-ENNEANDRIA, \\ MONOGYNIA.}

127. CINNAMUN is the under bark of the branches of a tree of the buy tribe (Laurus cinnamommm, Fig. 40,) which is chiefly found in the island of Ceylon, but which also grows in Nulubar and other parts of the East Indies.

This trec uttrins the height of twenty or thirly feet. Its leares we oval, euch from four to six inches long, and murked with thee principal nerre's. The flour's stund on slonder footstulks, and we of pale yellow colour; and the frut is someuthat shaped lilie un acorn.

There are two principal seasons of the year in which the Ceylonese enter their woods for the purpose of barking the cinnamon trees. The first of these commences in April, and the last in November: but the former is that in which the great crop is obtained. In this operation the batanclies of three years' growth are cut down, and the outside pellicle of the bark is scraped away. The twigs are then ripped up lengthways with a knife, and the bark is gradually loosened till it can be entirely taken ofy. It is then cut into slices, 
which, on being exposed to the sun, curl up in drying. The smaller pieces or quills, as they are called, are inserted into the larger ones, and the whole are after. wards tied into burdles.

Cinnamon is examined and arranged, according to its quality, by persons who, for this purpose, are obliged to taste and chew it. This is a very troublesome and disagreeable work; and few persons are able to continue it more than two or threc days successively, as the cinnamon deprives the tongue and lips of all the mucus with which they are covered. After this examination, the bundles are made up to the length of about four feet, and weight of eighty-eight pourds each.

From the roots of the trees numerous offsets shoot up. These, when they have attained the height of about ten feet, are cut down and barked, being then gbout the thickness of a common walking stick. 'The cinuamon which they yield is much finer than any other.

A French ship, bound in 1782, from the island of Bourbon, to Cape François in St. Domingo, and having on board various oriental productions, the cinnamon tree among the rest, was taken by the late Admiral Rodney, who presented the trees to the assembly of Jamaica; and, fiom this parent stock, different parts of that is!and were afterwards supplied. In Ceylon the cinnamon trees are said to be so common as to be used for fuel and other domestic purposes.

The sinell of cinnamon, particularly of the thinnest pieces, is delightfully fragrant; and its taste is pungent and aromatic, with considerable sweetness and astringency. If infused in boiling water in a covered vessel, it gives out much of its grateful flavour, and forms an agreeable liquid. An oil is extracted from cinnanon, which is heavier than water. This is prepared in Ceylon, and almost wholly from the small and broken pieces. It is, however, obtained in such small quantity that the oil of cassia (128) is generally substituted for it. Indeed the cassia bark is often substituted for cin- 
namon, to which it has considerable resemblance, although, in its qualities, it is much weaker, anci although it is immediately distinguishable by its slimy taste.

The virtues of cinnamon are not confined to the bark. The leaves, the fruit, and the root all yield oil of cunsiderable value. That from the fruit is hichhly fragrant, of thick consistence, and, in Ceylon, was fornerly niade into candles for the exclusive use of the king.

128. WILD CINNAMON, ar CASSIA, is the bark of a tree of the bay tribe (Luturus cassia), which grows in the East Indies and Cihina, and is distinguished iy having spear-shaped leuves, euch with three nerves.

This bark was well known to the ancients, and highly esteemed by them: but, since the use of cinnamon has been generally adopted, the cassia bark lias fallen into disrepute on arcouut of its inferiority. It is thicker and more coarse than cinnamon, of weaker quality, and abounds more with a viscid mucilagino:s matter. For many purposes, however, cassia, as being much less expensive, is substituted for cinnamon, but morc particularly for the preparation of what is called oil of cinnamon: and nearly the whole of what is at present sold under the name either of siniple or spirituous cinnamon water is prepared from cassia.

The buds, as well as the bark, of this tree are used in culinary preparations, and for several oiher purposes. They are chiefly imported from Clina.

129. CAMPHOR is a white resinous production of peculiar and powerful smell, wolich is extracted from two or three kinds of trees of the bay tribe that grow in the islands of the Eust Indies, and in China.

Of these the principal is Laurus camphora (Fig. 41) It is of considerable heighit, much branched, and has spearshaped leaves, with nerves, of pale yellowish wreen colour on the upper side, and bluish green benenth. Thit flouers are small and white, and stand on stalks which issue from the junclion of the leuves and branches.

Camphor is found in every part of the trees; in the 
interstices of the perpendicular fibres, and in veins of the wood; in the crevices and knots, in the pith, and in the roots. The modes by which it is extracted differ in different countries. In Borneo and Sumatra, the largest pieces are picked out with sharp instruments; and the smaller ones are procured by rasps, to which, along with bits of wood and other impurities, they adhere. The Chinese cut off the branches, chop them very small, and place them in spring water for some days. They then put them into a kettle, and boil them for a certain time, during whicl they keep constantly stirring them with a stick. As soon as the camphor, in a white and frosted appearance, is observed to adhere to the stick, the whole is strained. The liquor is subsequently poured into a basin, and, after some hours, the campinor coagulates into a solid mass.

In Japan it is usual to obtain camphor by cutting the roots and extremities of the branches into chips, and exposing them to the steam of water in close vessels. In other countries the roots, wood, and leaves, are all boiled in large iron pots, having a kind of tubular apparatus, which is stuffed witl straw, and leals to certain large vessels called receivers. In this operation most of the camphor becomes condensed in a solid form amongst the straw; and the remainder passes with the water into the receiver.

In a crude state camphor is formed into irregular lumps of yellowish grey colour, somewhat resembling nitre, or saltpetre. It is imported into Europe in canisters: and the refining of it was long kept a secret by the Venetains. The Dutch have since performed this work; and large quantities of camphor are now also refined by some of the English chemists. The best camphor is imported from siumatra.

The principal use of this drug is in medicine; and it was formerly in high repute. Dr. Cullen says that it has been employed with advantage in fevers of almost all kinds : but, since the free use of opium has been introduced, camphor has been little employed in this 
country, though its utility has been fully established by some of the most eminent practitioners of the Continent. It has often been found to relieve tooth-ache and rheunatism. Several preparations of camphor, in combination with other substances, are used in medicine, of which perhaps, the most common is that with spirit of wine. To insects the effluvium of camphor is so disagreeable that they quickly avoid it. Hence it is customary to place pieces of it in collections of natural history, to prevent their destruction by these voracious little creatures.

For carpenters' work, the roood of the camphor tree is much in request. It is light, and durable : and, in consequence of long retaining its aromatic smell, is not liable to be injured by insects.

Plants of the camphor and cinnamon trees were captured, from the French, in 1782, by Admiral Rodney, and afterwards conveyed to Jamaica, and propagated there.

Several shrubs and plants of our own country contain camphor in considerable quantity. The principal of these are rosemary, sage, lavender, and marjoram.

130. The COMMON SWEET BAY (Laurus nobilis) is an evergreen shrub, zohich grows in Italy and other southern parts of Europe, and is principally celebrated as that which was unciently used to form the crown of victory among poets.

Its leaves are of shining green colour, somezhat spearshaped, and often waved toward: the edge. The flowers appear in April and May, in clusters of three or four together on short footstalks. The corolla is in four segments of yellowish white colour, and is succeeded by an oval berry covered with a dark green rind.

This handsome shrub is common in our gardens and shrubberies. Its leaves afford, by distillation, an useful oil, which is occasionally employed in medicine. 'They are also employed, in cookery, to flavour custards, puddings, stews, and pickles; and Dr. Woodville assures 
us that they may thus be used not only with safety, but even with advantage as assisting áigestion.

The berries or tiuit of the bay tree, which have an aromatic smell, and a warm, bitterish, and pungent taste, were much used by the ancient Romans for culinary purposes. We import them chiefly from the coasis of the Mediterranean. From the berries, in a recent state, the people of Spain and Italy obtain, by pressure, a green aromatic oil, which is employed in medicine, externally, as a stimulant in nervous, paralytic, and other disorders.

1.31. The ALLJGATOR PEAR is " pear-shuped fruit, produced by uspecies of bay trec (Lalurus persea), that is much cultivuled in lhe West Indies.

This tree, zohich is an evergreen, has a struight stem, and grows to a considerable heishl. Ils leaves ure somezhut ooul, leuther.y, trunsversely veined, and of beuuliful green colour; und the flowers grow in buuches.

To the inbabitants of the West Indian islands, particularly the negroes, this fruit, which ripens in the months of $A$ ugust and September, is an agreeable, and in some respects, an important article of diet. When ripe the pulp is of yellow colour, of consistence somewhat harder than that of butter, and, in taste, not nuch unlike marrow. The negroes frequently make their meals of these pears, a little salt, and plantains ; and they are occasionally served up at the tables of the white people as fruit.

Their exterior surface is covered with a green skin; and in the centre there is a large round seed or stone, extremely hard and woody, with an uneven surface. This stone is used for the marking of linen. The cloth is held or tied over the stone: and the letters are pricked by a needle, through the cloth, into the outer covering of the stone. By this means it is stained of an indelible reddish brown colour, in the direction alnng which the needle has passed. The leaves are used by the negroes medicinally. 
132. SASSAFRAS is the wood of a North American tree of the bay tribe (Laurus sassafras), and is imported into Europe in long straight pieces, which are of light and porous texturc, and covered with a rough fungous bark.

'This trce is sometimes twenty or thirty feet high. The branches are crooked, and the leaves various, both in form and size, some of them being oval and entire, and others having two or three lubcs. They are pale green, and downy beneath. The flowers, which are of a dingy yellow colour, appear in pendant spikes.

This wood has a fragrant smell, and an aromatic and somewhat acrid, though sweetish taste, that are also observable in the bark, the smaller twigs, and the roots, all of which are imported into this country as well as the wood. Infusions and decoctions of sassafias are frequently taken as a medicine for improving the tone of the stomach and bowels, ill persons whose humours are in a vitiated state. Soon after its introduction into Europe, in the year 1560, this medicine was in such high repute as to be sold, on the Continent, at the rate of fifty livres per pound; and its virtues were extolled in numerous publications that were written on the subject. It is, however, now considered of little importance; and sassafras is seldom employed but in conjunction with other medicines, which, in their nature, are more powerful. Infusions of sassafras are sold in the streets of London, under the name of saloop.

We are informed tliat, in many parts of America, where the sassafras trees not only grow in great numbers in the woods, but are planted along the fences of enclosures, it is not unusual to make bed-posts of the wood, for the purpose of expelling bugs. Its powerful scent drives away these disagreeable insects; and some persons put ehips of sassafras into their wardrobes and chests, to prevent the attack of moths. This wood serves for the posts of enclosures, to which, by its lasting nature in the ground, it is peculiarly adapted.

'The bark of the sassafras tree is used by the American women for dyeing worsted, which it does of a permanent and beautiful orange colour.

\section{The CASHEW NUT is \& smull kidney-formed nut,
vol. II.}


which grows al the extremity of a somewhal pear-shapen Indian fruit.

The tree which produces it (Anacardium occidentale, Fig. 42) somezolut resembles a walinu lree in shape, as well as in the smell of its leaves, which are leathery, somerohat oval and shining. The flower's are red, and sweel-scenled.

The size of this fruit is nearly that of a large pear, and the colour of its pulp is sometimes yellow and sometimes red. The singularity of its form, witl a nut or stone at the extremity, instead of the centre, generally excites the surprise of persons when they first see it. In a ripe state the fruit is sometimes roasted, cut in slices, and used as an agreeable acid in punch. Its juice, when fermented, is made into wine; and, on distillation, yields a spirit which some persons prefer even to rum.

The nuts are eacli enclosed in two shells, connected together by a cellular substance, which contains a thick, inflanmable, and very caustic oil. The kernels of these nuts have a peculiarly sweet and pleasant flavour, and are eaten either raw or roasted, and sometimes even pickled. It is said that the negroes of Brazil, who eat of these nuts as part of their sustenance, find them peculiarly wholesome, and that they are relieved, by the use of then, from various disorders of the stomach. 'They are also used in medicine, as almonds; and, when ground with the chocolate nut, they greatly improve its flavour. Cashew nuts maly be kept, without any great alteration of their quality, for many years. If the shells be broken, and the nuts be laid for a little while on the fire, they open of themselves; and the kernels being: taken out, the thin brown skin which covers them must be removed previously to their being eaten. It is necessary to be cautious, respecting the oil, that it do not: come in contact witl the mouth or lips; as, in such case, it would inflame and excoriate them.

The oil of the cashew nut is sometimes applied, by, the inhabitants of the West Indies (though much caution is requisite in the use of it) as a means of corroding cancerous ulcers, corns, and ring-worms; and some of the West Indian ladies, when they imagine themselves too 
much tanned by the scorching rays of the sun, cut off the outer shell of the nut, and rub the oil upon their faces as a cosnetic. The immediate consequences of this extraordinary operation are swelling and blackness of the parts; and, in five or six days, the whole skin peels off, leaving the face so sore and tender, that it is impossible for the person using it to appear abroad in less than a fortnight; by which time the new skin is sufficiently hardened, and is as fair as that of a newly born infant. There are, however, few British females who would consent to be thus flayed alive for the sake of rendering themselves fair. 'This oil tinges linen a permanent rusty iron colour.

From the cashew nut tree a milky juice is obtained, by tapping or incision, which stains, of a deep black colour, whatever it touches. The fine black varnish so much used in China and Japan is the resinous juice of a tree called fsi-chu, which is conjectured to be the cashew nut tree.

\section{TRIGYNIA.}

134. The TRUE or OFFTCINAL RHUBARB (1Rheum palmatum) is a medicinal root which grows wild in various parls of Asiu.

The leavcs which issue from this root are large, and deeply cut into lobes; and the whole plant has a general resemblance to what in our country are called docks. The stem is erect, and si.r or seven feet hishli. The leaves stand on footstalks, that are. somerthat groored "lbove, and rounded at the edge. Those wolich procced fiom the stalk supply at the joints a kind of membraneous sheaths. Thi jlozers terminate the branches in clusters.

The importance and the properties of this root in medicine are universally known. Rhubarb is usually imported f:om "lurley, but it is occasionally also brought from Russia, China, and the East lndies. Dr. Woodville states that the Turkey rhubarb is brought over in oblong pieces, flattish on one side, and rounded on the other ; and that it is compact, hard, heavy, and internally of a dull colour, variegated with yellow and G 2 
white. The Chinese rhubarb is in roundish pieces, each with a large hole through the centre. It is softer than the former, and exhibits, whon broken, many streaks of bright red colour.

In some of the mountains of 'Tartary, rhubarb plants are found in great abundance. The roots, when first dug out of the ground, are thick, fleshy, externally of yellowish brown colour, and internally of bright yellow streaked with red veins. When they have attained sufficient size, they are dug up and cleansed; and the small fibres and the rind being cut off, they are divided into pieces of proper size. Each piece is then perforated in the middle, and they are strung on cords in such manner as not to touch each other, and are suspended to dry, either upon adjacent trees, or in the tents.

The sum expended for the importation of this drug is said to exceed 200,000l. per annum, a great proportion of which, it is presumed, might be saved to the country by cultivation of the plants in Great Britain. This was first attempted, about sixty years ago, by Dr. Hope, in the botanic garden at Edinburgh, and with such success as to prove that the climate even of Scotland would be no obstacle to its increase. In 1791, Sir William Fordyce received, from the Society for Encouragement of A rts, Manufactures, and Commerce, a gold medal, for having raised more than 300 plants of the true rhubarb fron seer. And, in 1783, Mr. Davis, of Minehead, in Somersetshire, brought to perfection as many plants as yielded three hundred pounds' weight of dried rhubarb. Since this period, rhubarb has been grown, in cifferent parts of England; to great exterit; and has so far flourished, that some of the roots have weighed seventy pounds and upwards. The principal difficulty has attended the curing of it; but this, after numerous experiments, has at length been performed in such manner, that the English drug has been found equal, or nearly equal, to that which is imported from Turkey and China.

The barli of rhubarb has been used for tinctures, and 
found, in every respect, as efficacious as the best part of the roots : and the seeds possess nearly the same qualities. The leares impart an agreeable acidity, somewhat similar to that of sorrel; and a marmalade, which may, with advantage, be adopted for children, is made from the fresh stalks, by stripping off the bark, and boiling: the pulp with an equal quantity of sugar.

135. The COMMON RHUBARB (Rheum rhaponticum), is a plant. which is cultivated in kitchen gardens, and has large, bhunt and smooth leaves, and the leaf-stalks furrorved on the upper side, and rounded at the edge.

This species of Rhubarb grows wild on the mountains of Rhodope, in Thrace, whence it was first propagated in other parts of Europe about the year 1610. It is chiefly in request for the footstallis of the leaves, which are used (in the early part of the year, when there is little fruit) for pies and tarts. The root has some of the qualities of the true rhubarb, and has occasionally been imposed upon purchasers for that drug.

\section{CLASS X.-DECANDRIA.}

\section{MONOGYNIA.}

136.SENNA is a drug, the dried leaves of an annual plant (Cassia senna) which grows in various parts of Africa and $A$ sia.

The stems of this plant are woody, and not unlike those of a shrub. The leaves ure roinged, and the leaflets oval, smooth, and pointed. The flowers, which grow in lengthened. clusters, and are of pale yellow colour, are succeeded by oblong, compressed, and kidney-shaped pods.

The cultivation of senna is carried on to considerable extent in Ethiopia, Arabia, Persia, and Upper Egypt, from several of which countries it has, from time im- 
memorial, been brought by the caravans to Alexandria, as the most convenient port whence it could be shipped or sold into Europe. From this circumstanee, it is sometimes denominated Alexundrian sennu. The process of stripping and drying the leaves is perfectly simple. When dried, they are of a yellowish green colour, have a faint, though not unpleasant smell, and a somewhat aerid, bitterish, and nauseous taste.

'These leaves have long been in use in Eastern countries as a medicine; and their repute, though not so great as in the East, is very considerable in Europe. They are administered in various ways; and the pods have the same effect as the leaves.

A kind of senna has of late been cultivated, with success, in Italy and some of the southern parts of Erance.

137. The OETICINAL CASSIA is a somezhat cylindrical pod, about an inch in diameter, and a foot or more in length, the fruit of a trce (Cassia fistula) which is cultivaled in Egypt, the East and West Indies, and South America.

This tree is forly ar. fifty fect high, and much branched. Its leaves are wintsch, with fire pair of leaflets, somczohat oval, pointed, snooth, and of pale grecn colour. The flowers are large, yellow, and grow in oblong cluster's. The pods arc divided, by transverse partitions, inlo numerous cells, cach containing one seed.

These pods are in request on account of the black, sweetish, but somewhat acid pulp, whieh is eontained in their eells, and which is used, in many eases, as a mild opening medicine. It is eustomary in Egypt to pluck the pods before they are quite ripe, and to plaee them in a house, from which the external air is, as mueh as possible, excluded. They are then laid in beds about six inehes deep, having palm leaves interposed betwixt them. On the two following days the whole are sprinkled with water; and, in the course of about six weeks, they are in a fit state to be packed for sale.

The East Indian and West Indian cassia somewhat differ, botl in appearance and qualities. Of the former the pods are smoother, smaller, and have a thinner 
rind; and the pulp is of a decper shining black colour, swecter, and more agreeable to the taste. In choosing cassia, those pods should be selected which are the heaviest, and in which the seeds do not lattle on being shaken.

138 IIGNUM VIT E and GUIACUM are the rood and resin of a large West Indian tree (Guiacum officinale, Fig. 77) which has winged leaves in two sets upon one footstalk, and regular flowers of five petuls.

The usual height of this tree is between thirty and forly feet. The leaves consist of two, three, and sometimes four puirs of leaflets, which are somezhat oval, and of shining dark green colour. The flowers spring, in clusters, from the division of the smaller branches; the petals are of a rich blue colour, and the stumens are crowned with yellowish unthers.

The roood, resin, bark, and even the flowers of this tree, are all of use either in the mechanical arts or in medicine. The former, which is yellow towards the outside, of deep blackish brown colour in the ceutre, and so compact and heavy as to sink, when immersed in water, is chiefly employed in the West Indies for the wheels and cogs of sugar mills. It is also formed into mortars, bowls, and domestic utensils of various kinds, for which, on account of its hardness, and not being liable to warp, it is peculiarly valuable. Lignum vitæ is chiefly imported into this country from Jamaica, in logs or pieces of four or five hundred pounds weight each, and is in great request for school boys'rulers, and numerous articlcs of turnery ware. A decoction of thc wood, when rasped, is occasionally administered as a medicinc in rhcumatic and gouty affections.

The resin of this trec is somctimes obtained by wounding the bark in different parts. It exudes through the wounds; and, when sufficicntly hardened by exposure to the sun, is taken off, and packed in small kegs for exportation. Sometinics it is obtaincd by sawing the wood into billets, each about three fcet in length, which are then borcd with an augur longitudinally, and laid upon a firc, in such position that the 
melted resin, which flows through the hole as the wood burns, may be received into a vessel placed for the purpose of containing it. This resin, which is frequently called gum guiacum, is of a greenish colour, but has sometimes a reddisl hue. Its taste is pungent and acrid. From the bark of the tree there is frequently a spontaneous exudation: this has the name of native gum, and is imported in small, irregular, bright pieces, which are much more pure than the gum obtained in any other way. Guiacum is used as a strengthening medicine, and a warm aromatic; it is employed as a remedy against rheunatic and other pains, and as an ingredient in many officinal preparations. On its first introduction, which was soon after the discovery of America, it was in such repute as to have been sold for seven crowns a pound.

In the West Indies the bark, flowers, and fruit, are each employed in medicine; and of these the former is frequently used instead of soap for washing, in which process it gives a good lather.

139. BALSAM OF TOLU is a reddish yellow, thick, and pellucid substance, of fragrant odour, which is oblained from a 'tree ('Toluifera balsamuni) which grows in South America.

: This tree is of considerable height; and has somerohat oval leaves, each on " short foot-stalk. The flowers are numerous, and in lateral branches; and the fruit is a round berry.

The name of this balsam has been obtained from its being chiefly procured from the province of Tolu, on the north coast of South America, near the isthmus of Panama. Incisions are made in the bark of the trees, at a particular season of the year, and a resinous fluid of yellowish white colour oozes out. This is collected in small gourd shells. At first it is about the consistence of treacle, but it thickens by being kept; and by age it becones hard and brittle. Its smell is peculiarly grateful, somewhat resembling that of lemons; and its taste is warm and sweetish. On being chewed, it adheres to the teeth. 
This balsam is used in medicine both in the form of a tincture and a syrup; and, in its medicinal virtues, it agrees with most other balsams. The syrup of Tolu is userl in several medicines; and is also made into lozenges, which may be procured of almost any chemist, and which are considered serviceable in appeasing the irritation occasioned by severe coughing.

140. BENZOIN or GUM BENJAMIN, is a concrete or solid and fragrant balsamic substance, the produce of a tree (Styrax benzos) which grows chiefly in the island of Sumatra.

This tree las oblong leaves zollich taper to a point, and are smooth on the upper surface, and downy leneath. The flowers ure in loose bunches; they usually hang all on the same side; and are generally closed, which gives ihem the appearance of buds.

In some of the northern parts of Sumatra, particularly near the sea coast, there are several extensive plantations of Benzoin trees. The seeds or nuts are sown in the rice fields, and they afterwards require no other attention than that the surrounding shrubs should be cleared away from about the young plants.

When the trees have attained the age of six or seven years, incisions are made into the bark; and from these the balsam exudes, in the form of a thick, whitish, resinous juice. By exposure to the air, this juice soon hardens : it is then pared from the bark, with a knife or chisel. For the first three years the trees yield the purest resins: this is of a white colour inclining to yellow, is soft, and fragrant. Afterwards, for the next seven or eight years, an inferior sort is yielded; this is of reddish yellow colour, degenerating to brown. At lengtl the trees, unable to bear a repetition of the process, are cut down, and split into pieces. From these is procured by scraping, a still worse sort of benzoin, which is dark-coloured, hard, and mixed, more or less, with parings of the wood and other impurities.

The inferior sorts of benzoin are exported to Arabia, Persia, and some parts of India, where they are burned, to perfume, with thcir smoke, the temples and the houses

$$
\text { c. } 5
$$


of the inhabitants; to expel troublesome inscets, and obviate the pernicious effeets of unwholesome air or noxious exhalations.

Bezoin is brought for sale to the mereantile parts of Sumatra, in large cakes, covered with mats. In order to paek it in chests, it is neeessary to break these eakes, and to expose it to the heat of the sun. The greater part of the benzoin which is brought to England is re. exported to countries where the Roman Catholic and Mahometan religions prevail; to be there burned as incense in the churehes and temples. The annual exportation of benzoin fiom London to Mogradure only has been estimated at:50,000 pounds' weight per amum.

That whieh is consumed in England is chiefly employed in medieine, in perfumes, and as cosmetics. It constitutes the basis of what are ealled I'urlington's or Friar's balsam, and Sesuit's drops; the salutary effects of whieh, partieularly in healing reeent wounds, is well known. This balsam is composed of benzoin, balsam of 'Tolu (13y), Soeotrine aloes (107), and rectified spirit of wine. Benzoin is also used in the preparation of what is called laties' court plaster; but in this it is supposed to be unneeessary if not prejudieial ; not only as it renders the plaster more diffieult to be moistened, previously to its application, but as the irritating quality of the benzoin may in some instanees dispose a fresh wound to fester. The mode of making court plaster is very simple. Five ounces of isinglass are dissolved in a pint of water. A quantity of thin black sarsnet being then stretched on a frame, a warm solution of the isinglass is applied with a brush equally over the surface; and, when dry, this is repeated a sceond or third time. It is finally brushed over with a weak solution of benzoin in spirits of wine, whieh communicates to it a pleasant aromatic smell.

If powdered benzoin be put into an earthen vessel over a slow fire, and the fumes of it be made to sublime into a paper cone fixed to the top of the pot, the 
substance thus formed is the flowers of benzoin of the shops, or Benzoic acid, as it is termed by chemists.

141. STORAX is a fragrant, concrete, or solid balsam, that is obtained from a tree (Styrax officinalis) which grows in the Levant, and in some parts of 1taly.

This tree grows to the height of twenty feet and upuards: it is much branched, and lias broad, alternate, oval leaves, somerohat pointed, smooth above, and downy beneath. The flowers are large, white, in clusters on short footstalks, and terminate the branches.

The best storax is obtained from Asiatic 'Turkey, in small transparent masses, of pale red $0 \ddot{r}$ yellowish colour, and generally abounding in whitish tears, resembling those of benzoin. "The drug, however, which is commonly sold in the shops as storax, consists of large, light picces, very impure, from the saw-clust with which it is mixed.

The mode of obtaining this balsam is similar to that employed for benzoin. (140): incisions are made in the trees, and, on its oozing from the round, it is scraped off, and collected together to be packed for sale. It was formerly customary to enclose it in reeds.

Storax is one of the most fragrant of the balsams, and is much used in some countries in perfumes, and for fumigation. It is also compounded in various ways with other substances, for medicinal use.

142. LOG.WOOD is " clark red wood, chicfly used in lyeing; and imported from Hondmras, and some of the islands of the West Indies.

The log-wood tiee (Hæmatoxylon campechianum, Fig. 43) is from sixteen to twenty.fom feet high, and, both in the trunk and manches, is extremely crooked. The branches are spinous, and the leaves winged, with, in general, fom or five pair of leaflets, which are somewhat heart-shaped. The flower's are of a reddish yellow colour, small, and numerous.

The district of Honduras in North America has long been celebrated for the production of log-wood, which grows wild chiefly in forests where the soil is moist, or near the banks of rivers and lakes. The cutting of it 
occupies a great number of hands, and is an unpleasant and very unhealthy pursuit.

In the year 1715 some seeds of the log-wood tree were introduced into the island of Jamaica; and this wood is now chiefly employed in that island as a fence against cattle. As an article of commercial export, it does not. appear to answer so fully as could have been wished; yet, in morassy parts of the island, it grows in considerable luxuriance.

Few kinds of wood are of more solid texture than this. Hence arises its weight, which is so great that it will sink in water. Its predominant colour is red, tinged with orange and black; and its hardness such that it is capable of being polished, and is scarcely susceptible of decay. For exportation to Europe, it is cut into billets or $\operatorname{logs}$, each about three feet in length.

The chief use of log-wood in this country is for dyeing green, purple, blue, and black colours, according to the different ingredients with which it is employed. It gives a purplish tinge to watery and spirituous infusions; but all the colours which can be prepared from it are fugitive, and cannot, by any art, be rendered so durable as those prepared from otler materials.

Independently of its use as a dyeing drug, log-wood possesses considerable utility as an astringent medicine, chiefly under the form of a decoction, or of an extract boiled down to a proper consistence.

The price of log-wood at Honduras is so low as not usually to exceed 12l. ar 14l. Jamaica currency per ton.

143. MAHOGANY is the wood of a well-linown tree (Sweitenia mahagoni, Fig. 44) of large dimensions, with winged leaves, and smull while flowers, which grows in Jamaica and Hon. duras.

The branches of this tree are numerous und spreading. Its leares are alternate and winged, with four or fice pair of leuflets, which are somewhat spear-shuped. The Rowers are mumerons, small, white, and in spikes or clusters, which arise at the junction of the lenves with the branckes, 
The cutting of mahogany constitutes a principal occupation of the British settlers in the vicinity of Honduras. The gangs of negroes cmployed in this work consist of from ten to fifty each, one of whom is styled the "huntsman." He is generally selected from the most intelligent of his companions, and his chief employment is to search for these trees in the woods, the principal of which lie adjacent to the river Balize. A bout the beginning of August, the huntsman is despatclied into the woods, and he cuts his way through the thickest parts, to the highest spots he can find. Here he climbs the loftiest tree, and thence attentively surveys the surrounding forest. At this season the leaves of the mahogany trees are of a yellow reddish huc, and an eye accustomed to them can discover, at a great distance, the places where they are most abundant. He now descends, and to such places directs his steps; and, having well marked the way, returns to his companions, to point out the places to them.

Here they assemble, and crect, against each tree to be felled, a stage so high as to allow of the tree being cut down at the height of about twelve feet from the ground. The last day of felling the trecs is appropriatcd to festivity; and these people have then a short interval of leisure for comforts in which they seldom can indulge at any other time.

After the branchcs are lopped, and the uselcss parts of the wood are cut off, the operation commences of conveying the trees, by cattle and trucks, to the water's side, a task of infinite and laborious difficulty. A sufficient number of pieces to form a raft being here collected, they are shoved from the bank into the water, and suffered to float singly upon the current to large cables which are placed across the river at some distancc below. As numerous gangs of mahogany cutters are usually cmployed near the banks of the same river, their trces also float to the same spot. Here therefore the whole are collected, amounting some- 
times to more than a thousand immense logs; and, each party claiming his own, the trees are formed into separate rafts for their final destinations.

in some instances the profit of cutting mahogany at this seitlement has been very great. A single tree has occasionally been known to contain 12,000 superficial fect, and to have produced upwards of 1,000l. sterling.

The body of the tree is of course the most valuable; but, for ornamental purposes, the limbs or large branches are generally preferred, their grain being much closer, and their veins being more rich and variegated than those of the other parts.

The Honduras mahogany is considered inferior to that produced in Jamaica. In this island mahogany was formerly much more abundant, and consequently much less expensive than it is now, because the low lands have gradually been thinned of such trees as could readily be carried to market, or conveyed on board vessels for exportation.

The date of the introduction of mahogany wood into England is 1721. Since this period it has been in very general request for making the more valuable binds of lousehold furniture. It admits of a high polish, and is excellently adapted for tables, chairs, desks, and other similar articles. In Jamaica, malıgany is employed as a strong and durable timber for beams, joists, planks, boards, \&c. Many attempts have been made to stain other kinds of rood so as to resemble it, but none of these liave been attended with success.

It has been lately discovered that the bark of the mahogany tree may be advantageously employed in medicine, as a substitute for Peruvian bark (62).

144. QUASSIA is a drug, the root of a trec (Quassia amara, Fig. 73) which grows in the West Inties and Sonth America, but perticularly in the colony of Surinam.

The leares of the quassia tree are winged, with iwo pair of oval and someuthet pointed leaftets, and un odd one at the end: these are smooth, decp green above and pale below; and the 
common footstalk is edged on each side with a lewy membrane. The flowers are bright red, und terminute the brinches in long cluster's.

This drug was first brought into use in Surinam, by a negro whose name was Quassia, and who employed it with great success in the cure of intermittent and other malignant fevers, which prevail in that flat and marshy country. 'The offer of a valuable consideration induced him to reveal the secret to Daniel Rolander, a Swede, who carricd specimens of the wood, togetler with a branch of the tree, the flower, and fruit, to Stockholm, in 1756 .

Since this period the drug has been generally employed in Europe; and its efficacy in the removal of many diseases has been perfectly ascertained. Dr. Cullen, however, observes, that though it is an excellent bitter, and that it will do all that any pure or simple bitter can do, yet his experience of it luad not led him to think it would do more. Quassia is said to possess antiseptic properties, and consequently to have considerable influence in retarding a tendency to putrefaction. It is also sometimes used instead of hops in tlee brewing of malt liquor.

The root, roood, and bark of the quassia tree are all occasionally employed in medicine, and the bark is said to be more intensely bitter than either of the other two.

\section{CLASS XI.-. DODECANDRIA.}

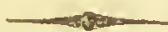

\section{MONOGYNIA.}

11.5. GAMBOGE is a yellow resinous gum obtained from a tree (Garcinia cambogia) chich grones in several purts of Cambogr or C'umboys in the empire of Tunkin.

The lcaves of this tree are oval, but acute. The flowers have crich five petuls, and firteen slamens: they are solitary, terminate 
the brunches, and hane scarcely any stalls. The fruit is a berry about the size of an orange.

The name of this gum has been derived from that of the country whence it is brought. The mode of obtaining it is by puncturing or cutting the branches of the trees. It issues from the wounds in a fluid state, but soon becomes hardened by the heat of the sun. After this it is formed into large cakes or rolls, in which state we receive it.

Gamboge is cliefly used as a pigment. When good, it is of a fine orange colour; and on being softened with water, is bright yellow, requiring no preparation previously to being lised. It is also given as a medicine; but its operations being very violent, it should be administered with great caution.

'The dried fruit of the gamboge tree is not unfrequently sent to our colonies in the East Indies, where it is used in sauces, and witl several kinds of food.

146. WELD (Reseda luteola) is a plant of the miguionette tribe, used in dyeing : it grous wild in barren and uncultirated places, particularly on coal-pit banks, in several parts of England.

The laves are spear-shaped, and entire, uith a tooth-lilie prosess on eus:h side of the base. The Rowers are yellow, and in long. spiices; and the culyx is ditided into four sigments.

In some parts of Erigland, particularly in the clothing counties, weld is cultivated to great extent; and it flourishes in sandy soils that could be turned to little advantage in any other way. When the plants are ripe, they are pulled up by the roots, dried, and tied into buudles for use.

The tinging quality of weld resides botl in the stems and roots. This imparts to wool, cotton, mohair, and silk, a very bright and beautiful yellow colour ; and blue cloths, dipped in a decoction of it, become green. The yellow colour of the paint ealled Dulch pink is obtained from this plant. 


\section{CLASS XII._ICOSANDRIA。}

\section{MONOGYNIA.}

147. The GUAVA, or BAY PLUM, is a West Indian fruit, of which there are two kinds, one white and round, and the other red and pear-shuped. The former is produced by a tree (Psidium pomiferum) which has shar'-pointed and highly ribbed leaves, and flowers three on each stalk; and the latter by a tree (Psidium pyriferuni) with oval leaves and single stulked flowers.

Equally delicious and wholesome, these fruits are in the highest estimation in the countries where they are produced. The rind or skin is lined with an applelike substance, which is used for tarts and other sweet preparations. It is also stewed and eaten with milk; and, in this form, is generally thought better than any other stewed fruit; from the same part a marmalade is made. This rind encloses an agreeable pulp, mixed with innumerable small sccds. The whole fruit is eaten raw, or prepared as a sweetmeat in various ways: the most common form in which we see it is that of a jelly.

The rood is used for fuel, and also makes excellent charcoal.

148. The COMMION MIYRTLE (myrtus communis) is a well known ormamental evergreen shrub, which is cultivated chiefly in greenhouses in this count'y, but grows wild in the countrics of the South of Europe.

Although this shrub is cultivated with us chicfly for ornament, it is of considerable utility to the inhabitants of the South of Europe. Its young shoots are used for tanning Icather ; and both its leaves and berries are $\mathrm{em}$ ployed in medicinc. From the formcr a distillcd water is obtained, which is sometines used in gargles. The berries are likcwise distilled; and an oil prepared from them has considerable repute as a means of thickening the hair. 
149. ALL-SPICE, or PIMENTO, is the dried berry of a West Indiun species of myrtle (myrlus pimenta, Fig. 45.)

This tree grous to the height of twenty feet and upucurds, and has someuhut oval leaves about four inches long, of deep shining green colour, and mumerons bunches of white flowers, each with four small petals,

In the whole vegetable creation there is scarcely any tree more beautiful or more fragrant than a young pimento about the month of July. Branched on all sides, richly clad with deep green leaves, which are relieved by an exuberance of white and strongly aromatic flowers, it attracts the notice of all who approach it.

Pimento trees grow spontancously, and in great abundance, in many parts of Jamaica; but they cannot be propagated without great difficulty. The usual method of making a new pimento walk, or plantation, is to appropriate for this purpose a piece of woody ground in the neighbourhood of an already existing walk, or in a part of the country where the scattered trees are found in a native state. The other trees are cut down; and, in a year or two, young pimento plants ate found to spring up in all parts, supposed to have been produced from berries scattered there by birds, which eagerly devour them.

About the month of September, and not long after the blossoms have fallen, the berries are in a fit state to be gathered. At this time, though not quite ripe, they are full grown, and about the size of pepper-corns.

They are gathered by the hand; and one labourer on a tree will strip them off. so quickly as to employ three below in picking them up; and an industrious picker will fill a bag of seventy pounds' weight in a day. 'The berries are then spread on a terrace, in the sun, for about seven days, to be dried; but this is an operation which requires great care, from the necessity of keeping them perfectly free from moisture. By the drying they lose their green colour, and become reddish brown; and the process is known to be completed by their 
colour, and by the rattling of the seeds within the berries. They are then packed into bags or hogsheads for the market. When the berries are quite ripe, they are of a dark purple colour, and filled wth a sweet pulp.

Pimento is thought to resemble in flavour a mixture of cinnamon, nutmegs, and cloves, whence it has obtained tlie name of "all-spice." It is much employed in cookery; and is chiefly used in whole grains. It is also employed in medicine, as an agreeable aromatic; and forms the basis of a distilled water, a spirit, and an essential oil. The leaves of the pimento trees yield in distillation an odoriferous oil, which is not unfiequently used in medicinal preparations, instead of oil of cloves.

150. The PEACH is a large, downy, and well-known garden finit (Amygdalus Persica), which is supposed to have been originally introduced into Europe from Persia, and was first brought into England about the year 1562.

This rich and delicious fruit is highly and deservedly esteemed at table, as an article in our desserts; and, when ripe and fresh, is grateful and wholesome, seldom disagreeing with the stomach, unless this organ be not in an healthy state, or the fruit be eaten to excess. When preserved in wine, brandy, or sugar, it loses its good properties. The kernels yield a salubrious bitter. 'The flowers, which are very beautiful, and appear early in the spring, emit an agreeable odour, liave a bitterish taste, and are used for medical purposes. The leaves are occasionally employed in cookery, but they ought not to be used without great caution, on account of their injurious properties.

There are many varieties of the peach, some of which are much more esteemed than others. The mode in which the trees are usually propagated is by a process termed budding, or grafting upon the stock of some other tree (see p. 147); and, by this process, those of any favourite kind may be exactly obtained. 
151. The Nectarine is a smooth-skinned variety of the peach, but of richer and more delicious flavour. The culture and management of the two kinds are exactly the same; and in all the circumstances of their growth, wood, leaves, and flowers, they precisely resemble each other.

152. The COHMON or SWEET ALMOND is a soft and pleasant favoured kernel, contained in a nut which is of flattish shape, and has a tender shell with numerous small holes on the outside.

The almond tree (Amygdalus com munis, Fig. 46) is usually twelve or fourteen feet high. Its beautiful pink flowers of five petals grow in pairs, and appear curly in the spring. The leaves are somewhat oval, pointed, and delicately serrated at the edges.

Our shrubberies contain no tree the flowers of which are more beautiful than those of the almond; and these flowers appear in March and April, a season when few other parts of the vegetable creation have recovered from their wintery state. Though known to the ancients from the most remote periods of antiquity, the almond tree has only been cultivated in England since the year 1562, and this almost wholly on account of the elegant appearance of its flowers; as the climate of Great Britain is not sufficiently warm for the fruit to be perfected with us.

The almonds that are consumed in this country are inıported, sometimes in the shell, but much more commonly without, from France, Spain, Italy, and the Levant; and they are packed in casks, boxes, and bales. The province of Valencia had formerly great celebrity for its almonds; but the cultivation of the trees in that part of Spain has for several years been much neglected.

'The chief uses of sweet almonds are in confectionary and cooking. They are also eaten with raisins in desserts after dinner; but they should be well chewed, as every piece that is swallowed entire is indigestible. By pressure, they yield a considerable proportion, some- 
times nearly half their weight, of oil. Indeed this is so plentiful that it may even be squeezed out of the kernel with the fingers. Some preparations of almonds are used in medicine, particularly that called milk of almonds, which is formed of pounded almonds, loafsugar, and water, well mixed together. In some parts of the East Indies, it is said that almonds supply the place of sinall money.

153. BITTER ALMIONDS are in no respect different from sweet olmonds, either as to the appearance of the kernels thcmselves, or the trees which producc them, except somewhat in the size of the flowers and fruit.

Like sweet almonds, they yield a large portion of oil. This has no bitterness; but the substance which remains after the pressure is intensely bitter. If these almonds be eaten freely, they cccasion sicliness and vomiting; and, to nuany quadrupeds and birds, they are a fatal poison. There was formerly a notion, but it is an erroncous one, that the eating of them would prevent the intoxicating effects of wine. They are fiequently used, instead of apricot kernels, in ratafia, and sometimes are employed in making a counterfeit cherry-brandy. The oil and emulsions of bitter almonds are used in medicine; and a powder and paste for washing the hands is made both from them and from sweet almonds. By confectioner's they are much in request for flavouring biscuits and other articles.

154. The POMEGR.ANATE is on apple-shaped fruit with thick rind, and crowned with thc leaves or teeth of the calyx. It is the produce of an evergreen shrub (Punica granatum, Fig. 4.7) which grows wild in the southern parts of Europe.

This shrub is uszally from fifteen to twonty feet high. The branches are armed with spincs; and the leaves are oblong, pointed, and durk green. 'The flowers, which are of a rich scarlet colour, have five rounded petals.

By the Greeks and Romans almost cvery part of the pomegranate tree (the root, leaves, flowers, and fruit) 
was considered to possess medical properties of a very remarkable and even marvellous description; and the country then chiefly celebrated for the production of it was that adjacent to the city of Carthage. The pomegranate is now, however, in little estcen, except on account of its fruit; the pulp or juice of which is pleasant to the palate, and, in common witl other summer fruits, allays heat and mitigates thirst, but has a slightly astringent flavour. This pulp is red, is contained in transparent membranes, and included in nine distinct cells. The tough rind of the fruit, which is of a bitter and astringent nature, was employed by the ancients in the dressing of leather; and it is still used in some parts of Germany, together with the bark of the tree, in the preparation and dyeing of red leather in imitation of what is called Morocco leather.

Pomegranates were first cultivated in England about the year 1595; but the fruit grown in this country seldoun attains a delicacy of flavour equal to that which is imported from Spain, Italy, and otler warm climates.

155. The CHERRY is a fruit of the prune or plum trite, the original stock of which is the wild cherry (Prunus cerasus) of our woods.

The gradual effects of cultivation, as they regard the clierry, have been the production of several kinds, which, both in size and flavour, infinitely exceed the fiuit of the parent stock, or wild cherry of the woods. The kinds that are best known are the May Duke, Early Kentish Cherry, White Heart, and Black Heart Cherries. The trees are propagated by grafting them usually upon the stocks of wild black and red cherry rrees, which are reared for that purpose (see p. 14.7.)

This agreeable fruit is eaten either fresh or dried. It is sometimes preserved with sugar as a sweetmeat; is made into jam, used in preparations of the liqueur called clierry-brandy, and made into wine. From wild black cherries the Siviss distil an ardent spirit, by the 
sale of which to the French and Germans they derive considerable profit.

The rood of the cherry-tree, which is hard and tough, is much used, particularly by turners and cabinetmakers on the Continent, for the manufacture of chairs and other furniture. The gum that exudes from the bark is, in many respects, equal to gum arabic (273); and is considered very nutritive. Hasselquist informs us that, during a siege, more than 100 men were kept alive for nearly two months, without any other sustenance than a little of this gum, which they occasionally took into their mouths and suffered gradually to dissolve.

156. The APRICOT (Prunus Armeniaca) is a fruit of the plum tribe, which grows wild in several parts of Armenic, and was first introduced into this country about the middle of the sixteenth century.

Some persons are inclined to consider the apricot as the most delicate of all our hardy fiuits. For pastry certainly none is more excellent. It is used for tarts, both green and when ripe; it is also preserved with sugar in both these states, and is sometimes dried as a sweetmeat. Care, however, should be taken to gather it before it becomes soft and mealy. 'The kernels of apricots have a pleasantly bitter flavour, and answer much better for several purposes in confectionary than bitter almonds, which are usually applied. They likewise contain a sweet oil, which, like that of almonds, was formerly used in emulsions.

The gum that issues from the apricot tree is nearly similar to that of the cherry (152). The rood is coarsegrained and soft, and consequently is seldom used in carpentry.

Apricot trees are chiefly grown against walls, and are propagated by grafting upon plum-tree stocks.

157. The COMMON, or DOMESTIC PLUM, in all its varicties, has been derived from a wild species of plum-tree (Prunus domestica), which grows in hedge rows and thiclets in 
several parts of England; and is distinguished by its branches being wilhoul thorns, and its fruit-stalls being single.

Were it not a well-established fact, few persons would suppose that the magnum bonum, or egg plum, the green gage, and several others, which are now common in our gardens, are indebted, for their parent stock, to the wild plum above mentioned. Tliese are all used at table; and, when sufficiently ripe, and eaten in moderate quantity, are pleasant and wholesome fruits, but, in an immature state, they are very unwholesome.

Prunes and French plums are the dried fruit of different kinds of plum-trees. They are usually packed in boxes, and are imported from the Continent, but particularly from the neighbourhood of Marseilles.Brignolles, a town of Provence, about thirty miles fiom Marseilles, is one of the most famous places in France for dried prunes. Prunes or St. Catherine's plums, constitute a lucrative branch of trafic, which is almost exclusively carried on in Tours and Chatelherault. Prunes are sometimes employed in medicine, but French plums are chiefly used at table.

The rood of the plum-tree is of little value; but the bark is in occasional request as affording a yellow dye.

158. The BULLACE PLUM is a small violet-coloured fruit of glolular shape, produced by a shrub (Prunus insititia) which grows wild in our hedges, and is known by its branches being thorny, and ils fruit-stallis in pairs.

The plum has a rough, but not unpleasantly acid taste, especially after it lias been mellowed by the frost. A conserve, called bullace chcese, is sometimes prepared by mixture of the pulp of the bullace with about thrice its weight of sugar. In several parts of Germany this fruit is preserved in vinegar and spice; and is occasionally used, in the manner of cherries, for the flavouring of brandy. An infusion of the floters, sweetened with sugar, is sometimes used medicinally for 
children. The rood is pleasingly veined, and is much valued by turners.

15.9. The SLOE is a snuall, round, and nearly black kind of pilum (Prumus suinosa), of extrenely austere taste, which is conimon in thickets and hedges throughout nearly every part of England.

The shrub that produces it has thorny branches, and the fruit-stalls are single.

The harshness and austerity of the sloe are proverbial. Its juice, if mixed with British made wines, communicates to them a red colour, and an astringent flavour, somewhat resembling that of port wine; a fact too well known to some of the dealers in that favourite liquor. The juice of unripe sloes, dried over a gentle fire, so nearly resembles the Egyptian acacia (273), that it has in many instances been substituted for that substance ; it is, however, harder, heavier, of darker colour, and somewhat sharper taste than the genuine kind. A conserve of this fruit, made with three times its weight of double-refined sugar, has been used with success as a gargle for sore throats.

An infusion of the flowers in watel, or the flowers boiled in milk, are sometimes employed medicinally; and the bark, reduced to powder, has been efficaciously administered in agues. If boiled in ley, the bark yields a red dye. The young and tender leaves of the sloe afford a substitute for tea, but some persons consider them unwholesome. The juice of the firuit, mixed with green vitriol, becomes an indelible black fluid, either for dyeing linen, or as writing ink. The roood, being extremely tough, is converted into walking-sticks, and made into the teeth of rakes; it is also sometimes used by lurners. Dr. Withering has remarked, that, from certain effects which he observed to follow the prick of the thorns of the sloe, he was inclined to consider they had some poisonous quality, especially in autumn. 


\section{PENTAGYNIA.}

160. The MEDLAR (Mespilus germanica) is usually considered a native Enghish fruit, having been remarked, morc than a century ago, to grow wild in hedges about -Minshull in Cheshive. It is distinguished ly leing depressed and concave at the top, the leaves of the calyri continuing . upon it; and by its containing several hard, compresscd, and cogular nuts.

It is the property of the medlar, which is cultivated in most large gardens, to be hard, and remarkably austere and disagrecable to the taste, until it liss, in part, undergone the putrefactive fermentation, when it becomes a soft, mellow, and, to many palates, a pleasant fruit. Medlars are usually gathered from the trees about the end of October, or beginning of November. To facilitate their becoming fit for the table, they may be placed in moist bran; but such as require to be kept for subsequent use should be deposited on dry straw. In a fortnight or three weeks those in the bran will be eatable, and the others will more gradually ripen. After they are perfectly lipe, they, however, soon become mouldy and decay.

The woud of the medlar-tree somewhat resembles that of the pear-tree, but is of no great value.

161. The COMMON PEAR is a well known grarden fruit, derived from an English stock, the wild pear tree (Pyrus communis), which grows in hedges and thickets in Sonersetslive und Sussex.

It would be an endless task to describe the different known varieties of the cultivated pear. Some of these are very large, and others extremely small; some have a rich and luscious flavour, and others, as the iron pear, are so hard and disagreeable to the taste, as to be absolutely unfit to eat. Pears are cliefly used in desserts; and one or two of the kinds are stewed with sugar, baked, or preserved in syrup. 
The fermented juice of pears is called perry, and is prepared nearly in the same manner as that of apples (162) is for cider. The greatest quantities of perry are made in Worcestershire and Herefordshire. The Squash, the Oldfeld, and the Barland perry are esteemed the best. Many of the dealer's in Champaigne wine are said to use perry in the adulteration of it; and, indeed, really good perry is little inferior, either in flavour or quality, to Champaigne.

Of the roood of the pear-tree, which is light, smooth' compact, and of yellowish colour, carpenters' and joiners' tools are usually made, as well as the common kinds of flat ruler's, and measuring scales. It is also used for picture frames that are to be stained black. The leaves impart a yellow dye, and are sometimes employed to communicate a green colour to blue cloth.

162. The APPLE, in all its numerous varieties, has been derived from the Crab-tree (Pyrus malus), which grows wild in almost every thicket, and in hedges of all parts of the kingdom.

The uses of apples are very extensive, and even the crab-tree is not witlout its use. The fruit is indeed small, and bad to the taste; but its fermented juice, which is called verjuice, is sometimes employed in cookery, occasionally in medicine, and frequently by wax-chandlers, for the purifying of wax. Dr. Withering conceives that, with a proper addition of sugar, a grateful liquor might be made from the juice of crabs, little inferior to hock. Hogs and deer are particularly partial to this fruit. The roood is tolerably hard, and, when made into the cogs of wheels, acquires a polish, and is very durable.

Apple-trees are all produced in an artificial manner, by a process termed grafting. This is performed by inserting young shoots of such trees as bear valuable fruit, on stocks that have been raised from the seeds. of crabs. Thus the shoot of an apple-tree, inserted 
into a crab stock occasions the crab-tree, from that time, to produce apples of nearly the same kind and quality with those of the tree from which the shoot was taken. Other stocks might be used, but those of the crab are considered the best. The same process is adopted in the propagation of nearly every kind of fruit-tree ; since, by experience, it has been ascertained that such as are produced from seed all partake of the nature of wild fruits, and have little resemblance to the fruit from which they spring.

There are several kinds of apples, and the varieties are every day increasing, through the attention that is paid, by different individuals, to the culture of this valuable fruit. Those best known as eating apples are the American apple called Newtorn pippin, the non-pareil, golden pippin, ribstone pippin, golden rennet, and lemon pippin; for the kitchen, the codlin and russet; and for cider, the golden pippin, coccagee, and red streak. Of these the non-pareil and golden pippin, from some unaccountable causes, are beginning to fail; the trees of late production not affording fruit of excellence equal to what has formerly been produced in this country.

It would be impossible in this place to enumerate all the uses of apples. They are employed in culinary preparations of several kinds, particularly in puddings and pies: they are a constant article in desserts; and are dried, baked, and made into jelly and marmalade. But by far the most important application of them is for the making of cider. The mode in which this is done in Herefordshire is very simple. After the apples have been gathered, they are sorted according to their different degrees of ripeness, and laid together, for a little while, to heat, by which those which are not perfectly ripe are greatly improved in flavour. The fruit is then ground in a mill, till even the kernels and rind are well bruised. It is allowed to stand, for a day or two, exposed in a large open vessel; after which it is pressed between several hair cloths. The liquor that issues from it is received into a vat, to be fermented; 
it is subsequently removed into casks till it becomes fine; it is then racked off into other vessels, leaving the lees behind. As soon as the fermentation has ceased, the casks are filled up with other cider, and the bung-holes are closed.

Cider is a more acid liquor than perry, and, generally speaking, is a wholesome and pleasant drink during the heats of summer; but the harsher kinds, or those which are prepared in leaden vessels, if freely drunk, are the cause of colics and other painful complaints. By distillation from cider an ardent spirit may be obtained. This lias an unpleasant flavour, of which, however, it may be deprived by a certain process with charcoal. By boiling the fresh juice of apples, and afterwards fermenting it, a roine may be made, which, when three or four years old, is said to acquire both the colour and flavour of Rhenish wine.

163. The QUINCE is a somewhat pear-shaped fruit, which is supposed to have been originally imported into this country from the island of Crete.

The quince-tree (Pyrus cydonia), is low and bushy. Its leaves are oval, entire, and whitish beneath. The flowers are large, of pule red or white colour, and do not grow in bunches, but each on a separate stalk.

Though quinces have an austere taste, and are not eatable when raw, they lose a considerable portion of their harshness if prepared in any manner by heat; and, when mixed with other fruit in cookcry, they communicate a very pleasant flavour. Hence it is that they are often mixed with apples in pies. Quinces are also boiled and eaten with sugar; made into marmalade, and preserved in syrup eitler whole or in halves. The juice of quinces, boiled with sugar, was formerly used as a medicine, but of late years it has been nearly discontinued. A proportion of one quart of the juice, mixed with a pound of sugar, and fermented, yields a delicious wine. On the Continent, a celebrated liqueur is prepared from this juice, in combination with sugar 
and brandy. A mucilage of the seeds is kept by apothecaries, and used in medicine, as more pleasant, but it is not so efficacious, as that of the simple gums.

Quince-trees grow wild on the banks of the Danube, but, with much less luxuriance than in a state of cultivation.

POLYGYNIA.

164. The HUNDRED.LEAVED, or COMMON GARDEN ROSE (Rosa centifolia), is a shrub too well linown 10 need any description.

This, the queen of flowers, is one of the most elegant and fiagrant of the vegetable productions. Its petals yield, on distillation, a small portion of aromatic oil, together with a ruater. which possesses botl the odour and taste of the flowers. This oil congeals in the common temperature of our atmosphere, and in that state is of white colour; but, when liquified by heat, it appear's yellow. So small, however, is the quantity that can be obtained, that an hundred pounds' weight of the flowers will scarcely yield half an ounce of oil. It is in much request as a perfume, under the name of ottar or essence of roses; and, though chiefly manufactured in the East Indies, is seldom imported from thence for sale, but considcrable quantities of it are brought from 'Turkey, at the price of from three to four pounds per ounce, exclusive of the duty. That from the East Indies, when genuine, has been sold at a much mole exorbitant rate than this; but it is not unfrequently adulterated with oil of sandal-wood (55.) The fraud, however, is easily detected by those who are accustomed to the smell of the latter, and also by the fluidity of the compound. The true ottar of roses is undoubtedly the most elegant perfune that is known.

From the petals of this rose are also prepared a conserve and symup, which are used in medicine. The simple distilled rose-water has little to recommend it beyond its fragrance: it is, occasionally used to im- 
part an agreeablc flavour to culinary preparations, and also to some kinds of cordials. It should be remarked that, although, from thcir fragrance, ruses are much used for nosegays, their odour has sometimes produced very alarming symptoms in pcrsons sitting or sleeping with such nosegays in confincd apartments.

165. The WILD BRIER, or HEP-ROSE (Rosa canina), is a common wild flower in hedges, and is distinguished by huving a somewhat egg-shaped fruit, smooth flower-stalks, the prickles of the stem hooked, and the leaves oval, pointed, smooth, and shining.

We possess no wild shrub more ornamental to the country, in its flowers, its foliage, or its fruit, than this; and its sweet and delicate scent, though less powerful, is perhaps as grateful as that of any rose that is known. 'The flowers, when distilled, afford a pleasant perfumed water. The fruit, or heps, contain an acid yot sweetisls pulp, with a rough prickly matter cnclosing the seeds. Of the pulp, when carefully separated from this substance, and mixed with sugar, is prepared the conserve of heps of the shops, which, though of little medicinal virtue itself, is used to give form to morc active medicines. In the north of Europe, the fruit of the rose, with the addition of sugar, is sometimes cmployed in the preparation of domestic wincs; and the pulp, in a dricd state, affords a grateful ingredient in sauces: but it is supposed that a still greater advantage might be derived from the froit by distillation. The leaves of this, and indeed of every kind of rose, have been recommended as a substitute for tca. On the Continent they arc employed in currying the finer kinds of leather.

On the branches of this trec a singular moss-like and prickly excrescence is fiequently found. This, which is caused by an insect (Cynips rosce), and forns the habitation of its oftspring, was formerly in great medicinal repute; but it is now seldom used. 
166. The RED OFFICINAL ROSE (Rosa gallica) differs from the hundred.leaved rose in huving the leaf-slalks more rough and prickly. The petals are of deep crimson colour, large, spreading, and not numerous.

In the period of its flowering, this rose, which is a native of the south of Europe, succceds the common garden rosc. It is used in several medicinal preparations. Of its petals, in conjunction with sugar, a conservc is made, an infusion, and a syrup; and the dried buds, with water and honey, are made into what is called honcy of roses.

167. The RASPBERRY (Rubus idæus) is a well-linown garden fruit, which grous wild in woods and thickets of several parts of England.

To most pcrsons the flavour of the raspberry is peculiarly grateful; and its perfunic very delightful. Raspberries are much used in cookery and confectionary, as well as to eat in dcsserts. With sugar they are made into jam and jelly, and also into cakcs. The juice, mixed with a certain portion of sugar and of brandy, constitutes the liqueur called raspberry-brandy. This juice is much in request for ice-creams, and is sometimcs manufactured into wine. A grateful syrup is obtained from raspberries, which is occasionally used in medicinc. The leaves are said to be a grateful food to kids.

White raspbcries arc swceter than the red ones.

168. Our wild hedge fruit, called BLACKBERRIES (Rubus finticosus), belong to the same tribe as the raspberry. These are much eaten by children, and sometimes, when taken in too great quantities, produce very violent effects, and liave caused fever, delirium, and other unpleasant symptoms. In Provence blackberries are employed for the colouring of winc. A syrup and jelly, and sometimes also wine, are prepared fiom thenl. The twigs are sometimes used in dyeing a black colour. Silkworms are occasionally fed upon the leaves of the blackberry. 
16.9. The STRAIVBERRY (Fragaria vesca) is a British vood fruil which has leen long cultivaled in gardens.

By cultivation the strawberry has been greatly increased in size, but its flavour continues much the same as that of the wild fruit. The varieties of the strawberry are very numerous.

None of oul fruits are more wholesome than these, and, even when eaten in large quantities, they seldom disagree with the stomach. They abound in juice, have a grateful, cooling, somewhat acid taste, and a peculiarly fragrant sinell; and are either eaten alone, or with sugar, milk, or wine. A palatable jam, wine, and vinegar, are prepared from strawberries. This fruit is sometimes preserved whole in syrup, and sometimes in wine.

\section{CLASS IV.POLY YNDRIA.}

\section{MONOGYNIA.}

170. CAPERS are the unopened flower-buds of a low shrub (Capparis spinosa, Fig. 48), which grows from the crevices of rocks and walls, and among rublish, in the soulhcrn parts of France, in Italy, and the Levant.

The slems of the caper bush are traiting, and two or three feet in length. The leaves are aliernale, of somewhat oval shape, veined, and of bright green colour: and the flowcrs are large and beautiful, with four pelals, and white with a tinge of red.

In the south of France, the caper bush is as common as the bramble is with us. It grows wild upon the walls of Rome, Sienna, and Florence; and, when trained against a wall, it flourishes even in the neighbourhood of Paris: notwitlıstanding which it is almost unknown in English gardens, where it cannot be made to flower without the aid of artificial heat. This shrub is cultiH. 5 
vated on a large scale, between Marseilles and Toulon, and in many parts of Italy.

In the early part of the summer it begins to flower, and the flowers continue successively to appear till the commencement of winter. The buds are picked, every morning, before the petals are expanded: and, as they are gathered, they are put into vinegar and salt. When a sufficient quantity is collected, they are distributed, according to their size, into different vessels, again put into vinegar, and then packed up for sale and exportation. This pickle is much used in sauce for boiled mutton. To persons unaccustomed to it, the taste of capers is umpleasant; but, after a little while, tlıe palate becomes reconciled to it.

The bark of the root cut into slices, and dried in small rolls $\mathrm{Or}^{\circ}$ quills like cinnamon, is sometimes used in medicine in cases of obstruction of the liver.

The flower-buds of the marsh marygold (Caltha palustris), and of nasturtiums, are frequently pickled and eaten as a substitute for capers.

171. The WHITE POPPY (Paparer somniferum) is a raturalized English plant, with smooth calyx and sccd-vessels, and with leaves cmbracing the stem, which grows wild in neglected gardens, and some corn-fields, and to which we are indebted for troo important medicines, opium and laudanum.

Although the white poppy has long been naturalized in this country, it is supposed that we were originally indebted for it to some of the northern parts of Asia. Throughout nearly the wlole of that quarter of the world it is cultivated with great attention, on account of the opium which is obtained from it. Opium is the dried juice of the seed-vessels, and is thus procured :After the petals have fallen off, and the seed-vessels are about half grown, the latter are wounded on one side, with an instrument laving four or five teetl, the gashes being made about an inch in length. A glutinous, milky fluid exudes from the wounds: this is carefully scraped aff, on the ensuing day, by a person 
who, in similar manner, wounds the opposite side of the head; the juice issuing from which is afterwards similarly collected. 'The whole is then put into earthen vessels, where it is worked by the liand, in the open sunshine, until it attains sufficient consistence to be formed into balls, calses, or loaves; after which it is covered over with poppy or tobacco leaves, and further dried, till it is in a proper state for exportation.

Opium is of reddish brown colour, inclining to black; and has a strong and very peculiar snell. It is adulterated in various ways; by an extract of the plant, obtained by boiling: by a powder of the dried loaves and stalks, mixed with some kind of gum; by rice flour, and by other substances not quite so agreeable as these.

The cultivation of opium is so extensively pursued in the East Indies that nearly 600,000 pounds" weight of it are annually exported from the Ganges. But there is no necessity for us to import, at a great expense from abroad, that which might be advantageously prepared in our own country. It is true that the sced-vessels of the white poppy do not attain so large size in this as in warmer climates; but the opium procured from it is of sufficiently cxcellent quality. From the seed-vessels of a single plant more than forty grains of this drug have been obtained; and, under very disadvantageous circumstances of weather, upwards of twenty-one pounds' weight have been procured fiom plants grown upon five acres of land. It has been calculated that, in favourable seasons, the produce of a single acre ought to be near fifty pounds. It is recommended that the seed be sown in autumn rather than in spring. When the sced-vessels have attained a sufficient state of maturity, they may be wounded, and the opium may be collected by children from eight to twelve years of age. The only proper time for collecting it is in the morning, and seven children and two men have been able to collect $1 \frac{1}{3}$ pounds in one morning, betwixt five and nine o'clorls 
The bestmode of reducing the opium to a proper consistenee appears to be to spread it thinly in shallow dishcs, and expose it, under glasses, to the rays of the sun.

We possess few medicines so valuablc as this. It is uscd as a powerful antidote, but ehiefly as a remedy for proeuring sleep and mitigating pain, whieh it does in a very remarkable manner. In the latter respeets, however, it is too often abused; and, if taken in large doses, it proves a deadly poison. But so much are the effects of opium diminished by the habit of taking it, that, although four grains have, in some instanees, proved fatal to grown persons, fifty times that quantity have been taken daily by others. The bad effects of too great a dose are best eountcraetcd by making the patient drink freely of aeids and coffee, and not permitting him to yield to the desire of sleeping, with which he is oppressed. The habitual use of opium, which is much indulged in by the Asiatics, is attended with the same bad effects as the habit of drinking ardent spirits: it brings on tremors, palsy, stupidity, and gencral emaciation; and, when once acquircd, it can scarcely ever be relinquished.

Possessing the above propertics, it is remarkable that opinm, combined in a certain propertion with vegetable acids, instead of inducing, will prevent sleep. In conscquenee of whieh it has oftcn, though injuriously, becn used by persons who are obliged to devote their nightits to sedentary or active pursuits. It is likcwise descrving of remark, that the sects of the poppy have none of the narcotie qualities of the opium. They are mild, sweet, and nutritive; and yield, by pressure, an oil littlc inferior to that of almonds. So numerous are these seeds that morc than 30,000 have been counted from a single secd-vessel.

Laudanum is a liquid preparation from opium and spirit of winc; and is uscd for most of the same purposes to which opium is applied. Its effects, as a poison, may be counteracted in the same manner as those of opium. 
172. ARNATTO, or ANNOTTA, is a red dyeing drug, generally imported in humps wrapped up in leaves, and produced from the pulp of the seed-vessels of a shrub (Bixa orellana) which grows spontaneously in the East and West Indies.

This shrub is usually seven or eight fieet high, and has henrtshaped and pointed leaves. The flowers, which have each ten large peach-coloured pelals, appear in loose clusters at the ends of the branches, and produce oblong and somezohat hairy pods.

The seed-vessels of the arnatto shrub are, in appearance, somewliat like those of the chesnut (235). They each contain from thirty to forty seeds, enveloped in a kind of pulp (of red colour and unpleasant smell), which is not much unlike the paint called red lead, wlien mixed with oil. In the West Indies the method of extracting the pulp, and preparing it for sale, is to boil it, and the seeds which are mixed witl it, in clear water, until the latter are perfectly extricated. 'They are then taken out, and the pulp is allowed to subside to the bottom of the water; this is drawn off, and the sediment is distributed into shallow vessels, and gradually dried in the slade until it is sufficiently hard to be worked into lumps or masses for sale.

Arnatto, though made in the West Indies, is an object of no great commercial importance; the demand for it not being sufficient to give much encouragement to its culture. It is now chiefly prepared by the Spaniards in South America, and for the purpose principally of mixing with clocolate, to which, in their opinion, it gives a pleasing colour and great medicinal virtue, as well as an improved flavour. The chief consumption of arnatto in England depends upon painters and dyers; and it is supposed that Scott's nankeen dye is nothing but arnatto dissolved in alkaline ley. This drug is sometimes used by the Dutch farmers to give a rich colour to butter; and the double Gloucester and several other kinds of cheese are coloured with it. Poor people occasionally use it instead of saffron. 
In countries where the arnatto shrubs are found, the roots are employed by the inhabitants in broth; and they answer all the purposes of the pulp, though in an inferior degree. 'The bark is occasionally manufactured into ropes; and pieces of the rood are used by the Indians to procure fire by friction.

173. The LIME or LINDEN-TREE is a British forcst tree, (Tilia europrea) distinguished by its heart-shaped and serrated leaves of bright green colonr, and by its berrics or seed-vessels, having each four cells and one bud.

The blossoms are whitish, in small clusters, and have a yellowish green floral leaf, nearly as long as the fruit-stalli, and uttached to it for about half its length.

No one can have passed a grove of lime-trees, in the month of July, without having been charmed with the perfume which, at this season, is emitted by the flowers. They are a great resort of becs, and supply those insects with materials for their best honey. Whether fresh or dricd, they easily fcrment, and a fine flavoured spirit may be distilled from them. The rood is closegrained, though soft, light, and smooth. It is much used by carvers and turners; and is in great request for the boards of leather-cutters. When properly burnt it makes an excellent charcoal for gunpowder, and for painters.

If the bark be softened in water, the fibrous immer part may be separated: of this the Russians manufacture fishing-nets, mats, shoes, and rustic garments; and ropes and other cordage, made from it, are stated to be so remarkably strong and elastic, that, in this respect they arc superior to iron chains. In some countries the leaves are dried as a winter food for sheep and goats; and, from these and the bark, a smooth but coarse brown paper may be manufactured. An inferior kind of sugar may be made from the sap ; and the seeds, by pressure, yield a sweet and pleasant oil.

The lime is an eligible tree to form shady walks and 
clipped hedges: but its leaves fall very early in the autumn. In ricl soils it attains a prodigious size; and instances have been mentioned of these trees having existed during more than six centuries.

174. TEA, both black and green, consists of the dried leaves of an evergreen shrub (Thea bohea and Thea viridis, of Linneus, Fig. 49.), with indented and somewhat spear-shaped leaves and white flowers with six petals or more, which is much cultivated in China.

The tea shrub attains the height of five or six feet, and is much branched. The leaves, when full grown, are about $1 \frac{1}{2}$ inch long, narrow, tapering, and of dark glossy green colour, and firm texture. The flowers are not much unlike those of the white wild rose, but smaller; and they are succeeded by a fruit about the size of a sloe, zohich contains two or three seeds.

The tea-tree flourishes, with great luxuriance, in valleys, on the sloping sides of mountains, and on the banks of rivers, in a southern exposure, betwixt the thirtieth and forty-fifth degrees of north latitude. It is chiefly cultivated near Pekin, and around Canton, but it attains the greatest perfection in the mild and temperate climate of Nankin.

The collecting of the leaves is conducted with great care : they are picked singly, and, for the most part, at three different times of the year; about the end of February, the beginning of April, and the end of May. The drying and preparation of then, for use, are processes too long to adnit of minute detail respecting them in this place. It may, however, be observed that for these purposes buildings are erected, which contain from five to ten, and some of them even tirenty, small furnaces, each having, at the top, a large iron pan. There is also a long table covered with mats, on which the leaves are laid, and rolled by persons who sit round it. The iron pan being heated by a fire in the furnace beneath, a few pounds of the leaves are put upon it, and frequently turned and shifted. They are then thrown upon the mats to be rolled betwixt the palms of the hands: after which they are cooled as speedily as pos. 
sible. That the moisturc of the leaves may be completely dissipated, and their twisted form be better preserved, the above process is repeatcd scveral times with the same leaves, but with less he:st than at first. "The tea, thus manufactured, is afterwards sortcd, according to its kind or goodness. Some of the young and tender leaves arc never rolled, but are merely immersed in hot water, and dried.

How long the use of tea has been known to the Chinese we are entirely ignorant; but we are informed that an infusion of the dried leaves of the tea slirub is now their common drink. They pour boiling water over them, and leave them to infuse, as we do in Europe; but thcy drink the tea thus made without either milk or sugar. The inhabitants of Japan reduce thc leaves to a fine powder, which they dilute with water, until it acquires nearly the consistence of soup. The tea equipage is placed befor'c the company, together with a box in which the powdered tea is contained: the cups are filled with warm water, and then as much of thc powder is thrown into each cup as the point of a knife can contain, and it is stirred about, until the liquor begins to foam, in which state it is presented to the company.

It was formerly imagined that black and green tea were the production of different species of shrubs; but thc Chinese all assert, that both are produced from the same specics, and that the sole difference which exists betwixt them arises from the seasons when the leaves are gathered, and the modes of curing them. The teas principally consumed in Europe are four kinds of black, and three of green.

\section{Black Teas.}

(a) Bohea, or Voo-yfe, so called from the country in which it is produced, is sometimes collected at four gatherings. As the leaves are picked, they are put into flat baskets, which are placed on shelves or planks, in the aị or sun, from morning till night; after which 
they are thrown, by small quantities at a time, into a flat cast-iron pan, which is made very hot. They are twice stirred quick with the hand: then taken out, again put into the baskets, and rubbed between men's hands to roll them. After this they undergo another roasting, in larger quantitics, over a slower fre : and are then sometimes put into baskcts over a charcoal fire. When the tea is, at last, sufficiently dried, it is spread on a table; and the leaves that are too large, and those that are unrolled, yellow, broken, or otlierwise defective, are picked out, and the renıainder is laid aside to be packed.

The best bohea tca is a small blackish leaf, is dusty, smells somewhat like burnt hay, and has a rough and somervhat harsh taste. The average annual importation of bohea into this country, in the ten years fiom 1791 to 1800 , was $3,310,135$ pounds.

(b) Congo, or Cong-foo, derived from a word which implies much care or trouble, is a superior kind of bohea, less dusty, and with largcl leaves. These are gathered with peculiar care, and there is some little difference in the preparation of congo and bohea. The leaves of the latter, of souchong, hyson, and the fine singlo teas, are said to be beaten, with flat sticks or bamboos, after they have been withered by exposure to the sun or air, and have acquired toughness enough to keep them from breaking.

Of congo the annual average quantity imported in the above years amounted to $9,564,20 \%$ pounds.

(c) Souchono, from a Chinese word which signifies small good thing, is made from the leaves of trees three year's old; and, where the soil is good, even of the leaves of older trees. Of true souchong very little is produced; what is sold to Europeans for this is only the finest kind of congo, and the congo usually purchased by them is but the best sort of bohea. Such is the delicacy of this tea that, upon a hill planted witl tea-trees, thcre may only be a single trce, the leaves of which are good enough to be called souchong; and even 
of these, only the best and youngest are taken. The others make congos of different kinds, and bohea.

(d) Pekoe is distinguished by having the small white flowers of the tree intermixed with it. 'This, which is chiefly consumed in Sweden and Denmark, is usually made from the tenderest leaves of trees three years old, gathered just after they have been in bloom, when the small leaves that grow between the first two that have appeared, and which altogether make a sprig, are white, and resemble young hair or down.

\section{Green Teas.}

It has been assertcd that green teas are indebted for their qualities and colour to a process of drying them upon plates of eopper. This is eertainly incorrect. The leaves for green tea are gathered, and immediately roasted, or taelhed, as it is called, upon east-iron plates, and then are very mueh rubbed hetwixt men's hands, to roll them. They are afterwards spread out and separated, as the leaves in rolling are apt to adhere to each other; and are again placed over the fire, and made very dry. After this they are pieked, cleansed from dust, several times tached or roasted, and finally put hot into the chests in which they are to be paeked.

The principal kinds of green tea are singlo, hyson, and gunpowder.

(a) Singlo, or Song-lo, is so named from the place where it is chiefly eultivated. Of this tea there are three or more sorts ; but the leaves of the best are large, fine, flat, and elean. It is gathered at two seasons, the first in April, and the sceond in June. As we sec it, the leaf is flattish, and yields, on infusion, a pale ambercoloured liquor.

(b) Hyson, or Heecchun, has its name from that of an Indian merchant who first sold this tea to the Europeans. There are two gatherings of hyson. It should have a fine blooming appearanec, be of a full-sized grain, very dry, and so crisp that, with slight pressure, 
it will crumble to dust. When infused in water the leaf should appear open, clear, and smooth, and should tinge the water a light green colour ; the infusion ought to have an aromatic smell, and a strong pungent taste.

(c) Gumpowder tea is a superior kind of hyson, gathered and dried with peculiar care. This tea should be chosen in round grains, somewhat resembling small shot, with a beautiful blaom upon which it will not bear tbe breath : it should have a greenish hue, and a fragrant pungent taste. Gunpowder tea is sometines adulterated; an inferior 'kind being dyed and glazed in such manner as to resemble it; but, on infusion, this is found in every respect very inferior.

Tea, both black and green, is sometimes imported in balls from the weight of two ounces to the size of peas.

The dried leaves of the tea plant, are a commodity which, a century and a half ago, were scarcely known as an article of trade. The earliest importation of tea into Europe is said to have been by a Dutch merchant in 1610; but the time of its first introduction into England has not been correctly ascertained. So scarce an article was it, for many years after the above period, that, in 1666, twenty-two pounds and three quarters of tea, estimated at fifty shillings a pound, were presented, as a valuable gift, to King Charles the Second. The first importation of tea by the East India Company was in 1669, and this consisted only of two canisters, weighing 143lb. 8 oz. So rapidly, however, has the consumption of this article since increased, that, notwithstanding the immense distance from which it is brought, it now amounts to more than tiventy millions of pounds' weight per annum. Such is, at present, the extent of the tea trade, that it affords constant employment for at least 50,000 tons of shipping, and 6,000 seamen; and its inportance to us is the greater since it has been the means of opening, in China, a market for the sale of woollen goods, one of the most essential articles of our 
manufacture, to the amount of more than one million of pounds sterling per annum.

If good tea be taken in moderate quantity it is considered by niedical men to be beneficial, by exhilirating the spirits and invigorating the system; but, when taken too copiously, it is apt to occasion weakness, tremor, and other bad symptoms.

The tea plant may be propagated in the temperate climates of Europe, as well as in the Indies : under the shelter of a south wall it will even flourish in our own gardens. It is, however, somewhat remarkable that the fresh leares, if used for tea, produce giddiness and stupefaction; but these noxious properties are capable of being dissipated by the process of roasting.

In some of the souchern parts of England there are smugglers who have reduced to a regular process the management of the leaves of the ash, the sloe, and some other trees, for the adulteration of tea. The article thus prepared has the name of smouch, and is sometimes mixed in the proportion of about one-third, with the ordinary teas. 'The preparation of it, however, if discovered, is subject to very heavy penalties.

175. CLOVES are the unexpanded flower-buds of an East Indian tree (Caryophyllus aromaticus, Fig. 50.) somezhat resembling the laurel in its height, and in the shape of its leaves.

The leaves are in pairs, oblong, large, spear-shaped, and of bright green colour. The flowers grow in clusters, which terminate the branches, and have the calyx divided into four small and pointed segments. The petals are small, rounded, and of bluish colour; and the seed is an oval berry.

In the Molucca islands, where the preparation of different spices was formerly carried on by the Dutch colorists to great extent, the culture of the clove-tree was a very important pursuit. It has even been asserted that, in order to secure a lucrative branch of commerce in this article to themselves, they destroyed all the trees growing in other islands, and confined the propagation of them to that of 'Ternate only. But it 
appears that, in 1770 and 1772 , both clove and nutmeg trees were transplanted from the Moluccas into the islands of France and Bourbon ; and, subsequently, into some of the colonies of South America, where they have since been cultivated with great success.

At a certain season of the year the clove-tree produces a vast profusion of flowers. When these have attained the length of about half an inch, the four points of the calyx being prominent, and having in the middle of them the leaves of the petals folded over each other, and forming a small head about the size of a pea, they are in a fit state to be gathered. This operation is performed betwixt the months of October and Febrary, partly by the hand, partly by hooks, and partly by beating the trees with bamboos. The cloves are either received on cloths spread beneath the trees, or are suffered to fall on the ground, the herbage having previously been cut and swept for that purpose. They are subsequently dried by exposure for a while to the smoke of wood fires, and afterwards to the rays of the sun. When first gathered they are of reddish colour, but, by drying, they assume a deep brown cast.

This spice yields a very fragrant odour, and a bitterish, pungent, and warm taste. It is sumetimes employed as a hot and stimulating medicine, but is more frequently used in culinary preparations. When fresh gathered, cloves will yield on pressure a fragrant, thick, and reddisl oil; and by distillation a limpid essential oil. The latter is imported into Europe, but is frequently adulterated, and sometimes even to the amount of nearly half its weight. Oil of cloves is used by many persons, though very improperly, for curing the tooth-ache, since from its pungent quality it is apt to corrode the gums, and injure the adjacent teeth. When the tooth is carious, and will admit of it, a bruised clove is much to be preferred. 
176. LADANUM, or LABDANUM, is a resinous drug which exudes, and is collected, from the leares and hranches of a beantiful species of cistus (Cistus Creticus), achich grows in Syria and the Grecian islands.

The height of this shrub seldom exceeds three or four fcet. Its leaves, which stand in pairs on short foot-stalls, 'arc oblong, wrinkled, rough, and clummy. The flowers appear in Junc and July, and consist of filc large rounded petals of light purplish. colour, each marked with a dark spot at the lase.

The ancient mode of collecting ladanum, if the accounts which have been stated respecting it may be credited, was not a little curious. Goats, which delight in grazing upon the leaves and young branches of the shrubs that produce it, were turned loose into the plantation, and the resin that adhered to the long hair of their beards and thighs was afterwards detaclied by combing them.

The present method is different, and is a laborious and troublesome employment. T'ournefort informs us that he saw seven or eiglit country fellows, in their shirts and drawers, and in the lottest part of the day, drawing over the slurubs a kind of whip, or rake, with numerous long straps or thongs of leather. From these they collected the resin, by scraping it off with a kind of linife; after which it was made into cakes of different sizes for sale. As loose sand generally adheres, in considerable quantity, to the viscous leaves of the shrub, it is not unusual for dealers in this cirug to adulterate it with sand.

We import ladanum principally from the Levant and the Persian Gulf; and it comes to us in cakes or masses of different size, dark colour, and about tne consistence of soft plaster; and also in rolls, lighter coloured and much harder, which are twisted up so as somewhat to resemble the rolls of wax tapers.

The smell of ladanum is strong, but not disagreeable; and its taste is warm, aromatic, and somewhat unpleasant. This drug was formerly much used as an internal medicine; but it is now employed only externally, as an ingredient in plasters. 
177. The TULIP-TREE (Liriodendron tulipifera) is an American production which yields a very beatiful and caluable kind of wood.

It sometimes grows to the height of sixty or serenty fect; and has loicd leaves, and tulip-shaped flucers.

While young the rood of the tulip-tree is white; but, at an advanced age, it assumes a fine yellow colour, or a streaked appearance of different shades of red. This wood is equally useful in ornamental furniture, and as a timber fol building. It is occasionally employed in the construction of light vessels; and the trunks of tulip-trees are frequently hollowed by the Indians into canoes. When they have been grown in a favourable soil and climate, one of them is sufficiently large to be made into a canoe capable of containing several people.

On account of its quick growth and easy culture, this noble tree well deserves the attention of planters in our own country.

\section{CLASS XIV - DIDYNAMIA.}

\section{GYMNOSPERMIA.}

178. LAVENDER is a well known perennial garlen plant (Lavandula spica) which grous wild in the south of Eucrope, and the flowers of which yield a gruteful perfume.

Such is the fragrance of this delightful flower, and so easy is its culture, that we can now scarcely enter a garden in whieh it is not found. It will grow in almost any soil, but it fourishes most luxuriantly in clayey ground; and in situations whence, without inconvenience, it can beconveyed to the metropolis, it is a very valuable crop. 
When cultivated to any extent, lavender should be planted in rows two or three feet apart, and the sets should be about two feet from each other. It is usually propagated from slips. During dry weather, in the month of July, the flowers should be gathered, by cutting off the heads close to the stem; after which they must be tied in bundles to be distilled.

When distilled with water, the flowers of lavender, if in a mature state, yield an essential oil ; generally in the proportion of about one ounce of oil to sixty ounces of flowers. This nil is of a bright yellow colour, and possesses the perfect fragrance of the lavender. But, if distilled with rectified spirit, the virtues are more completely extracted. From the leaves a vcry small proportion of oil can be obtained.

The preparations of this plant that are used in medicine are, the essential oil, a simple spirit, and a compound tincture. Lavender, however, is much more frequently and more extensively employed as a perfume than medicinally. The flowers are deposited in chests and wardrobes among linen, not only on account of their fragrant smell, but also from an opinion that their odour will prevent the depredations of moths and other insects. The perfume called lavender ruater may be prepared by mixing three drachms of oil of lavender, and one drachm of essence of ambergris, with one pint of spirit of wine.

Lavender is supposed to have been first cultivated in England about the year 1558.

179. COMMON or SPEAR-AINT (Mentha viridis), ons of our most frequent garden herbs, is a native British plant, and grours wild in watery places, and neur the banks of rivers, in several jurts of England.

The ancients ascribed many virtues to different kinds of mint, but it is not now possible to ascertain correctly the respective species, though there can be little doubt that spear-mint was one of the most important of them. Its tlavour is to many persons pe- 
culiarly agreeable, and, on this account, it is employed for several culinary purposes, both in a green and dried state.

'The leaves are used in spring salads, are boiled with peas, and put into soup. In conjunction with vinegar and sugar they form a sauce for la mb; and prepared with sugar, they are made into a grateful conserve. Spear-mint is occasionally used in medicine, and the officinal preparations of it are the conserve, all essential oil, a simple distilled water, a spirit, and a tincture, or extract. In drying, the leaves lose about threefourtls of their weight, but without suffering much either in taste or smell.

180. PEPPER MINT (Mentha piperiti) is a British plunt, which groues in watery places, and is cullicaled chierfy on uccount of an oil and distilled water which are prepared from it.

'This is the strongest and most aromatic of all the mints; and, on this account, is more used in medicine than any other species. When distilled witl water it yields a considerable quantity of essential oil, of pale: greenish yellow colour. The well-known liquor called pepper mint ruater, prepared from this plant, is an excellent stomachic: but is too often used in cases of impaircd appetite, and for the relief of various imaginary complaints.

\section{$\triangle$ NGIOSPERMIA.}

181. The FUX-GLOVE (Digitalis purpurea) is a stufeluz British plant, with long, ercet spikes of lurge, purple, and somenchut be!l-shuped Plowers, murked iniernally with dark spols in whilish. ring.s, and containing four stamens, with lerge ycllow anthers.

The calyx, "flawer-cup, has five printed divisions. The extremity of the blossom is dicided into five segments; ind the seedressel is egr-shaped, and contuins many secds. The leares are large,
wrinkled, and someutht douny benealh.

The gravelly or sandy hedge-banks or liills of all the midland countries of England are adornet, in the later: months of summer, with this, one of the nost beautiful, most dangerous; and yet, if properly applied, one of

YOL. II, 
the most useful of all our wild plants. For its medicinal virtues it has long been esteemed. The Italians have an adage which implies that "the fox-glove heals "all sores:" hence it is said, that they apply the bruised leaves, and the juice of the leaves, in the healing of different kinds of wounds, and particularly for the removal of sciophulous swellings.

The juice of this plant has a bitter and nauseous taste ; and, when taken internally, acts violently on the stomach and bowels, and brings on stupor and drowsiness; notwithstanding which, in careful hands, it mar be rendered a valuable medicine in dropsy, consumption, and epilepsy. It is given in powder. tincture, and infusion of the dried leaves; and such is its strength, that Dr. Woodville states, the dose of the dried leaves, in powder, should not exceed from one to three grains per day.

182. The CALABASH.TREE (Crescentia cujela) is a production of the West Indies and Amoricn, alond the height and dimensions of an apple-tree, with crnolied horizoutal branches, wedgeshaped leares, jale white flower's on the trumk and branches, and a roundish fruit, from two inches to a foot in diameter.

'The uses to which the fruit of the calahash tree is applied are very numerous. Being covered with a greenish yellow skin, which encloses a thin, hard, and almost woody shell, it is employed for various kinds of domestic vessels, such as water cans, goblets, and cups of almost every shape and description. So hard and close-grained is the calabash, that, when it contains any kind of fluid, it may even be put on the fire without injury. When intended for ornamental purposes, the vessels that are made of the shell of this fruit are sometimes highly polished, and have figures engraven upon them, which are variously tinged with indigo and other colours. The Indians make musical instruments with the calabash.

'The calabash contains a pale, yellow, juicy pulp, of unpleasant taste, which is esteemed a valumble remedy in several disorders, both external and internal. 


\section{CLASS XV.-TETRADYNAMIA.}

\section{SILICULOSA.}

183. SEA KALE (Crambe maritima) is a well lenown plant in our kitchen gardens, the early shoots of which are blanched, and eaten in the same manner as asparagus.

This plant grows wild on sandy sea-coasts in various parts of England; and lias been transplanted thence into the gardens. "The mole of management is, in the autumn, to place lare inverted garden-pots over the plants, and to cover the whole bed and the pots with dung and litter. The heat of the fermenting dung causes the plants to shoot early in the spring; and the pots proteet them and keep them clear of the litter. By this means also, as they have no access to the light, they beeome blanched, tender, and of extremely sweet and delicate flavour.

Sea kale is ready for use some time before asparagus appears; and, for the table, it is preferred by most persons to that favourite vegetable. If the leaves of sea kale be eaten when full grown, they aire said to occasinn giddiness; but horses, cows, swine, and other animals, feed upon them without injury.

1S4. TOAD is a dyeing drug, produced by a Brilish plunt. (Isatis tinctoria), with arroiv-shaped leaves on the stem, yellow cruciform flowers, and oblong seed-vessels, cach containing one seed.

This plant is believed to lave been the same that was adopted by the ancient Britons for staining, or painting their bodies a blue eolour, to render them, in appearance, at least, more terrible to their enemies. It grows wild on the borders of corn-fields, in some parts of Cambridgeshire, Somersetshire, and Durham: and 
is eultivated in several of the clothing distriets of England.

As soon as the plants are in a suffieient state of maturity, they are gathcred. The leaves are picked off, and submitted to the action of mills, somewhat similar to the mills that are used for the grinding of oak-bark. In these they are redueed to a pulp. The woad is then laid in small heaps, which are closely and smoothly pressed down. After eontinuing about a fortnight in this state, the heaps are broken up, and their substance is formed into balls, whieh are exposed to the sun to be dried. When the balls are perfectly dry, they are ready for use; and are employed, not only in dyeing blue, but also as the basis of several other eolours.

185. HORSE-RADISH (Cochlearia armoracia) is a wellknown kitchen gurden phent, which grows wild by the sides of ditches and the baulis of rivers, in several parts of the north of Englund.

The root of horse-radish is mueh used for eulinary purposes. It is remarkable for great pungency both of smell and taste. When seraped, it is mixed with pickles to heighten their flavour, and is eaten with roast beef, fish, and several other kinds of food. Whenever more of the roots are dug out of the earth at cnce than are immediately wanted, they may be preserved for some time, in a juicy state, by putting them into dry sand.

Horse radish is also in eonsiderable repute as a medieine, and is a powerful stimulant, whether externally or internally applied. Notwithstanding this, we are informed by Dr. Withering, that an infusion of horseradish in eold mills is one of the best and safest cosmetics that are known.

\section{SILIQUOSA.}

136. COMMON MUSTARD is made from the poudered. seeds of a plunt (Sinapis nigra), which grows wild in corn-fields and by roud sides, in most purts of England, and is known by its yellow cruciform flowers, with expanding calyx, and its pods peing smooth, square, and close to the stem, 
In light and otherwise barren lands mustard is cultivated to great advantage. That which is produced in the county of Durham has much celebrity; though the powdered seeds of charlock have, in many instances, been substituted, and sold in place of it. Mustard is in daily use at our tables, and the seeds, whole or bruised, are employed in pickles, and for numerous other culinary purposes. These seeds yield, on pressure, a considerable quantity of oil,which is soft and insipid to the taste, and partakes but little of the acrimony of the plant.

Different preparations of mustard are sometimes used in medicine. The seeds, taken internally, are serviceable in asthma, rheumatism, and palsy. Cataplasms of mustard are employed, on account of its stimulating properties, on benumbed or paralytic limbs. An infusion of the powdered seeds, taken in considerable quantity, opcrates as an emetic, and, in smaller quantity, is an useful aperient and diuretic.

187. RAPE and COLE SEED (Brassica napus) are different varieties of a plant with yellow cruciform flowers and spindle-shaped root, which grows wild upon ditch banks, and amongst corn.

This plant is distinguished from others of the sume tribe by its roots being a regular continuation of the stem.

In several parts of England rape and cole seed are sown intermixed, the plants being distinguishable in their growth by the cole exceeding the rape in height, being more soft and tender, and less branched and bushy. When sown separately the cole is usually, though not always, consumed as food for sheep and cattle; and the rape is allowed to stand for seed. For the cultivation of rape the soil ought to be rich and deep.

The harvest commences about the month of August ; and as the seed, when in a state of maturity, is easily shed, it is customary, in some places, to thresh the plants on a large cloth in the field. Rape-cloths are sometimes so largc as to measure twenty yards square, - and to weigh more than half $a$ ton. The threshing is 
almost always considered a sort of festival, at whieh a great portion of the neighbours attend, in order to expedite the work; and they are repaid by the good eleer of their brother farmer. In other plaees the rape is carried on a cloth, in a low kind of waggon, to bo threshed out of the field.

Oil is obtained from rape-seed by pressure. This is used, in large quantities, by eluthiers and others. It is also used in medieine; and for making the soap ealled green soap. It is likewise useful for various purposes in domestie life, and particularly for burwing in lanips; but it is apt to become rancid, though there are mcans of purifying it. After the oil has been extraeted, the refuse is ealled oil-cake, and is employed for the fattening of oxen; and, in Norfulk, is sometimes broken to pieces, and strewed upon the land as manure. The roots of rape plants may be eaten like turnips, but they have a stronger taste. 'The stalks, or haulm, if strong, may be advantageously eniployed in the formation of the enclosing fenees of farm-yards. They are, however, generally burnt; and in sonie parts of the country, the ashes, which are equal in quality to the best pot-ashes, are colleeted together and sold.

188. The TURNIP (Brassica rapa) is a well-known edible root, which is cultivated to grcat cxtent in ulmost every part of England.

To the farmer tumips are, in various partieulars, a most valuable crop. 'Ihey afford a profitable intervening erop with corn. Both the tops and roots are eaten by sheep. Horses and eattle may be advantageously fed upon the roots during winter; but the nill of eows reecives an unpleasant flavour from them. 'This flavour is also communieated to the butter ; but it may be taken off by dissolving a little nitre in spring water, and putting a small tea-cupful of it into about cight gallons of milk, when warm firom the cow. Thumps also serve as food for mankind, cither boiled or roasted. In the years 1629,1636 , and 1693 , diring the pressure 
of a severe famine, bread is stated to have been made of turnips in several parts of England, particularly in the county of Essex. The process was to put the turnips into a kettle over a slow fire, till they became soft; they were then taken out, squeezed as dry as possible, mixed with an equal quantity of flour, and, after having been kneaded with yeast, salt, and a little warm water, were made into loaves and baked. In bread thus made the peculiar taste of the turnip is said to be scarcely perceptible.

These roots have been much recommended as sea store, from the possibility, with care, of preserving them for a great length of time uninjured, and from their furnishing an agreeable and wholesome food for sailors on long voyages. The young and tender tops of turnips, when boiled, afford an agreeable substitute for greens.

For the cultivation of turnips a light soil, particularly such as consists of a mixture of sand and loam, is found preferable to rich and heavy land. Turnips are raised from seed, which it has long been the established custom to sow in the month of June. As soon as the young plants have attained a tolerable size, they are hoed, for the purpose of thinning them. In their growth they suffer much by the attacks of slugs, caterpillars, and insects of different kinds, particularly of a small, dark beetle with two longitudinal yellowish stripes (Chrysomela nemorum), which is called by farmers the turnip$f y$. For the destruction of this insect many plans have, at different times, been devised.

Turnips are either eaten on the land, or are drawn out and stacked, or preserved under ground for winter use; and, in this state, they may be kept sound till April.

There are several kinds of turnips ; but of these the common rolite, or Norfolk turnips, and the Ruta-baga, or Swedish turnips, are the principal. The latter, which indeed constitute a distinct species, are generally of a yellowish colour, and are so hardy to suffer no injury even fiom the most intense cold; but their sub. 
stance is so compact as sometimes to break the teeth of sheep which feed upou them.

189. The COMMON CABBAGE. (Brassica oleracea) is a well-known plant, the original stock of zohich grows on cliffs by the sea-side, in Kent, Cornoall, Yorkshire, and Wales.

'This wild plant is likewise the original of the vorious kinds of colewort, borecole, cauliflower, and brocoli.

The effects of cultivation on the cabbage are very remarkable. 'In the wild plants the leaves are extended: but in the common garden cabbage they are set so close together as to lie upon each other, almost like the scales of a bulb: ancl, increasing in compactness as they Increase in size, those in the interior being excluded from the effects of the light, clo not assume a green, but are of yellow colour.

Other plants of this species form their stalks into a head, as the cauliflorver and brocoli; and others grow, in a natural way, without forming either their leaves or stalks into heads, as the colervorts or Dorsetshive liale, the borecoles, turnip-rooted cabbage, and other's.

In some parts of England, cabbages of different kinds are much cultivated as food for cattle, and they succeed well in rich and finely prepared land. 'The seed is sown - in . February or March. In April or May the young plants are taken out, and set in rows, at a little distance fiom each other ; and, in the ensuing autumn and winter, the cabbages afford a valuable stock of food.

All the kinds of cabbage are useful for domestic purposes; and some of them afford a peculiarly sweet and delicate food. An agreeable pickle is made of them, and the Germans, and people of other northern countries of the Continent, prepare fiom them a fivourite food called-sour-crout. These plants were known to, and mucl userl by, the ancient Greeks and Romans.

Cabbages are biennial plants, or are sown one year, produce seed in the ensuing year, and then die. 


\section{CLASS XVI.-MONADELPHIA.}

\section{TRIANDRIA.}

190. TAMARINDS are the pulp and sceds produced by the pods of a large tree with winged leaves (Tamarindus Indica, Fig. 51), which grows in the East und West Indies, America, and several parts of Asiu.

This tree is from thirty to forty feet in height; and its leaves consist usually of fourteen pairs of leaflets. The flowers are formed in chisters, from the sides of the branches, and have each three yellowish petals, benutifully marked with red veins.

The fruit of the tamarind-tree is a roundish but sonerohat compressed pod, four or five inches in length, the external part of which is very britlle. Each pod contuins thrce or four hard seeds, enveloped in tough skins, surrounded by a dark.coloured. acid pulp, and conrected together by uumerous tough and woody fibres.

Previously to the exportation of tamarinds, the pulp, with the seeds and fibres, are freed from their shell: and those which we receive from the West Indies are usually preserved in syrup. In Jamaica the fruit is gathered about the month of July. When fully ripe, and after the pods are cleared away, the remainder is placed in layers, in small casks ; and boiling syrup, just beforc it begins to granulate, is poured upon them until the casks are filled, after which the heads are put in and fastened up for exportation.

The East Indian tamarinds are generally packed witlout any admixture. They are more esteemed than the others; and, when in the pods, are easily distinguished from them by these being longer, and containing six or seven seeds; the pulp also is drier and of darker colour.

It is said that we are indebted to the Arabians for a knowledge of the use of tamarinds. In hot climates they are a most refreshing and delicious fruit; and, dissolved in water, are much used as a cooling and 
agreeable beverage, particularly by persons suffering under fever. They also give great relief in sore throats, and other complaints.

\section{POLYANDRIA.}

191. The SOUR-GOURD, BOABAB, or AFRICAN CALABASH-TREE (Adarsonia digitata), is probably the largest of all vegetable productions. The trunk, although not usually more than twelie or fifteen feet high, isfiequenlly from sixty to eighty fiet in girth. The lowest branches extend almost horizonially; and, as they are sometimes near siaty feet in length, they bend, by their own weight, to the ground; und thus the whole tree forms an hemispherical mass of verdure, which measures from 120 to 130 fect in diameter.

'The fruit is oblong, about ten inches in length, pointed at both ends, and covered with a greenish down, under which there is a blaclissh and woody rind. Its interior consists of a whitish, spongy, and juicy substance, with several brown seeds.

This tree is a nutive of Senegal and other parts of Africa.

The virtues and uses of the sour-gourd tree and its fruit are numerous and of great importance to the inhabitants of the countries in which it is found. 'The burk and leaves are dried, powdered, and preserved in bags, to be employed as a seasoning for food. 'l'wo or three pinches of this powder are put, by the negroes, into their messes, under an impression that it promotes perspiration and moderates the heat of the blood

The pulp of the fruit has an agreeably acid flavour. This is rot only enten when fresh, but is dried and powdered for medicinal uses; a kind of soap is also prepared from it.

In Senegal, when the trees are decayed, the trunks are hollowed, by the negroes, into burying places for their poets, musicians, and buffoons. These persons are much cstecmed whilst they live, although they are supposed to derive their superior talents fiom sorcery; or an alliance with demons. When dead, lowever, their bodies are regarded with horror, and are not allowed the usual burial, under a notion that the earth 
would, in such case, refuse to produce its accustomed fruits. The bodies -enclosed in these trees are said to become perfectly dry without decaying, and thus to form a kind of nummies, without the process of embalmation.

192. COTTON is a soft vegetable down, which is contained in the seed vessels, and envelopes the seeds of the cotton-plant (Gosypium herbaceum, Fig. 5\%), which is cultivated in the East and West Indies, and numerous other countries of hot climates.

This, though an anmual plant, grows to a considerable height. It has leaves of bright green colour, marked with brownish veins, and each divided into five lobes. The flowers have only one petal, in five segments, with a short tube, and are of pale yelloiv colour, with five red spots at the bottom.

The cotton pods are of somewhat triangular shape, and have each three cells. These, when ripe, burst, and disclose their snow-white or yellowish contents, in the midst of which are contained small black seeds, in shape somewhat resembling those of grapes.

We are informed, by $\mathrm{Mr}$. Edwards, that the plants are raised from seerl, the land requiring no other preparation for them than to be cleared of its native incumbrances. The seeds are usually sown in rows six or eight feet asundcr, and the holes in which they arc put are about four feet apart. At the end of five months the plants begin to flower, and in two months more the pods are formed. After the cotton is gathered, it is freed from the seeds to winch it is attached, by a very simple machine, consisting of two small rollers that are close and parallel to each other, and move in opposite directions. "The cotton is next hand-picked, to frce it from decayed leaves, broken seeds, and other impurities : after which it is packed, for sale, in bags of about two hundred pounds each.

Though the cotton plant flourishes best in tropical climates, it is capable of cultivation in such as are not so hot; and it is now an object of attention in several of the southern parts of Europe. 
We receive great quantities of cotton from America, and the East and West Indies. The whole quantity imported into this country, in the year 1802, cxceeded $60,000,000$ pounds' weight; whilst the average annual importation, anterior to 1780 , did not amount to one tenth part of this; so rapid has been the increase and prosperity of our cotton manufactories. Calicoes and muslins of all kinds are made of cotton; fustians, corderoys, and innumerable other articles. Nankeens, which are manufactured in India, are made of a kind of cotton which is naturally of a reddish buff colour.

After the cotton is imported into England, the first process whichl it goes through is that of carding. Some years ago, this was performed by the hand, upon the knee, with a single pair of cards; but it is now performed with cylindrical cards, worked by machinery. The next and most important inprovements in the manufacture of cotton, were made at Cromford, in the county of Derby, by the late Sir Richard Arkwright; who, in 1768 , first introduced the method of spinning cotton by machinery. By this contrivance cotton was carded, roved, and spun, with the utnost expedition, correctness, and equality. Other machines have, at different subsequent periods, been invented by various mechanics and manufacturers, particularly that called a jenny, by which one person is able to spin a liundred hanks of cotton yarn a-day, containing, in the whole, near a million of yards. The concluding operation is that of weaving, which is parformed with a machine called a loom, in the same manner as flax (97) and hemp (259).

Cotton is capable of being manufactured into paper, which is little inferior to that made from linen rags. 


\section{CLASS XVII.-DIADELPHIA.}

\section{DECANDRIA.}

193. The COMMON BROOM (Spartium scoparium) is a shrub conmon on sandy pastures and healhs in nearly all the soulhern parts of England; and is distinguished by having large, yellow, bullerfly-shaped flowers, lecives in threes, and single, and the lranches angular.

Few of our wild plants are applicable to rnore numerous purposes of domestic utility than this. Its twigs are tied in bundles, and formed into brooms. Some persons roast the seeds, and make them into a kind of coffee. 'The fibrous and elastic parts of the bark, after having been separated by soaking in water, may be manufactured into corclage, matting, and even into a coarse kind of cloth. Tlie twigs and young branches have been successfully employed as a substitute for oak bark, in the tarming of leather. They may also be rendered serviceable as thatcl for houses, and corn ricks; and some persons mix them with hops in brewing; but it is doubtful whether, in this respect, they are wholesome. 'The flower-buds, when pickled, have occasionally been used as a substitute for capers.

The rood, where the dimensions are sufficient for the purpose, is employed by cabinet-makers for veneering; and it is stated by Dr. Mead, that a decoction of the green tops, in conjunction with mustard, has been found efficacious in the cure of dropsy.

194. SPANISH BROOM, or SPART (Spartium junceum), is a well-known ornamenlal flowering shrub in our gardens, which has opposite, round branches, that flower at the lop, and spcar-shuped leaves.

In the province of Valencia, and other parts of Spain, great attention is paid to the manufacture of various articles from the twigs and bark of this shrub. They 
arc plaited into mats, carpets, coverings for plants, baskets, ropes, and cven shocs. A grcat portion of these twigs was formerly exportcd to differcnt French ports in the Mediterranean, particularly to Marseilles; but, in 1783, on account of the cmployment of which it deprived the Spanish people in working them, their exportation was prohibited by the government.

195. FURZE, GORZE, or WHIX (Ulex Europxus), is a well-linown thorny shrul, which is common on healls and waste ground in almost every jart of England.

The chief use to whieh furze is applied, is for the heating of ovcns; and, in this respect, it is valuable, from its burning rapidly, and enitting a great degree of heat. Its ashes are used for a ley, which is of considerable service in the washing of linen.

In some parts of the country, furze is sown on banks, round ficlds, for the purpose of a fence; and it will flourish even close to the sea side, where the spray of the sca destroys almost every other shrub. But it will not bear severe cold, and it is often destroyed by intense frost. Furze does not often occur in the northern parts of our island.

Horses, sheep, and cattle may be fed on this shrub; and, in several places, the seeds of it are sown, cither by themselves, or with barley, oats, or buck-wheat (126). The plants are mown a year afterwards. They will grow for several years, and producc from ten to fifteen tons per acre of food, which is equal, in quality and excellence, to the same quantity of liay. They are bruised before they arc eaten, either in a machine, or by heavy mallets or blocks of wood. 'This opcration is requisite, in order to break the prickles, and prevent these from being injurious to the moutls of the animals that eat them.

196. COWHAGE, or COW-ITCH, is usharp and barled hind of down or hair, which thickly clothes the pods of a bean-like climbing plant (Dolichos pruricris, Fig. 53), that 
groivs in the West Indies, and other countries of warm climales.

This is an herbaccous plant, which cntwines round the adzacent trees or shrubs, and often rises to a considerable height. The leaves grow in threcs upon long foot-stalls; and the flowers cre large, hutterfly-shaped, of purpliste colour, and form long and pendant spities, which have a very beantiful appearance.

It is the property of cowhage, when rubbed upor the skin, immediately to penctrate it, and to causc an intolerable itching. Hence it is sometimes wantonly employed for mischievous purposes; and hence also it is found very troublesome to cattle and domestic animals, in places where the plants grow. Notwitlistanding this, it may be swallowed in safety, and, if taken into the stomach and intestines, is said to be an useful remedy for the destruction of worms. $\Lambda$ s a medicine, it is mixed with syrup or treaclc into the form of an electuary.

197. SOY is a dark-coloured sauce, whick is prepored from the seeds of a Chinesc plant (Dolichos soja), that has an erect and hairy stem, erect bunches of flowers, and pendulous bristly pods, each contuining atout two sccds.

There is a jolie amongst scamcn, that soy is made from beetles or cock-roaches. This probably originates in the seeds of the plant from which the sauce is inanufactured having some fancied resemblance, in shape and colour, to a beetle. These sects are used in China and Japan as food. They are made into a kind of jelly or curd, which is esteened very nutritious, and which is rendered palatable by seasoning of different kinds.

The liquid which we know by the name of soy is thus prepared. After the seeds have becn boiled until they bccome soft, they are mixed with an equal weight of wheat or barley meal, coarscly ground. This mixture is fermented; and a ceriain p)roportion of salt and water being added, the whole is allowed to stand for two or threc nonths, care being taken to stir it cvery day; and, by the end of that cime, it is ready for use. 
Soy is cliefly prepared in China and Japan; but that imported from Japan is considered preferable to any other. The quantity annually vended at the East India Company's sales is from eight hundred to two thousand gallons, at an average price of sixteen or eighteen shillings per gallon.

198. $B E A N S$ (Vicia faba) are well-known seeds, originally introduced fiom Persia, of which there are several linds or varieties; some of these are cultivated in fields, and others in gardens.

Field, or horse-beans, as they are frequently called, are small and somewhat round. The cultivation of them is pursued to a considerable extent. They are esteemed, in many respects, an advantageous crop to the farmer, and will thrive on any land where the soil is sufficiently stiff. They are usually sown in the month of February; sometimes in the autumn; but, in case of severe firost, all the plants that are not well and deeply covered with snow will perish. There is also much uncertainty in the crop, owing to the state of the weather in the spring and summer; and particularly to the ravages of small black insects, myriads of which are frequently seen to crowd the tender tops of the plants.

The bean-harvest is seldom completed till nearly the end of September, owing to the bulk and succulence of the plants; and the produce is from two and a half to five quarters per acre.

There are several varieties of field-beans; but the fine and very small ones usually bear the highest price. Bean flour is not only thought more nutritive, but is found to be more abundant than that of oats. Beans are chiefly applied to the feeding of horses, hogs, and other domestic animals; and it is supposed that meal. men often grind them amongst wheat, the flour of which is to be made into bread. By some persons they are roasted, and adopted as a substitute for coffee. 
With the Roman ladies bean-flour was in inuch repute as a cosmetie.

Garden-beans are almost wholly confined to eulinary uses. What are ealled French-becins, and Kidney-beans, belong to a different tribe from the present.

Bean stalks, if subjected to a eertain proeess, are capable of being converted into paper.

199. VETCIIES are a small species of beans (Vicia sa(iva) which grow wild in dry meadows, pastures, and cornficlds, and are also culivited in most parts of England.

The pods are senerally in pairs; and the leaves winged, huving each alout six pairs of leuflets, with a branched tendril at the cxtremity. At the liases of each of the leaves there is a small stipule, marked with a dark spot.

The principal use of vetches is as provender for horses and eattle. They are grown so early as to allow of being fed off, or eut for this purpose, in sufficient time for turnips to be sown the same year. When the land is to be prepared for a wheat erop it is sometimes customary to plough in the vetehes as manure. The sects afford a grateful food for pigeons.

300. PEAS (Pisum sativun) are $a$ kind of seeds too well known to need any clescription.

There are several kinds of peas, some of which are cultivated in gardens, and others in fields. 'The former are principally used for culinary purposes. In the early part of the year, gardeners in the neighbourhood of London raise them on hot-beds. The kind they select for this purpose are the dwarf peas. These are sown about the middle of October in warm borders; and afterwards, towards the end of January, they are renoved into the hot-beds. The inducement, of eourse, is the enormous prices that are paid for the earliest peas brought in to the market. The podding or picling of green peas for the Loniton market is also a valuable braneh of the business of some farms within a few miles of the metropolis. Many attempts have been made to preserve green peas for use in wirter; one of 
these is by bottling them, and another by drying them in an oven, and afterwards keeping them in paper bags; but none of the modes have been attended with complete success.

Field peas are sown about March wr April, and succeed best in light, rich soils. They are generally considered an uncertain crop; but this is owing, in a great degree, to want of due attention to their culture.

In common with most other seeds of this class, peas yield a nutritive food to persons of strong stomachs. When boiled in a fresh or green state, they are both wholesome and agreeable; and, when ripe and ground into meal, they are peculiarly serviceable for the fattening of swine. The flour of peas is not unfrequently mixed by bakers amongst that of wheat for bread; but bread made of this flour alone is heavy and unwholesome. Three parts of rye-flour and one of ground peas are said to yield a palatable and nourishing bread. Peas that are freed from their husks, and split in mills constructed for the purpose, are used for soup. The liaulm or strato of tield peas, if saved in favourable seasons, affords not only an excellent fodder for working horses, but is also an useful food for horses, cattle, and sheep.

It has been presumed that the everlasting pea, which is commonly grown as an ornamental flower in our gardens, would be an advantageous green food for horses and cattle.

201. LIQUORICE is the root of a perennial plant (Glycyrrhiza glabra), with winged leaves, and purplish butterflyshaped flowers, which grows wild in the south of Europe, and is cultivated near Ponlefract in Yorkshire, Worksop in Nottinghamshire, and Godalming in Surrey, and by many gardeners in the vicinity of London.

The stalks of the liquorice-plant are usually four or fire feet high. The leaves are winged, and the leaflets eggr-shuped, with an odd one at the catremity. The flowers grow in long spikes from the junction of the leaves and branches. The roots are long, round, tough, of brown colour externally, and yellow willin. 
The prineipal use of liquorice is in medieine. It contains much saccharine matter, joined with some portion of mucilage; and is onc of the few sweet substanees which tend to allay thirst. Liquoriee is an exeellent ruedieine in eoughs and hoarsenesses. When boiled in a little water, it gives out nearly all its sweetness; and this, when the moisture is evaporated, produees, by different processes, what are ealled Spanish liquorice, liquorice cakes, liquorice lozenges, and Pontefract calies. The former of these is used to great extent in the brewing of porter. It is said that more than two hun'dred tons' weight of it are anntally manufactured in Spain, a eonsiderable portion of whieh is sold to the London brewers for this purpose. Liquorice powder, whieh is used in medicine, is often adulterated with flour, and probably also with less wholesome articles. The root itself niay be employed as stopples for beer or wine bottles.

The soil in whiel liquorice is eultivated should be deep, light, and sandy; and the roots, whieh strike deeply into the ground, should be planted in rows, at the distance of a foot and half or two feet from eaeh other. Three years elapse, after the roots are planted, before the liquoriec is in perfeetion.

202. SAINT-FOIN (Hedysąrum onobrychis) is a British perennial plant with winged leaves, somerohat pyramidal bunches of butterfly-shaped flowers, marked wilh red, white, and purple; and oblong, hairy pods, each containing a single seed.

This plant is eultivated in several of the farming distriets of England, as food for horses and cattle; and it sueeeeds best on dry and ehalky lands, in high and exposed situations. The seed should be sown in February or March, and, during the first year, the plants should remain untouched. In the cnsuing summer a crop of hay may be obtained from them; and after this the saint-foin may regularly bo mown twice every year, for ten or fiftecn years. When intended for hay. 
saint-foin should not be cut before it is in full blonm, about the beginning of July, as otherwise the quality of the hay would be much injured. Some farmers assert that saint-foin, when cows are fed with it, both increases the quantity and improves the quality of their milk; but, in the opinion of others, the quality is rather injured than improved by it. No pasture is considered more excellent for sheep than this. Saint-foin is also sometimes sown with clover, and sometines with barley.

203. COMMON RED or BROAD CLOVER (Trifolium pratense) is a well-known field plant, much cultivated in this country.

Clover is chiefly grown in firm and good soils, either as green food for horses and cattle, or to be cut for hay. On grass farms it is sometimes sown in conjunction with spring corn, and sometimes with ray-grass (51); and its utility in the fattening of cattle is well known. This species of clover grows wild, in meadows and pastures of most parts of Europe; and, in some countries, during a scarcity of provisions, the flowers have been made into a kind of bread. In Sweden the heads are used as a green dye.

204. LUCERN (Medicago sativa) is a perennial plent with small purple butterfly-shaped floucers, twisied pods, the slem erect and smoolh, and the leares in threes.

Although a wild plant in nearly every country of the temperate parts of Europe, this useful vegetable has only of late years been introduced into cultivation. It flourishes most luxuriantly in deep, rich, and friable loams, and cannot be too strongly recommended as food for cattle. The value of lucern may be considerably increased by sowing it with oats; and, though an expensive crop, it yields great profit.

205. INDIGO is a blue dye prepured from a plant (Indigofera tinctoria) with a shrubliby stem, obloner, smooth, and winged leates, bunches of flowers shorter than the leares, and cylindrical pods slightly curved, which grous in America and the I'est Indies. 
The culture of indigo is an object of considerable importance in the West Indian jslands, and in some parts of America. The grounds appropriated to it are sown about the middle of March, in rows fifteen inches asunder. 'The plants come into flower about three months afterwards, and are in a state to be cut about the month of August. They are cut with a kind of reaping hook, a few inches above the root. The plants are then laid in strata, in a vat or cistern constructed of strong mason-work, and so much water is poured in as will cover them. In this state they are left to ferment, and the fluid or pulp, which is first green, afterwards becomes of deep blue colour. It is now drawn off into another vat, where it is strongly and incessantly beaten and agitated, until the colouring matter is united into a body. The water is then let off by cocks in the sides of the vat; and the indigo, after undergoing some further preparations, is cast, in boxes or moulds, into small pieces, each about an inch square, and packed up for sale. The vapour which issues from the fermented liquor is extremely injurious to the negroes who attend the process; and, as peculiar attention is requisite both to this and the granulating of the pulp, many indigo-planters have failed in the manufacture of this article.

Indigo is employed by dyers, calico.printers, and paper-stainers, to an extent so great that nearly 500,000 pounds' weight of it are amnually imported into this kingdom. The stone-blue used by laundresses, and the colours called Saxon-blue, and green, are made from indigo. Painters use it as a water-colour. 'This article is frequently aclulterated with earth, ashes, and pounded slate. The genuine drug ought to be of rich, dark blue colour, approaching to black; and, when broken, should display the lustre of copper. It ought not to sink in water, nor to leave any sediment when dis. solved. 


\section{CLASS XVIII-POLYADELPHIL.}

\section{DECANDRIA.}

206. CHOCOLATE is a lind of ealie or lard paste, somelimes mude of different ingredients, but the basis of uhich is the mulp of the cacuo or chocolate nut, a produee of the IFest. Indies and America.

'T'le chocolate tree (Theohroma cacao, Fig. 54,) lolk in size and shupe, somechat resendbles a young cherry tree, but il separat's near the ground into forr or five stems. The lcaves are ench about four inclies in length, smooth but not glossy, und of dall green colour. The flower's are suffion-colowed, and rery beutiful.

The fruit of the chocolate-tree somewhat resembles a cucumber in shape, but is furrowed deeper on the sides. Its colour, while growing, is green; but, as it ripens, this changes to a fine bluish red, almost purple, with pink veins; or, in some of the varietics, to a delicate yellow or lemon colour. Each of the pods contains from twenty to thirty nuts or kernels, which in shape are not much unlike almonds. These are arranged in lows, surrounded by a sweet pulpy substance, and are called cacao or chocolaic-nuts.

Plantations of thocolate trees ale numerous on the banlis of the river Magdalana, in South America, and in the Caraccas ; but, at prosent, there are very few in oul own colonies. Wliey are usually formed in morassy situntions : and are shellered from the intense heat of the sun by lalger trees which are planted in them. There aro two principal crops of chocolate-nuts in the ycal"; the first in June, and the second in December. As soon as the fiuit is ripe, it is gathered, and cut into slices; and the nuts, which at this time are in a pulpy state, are taken out with the hand; for the thinness of their husk precludes the possibility of using a machine. They are then laid in skins, or on leaves, to be dried in 
the sun. They have now a sweetish acid taste, and may be eaten like any other fruit. When perfectly dry they are put into bags, each containing about a hundred weight; and, thus packed, are exported to foreign countries.

Previously to the preparation of these nuts into the substance which we call chocolate, they are gently toasted, or parched over the fire, in an iron vessel, after which process their thin external covering is ensily separated. The kernel is then pounded in a mortar, and subsequently ground on a smootle warm stone. Sometimes a little arnatto (173) is added; and, with the aid of water, the whole is formed into a paste. This, whilst loot, is put into tin moulds, where in a short time it congreals; and in this state it is the chocolate of the shops. In South America and Spain other modes are adopted; the chocolate is mixed with sugar, long pepper (21), vanilla, cinnamon, cloves, almonds, and other ingredients, according to the taste of the respective in'rabitants. $\mathrm{Mr}$. Edwards was of opinion, that the cakes of chocolate used in England werc made of about one half genuine chocolate, and the remainder of flour, or Castile soap.

Chocolate was first introduced into Europe by the Spaniards; and that from the Caraccas is considered the best. It should be used whilst new, as neither the seeds nor the cakes will keep wcll more than two ycars. The chocolate used in this country must be manufactured in England, for, by an Act of the legislature, the importation of chocolate paste is prohibited, under heavy penalties. The mode in which this substance is immediately prepared for use is well known.

By the natives of South America chocolate muts are used for food, and also as a circulating medium instead of coin: about 1200 of them being considered equal in value to a dollar.

A white oily matter, about the consistence of suet, is obtained by bruising these nuts, and boiling the pulp. The oil is by this means liquefied, and rises to the surface, 
where it is left to cool and congeal, that it may the more easily be separated. This, which is called butter of cacao, is without smell, and, when fresh, has a very mild taste. Its principal use is as an ingredient in pomatums. From the nuts, when slightly roasted, an oil is sometimes obtained by pressure, which is occasionally used in medicine.

\section{ICOSANDRIA.}

207. The CITRON,LIME, and LEMON, we different ravicties of the fruit of a small evergreen shrub, the origimal or parent stock of which (Cirrus medica) was imported from Asia into the southern purts of Europe.

The citron is oblong, with a sery thick rind ; the lemon is oblong: with " small lump of protuberance at the end; and the lime his no protubcrance, has a very thin rind, and is about the size of a small egg. These ure the principal marlis of discrimination beturixt these fruits, but they are not quite constunt.

The lemon shub (Fig. 56) has lurge and slightly indented shiming leaces, of somcwhat oz:al shape, but pointed ; and on the foolstallis of the leares there is no remarliable uppendage. The flowers are lurge and white, lut purplish on the oulside of the petals.

It is generally supposed that the citron-tree was first introduced from Assyria and Media into Greece, and thence into the southern parts of Europe, where it is now cultivated to considerable extent. It is also grown in the islands of the West Indies. The fruit, partaking of the sane quality as the lemon, with the exception of being somewhat less acid, is seldom eaten raw; but, preserved in sugar as a sweetmeat, it is much used by confectioners and others. The principal consumption of citron is on the Continent, where it is also occasionally employed in medicine.

The lemon-tree is a native of Upper Asia, whence, like the citron, it was brought into Greece, and aliterwards transplanted into Italy. 'The juice, which is one of the sharpest and nost agreeable of all acids, is used in cookery, confectionery, medicine, and in various other ways. By calico-printers it is very extensively employed, as a discharger of colour, to produce, with 


\section{CITRON, LIME, AND LEMON.}

more clearness and effect, the white figured parts of coloured patterns that are dyed with colours formed from iron. Its juice is procured by simply squeezing the fruit, and straining. it through linen or any loose flter ; and in Sicily, and other parts of the Mediterranean, it forms an important article of commerce. Being one of the most valuable remedies for the scurvy, with which we are acquainted, it genelally constitutes part of the sea store of ships that are destined for long royages.

Several modes have been recommended for preserving lemon juice. One of these is to put it into bottles, with a small quantity of oil, which, floating on the surface, prevents the immediate contact of the air, and retards the decomposition of the acid; though, in this case, the original fresh taste soon gives place to one which is less grateful. In the East Indies lemon juice is sometimes evaporated, by a gentle heat, to the consistence of a thick extract. Sometimes it is crystallized into a white and acid salt; but what is sold in the shops, under the name of essential salt of lemons, for taking out ink-stains and ironmould spots from linen, is only a preparation from the juice of sorrel.

The external part of the rind has a grateful aromatic and bitter taste, which renders it useful in cookery. When dried it is considered a good stomachic, promotes the appetite, and is otherwise serviceable as a medicine. It is often candied and made into a sweetmeat, under the name of lemon chips. When distilled it yields a light and almost colourless oil, which, in smell, is nearly as agreeable as the fiesl peel, and is frequently employed as a perfume.

Lemons are sometimes preserved in syrup. Sniall ones with thick rinds are converted into a grateful pickle; and a marmalade and syrup are also made of them. For the purpose of keeping the fruit, it is recommended that a fine packthread about a quarter of a yard long, should be run through the protuberance at the end of the lemons: the ends of the string are

VOL. II. 
to be tied together; and suspended, on a hook; in an airy situation, and in such manner that each lemon nay hang perfectly free and detached.

The cultivation of the lime is much attended to in several parts of North America and the West Indies. Its juice affords a more grateful acid than that of the lemon, which is there in little repute, and is, comparative$\mathrm{ly}$, but seldom seen. A plate of limes is said to be a constant dish at entertainments in the West Indies; and the juice is used for all the same purposes as that of lemons is with us.

208. ORANGE (Citrus aurantium, Fig. 55). The difserence betwixt orange and lemon-trees is immediately known by the ormer having " lind of winged appendage on the leafstalls, of achich the lattcr are destitute.

We are informed that the first orange-tree introduced into Europe was sent as a present, fiom some part of Asia, to the Condé Mellor, prime minister of the King of Portugal. It was the only one of a great number which were contained in the same chest that survived; and it became the parent stock of multitudes of subsequent trees.

The delightful perfume of an orange grove is such as to scent the air for miles, and the flowers appear in succession during the whole summer; and flowers and ripe fruit are found on the same tree. Orange flowers are valued as a perfume, and yield their flavour to rectified spirits; and, in distillation, buth to spirits and water. In Portugal and Italy a fragrant red-coloured oil is obtained from them, which, by some persons, is considered of more delicate and agreeable fiagrance than even ottar of roses.

The juice of the orange, when ripe and of good kind, is extremely sweet, grateful, and wholesome. In fevers, and other complaints, it is of considerable use for allaying lieat and quenching thirst; and, in scurvy, it has been found a very valuable remedy. The rind, which yiclds a grateful aromatic bitter, is sometimes 
used in medicine, and, in particular, has obtained notice for the cure of intermittent fevers or agues. It is frequently preserved in syrup, and also in sugar, under the name of preserved orange-peel, and orange-chips; and is much esteemed in desserts.

In cookery, and by confectioners, oranges are used in numerous ways; for marmalade, in biscuits, cheese. cakes, jelly, puddings, and tarts; and an agreeable wine is prepared from oranges, with water, sugar, and some other ingredients.

Seitle or bitter oranges are a large, dark-coloured, and rough-skinned variety of the common spccies. These are much used in medicine and cookery.

Bergamot is a well known perfume, obtained from the rind of a variety of orange much cultivated near the town of Bergamo in Italy, whence it has obtained its name. The rind is cut into small pieces, and the oil is pressed out into glass vessels. Sometimes a fragrant water is distilled firom the peel.

209. The SHADDOCK (Citrus decumana) is "yellowish gicen fruit, of the orange kind, as large as the hoad of a child, wilh twelve or more cells, and contains a red or rhitish pulp. It is ver'y common in many pur'ts, both of the East and W'

In hot climates the shaddock is mucl esteemed on account of its agreeable flavour, which is a pleasant mixture of sweet and acid. It is safely eaten, even in considerable quantities, and is esteemed very salubrious. 'The rind is thick, and has a disagreeable bitterish taste. This firuit is indebted, for its nane, to a Captain Shaddock, who is said to liave first brought it from China, or, as some say, from Guinea, and transplanted it into one of the Wostudian islands.

210. C.A.JEPUT is " grienisi coloural oil produced from the fruit of a iree (Mclaleuca lencadendron) which grows in the
East Tndics.

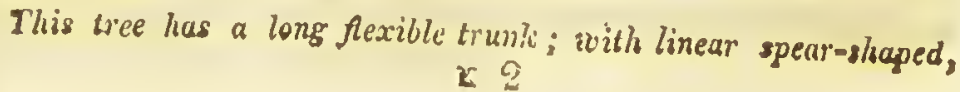


alternate leaves, which are smooth, ash-coloured, and each with fite nerves. The floccer's ure white, and in long, terminul spikes.

The leaves of the cajeput-tree have an aromatic odour, somewhat resembling that of cardamom seed (15); and they yield, by distillation, an essential oil, which manifests this aromatic principle still more strongly.

Among the Malays cajeput oil is a medicine in great repute; but its uses are so little known in this country that it is rarely kept even in the shops of the metropolis. In acute rheumatism and gout, however, it has been known to afford immediate relief by being rubbed on the part affected; but it ought not to be applied without great care, as it is very powerful in its effects. Cajeput oil is one of the most valuable remedies which have hitherto been discovered for the toothach. From whatever cause this affection of the face may" proceed, whether from a carious or hollow tootl, rheumatic acrimony, or cold, this oil has generally been found efficacious in removing it. It is best applied by being dropped on lint, and placed in the cavity of the tooth, or round the gum. Hence it deserves a place in the medicine chest of every private family.

If taken internally, in a dose of five or six drops, it heats and stimulates the whole system; and it is said to have had a beneficial effect in dropsies and intermittent fevers. In India it is used, both internally and externally, in palsies, deafness, gout, rheumatism, and several other complaints.

Its odour is remarkably destructive to insects. A few drops of it, in a cabinet or drawer in which animal or vegetable specimens of natural history are kept, in a dried state, have, on this account, been found useful.

Cajeput oil is chiefly prepared in the island of Bouro, one of the Moluccas; and it is imported into Europe from the East Indies. But, from its high price, it is so frequently adulterated, that it is seldom to be had genuine in Europe. 


\section{CLASS XIX.-SYNGENESIA.}

\section{ÆQUALIS.}

211. The ARTICHOKE (Cynara scolymus) is a well-linown plaxt which is grown chiefly for culinary purposes, and was origi. nally imparted into this country fiom the south of Europe.

This plant was cultivatcd with us as early as the year 1580 . The parts that are eaten are the receptacle of the flower, which is called the bottom, and a fleshy substance on each of the scales of the calyx. The choke consists of the unopened florets, and thc bristles that separate them from each other: these stand upon the receptacle, and must be cleared away before the bottom can be eaten. Its name has doubtless been obtained from a notion that any one unlucky enough to get it into his throat must certainly bc choked.

With us artichokes are generally plain boiled, and eaten with melted butter and pepper; and they are considered both wholcsome and nutritious. The bottoms arc sometimes stewed, boilcd in milk, or added to ragouts, French pies, and other highly seasoned dishes. For winter use they may bc slowly dried in an oven, and kept in paper bags in a dry place. On the Continent artichokes arc fiequently eaten raw, with salt and pepper.

By the country people of France the flowers of the artichoke are sometimes used to coagulate milk, for the purpose of making cheese. The leaves and stalls contain a bitter juice, which, mixcd with an equal portion of white winc, has bcen successfully employed in the curc of dropsy, when other remedics have failed. The juice, prepared with bismutl, imparts a permanent golden yellow colour to wool. 
212. The CARDOON (Cynara cardunculus) is a species of artichoke which grows wild in the south of France, and has smaller. fower's than the common articholic, and the scales of the culyx terminuted by long, shurp spines.

The stems rise to the height of four or five feet, and ure upright, thick, and cottony. The leaves are lerge and winged, and the Alou'ers of blue colour.

'The parts of the cardoon that are eaten are not those belonging immediately to the flower, as of the artichoke, but the roots, stalks, and middle ribs of the leaves; and chiefly the latter, which are thick and crisp. But, as all these are naturally very bitter, the plants, previously to being used, are blanched, by being tied up like lettuces, about the month of September, and having earth thrown upon their lower parts, to the depth of eighteen inches or two feet.

Cardoons come into season for the table about the end of November; and are either eaten alone, or as a sauce to animal food, particularly to roasted meat; or are introduced as a dish in the second course. They are, however, not so much used in England as on the Continerit; and this in consequence chiefly of the trouble attending their cultivation, and their preparation for the table, so as to reuder them palatable.

215. LETTUCE (Lactuca sativa) is un esculent regretuble, that is cultivated in nearly every kitchen garden in the hingtom.

The different kinds or varieties of lettuce are cxtremely numerous: but those best known are the cos lettuce, and cabbage lettuce, the former having upright leaves, and the latter hiving its leaves folded over each other like those of a cabbage. Their culture is very simple. The seeds are sown at various seasons of the year, that the plants may be ready, in succession, for the table. After a while, they are planted out from the seed-bed into another part of the garden, at a certain distance from each other, to allow of room for their expansion and growth. When the cos let- 
tuces have attained a sufficient size, their leaves are tied together witl strings of matting, to blanch them for use. From seeds that are sown towards the end of summer, lettuces may with care be obtained in perfection during-the ensuing winter and spring.

Lettuces have an odour. somewhat resembling that of opium; and they also possess somewhat similar narcotic properties, which reside in the milky juice. 'The properties of this vegetable as a salad, if eaten without oil, are considered to be emollient, cooling, and wholesome.

214. ENDIVE (Cichorium endivia) is a common vegetable in kitchen gardens, having curled or crisped leaves.

We are supposed to have been originally indebted to the East Indies for this useful winter salad. It is chiefly cultivated in the south of England; being sown generally about June or July, and afterwards planted out, like lettuce.

The chief excellence of endive consists in the whiteness of its inner leaves. It is, therefore, adviseable, either to cover the plants with flower-pots, or, when full grown, to tie them loosely together, for two or three weeks. By so doing, they will beconie perfectly blanched; and, in winter, they may be preserved, either by covering them with straw and nats, or by putting them in sand in a dry cellar.

The liench consume a great quantity of endive at their tables. They either eat it raw in salads, boiled in ragouts, fried with roast meat, or as a pickle. It is a wholesome vegetable, which seldom disagrees with the stomach.

\section{SUPERFLUA.}

215. CAMOMILE (Anthemis nobilis) is a woll-known plant, the dried daisy-like flowers of which are fiequently used in medicine.

The principal use to which camomile flowers are applied is to excite vomitting, and promote the ope- 
ration of emetics. They have likewise occasionally been substituted for Peruvian bark, in the case of intermittent fevers or agues, particularly on the Continent, but not with much success; and are used as a valuable stomachic. Both the leaves and flowers are employed in fomentations and poultices. They each, but particularly the flowers, have a powerful, though not an unpleasant smell, and a bitter taste.

They are administered in substance, as a powder or electuary, in infusion as tea, in decoction or extract, or in the form of an essential oil obtained by distillation.

So fragrant is the camomile plant, that the places where it grows wild, on open gravelly commons, may easily be discovered by the somewhat strawberry-like perfume which is emitted by treading on them. This quality alone has sometimes induced the cultivation of camomile for a green walk in gardens.

216. TARRAGON (Artemisia dracunculus) is a hurdy plant of the wormwood tribe, which grows wild in India and the southern parts of Europe, and is cultivated with us in gardens for culinary uses.

It has a somewhat shrubby stern; smooth, spear.shaped leaves tupering at each end; and flower's roundish, erect, and on footstalks.

This is a hot and bitter vegetable, which is sometimes eaten with lettuces, or other salad herbs; and sometimes used as an ingredient in soup. Its seeds are pungent; and nlay be advantageously substituted for the more costly spices obtained from the Indies. The Indians frequently eat the leaves of the tarragon plant with bread.

The sauce called tarragon vinegar is made by infusing for fourteen days, one pound of the leaves of tarragon, gathered a short time before the flowers appear, in one gallon of the best vinegar; straining this through a flannel bag, and fining it by means of a little isinglass. 
A distilled water is sometimes prepared from the leaves of tarragon.

\section{FRUSTRANEA.}

217. The JERUSALEMI ARTICHOKE is a somewhat potatoe-shaped root, produced by a species of sunflower (Helianthus tuberosus) which grows wild in severul parts of South America.

This plant bears single stalks, which are frequently eight or nine feet high, and yellow flowers, much smaller than those of the common sunflower.

So extremely productive are these valuable roots, that betwixt seventy and eighty tons' weight of them are said to have been obtainec, in one season, from a single acre of ground. They succeed in almost any soil; and, when once planted, will continue to flourish in the same place, without requiring either much manure, or much attention to the culture. The season in which they are dug up for use is from about the middle of September till November; when they are in greatest perfection. After that they may be preserved in sand, or under cover, for the winter.

The roots are generally eaten plain boiled; but they are sometimes served to table with white fricasseesauce, and in other ways. Their flavour is so nearly like that of the common artichoke, that it is difficult to distinguish them from each other. We are informed that Jerusalem artichokes are a valuable food for hogs and store pigs; and that if washed, cut, and ground in a mill, similar to an apple mill, they may also be given to horses.

218. The COMMON or ANNUAL SUNFLOWER (Helianthus annuus) is a Peruvian plant, with large yellow flowers, that is well lenown in our gardens.

The uses to which this plant may be applied are such as to render it well deserving of attention in rural economy. Its stalks contain a white, shining, fibrous substance, which might be advantageously employed in 
the manufacture of paper; and the woody part of the stalks makes excellent fuel. Its lipe seeds, when subjected to pressure, yicld a great proportion of sweet and palatable oil. These seeds may also be used for the feeding of poultry. The receptacles of the florvers, it is said, may be boiled and eaten like artichokes.

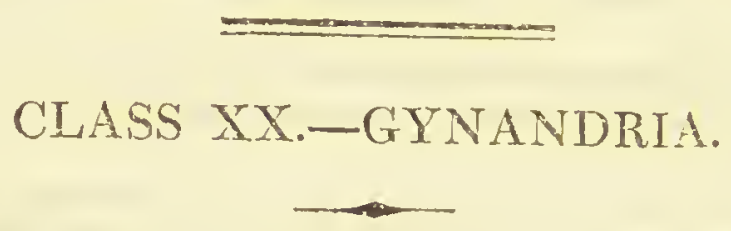

\section{DIANDRIA.}

219. SALEP is the powder of the dried roots of screral well-known field-plants of the orchis tribe (Orchis morio, $\mathrm{O}$. mascula, \&c.)

As an article of diet, salep is supposed to contain the largest portion of nutriment, in an equal compass, of any known vegetable production; even arrow root (17) is, in this respect, inferior to it. The orchises from which it is manufactured flourish in great abundance in meaduws and pastures of several parts of England, flowering about the months of May and June. As soon as the flower-stalks begin to decay, the roots should be dug up, and the newly formed bulbs, which have then attained their perfect state, should be separated. When several roots are collected, they should be washed in water, and have their external skin removed by a small brush, or by dipping them in hot water, and rubbing them with a coarse linen cloth. The next process is to place them on a tin plate, and put them into an oven for about ten minutes, by which time they will have lost the milky whiteness which they before possessed, and will have acquired a transparency like horn. They are then to be spread in a room, where, in a few days, they will become dry and hard. 
Although salep might be procured in great abundance in our own country, we import nearly the whole of what we use from the Levant, and generally in oval pieces of yellowish white colour, somewhat clear and pellucid, and of almost horny substance. When these, or the powder prepared from then, are put into boiling water, they dissolve into a thick mucilage.

With the 'Turks, salep has great celebrity, on account of the restorative qualities which it is supposed to posscss. It is much recommended as nutritive food for persons recovering from illness; and, in particular, as a part of the stores of every ship about to sail into distant climates. It not only possesses the property of yielding an invaluable nutriment, and, in a great measure, of concealing the saline taste of sea-water, but is likewise of essential service against the sca-scurvy. When it is stated that onc ounce of this powder and an ounce of portable soup, dissolved in two quarts of boiling water, will form a jelly capable of affording sustenance to one man for a day, the utility of salep will be further secn as a mcans of preventing fimminc at sea for an infinitely longer time than any other food of equal bulk.

\section{$\longrightarrow+2$ \\ CLASS XXI. MONOECIA.}

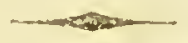

MONANDRIA.

920. The BREAD FRUTT is a large globular berry, of palc green colour, about the size of a cliild's hend, marked on the surface woith irregular siv-sided depressions, and containing
a white and somewhat fibrous putp, which, when ripe, becomes
juicy and yellow. juicy and yellow.

The tree that produces it (Artocarpus incisa, Fig. 57) grows voild in Otaheite and other islands of the South Seas, is about forly feet high, las large and sprending tranches, and large 
bright green leaves, each deeply divided into seven or nine spear-shaped lobes.

We are informed, in Captain Cook's first voyage round the world, that the edible part of this fruit lies between the skin and the core; and that it is white as snow, and somewhat of the consistence of new bread. It is generally used immediately when gathered; if it be kept more than twenty-four hours it becomes hard and chokey. The inhabitants of the South Sea Islands prepare it as food, by dividing the fruit into three or four parts, and roasting it in hot embers. Its taste is insipid, with a slight tartness, and somewliat resembles that of the crumb of wheaten bread mixed with Jerusalem artichoke (217). Of this fiuit the Otaheitans make various messes, by putting to it either water or the milk of the cocoa nut (233), then beating it to a paste with a stone pestle, and afterwards mixing it with ripe plantains (270), bananas ( 271 ), or a sour paste, made from the bread fruit itself, called malieé.

It continues in season eight months of the year ; and so great is its utility in the island of Otaheite, that (observes Captain Cook), if, in those parts where it is not spontaneously produced, a man plant but ten trees in his whole life-time, he will as completely fulfil his duty to his own and to future generations, as the natives of our less temperate climate can do by ploughing in the winter's cold, and reaping in the summer's heat, as often as these seasons return; even if, after he has procured bread for his present household, he should convert the surplus into money, and lay it up for his children.

Not only does this tree supply food, but clothing, and numerous other conveniences of life. The imner bark, which is white, and composed of a net-like series of fibres, is formed into a kind of cloth. The wood is soft, smooth, and of yellowish colour': and is used for the building of boats and houses. In whatever part the tree is wounded, a glutinous milky juice issues, which, when boiled with cocoa-nut oil (233), is employed for making bird-lime, and as a cement for filling up cracks 
in such vessels as are intended for holding water. Some parts of the flowers serve as tinder in the lighting of fire; and the leaves are used for wrapping up food, and for other purposes.

As the climate of the South Sea Islands is considered not much to differ from that of the West Indies, it was (about thirty years ago) thought desirable that some of the trees should be transferred, in a growing state, to our islands there. Consequently, his Majesty's ship the Bounty, in 1787, sailed for this purpose to the South Seas, under the command of Lieutenant, afterwards Admiral Bligh. But a fatal mutiny of the ship's crew prevented the accomplishment of this benevolent design. The commander of the vessel, however, returned in safety to lis country; and a second expedition under the same person, and for the same purpose, was fitted out in the year 1791. Captain Bligh arrived in safety at Otaheite, and, after an absence from England of about eighteen months, landed in Jamaica with 352 bread fruit-trees, in a living state, having left many others at different places in his passage thither. From Jamaica these trees were transferred to other islands; but the negroes, having a general and long established predilection for the plantain (270), the bread-fruit is not much relished by them. Where, however, it has not been generally introduced as an article of food, it is used as a delicacy; and whether employed as bread, or in the form of pudding, it is considered highly palatable by the European inhabitants.

221. The JACK FRUIT is a species of bread fruit that is grown in Malabur and other parts of the East Indies.

The tree which produces this fruit (Artocarpus integrifolia) differs from the common bread fruit-trce, in having the leaves entire, each about a span in length, oblong, blunt, serrated at the edges, bright green, and very smooth on the upper surface, paler beneath, and clad with stiff hairs.

Few of the fruits even of eastern climates are so large as this. Its weight is sometimes upwards of 
thirty pounds; and it generally contains betwixt two and three hundred nuts or seeds. These are each about three times as large as an almond, of somewhat oval shape, blunt at one end, sharp at the other, and a little flatted on the sides. Some varieties of the fruit, lowever, eontain no nuts.

The season in whieh the jaek fiuit is in perfeetion is about the month of Deeember. Though esteemed by many persons, it is so diffieult of digestion, that great eaution is requisite in eating it. The unripe fruit is sometimes pickled; it is sometimes cut into sliees, and boiled as a vegetable for the table; and sometinies fried in palm-oil. The nuts are eaten roasted, and the roood serves for building materials.

\section{TRIANDRIA.}

222. HAIZE, or INDIAN CORN (Zea mays, Fig. 58), is a species of groin much cultioated in America and other climates: the grains are of yellow colour, somewhat shaped like Rattened peas, and grow closely set round the upper part of high perpendicular stalks.

To the inhabitants of many countries of warm climates the cultivation of maize is a very important pursuit. These plants are propagated by sowing the secd in rows, in Mareh, April, or May: they generally produce two crops in the year, and yield, aeeording to the soil, from fifteen to forty bushels per acre. As soon as they are ripe, the ears are gathered. 'They are shortly afterwards threshed, and the grain, when separated, is spread out to dry in the sun; for, if it were heaped together in this state, it would ferment, and sprout or grow.

'The Ameriean Indians parch this kind of corn over a fire, in such manner as not to burn it. Afterwards they pound it, sift the meal and preserve it for their chief food. They make it into puciclings and cakes, or bread, the quality of which is extremely nutritive. Maize is useful for poultry and cattle of every lind; and, if conrerted into malt, a wholesome beverage may be brewed 
from it. Of the leafy husk which surrounds the ear of the maize a beattiful kind of writing paper is manufactured at a paper-mill near Rimini in Italy; and a greyish paper may be manufactured from the whole plant. The strlls are said to afford an excellent winter food for cattle. When the young ears are beginning to form, they have a sweet and agreeable taste. If, in this state, the leaves be stripped off, and the ears be subjected to pressure, a pleasant and palatable milky juice may be obtained from them.

It is supposed that maize might, with advantage, be cultivated in England.

223. The COMMON CUCUMBER (Cucumis satirus Fig. 59.) is an oblong, rough, and cooling fruit, which is cullivated in our kitchen gardons, and is supposed to have been originally imported into this country from some part of the Levant.

Cucumbers are always eaten before they are ripe, and usually with vinegar, oil, pepper, and salt. They are sometines stewed; and when young (under the nume of gerkins), are pickled with vinegar and spices, or preserved in syrup as a sweetmeat.

As the cucumber plants are too tender to sustain the coldness of our climate exposed to the open air, it is necessary to sow the sced in hot-beds, or under handglasses; though, in the beginning of summer, the glasses may, without danger, be removed. The fruit is much improved by putting a piece of slate or a tile under each, instead of allowing it to lie upon the naked ground.

234. The COMMON MELON, or MUSK MELON, is a species of cucumber, produred by a creeping herbaceons plant (Cucums melo), which has leaves with :ounded angles, and grows wild in 'Turtary.

In hot climates this fruit attains great perfection and a peculiarly fine flavour; and even in England, where it is cultivated in hot-beds, and sheltered by glass frames, it is ont of the coolest and most delicious summer fruits 
that we possess. Its size and form vary beyond deseription. Sometimes it is smooth, and only three or four inehes in length: sometimes its whole surfaee is rugged, or netted, and is many pounds in weight. Melons are, in eolour, grey, yellowish, or green, externally; whilst their flesh is white, yellow, reddish, or green.

They are usually eaten with sugar; sometimes with pepper or ginger, and salt; and sometimes alone. In Franee, they are often eaten as a sanee to boiled beef. The smaller kinds are pickled; and one particular sort of melons are filled with mustard seeds and shred garlic., and pickled under the name of mangos (73).

The propagation of melons is by seed, sown in $\mathrm{Fe}-$ bruary or Mareh; and the cultivation is somewhat similar to that of the cueumber, but is attended with considerably more trouble and expense.

225. The PUMPKIN, or POMPION, is a species of gourd which grows to un enormous size, contuins several cells, and numerous sseds zoith tumid margins, and is produced by a creeping plant, with lobed leaves (Cucurbita pepo).

The shape of the pumpkin is generally slobular, or flutted at top and bottom, and ribbed. The rind is glossy, and of yellow or green colour. The flesh is firm, but mellting, and the whole zeeight is sometimes mure than ihirly pounds.

The Germans cultivate this plant in extensive fields, for various eeononical purposes, but partieularly for the feeding of swine, and other animals. They cut it into pieees, and throw it into fish-ponds, as food for carp. Little trouble is required in its culture; and it will floorish on any tolerable soil, in a warm and sheltered situation. The pulp is served at table in various forms, but particularly in pies, and as an ingredient in puddings and paneakes. The Americans frequently gather pumplins when half grown, and eat them boiled as a sauce to meat. If the seeds be subjected to pressure, they will yield a proportion of oil so great as nearly to amount to their own weight; and, 
when ground with water, they afford a cooling and nutritious kind of milk.

226. The BOTTLE GOURD is an American fruit with woody rind, and of very various shape, belonging to the same tribe as the pumplin, and produced by a creeping plant $(\mathrm{Cu}-$ curbita lagenaria) roith somewhat angular and downy leaves, each having two glands at the base underneath.

This fruit is at first green, but when ripe, it assumes a dull yellow colour ; and the flesh is spongy and very white. Its size and shape are so varied, that it would be impossible to describe them ; sometimes it has a long slender part next the stalk, like the neck of a bottle; sometimes it is swollen, and sometimes of great length, and of form so curved as to be shaped almost like a bugle horn, or the musical instrument called a serpent.

So hard and strong is the rind of the bottle-gourd, that this, when freed from the pulp, is frequently converted by the Americans, as well as the inhabitants of the West Indies, into drinking cups, flagons, bottles, and other domestic utensils ; but, on being first used, it communicates a disagreeable taste to the juices contained in it. The pulp, boiled with vinegar, is sometimes eaten.

227. The WATER MELON (Cucurbita citrullus) is a roundish or oblong species of gourd, with thin smooth rind, marked with star-like spots, the leaves deeply divided into lobes, and the flowers somewhat resembling those of the cucumber.

Persons who have visited hot climates know well how to appreciate the grateful coolness and delicious flavour of the water melon, the flesh of which is so succulent that it melts in the mouth; and the central pulp of which is fluid, like that of the cocoa-nut, and may be sucked, or poured out through a hole in the rind, and thus made to afford a most refreshing beverage.

'To the inhabitants of Egypt, China, the East Indies, and other countries, where they are cultivated to a great extent, water melons are extremely valuable, 
both as food and physic. They are allowed to be eaten in fevers, and other inflammatory complaints. Theirflesh or pulp is, in general, of reddish colour ; one kind, however, called by the French pastèque, has a whitish green pulp. The latter are frequently pickled in vinegar, like gerkins; and are eaten in fricassees, or baked in sweet wine.

Both these varieties may be grown in our gardens, under hot-bed frames, in the same manner as cucumbers.

\section{TETRANDRIA.}

228. The BIRCH (Betula alba) is a forest-tree, easily known by the smooth appearance and silvery colour of its bark, by its leaves being soncwhat triangular, but acute, their smallness in comparison with those of other timber trees, and by the sinall branches being slender and flexible.

Although the birch is by no means considered a valuable timber tree, yet its rood is used for numerous purposes. Being of white colour, and firm and tough in texture, it is variously employed by hoop-benders and wheel-wrights. Turners use it for trenchers, bowls, ladles, and other wooden ware. Ox yokes, small screws, women's shoe-heels, pattens, and, in France, wooden shoes are made of it. The North American Indians use the wood of the birch-tree for canoes, boxes, buckets, baskets, kettles, and dishes, curiously joining it together with threads made of roots of the cedar-tree. Birch-trees are not unfrequently planted with hazels, for the purpose of the wood being converted into charcoal for forges. This cliarcoal is much esteemed; and the soot which is formed on burning the wood constitutes a good black substance for printers' ink.

Nearly all the other parts of the birch-tree are applicable to useful purposes. The inhabitants of Sweden employ the bark in the tanning of leather; and, after burning it to a certain degree, they also use it as a cenent for broken china and earthen ware. The navigators of 
the river Volga construct of it portable boats, cradles, \& $\mathrm{c}$. It is serviceable in dyeing a yellow colour. In Norway it is dried, ground, mixed with meal, and boiled with other food for swine. Houses or huts, in many parts of the north of Europe, are covered with the outward and thicker part of the bark, instead of slates or tiles. It is spun into a coarse kind of rope, woven into shoes and hats; and, in Kamschatka, even made into drinking cups. The Laplandors fasten together large pieces of it as outer garments to keep off the rain. Abounding with much resinous matter, slices of tlie bark are sometimes twisted together to make torches. During a scarcity of corn the bark of the birch-tree has, in several instances, been ground with bread corn, and successfully used as food by mankind.

In most parts of England the twigs of this tree are made into besoms. They are also made into the tops of fishing rods; and, when smeared with bird-lime (56), are used by bird-catchers. The Norwegians frequently employ them as fodder for their horses. The leaves afford à yellow dye.

A wholesome wine is made from the sap or juice of the bircll-tree. The juice is obtained by boring holes in the trunks of the trees, about the beginning of March, before the leaves appear. Into each of these lioles a piece of elder stick, hollowed through the middle, by clearing out the pith, is placed. This conducts the juice, as it flows from the wound, into a vessel put to receive it. If a tree be large, it may be tapped in four or five places at once; and, from several trees, many gallons of juice may be obtained in a day. 'The juice thus procured is to be boiled with sugar, in the proportion of four pounds to a gallon, and treated in tie same manner as other made wines. A good spirit might no doubt be obtained frorn the juice of the birch-tree by distillation.

229. The ALDER, or OWLER (Betula alnus, Fig. (33), is a tree which grozos in wet situations, and is distinguished by its flower-stallis being branched, and its leaves being roundish, 
waved, serrated, and downy at the branching of the veins be neath.

There are few means of better_employing swampy and morassy grounds than by planting them with alders; for although the growth of these trees is not rapid, the uses to which they are applicable are such as amply to repay the loss of time requisite before they come to perfection.

The rood of the alder, which is in great demand for machinery, is frequently wrought into cogs for millwheels, and is peculiarly adapted for all kinds of work which are to be constantly kept in water. It is consequently used for pumps, sluices, pipes, drains, and conduits of different description, and for the foundation of buildings situated in swamps. The water pipes which are laid under the streets of many of our large towns are made of alder; and, for its utility in the formation of sluices, it is much cultivated in Holland. It is commonly used for bobbins; and women's shoe-heels, ploughmen's clogs, and numerous articles of turnery ware, are formed of it. This wood serves also for many domestic and rural uses, for spinning-wheels, troughs, the handles of tools, ladders, cart-wheels; and, as coppice wood, it is planted to be cut down every ninth or ter:th year, for poles. The roots and knots furnish a beautifully veined wood, nearly of the colour of mahogany; and well adapted for cabinet work and furniture.

The bark may be advantageously used in the operations of tanning and leather-dressing; and by fishermen, for staining their nets. This, and the young twigs, are sometimes employed in dyeing, and yield different shades of yellow and red. The Laplanders chew the bark of the alder, and dye their leather garments red with the saliva thus produced. With the addition of copperas, it yields a black dye, which the dyer's of cotton use to considerable extent; and, for this purpose, it is purchaseable in some countries, at the rate of seven pence or eight pence per stone.

In the highlands of Scotland, we are informed that 
young branches of the alder, cut down in the summer, spread over the fields, and left during the winter to decay, are found to answer the purpose of manure. The fresh gathered leaves, being covered with a glutinous moisture, are said to be sometimes strewed upon floors to destroy fleas, which become entangled in it, as birds are with bird-lime. But these agile and troublesome insects must be numerous indeed to render the setting of traps for them of any avail towards their destruction.

230. The COMMON NETTLE. There are two kinds of nettle common in England, one of which (Urtica dioica) has heart-shaped leaves, and the other (Urtica urens) has oval leaves.

Although generally considered a noxious weed, the nettle is a plant of extensive utility. By the country people the young and tender leaves and tops are boiled for food, and are eaten as a substitute for greens and other pot-herbs. Asses eagerly devour the leaves of nettles; and if these be boiled, and mixed with other food for poultry, they are said to promote their laying of eggs. A kind of rennet is made, in the Highlands of Scotland, by adding a quart of salt to three pints of a liquor produced by the boiling of nettles. A table spoonful of this is said to be sufficient to coagulate a bowl of milk. From the fibrous stallis of the nettle, dressed in the manner of flax or hemp, cloth and paper may be made. The manufacture of these has been pursued witl success in some parts of the Continent; and in our own country a coarse kind of canvass has been produced from them. The roots, when boiled, communicate a yellow colour to woollen cloth, linen, and cotton.

It must be remarked that the stings of nettles, when examined by a microscope, are shown to be extremely curjous objects. They consist of a slender, tapering, sharp, and hollow substance, with a minute hole at the point, and a bag at the base. When the sting is pressed, it perforates the skin, and the same pressure forces up from the bag, into the wound, a corrosive liquor, which 
forms there a blister, and excites a burning and painful inflammation. If the nettlc be suddenly and strongly grasped, the stings are bent or broken, and, in this case, occasion no pain.

In consequence of their stinging quality, nettles have been employed, with alvantage, in l'estoring scnsation to paralytic limbs, by whipping them with these plants. They were formerly much used as a styptic; and are said to have been found useful in jaundice, scurvy, gout, and other complaints; but most of the accounts that have been given of their great medicinal virtues have now little credit. The flowers and seeds are said to have been tricd in Italy, and found an efficacious substitute for Peruvian bark (62) in agues and other complaints. A leaf of the nettle put upon the tongue, and then pressed against the roof of the mouth, is stated to be a remedy for blecding at the nose.

231. The MULBERRY-TREE (Morus nigra, Fig. 72) is a native of Italy, and is known by its heart-shaped and rough leaves, and its large juicy lerries, each consisting of scveral smaller ones.

The flowers of the mulberry appear in June, and the fruit becomes ripe in September, the berries continuing to ripen in succession for about two months. These, if eaten before they are ripe, are astringent; but, when ripe, are plcasantly acid, though of very peculiar flavour. An agrceable syrup, made from the juice of the lipe fruit, is kept in apothecaries' shops for medicinal uses. 'The juice itself is employed to impart a dark tinge to liquors and confections; and, when properly fermented, it becomes a pleasant winc. In cider countics it is not unusual to mix mulberries with the apples destined for cidcr, by which is made a delicious beverage called mulberry cider. Mulberries stain the fingers, as well as linen, cotton, or woollen, of a red colour, which is difficult to bc extracted; but which may be renoved by verjuice, or the acid of lemons.

In Italy, and other countries were silkworas are 
bred, the leaves of the mulber'y-tree, but particularly those of the WHITE MULBEn 1 , which is distinguished by its having obliquely heart-shaped and smootll leaves, are requisite for the feeding of these insects; and they are very extensively cultivated for this purpose. The rood is hard and of yellow colour; and is applied to numerous uses in carving and turnery. The bark is so fibrous that it may be manufactured into cordage, ropes, and coarse paper; and that of the root has an acrid and bitter taste, is powerful in its effects, and has been successfully used as a remedy against worms, particularly the tape-worm. Mulberry-trees flourish best in a light and rich soil, and in open situations.

232. The BOX-TREE (Buxus sempervirens) is a shrubly evergreen tree, twelve or fifteen feet high, which has small, oval, and opposite leaves, and grows wild in several parts of Britain.

It has been remarked that this tree was formerly so common in some parts of England, as to have given name to several places, particularly to Box-hill in Surry, and Boxley in Kent; and, in 1815, there were cut down at Box-hill, as many of these trees as were sold for upwards of $10,000 l$,, a circumstance perhaps unparalleled in their history. The box-tree was much admired by the ancient Romans, and also by our own ancestors, on account of its being easily clipped into the form of animals, and other fantastic shapes. In the South of Europe it is cultivated in gardens, and kept in flower-pots, with as much attention as we bcstow upon myrtles.

The rwood is of yellowish colour, close-grained, very hard and heavy, and admits of a beautiful polish. On these accounts it is much used by turner's, by engraver's on wood, carver's, and mathematical instrument makers. Flutes and other wind instruments are formed of it ; and furniture made of box-wood would be raluable were it not too heavy, as it would not only be very beautiful, but its bitter quality would secure it from 
the attacks of insects. In France it is much in demand for combs, knife-handles, and button-moulds; and it has been stated that the quantity of box-wood annually sent from Spain to Paris is alone estimated at the value of more than 10,000 livres.

An oil distilled from the shavings of box-wood has been found to relieve the tooth-ach, and to be useful in other complaints; and the powdered leaves destroy worms.

\section{HEXANDRIA.}

233. The COCOA-NUT is a woody fruit, produced in nearly all the countries of hot climates; of onal shape, from three or four, to six or cight inches in length, covered with a filrous husk, and lined internally with a white, firm, and fleshy kernel.

The tree (Cocos-nucifera) which produces the cocoa.nut is a kind of palm, from forty to sixty feet high. It has, on iis summit only, a hind of leaves, which appeur almost like immense feathers, each fourlecn or fifteen feet long, three feet broad, and winged. "Of these the npper ones are erect, the middle ones horizontal, and the louser ones drooping. The trunk is straight, nated, and markcd with the scars of the fullen leaves. The muts hang down from the summit of the tree, in clustcrs of a dozen or more together.

The external rind of the cocoa-nut has a smooth surface, and is of somewhat triangular shape. This encloses an extremely fibrous substance of considerable thickness, which immediately surrounds the nut. The latter has a thick and hard shell, with three holes at the base, each closed by a black membrane. The kernel lines the shell; and is sometimes nearly an inch in thickness, and encloses a considerable quantity of watery liquid, of whitish colour, which has the name of mill.

Food, clothing, and the means of shelter and protection, are all afforded by the cocoa-nut-tree. The kernels of the muts, which somewhat resemble the filbert in taste, but are of much firmer consistence, are 
used as food in various modes of dressing, and sometimes are cut into pieces and dried. When pressed in a mill, they yield an oil, which, in some countries, is the only oil used at table; and which, when fresh, is equal in quality to that of almonds. It, however, soon becomes rancid, and, in this state, is principally used by painters. The Indians prepare an oil from cocoanuts, by steeping the kernels in water till they putrefy, and then boiling the pulp. In this operation the oil rises to the surface, and is skimmed off. This oil is used for anointing the hair, in cookery, for burning in lamps, and for various other purposes. The milk, or fluid, contained in the nuts, is an exceedingly cool and agreeable beverage, which, when good, soinewliat resembles the kernel in flavour.

Cocoa-nut-trees flourish best in a sandy soil, and first produce fruit when six or seven years old; after which each tree yiclds from fifty to a hundred nuts annually.

The fibrous coats or husks which envelope the cocoanuts, after they have been soaked for some time in water, become soft. 'They are then beaten. to free them from the other substances with which they are intel'mixed, and which fall away like saw-dust, the stringy part only being left. This is spun into long yarns, woven into sail-cloth, and twisted into ropes and cables, even for large vessels. The cordage thus manufactured is valuable in several respects, but particularly for the advantages that are derived from its floating in water. The woody shells of the nut are so hard as to be capable of receiving a higl polish ; and they are formed into drinking cups, and other domestic utensils, which are sometimes expensively mounted in silver.

On the summit of the cocoa-nut-tree the tender leaves, at their first springing up, are folded over each other, so as somewhat to resemble a cabbage. These are occasiona!ly eaten in place of culinary greens, and are a very delicious food; but, as they can only be ob-

VOL. II, 
tained by the destruetion of the tree that produces them, and which dies in eonsequenee of their being removed, they are eonsidered too expensive a treat for frequent use. 'The larger leaves are empleyed for the thatehing of buildings, and are wrought into baskets, brooms, mats, sacks, hammoeks, and many other useful artieles.

The trunls are made into boats, and sometines eonstitute timber for the eonstruction of houses; and, when their eentral pith is cleared away, they form exeellent gutters for the eonveyanee of water. If, whilst growing, the body of the tree be bored, a white and sweetish liquor exudes from the wound, which has the name of toddy. "This is eolleeted in vessels of earthen-ware, and is a favourite beverage in many eountries where the trees grow. When fresh it is very sweet; in a few hours it beeomes somewhat aeid, and, in this state, is peeuliarlyagreeable; but in the spaee of twentyfour hours it is eomplete vinegar. By distillation this liquor yields an ardent spirit, whieh is sometimes called rack, or arrack; and is more esteemcil than that obtained by distillation from riee or kugar, and merely fermented and flavoured with the coeoa-nut juiee. If boiled with quick-lime, it thiekens into a syrup, whieh is used by eonfectioners in the East Indies, though it is much inferior to syrup produced from the sugarcane.

\section{POLYANDRIA.}

234. The COMMON ARUM, CUCKOO PINT, or LORDS AND LADIES (Arum maculatum), is a wellknown plant, which grows in shady hedge bostoms; and has, alout the month of May, a club-shaped spike, ficquently of purple colour at the top, issting fiom a green sheath with untich it is cnvcloped.

The aeridity of every part of this eommon plant, whilst in a reeent state, is sueh that, if tasted, there is left upon the tongue an intolerably clisagreeable burning and pricking sensation, whiel continues for a long 
time afterwards; and whieh no one, who has once tasted it, will be inclined to experience a second time. If bruised and applied to the skin, a blister will shortly afterwards be raised.

It was from this property that the roots, which are whitish, and each about the size of a nutmeg, were formerly used interrally in medicine, as a powerful stimulant, and externally for blisters. In some parts of France they are employed in bleaehing, fiom an opinion that, by their eorrosive quality, they render the linen white. Their acrimony is wholly dissipated by drying; and, in a dried state, they afford an almost tasteless farinaceous powder, whieh may even be made into bread. The powdered roots of the common arum are eonverted, by the Freneh, into an harmless eosmetie, whieh is sold at a high price under the name of Cypress porvder.

In eonsequence of a premium which was offered by the Society for Eneouragement of Arts, Manufactures, and Commeree, for diseovering a method of preparing stareh from materials not used as food for man, an experiment was made, by Mrs. Jane Gibbs, of Portland, in Dorsetshire, upon the roots of the eommon arury. A peck of the roots was found to produee about four. pounds' weight of stareh; and she prepared, in the whole, about two hundred weight. The proeess was to elean the ronts, and pound them in a mortar witl water: the pulp thus formed was strained, and after being allowed to settle, the water was poured off, and the starch remained at the bottom:

Whilst speaking of the arum, it may be stated that the flowers of some of the foreign species (Arum crinitum and $A$. dracunculus) have so strong a smell, like carrion, that even flesh-flies are attraeted to deposit their eggs in them; and that the strueture of the flowers is such that, when the inseets attempt to retreat, they are prevented by the reversed hairs which are there found, and are destroyed. Some of the species are considered wholesome food; one (Arum 
esculentum) is much cultivated for this purpose in the West Indies and South America. The leaves of this plant, when boiled, are much esteemed as potherbs, and the roots are eaten either baked or boiled.

235. The SWEET CHESNUT (Fagus castanea, Fig.65) is a stately tree, which grows wild in some of the southern and western parts of England, and is distinguished by having spear-shaped and pointed leaves, with tapering serratures at the elge.

The flowers appear in long hanging spikes or clusters, about the month of May; and the fruit, which is ripe in September, is enveloped in a husk defended by a great number of
complicated prickles.

Notwithstanding the known durability of the oak, there does not appear any well auchenticated instance of the age of an oak being equal to that of the celebrated chesnut-tree, at Tortworth in Gloucestershire, which was known as a boundary mark in the reign of King John. This tree is supposed to have then been more than 500 years old, making its age at this time to exceed 1100 years. The diameter of its trunk is fifteen feet, and it still continues to bear fruit.

Few of our forest trees are more beautiful than the chesnut. It is true that the generality of painter's prefer the oak for its picturesque form; but, in the landscapes of Salvator Rosa, and other celebrated masters, chesnut-trees are ver'y conspicuous.

The timber of this tree was formerly much in use. The beams and rafters of many of our most ancient churches are formed of it; and its appearance so nearly resembles that of the oak, that it requires the eye of a good judge to distinguish them from each other. For the heads and staves of casks, the wood of the chesnut is considered peculiarly excellent; and pipes, made of it for the conveyance of water under ground, are said to be more durable than those either of elm or oak. For furniture it may be stained so as somewhat to resemble mahogany. Hop-poles, and poles for espalier. 
and dead fences, made of young chesnut-trees are preferred to most others.

Much of the fruit of the chesnut is consumed as food by the poorer classes of people of the Continent, but particularly by those of Spain and Italy; and, when dried and powdered, it is no mean substitute for flour, in bread and puddings. Chesnuts are imported into this country in considerable quantities, both from France and Spain, and are roasted and eaten in desserts; those which are grown here being much smaller than what we receive from abroad. On the Continent they are sometimes used for making starch, and in the bleaching of linen.

236. The BEECH (Fagus sylvatica, Fig. 64) is a forest tree known by its waved and somewhat oval leaves, and its triangular fruit, consisting of three cells, and enclosed, by pairs, in a husk which is covered with simple prickles.

There are beech woods in many parts of England, but the trees flourish best in rich, calcareous soils. These roods, it lias been observed, are peculiarly dry and pleasant to walk in; and, under their shade, afford to the botanist many interesting plants, such as the bird's nest (monotropa), winter green (pyrola), and some rare orchidece. Beech-trees bear lopping well, and may be trained so as to form lofty hedges, which are the more valuable for shelter, as the leaves, though faded, remain through the winter, and the twisted branches may be formed into a very strong fence.

The wood is hard and brittle, and, if exposed to the air, is liable soon to decay. It is, however, peculiarly useful to cabinet-makers and turners. Carpenters' planes, tool-handles, and mallets, are made of it. W'hen split into thin layers, it is used to make scabbards for swords. Chairs, bedsteads, and other furniture, are occasionally formed of beech.

The fruit of this tree, which has the name of beectmast, and is ripe in September, is palatable to the taste; but, if eaten in great quantity, it occasions 
giddiness and head-aches. When, however, it is dricd and powdered, it may be made into a wholcsomc brcad. 'The inhabitants of 'Scio, one of the Ionian Islands, were once enabled to endurc a memorable siege by the beech-mast which their island supplied. 'This fruit has, occasionally, been roasted and used as a substitute for coffee. When subjected to pressure, it yields a swect and palatable oil, which, if properly made, is equal, in quality, to the best olive-oil, and has thc advantage of continuing longer than that without becoming rancid. Beech-oil is manufactured in several parts of France; and is used by the lower classes of Silesia instead of butter. The cakes which remain after the oil is cxtracted arc a wholesomc food, and may also be advantageously employed for the fattening of swine, poultry, and oxell.

In some countries the leaves of the beecli-trec are collected in the autumn, before they have becn injured by the frosts, and arc used instead of feathers for beds; and mattrasses formed of them are said to be prefcrable to those either of straw or chaff.

237. The OAK. (Quercus robur, Fig. 68) is a well-known timler tree, of native growth in this country, as well as other countries in northern temperate climates.

It is to this valuable tree that our navy is indebted for its existence; and without it this invincible barrier of the country could not be supported. Oak timber being hard, tough, tolerably flexible, and not very liable to splintcr, is, in Europe, preferrcd to cvery other kind for the construction of ships of war. It is also well adapted to every purpose of rural and domestic economy, particularly for staves, laths, and the spokes of whcels. Until the introduction of mahogany, it was very generally used for furniture; and, in large mansions, it was customary even to line the walls of rooms with rvainscot, or panelling of oak.

This tree is remarkable for the slowness of its growth, for its great longevity, and the dimensions to which it 
attains. It has, however. been remarked that the trunk of the oak seldom increases to a greater proportionate diameter than about fourteen inches in eighty years. As to its dimensions, it is stated that an oak belonging to Lord Powis, and growing, in 1764, in Bromfield Wood, near Iudlow, measured sixty-eight feet in girth and twenty-three feet in height, and contained in the whole 1455 feet of timber.

Before oak timber is in a state to be used it is requisite that the trees should be barked, and suffered to stand uncut for three or four years, that they may become perfectly dry. The bark thus obtained is extensively used in the tanning of leather; and afterwards it serves as fuel, and for making hot-beds for the growth of pines, and some other plants. The astringent properties of oak-bark render it of use for medical purposes. The saw-dust of this tree, and even the leaves, though much inferior to the bark, have been found useful in tanning. The former of these is the prineipal vegetable production of this eountry, whieh is used in the dyeing of fustian.

On the leaves and buds of the oak eertain exerescences are formed, in eonsequence of the puneture of insects, as the lodgment for their eggs and a habitation for their future young. These are termed galls, and if, when arrived at a certain state, they are infused in a weak solution of vitriol, they impart to it a purple or violet tinge; and, after the whole colouring matter is extraeted, this becomes perfectly black. Considerable quantities of galls are used in dyeing, and for other purposes.

Acorns, or the seeds of the oak, possess an astringent quality, and have a bitter taste, both of which may be extracted by steeping them, for some time, in cold water, or by boiling them. After this simple process, they are not an inpalatable fruit. With the aneient Britons they were an article in great request, and even constituted an important part of their food; and there can be little doubt that, carefully prepared, dried, and 
reduced to powder, they might, in times of scarcity, be adopted as a substitute for bread-corn. By pressure an oil is obtained from them which may be used for lamps; and a kind of coffee is prepared from them in some parts of tbe Continent.

The branches of the oak, as well as those of several other kinds of trees, are burned for the formation of charcoal; and it is a remarkable circumstance that the properties of charcoal, from whatever wood it may be made, are nearly the same. One of the most remarkable of these is, that it is not liable to decay by age. Hence it was customary, with the ancients, to char or burn the outside of stakes, or other wood, which were to be driven into the grourid, or placed in water. Char'coal'may be preserved without injury, for an almost indefinite length of time; and, in the ancient tombs of the inhabitants of northern nations, entire pieces of charcoal are at this day frequently discovered.

Besides the great use of charcoal in the composition of gunpowder, and to artists and manufacturers of different kinds, it has lately been employed, with consider-, able success, in correcting the rancid and disagreeable smell of train oil, so as to render it fit to be burned in chamber lamps; and several manufactories of this oil have been established in the neighbourhood of London. Newly-made charcoal, if rolled up in clothes which have contracted a disagreeable odour, will effectually destroy it : and if boiled with meat beginning to putrefy will take away the taint.

This substance is used by artists in the polishing of brass and copper-plates, for the drawing of outlines, and numerous other purposes. When purified, it forms perhaps the best tooth-powder that is known. The mode of purifying it is to reduce it to powder, wash it repeatedly with water, and then dry it by means of a strong heat in close vessels. This heat expels the foreign contents with which it is impregnated; but however intense, if the vessels are closed, it in no respects alters the quality of the cliarcoal. 
The vapour of burning charcoal is extremely pernicious; and persons exposed to it in confined rooms are liable to be suffocated in a very short time. The best remedy is immediately to take them into the strongest draught of cold air that can be obtained, to loose all their garments, and apply volatile spirits to their nostrils.

238. CORK is the exlernal bark of a species of oak (Quercus suber) which grows in S'pain, Portugal, and other southern parts of Europe, and is distinguished by the fungous terture of its bark; and by its leaves being evergreen, oblong, somewhat oval, downy underneath, and waved.

The principal supply of the cork that is consumed in Europc, is obtained from Catalonia in Spain; and the culture and the preparation of it yield to the inhabitants of that province near $250,000 \%$. per annum.

In the collecting of cork, it is customary to slit it with a knife, at certain distances, in a perpendicular direction from the top of the trees to the bottom; and to make two incisions across, one near the top and the other near the bottom of the trunk. For the purpose of stripping off the bark, a curved knife with a handle at each end is used. Sometimes it is stripped in pieces the whole length, and sometimes in shorter pieces, cross cuts being made at certain intervals. In some instances the perpendicular and transverse incisions are made, and the cork is left upon the trees until, by the growth of the new bark beneath, it becomes sufficiently loose to be removed by the hand.

After the pieces are detached they are soaked in water; and, when nearly dry, are placed over a fire of coals, which blackens their external surface. By the latter operation they are rendered smooth, and all the smaller blemishes are thereby concealed: the larger holes and cracks are filled up by the artful introduction of soot and dirt. The pieces are next loaded with weights to make them even; and lastly they are dried, stacked, or packed in bales for exportation.

I. 5 
Many of the uses of cork were well known to the ancients. Its elasticity renders it pcculiarly serviceablc for the stopping of vcssels of different kinds; and thus proventing either the liquids therein contained from running out, or the external air from passing in. The use of cork for stopplng glass bottles is generally considered to have been introduced about the fifteenth century. The practice of employing this substance for jackets to assist in swimming is very ancient; and it has lately been applied in various ways towards tlie preservation of life, when endangered by shipwreck. The floats of nets uscd for fishing are frequently made of cork : pieces fastened together makc buoys, which, by floating on the surface of the water, afford direction for vessels in harbours, rivers, and othcl places. In some parts of Spain it is customary to line the walls of houscs with eork, which not only renders them warm, but prevents the admission of moisture. The ancient Egyptians sometimes made coffins of it. On account of its lightness, cork is used for false legs; and, from its being impervious by water, it is sometimes placed betwixt the soles of shoes to kecp out moisture. When burned, it constitutes that light black substance known by the name of Spanish black.

In the cutting of corks for use, the only tool employed is a broad, thin, and sharp knife; and, as the cork tends very much to blunt this, it is sharpened upon a board by one whet, or stroke on each side, after cvery cut; and, now and then, upon a common whet-stone. The corks for bottles are cut in the length way of the bark, and consequently the pores lie across. Bungs, and corks of large sizc, are cut in a contrary dircction: the pores in these are therefore downward, a circumstance which renders them much more defectivc in stopping out the air than the others. The parings of cork are sold to the makers of Spanish black, 
239. The WWALNUT is a well-known shell fruit, produced by a trce (Juglans regia, Fig. 69), which grows wild in the northern parls of China and Pcrsia, and has winged leaves; the leaflets, about nine in number, large, oblong, smooth, thick; and the end one with a stalk.

Although greatly admired, both for the beauty of its foliage, and for the exeellence of its fruit, the cultivation of the walnut-tree in England is by no means attended to so nuleh as it was formerly, when its rood was considered the most ornamental timber produeed in our island. It is pleasingly veined, and admits of a fine polish, but its colour is much less rich than that of malogany; and consequently, except for the making of gunstocks, it has, of late, been wholly superseded by that more favourite wood. On the Continent, how. ever, the walnut-tree is still in request for furniture of various kinds.

The fruit of the walnut-tree is covered cxternally with a thiek and smooth green husk, the juice of which stains the fingers black. In an unripe state, before the shells are formed, the whole fiuit may be made into a pickle, and also into ketehup. In medicine the unripe firuit is eonsidered of use for the destruetion of worms, and is usually administered in the form of an extract.

Walnuts become ripe about the beginning of Oetober; and, as they grow in clusters, generally at the ends of the branches, it is customary to beat them down with long poles. The kernel, which is covered with a tough, yellow, and bitter skin, is more estecmed than that either of the hazel-nut or filbert. It yields, on pressure, a sweet kind of oil, which, in quantity, amounts to about half the weight of the kernel.

There are several varieties of walnut, which are well known to the cultivators of that tree.

240. The IIICKORY-NUT (Juglans alba) is a North American species of walnut, the shell of which is very hard, does not split asunder like that of the walnut, and is of smoother and lighter colour than that, 
Its kernel is sweet and well tasted, and affords a considerable portion of oil.

24.1. The HAZEL-NUT and FILBERT are well-lincu'n fruits, the former of a shrub (Corylus avellana, Fig. 67) which grows in hedges and thickets; and the latter of a somewhat similar shrub, which is cultivuted in orchurds and litchen gardens.

Each of these kinds of muts is much esteemed, but particularly the latter ; the flavour of its kernels being very delicious. They are, however, difficult of digestion, and, when eaten in considerable quantity, sometimes produce very unpleasant effects. The oil which is obtained from hazel-nuts by pressure is little inferior in flavour to that of almonds; and, under the name of mut-oil, is often used by painters. Chemists employ it as the basis of fragrant oils artificially prepared, because it easily combines with and retains odours. This oil is found serviceable in obstinate coughs.

If nuts be put into earthen pots and well closed, and afterwards buried eighteen inches or two feet deep in the earth, they may be kept sound through the winter.

In many parts of the country hazels are planted in coppices and hedgerows for several useful purposes; but particularly to be cut down, periodically, for charcoal, for poles, fishing-rods, \&c. Being extremely tough and flexible, the branches of the liazel are used for making hurdles, crates, withs or bands, and springles to fasten down thatch. They arc formed into spars, handles for implements of husbandry; and, when split, are bent into hoops for casks. Charcoal made from hazel is much in request for forges; and, when prepared in a particular manner, is used by painters and engraver's to draw thcil outlines.

In countries wherc yeast is scarce, it is not unusual to twist loosely together the slender branches of this shrub; and to steep them in ale-yeast during its fermentation. They are then hung up to dry; ind, at the next brewing, are put into the wort instead of yeast. The 
roots are used by cabinet makers for veneering : and, in Italy, the chips of hazel are sometimes put into turbid wine for the purpose of fining it.

24\%. The HORNBEAM (Carpinus betulus, Fig. 73) is a forest tree which grows to the height of sixty or seventy feet, yet seidlom exceeds fijteen or eighteen inches in diameter, has smooth white bark, marlied with grey spots, and leaves about three inches long and two broad, oval, pointed, and serrabed.

As a timber-tree the hornbeam is more esteemed on the Continent than in this country. It grows readily in stiff soils, particularly on the sides of hills; and is easily transplanted. The rood, which is white, hard, and tough, is used by tumers; and is wrought into $\operatorname{cogs}$ for mill-wheels, screw-presses, the heads of beetles, handles of working tools, and other instruments and machinery in which great strength is required. - As fuel it is preferred, on account of its readier inflammability, than most other kinds of wood. The inner barle is used, in some countries, for dyeing yellow.

From the foliage of the hornbeam being luxuriant, and admitting of being clipped, without injury, into any of those forms which the old French garden style required, this tree was formerly much mole planted in England than it is at present. It preserves a great portion of its withered leaves through the winter: and, if properly planted as a hedge, it torms an cxcellent fence. "The German husbandman,. when he erects a fence of hornbeam, throws up a parapet of earth, with a ditch on rach side, and plarits his sets (which he raises from layers) in such a manner that every two plants may be brought to intersect eacli other, in the form of a St. Andrew's cross. In that part where the plants cross, he scrapes off the bark, and bends them closely together witl straw. In consequence of this operation the two plants consolidate into a sort of indissoluble linot, and push, from the place of junction, horizontal slanting shoots, which form a living palisado or chevaux de frise; so that such a protection 
may be called a rural fortification. 'These hedges, being annually and carefully pruned, will, in a few years, become impenetrable in every part. It is not uncommon in Germany, to see the high roads thus guarded for many miles together; and great advantage might be derived from adopting the sanie plan in many parts of our own kingdom.

243. The PLANE-TREE (Platanus orientalis, Fig. 71) is distinguished by having broad leares, euch with about fice principul divisions, and these subdicidcd into smaller ones.

By the ancient Greeks and Romans the plane-tree was higlily valued, on account of its grateful shade; and the latter were much delighted by training it in such manner as to adnit of their sitting beneath its branches. Wherever they built their magnificent colleges for the exercise of youth, in the gymnastic arts, as riding, wrestling, running, leaping, throwing the discus, \&c. and where also the gravest plilosophers met to converse together and iniprove their studies, they planted avenues and wallis of plane trees for refreshment and shade.

Though now frequently planted in parks and pleasure grounds, the'sycamore (122) is, in many instances, preferred to it. 'The plane, though a native of Asia and the southem parts of Europe, is very hardy, grows rapidly, and will flourish in any common soil, and in any aspect.

- Its rood, at a certain age, becomes much veined; and, consequently, is valuable for many kinds of dos mestic furniture, but particularly for tables.

244. The CABBAGE TREE (Areca olcracca) is an Amevican species of palm, which grows to the height of a lundied feet and upuarls, and is destitute of leaves until within a few foet of the summit. The leares, sometimi's neur tuenty feet long, ace uinged, und the leaflets are entive.

Such is the general elegance of this tree that it is fiequently denominated the queen of woods. Its fivit, which grows in bunches from the top, is an oblong and 
obtuse kind of berry, of bluish purple colour, and about the size of an olive. The sheaths of the flowers, and the floral leaves, when first developed, are folded round each other, enclosed in a thin, green, and spongy bark, eight or nine inches in circumference, and constitute the part which is denominated the cabbage. This is white, and, when boiled, is esteemed a great luxury. It is also eaten raw as a salad, and fried with butter; and its taste is said to resemble that of an artichoke. This part is likewise frequently made into a pickle with vinegar and spices.

We are informed that the cabbage-trec was first introduced into Jamaica by Admiral Knowles, when governor of that island; and that it has since been cultivated there with great attention. But it is chiefly planted for its beauty, being considered too valuable to be often cut down for the small portion of food which it thus affords, however delicious that may be.

In the leaves of this tree there is a thread-like substance, which is sometimes spun, like hemp, and made into different kinds of cordage. The sockets or grooves formed by the broad part of the footstalks of the leaves are used by the negroes as cradles for their children; and, on the inner sides of the very young footstalks there are tender pellicles, which, when dried, may be converted into paper. 'The trunks, when cleared of the pith, serve as water pipes and gutters. Of the pith a kind of sago is made; and in this pith, after the trees are felled, there is bred a large species of caterpillar which the inlabitants of some of the West Indian islands eat as a great delicacy.

245. The CATECHU, ARECA, or BETEL-NUT-TREE, (Areca catechu), is a species of palm which grows in the East Indies.

It is generally from thirty to forty feet high, and ils trunle is six or eight inclu's in diameter. The leares, which grow on the summit, are winged, having the lenflets folded baek; amd the fruit is a pulp!l berry with thin skin, contuining a nut about an inch in length, and of a rounded conical form. 
The kernel of the areca-nut, which is covered by a thin, smooth, and yellowish shell, is somewhat like a nutmeg, but contains, in the centre, a white, soft, greyish, and almost liquid substance, which becomes hard as the nut ripens. This fruit is in general use by the Indians, who cut it into slices, mix it with other substances, wrap it in the leaves of betel (22), and chew it much in the same manner as the common people of our country chew tobacco. The consumption of these nuts in India is almost beyond calculation. They are an article of considerable trade, from port to port; and also from India to China, but they are seldom brought into England, though they might be of use in some of our manufactures.

The drug called catechu, and formerly terra japonica, was supposed to be an extract prepared from the above nuts; but it is now ascertained to be made from the wood of a species of mimosa.

\section{MONADELPHIA.}

246. The SCOTS FIR (Pinus sylvestris), which has its name from grouing wild in different parts of Scolland, is lnnwn from other trees of the same lribe by having its slender and somerchat needle-shaped leaves in pairs; its comes or secd-resscls somewhat egg-shaped, mostly in pairs, us long as the leaves, and the scules blunt.

This useful tree flourishes with greatest luxuriance on the north and north-east sides of hills, in a poor and sandy soil, especially where this is mixed with lnam. If planted among rocks, or in bogs, it seldom attains a large size; in black soil it becomes diseased; and in chalky land it frequently pines away and dies.

Its timber, under the name of deal, is employed as the wood-work of houses; for rafters, flooring, doors, the frames of windows, tables, boxes, and other purposes, infinitely too various to be enumerated. Frigates, and other ships of large size, have sometimes been constructed of deal; but these are by no means so durable as vessels that are built of oak. Much of the deal which 
we use is imported from Norway, and other northern parts of Europe. That from Christiana, which is called yellorv deal, or red deal, is frequently brought over in planks, but more commonly in boards, each about ten inches and half in width. The wood of such trees as are raised in England is equal to the foreign wood in weight and durability, but its grain is generally coarser.

The outer bark of the fir-tree may be uscd in the tanning of leather; and it is said that, in the northern parts of Europe, the soft, white, and fibrous inner bark is, in times of scarcity, made into a kind of bread. For this purpose it is dried over a fire, reduccl to powder, kneaded with water, and a small portion of corn-flour, into cakes, and baked in an oven. Children in Norway are very fond of the fresh bark, in the spring of the year, either shaved off with a knife, or grated with a rasp.

Common Turpentine is the resinous juice chiefly of the Scots fir, obtained by boring holes into the trunks of the trees, early in spring, and placing vessels beneath for its reception. It is of brown colour; and has a strong odour, and disagreeablc taste. In the distillation of turpentine an essential oil is produccd, called oil of turpentine, which is extremely pungent. When the distillation is continued to dryness, the substance which remains is known by the name of common resin or rosin; but, if water bc mixed with it, while yet fluid, and incorporated by violent agitation, a substance is formed called yelloru resin.

Common turpentine is mostly employed as an ingredient in the plasters used by farriers. The oil is occasionally used in medicine; and, lately, it has been considered efficacious in cascs of worms. It is much employed by painters for rendering their colours more fluid; as well as in the composition of different kinds of varnish used in floor-cloth, umbrella, and other manufactures. The noxious spirit called gin was formcrly flavoured with juniper berries; but as these are now 
too expensive, oil of turpentine, the tastc of which in a slight degree resembles that of juniper, is applied to the same purpose; and considerable quantities of turpentine are thus consumed. The common resin is used in plaster's, for which its great adhesiveness renders it peculiarly applicable. It is also of considerablc importance in the arts; and musicians rub the bows and strings of violins with it, to take off the greasy particles which are thcre collected, as well as to counteract the effects of moisture. Yellow resin is used in plasters, and for other purposes in medicinc.

$T a r$ is obtained from the roots and refuse parts of the fir-tree, by cutting them into billets, piling these, in a proper manner, in pits or ovens formed for the purpose, covering them partly ovcr, and setting them on fire. During the burning, a black and thick matter, which is the tar, falls to the bottom, and is conducted thence into vessels which are placed to receive it, and from which it is afterwards poured into barrels for sale.

Tar is an article of great utility in manufactures, and for various economical purposes. It is much employed for smearing the rigging, and other external parts of ships, to prevent their receiving injury from moisture. It has been used in medicine both internally and externally; and particularly tar-water, or water impregnated with tar, was, some years ago, a popular remedy in various disorders, but its virtues have been too much extolled. Although considerable quantities of tar are prcpared in this country, these are insufficicnt to supply the demand; consequently we, cvery year, import great quantities of it from IRussia, Sweden, America, and other countries.

Pitch is usually made by melting together coarse hard resin and an equal quantity of tal ; or, as some writers state, by boiling tar with a certain portion of water, until it becomes so thick that, on cooling, it forms a hard black mass.

By the ancients pitch was much employed for giving flavour and fragrance to their wines. With us it is of 
extensive use to mechanics, and in numerous manufactures; but the principal clemand for it is in ship-building, to secure the joints and crevices of the planks and timbers, and for other purposes. When mixed with a certain quantity of oil and suet, it is made into shoemakers' ruax; and, in conjunction with whale fat, forms carriage-grease, or the substance with which the wheels of carriages are smeared. The best pitch is imported from Sweden and Norway; and is of a glossyblack colour, perfectly dry, and very brittle.

Lamp-black is a soot formed by burning the dregs and coarser parts of tar in furnaces constructed for that purpose. The smoke is conveyed through tubes into boxes, each covered with linen, in the form of a cone. Upon this linen the soot is deposited: and it is, from time to time, beaten off into the boxes, and afterwards packed in barrels for sale. This substance is employed in printing and dyeing; and has its name from the practice that was formerly arlopted of making it by means of lamps.

247. The WEYMOUTH PINE is chiefly distinguished by its leaves growing in fives, and its cones being smooth, cylindrical, and longer than the leaves.

This species of fir-tree grows wild in North America, and sueceeds well in strong land in England. Its timber is white, of more open grain than Scots fir, and not so heavy as that. In America, it is principally used for the masts of ships, for which, by its toughness, it is peculiarly calculated.

248. The SPRUCE FIR (Pinus abies), a native of Norway, and other Northern parts of Europe, is known by its short and four-sided leaves growing singly, and surrounding the branches; its cones being cylindrical, the scrles somezhat square, flattened, and notched at the top.

'The roood of the spruce fir is what the English carpenters usually denominate white deal. It is considered next in value to that obtained from the Scots fir; and 
is remarkable for having few knots. On account of its lightness it is peculiarly adapted for packing-cases and musical instrumerits.

From incisions made into the trunk of the spruce firtree, a fine and clear turpentine oozes, which, after being boiled in water, and strained through a linen cloth, acquires a somerwhat solid consistence, and reddish brown colour; and is called Burgundy pitch. This is employed as an ingredient in several kinds of ointments and plasters: and is principally manufactured in Saxony.

The article called essence of spruce, which is used in making spruce beer, is prepared from the branches of this tree, and from those of a species nearly allied to it which grows in America.

249. The LARCH (Pinus laryx), a native of the Alps, and the mountains of Germany, is a species of fir, which has its leaves in tufts, and its cones oblong, and of somewhat oval shape, themargins af the scales bent back, and jagged.

The cultivation of larch-trees has of late been much recommended for adoption in this country, on account of the value of their timber, which for strength and durability, is equal to most kinds of deal. It is well calculated for masts, and the framework of vessels, being capable of sustaining much greater pressure even than oak. For wood-work constantly immersed in water, it is peculiarly calculated, as, in such situations, it is asserted to become almost as hard as stone. In Petersburgh larch timber is applied to no other use than that of ship-building. Line of battle ships are constructed of it in Archangel, and these generally last about fifteen years; though, in milder climates, it is imagined that they would last much longcr.

For gates, pales, and similar work, exposed to the vicissitudes of weather, they are admirably serviceable; and for flooring and other internal purposes are at least equally durable. Buildings constructed of larch timber are said to have continued sound for 200 years; and, in 
some of the old palaces in Venice, there are beams of larch yet existing that are as sound as when they were first placed. But the very combustible nature of this wood renders it objectionable for such uses. No rood with which we are acquainted affords more durable staves for casks than larch; and, in the opinion of many persons, it is further valuable by inproving the flavour of the wine contained in them. The wood is of delicate colour, not unlike the cedar used for black-lead pencils, but is knotty almost throughout.

From the inner bark of the larch the Russians manufacture a soft and fine kind of white gloves. The trunk, if tapped betwixt the months of March and September, yields an extremely pure turpentine, which has the name of Venice turpentine; and is of considerable use in medicine. It is usually thinner than any other kind of turpentine, and of clear whitish, or yellowish colour. The drug of this name, which is generally met with in the shops, is now imported from New England, but was formerly brought from Venice. A brown gummy substance, known in Russia by the name of Orenburg gum, is obtained by a curious process from the sap of the tree. On the large branches of the larch are produced small, sweetish grains, somewhat resembling sugar; which are fiequently substituted for the drug called manna (252).

The cultivation of the larch was first introduced into Britain towards the conclusion of the seventeenth century. The trees will grow in almost any soil; and the proper season for felling them is the month of July. They, however, seldom attain any large size in this country; and they are said to decay and become covered with moss, when about forty years old.

250. The CYPRESS-TREE (Cupressus sempervirens) is a dark-coloured evergreen, a native of the Levant, the leuves of which are extremely smull, and entirely crover all the slender lranches, lying close upon them so as to give them a somewhat quadrangular shape.

In some of the tress the branches diminish gradually in 
length from the bottom to the top, in such manner as to form a nearly pyramidal shrope.

In many of the old gardens in this country cypresstrees are still to be found, but their generally sombre and gloomy appearance has caused them, of late years, to be much neglected. They are, however, very valuable on account of their roood, which is hard, compact, and durable, of pale or r'eddish colour, with deep veins, and pleasant smell. We are informed by Pliny that the doors of the famous temple of Diana, at Ephesus, were of cypress wood, and that, although they were 400 years old at the time when he wrote, they appeared to be nearly as fresly as new. Indeed this wood was so mucli esteemed by the ancients, that the image of Jupiter in the capitol was made of it. The gates of St. Peter's church at Ronle are stated to have been or cypress, and to have lasted more than 1000 years, from the time of the Emperor Constantine until that of Pope Eugenius the Fourth, when gates of brass were erected in their stead. As this wood, in addition to its other qualities, takes a fine polish, and is not liable to suffer from the attacks of insects, it was formerly much esteemed for cabinet furniture. By the Greeks, in the time of Thucydides, it was used for the coffins of eminent warriors; and many of the cliests which enclose Egyptian nummies are made of it. The latter afford very decisive proof of its almost incorruptible nature.

'The nane of this tree is derived from the island of Cyprus, in the Mediterranean, where it still grows in great luxuriance. Its gloomy hue caused it to be consecrated by the ancients to Pluto, and to be used at the funerals of people of eminence. Pliny states that, in his time, it was customary to place branches of the cypress-tree before the houses in which persons lay dead.

251. The CASSAVA, or CASSADA (Jatropha manihot) is a South American shrub, about three feet in height, with broad, shining; and somewhat hand-shaped leaves, and beuntiful white and rose-coloured flowers. 
It is a very remarkable eireumstance, that the roots of the cassava, if eaten raw, are a fatal poison both to man and beast, and that, when prepared by heat, they yield a safe and valuable food; on which, indeed, many both of the Indian and European inhabitants of South America almost wholly subsist. The roots are the only edible parts of the plant. These, which are white, soft, and farinaceous, from one to two fect in length, and five or six inches in circumference, are dug out of the earth, at a eertain season of the year, washed, stripped of their rind, and ground to a pulp. 'The juice, or poisonous part, is pressed out, and carefully thrown away; as eattle, and other animals, which have aceidentally drunk of it, have almost instantly died. The flour that remains, after pressure, is formed into thin round rakes and baked. To an European, accustomed to other bread, these, though sweetisl, and not unpalatable, have an insipid taste. If plaeed in elose vessels, and preserved from the attaeks of inseets, eassava bread may be kept for several months without injury.

With the natives of South Ameriea, it is not unusual to throw a great number of eakes of eassava together to heat, after which they soak them in water, which causes a rapid fermentation to take plaee; and from the liquor thus obtaired, they make a very sharp and disagreeable, but intoxicating beverage, whiel will not keep longer than twenty-four hours without spoiling.

From the pure flour of eassava is formed the substance ealled tapioca, whieh is frequently imported into this country, and is used for jelly, puddings, and other culinary purposes. It is prepared from the fibrous part of the roots by taking a small quantity of the pulp, after the juice is extraeted, and working it in the hand till a thiek white cream appears on the surfaee. This: being separated, and washed in water, gradually sub. sides to the buttom. After the water is poured off, the remaining moisture is dissipated by a slow fire, the substariee being constantly stirred, until at length it is formed into grains about the size of sago (266). 
These become hard by keeping, and are the purest and most wholesome part of the cassava.

The roots of another species of this shrub, called sroet cassava, are usually eaten with butter, and merely after being roasted in hot ashes. They have much the flavour of chesnuts, and are an agreeable and nutritive food.

252. The TALLOW TREE (Croton sebiferum) is a native of China, and in habit somezohat resembles a cherry-tree, but has shining egg-shaped, and pointed leaves, that form tufts at the extremity of the branches.

The fruit of this tree, from which the Chinese obtain a kind of tallow for the manufacture of candles, is enclosed in a husk, not much unlike that of the chesnut, and consists of three round white kernels. All the preparation that is requisite is to melt these kernels, adding a little oil, to render them softer and more pliant than they would otherwise be. The candles made from this substance are very white, but are sometimes coloured by adding a little vermilion. They are more firm than those of tallow, but not equal in quality to candles either of wax or spermaceti. 'The wicks that are used are not, like our's, made of cotton, but consist of little rods of light, dry wood, with the pith of a rush entwined round them.

253. INDIAN RUBBER, or CAOUTCHOUC, is the dried juice of a large and much branched tree (Siphonia elastica, liig. (60), which grows in Gniana, and other parts of South America.

This tree has sometuhat oval leaves, entire, veined, and smooth, arranged in threes, and on long foot-sialks.

'The flowers are small, in bunches, near the ends of the branches, and the finit is triangular.

It was not until about the year 1736, that this very extraordinary natural production was made known in Europe. It is obtained by making incisions through the bark of the tree, chiefly in wet weather. From the wounds thus formed the juice flows abundantly. It is 
of milky-white colour, and is conducted by a tube or leaf, supported by clay, into a vessel placed to receive it. Some writers assert that, on mere exposure to the air, it gradually hardens; and others that, for this purpose, it goes through a certain process, which the Indians kecp a profound secret. It is usually brought to Europe in the shape of pear-shaped bottles, which are formed by spreading the juice over a mould of clay. These are exposed to a dense smoke, or to a fire, till they become so dry as not to stick to the fingers; and then, by certain instruments of iron or wood, they are ornamented on the outside with various figures. This done, the clay in the inside is moistened with water and picked out.

Indian rubber is remarkable for the flexibility and elasticity which it acquires on attaining a solid state; and also for the numerous useful purposes to which it is capable of being applied. By the Indians it is sometimes formed into boots, which are impenetrable by water, and which, when smoked, have the appearance of leather. Bottles are made of it, to whose necks are fastened hollow reeds, through which the liquor contained in them can be squirted at pleasure. Ons of these, filled with water, is always presented to each of the guests at their entertainments. Flambeaux are likewise formed of this substance, which give a very britliant light; and it is said that a torch of Indian rubber, an inch and half in diameter, and two feet long, will burn twelve hours. The inhabitants of Quito prepare a species of oil-cloth with the hardened juice of this tree.

The principal uses to which Indian rubber is applied by us are, for the effacing of black-lead marks; for flexiblesyringes, tubes, and other instruments used by surgeons and chemists; and for the formation, by means of turpentine or linseed oil, of a varnish for air-balkoons.

Various experiments liave been made to dissolve this substance, so that it may assume its naturally elastic state, under any figure that may be required. This has

VOL. II. 
been effected by means of ether, but the process is too expensive for common use. A simple method of forming tubes of it is to split a piece of cane and to put between the pieces a slip of whalebone. If the Indian rubber be cut into slips, and twisted closely round the cane, and the heat of boiling water be applied, the whole will become united into one piece or tube, from which the whalebone first, and afterwards the cane, may easily be separated.

It has been proved that cloth of all kinds may be made impenetrable by water, if impregnated with the fresh juice of the Indian rubber tree; and that boots, gloves, and other articles, made of cloth thus prepared, may be joined without sewing, and only by moistening the edges with the juice. These are not only more durable, but retain their shape better than sucli as are made of the juicc without any connecting substance.

It has lately been ascertained that, in Prince of Wales's Island, and also in Sumatra, there are trees of a class and order totally different from that above described, which yield a juice similar to this, and applicable to all the same purposes.

254. The CASTOR-OIL PLANT (Ricinus palma christi) is a native loth of the East and West Indies, and has a stem from five to fifteen or sivteen feet in height, and large bluishgreen laves, divided into seven lobes, serrated and pointed, the footstallis long, and inserted into the dist.

The flowers are produced in a terminating spitic, and the sced-vessels are covered with spines, and contain each three flattish oblong sceds.

It is to the seeds of this plant that we are indebted for the drug called castor-oil. This is sometimes obtained by pressing the seeds, in the same way as is practised with respect to oil of almonds (152). But the mode chiefly adopted in the West Indies, whence we principally import it, is first to strip the seeds of their husks or pods, and then to bruise them in a mortar; after- 
wards they are tied in linen bags, and boiled in water until the oil which they contain rises to the surface; this is carefully skimmed off, strained to free it from any accidental impurities, and bottled for use. The oil which is obtained by boiling is considered more mild than that obtained by pressure, but it sooner becomes rancid. The mildest and finest of the Jamaica castoroil is limpid, nearly colourless, and has scarcely more taste or smell than good olive-oil.

The uses of castor-oil in medicine are well known.

The plant is sufficiently hardy to grow and ripen its seeds in the open ground of gardens, in the south of England.

\section{CLASS XXII.-DICECIA.}

DIANDRIA.

455. WILLOW, OSIER, or WITHY.-Of this very extensive tribe nearly fifty distinct species have been discovered in our own island. The slender branches of many of these are applied to useful purposes, but particularly for making baskets, bird-cages, and what is called wicker-work; springles for fastening down thatch, wheels or traps for catching lobsters and eels; hoops and crates. 'The rood is useful for the handles of hatchets, prongs, spades, and other rural implements; and also furnishes shoemakers with cutting and whetting boards, on which they cut leather and sharpen the edges of their knives.

As willows generally flourish in wet situations, some of the species are planted with a view to prevent the banks of rivers and brooks from being washed away by
floods. 
The bark of some kinds of willow has been applied, with effect, as a substitute for Peruvian bark, in the cure of intermittent fevers. It has also been esteemed useful in the tanning of leatler; and, in combination with alder, for striking a deep black colour, in the dyeing of linen.

The bark of other species may be manufactured into paper. In the year 1788, Mr. Greaves of Milbank, near Warrington, Lancashire, made fifteen reams of coarse paper from the bark of withen twigs, intermixed with a few nettles. The latter, however, he afterwards discovered, would better have been left out, as there was in them a woody substance, which does not well incorporate with other vegetables. The paper he made was considerably cheaper than paper of equal size and thickness made from ropes; and it was found that pasteboard, for book backs, made of withen bark, would be much cheaper than similar pasteboard manufactured from ropes. The process by which this paper and pasteboard were manufactured was as follows; the bark was stripped from the twigs in September, the time at which they are usually cut for maling white baskets; it was then hackled, like flinx or liemp, and dried in the sun, which gave it somewhat the appearance of brown hemp: but this having been attended witl considerable trouble, other parts of the bark were dried with the leaves, as they were stripped off from the twigs, and were then submitted to the operation of the paper-mill.

The flowering branches of one species, the common sallow (Salix cineria), are called palms, and are gathered by children in many parts of England on Palm Sunday.

\section{TRIANDRIA.}

256. NUTMEGS are the kernels of a fruit produced it several islands of the East Indies.

They are each surrounded by the spice called mace, ana', externally, ly a husk about half an inch in thickness, which hus somewhat the appearance of a small peach Fig. 80). 
The nutmeg-tree (Myristica aromatica) is not unlike our cherry-tree, boll in growlh and size. Its leaves arc nearly oval, but pointed, waved, obliquely nerved, of bright green colour alove, and whitish beneath. The flowers are small and hang zupon slender stalks.

When this fruit is nearly ripe the husk opens at the end, and exposes a net-work of scarlet mace. Underneath the mace is a black shell, about as thick as that of a filbert, and very hard; and in this is contained the nutmeg.

The gathering of nutmeg's is performed by persons who ascend the trees for that purpose, and pull the branches to them with long hooks. The husks are stripped off in the woods, and the remaining part of the fruit, with its surrounding mace, is taken home. After the mace has been carefully stripped off, with a small knife, the nuts, which are still covered with their woody shell, are dried, first in the sun, and then upon a frame of split bamboos placed over a slow fire, until, when shaken, the kernels are lieard to rattle within the shells. These now easily fly to pieces when beaten with small sticks; and the nutmegs, being taken out, are soaked in sea-water and lime, and are then thrown in great numbers together to heat, by which their vegetating principle is destroyed. The nutmegs are finally sorted into parcels, according to their quality, and packed in bags tor sale and exportation.

The nutmegs vended at the East India Company's sales in 1804, amounted in weight, to 117,936 pounds, and produced 54,733l. exclusive of the duties. This kind of spice has long been employed both for culinary and medicinal purposes. Distilled with water, nutmegs afford a large portion of essential oil, which resembles, in flavour, the spice jtself. When heated and pressed they yield a considerable quantity of limpid yellow oil. In the shops a thick and fragrant kind is sold, which, though called oil of mace, is, in reality, expressed from the nutmeg. The best oil of this description is imported from the East Indies in stone jars. Oil of nut- 
megs is chiefly made from the imperfect fruit, and such as would be unfit for the European market.

Mace, or the covering of the nutmeg, that lies betwixt the outer coat and the shell, is an unctuous membrane, first of a light red, and afterwards, when dried, and as we see it, of yellowish colour. After it is taken from the shell it is exposed to the sun, then moistened witl sea-water, and finally so far dried as to allow of its being packed in bales for exportation. In these it is pressed closely down, by which its fragrance and peculiar qualities are preserved. Mace is liable to seizure if imported in packages of less than 300 pounds' weight. We usually see it in flakes each about an inch in length, and presenting a great variety of ramifications. This spice has a very fragrant and agreeable odour, and, to most persons, a pleasant, though somewhat acrid taste. It possesses nearly all the virtues of the nutmeg, but with less astringency; and, like that, is cmployed in numerous ways, both in culinary preparations and medicine.

In the island of Banda it is sometimes customaly to boil the entive fruit of the nutmeg-tree, and afterwards to preserve it in syrup, and also to pickle it in spiced vinegar, in nearly the same manner as we pickle walnuts. In several parts of the East the inhabitants preserve the outer husk of the nutmeg as a sweetmeat, or eat it stewed with other food.

257. The DATE is a frnit shaped somewhat like a large acorn, and coocred cxternally with a yellowish meml brane or skin, which contuins a fine, soft, and sweetish pulp, and, in the centre, an ollong, hard stone.

The trees (Phonix dactylifera) which produce this fruit, grow chiefly on the shores of the Mediterranean, are forty feet and upwards in height, have an upright stem, narked through their whole length with protuberances, and terminated at the sumunit with a cluster of vinged leaves or branches, each eight or nine feet in length.

The cultivation of the date is attentively pursued on the African coast of the Mediterranean; in several 
parts of Persia, Arabia, and even in Spain. The latter country, however, is not sufficiently warm to ripen the fruit in perfection, without the constant labour of the cultivator. He is obliged to ascend the trees, from time to time, to examine the flowers and turn them towards the sun. 'This is chiefly clone in the spring of the year; and, during the month of August, another and much more dangerous operation is requisite, namely, to tie all the branches into one bundle, and cover them over with broom. To make this bundle, the person employed is obliged to leap, as it were, over the flexible branches, for the purpose of surrounding and uniting them with a cord. This operation over, he places a ladder at the bottom of the tree, on which he stands to make a second band; he then places his ladder on this second band, ascends and ties the top with a third cord. His bundle being formed, he throws down his instruments, replaces his ladder by a gradation contrary to the former, and descends, from band to band, to the stem of the tree, down which he slides to the bottom.

Among the Africans and Egyptians the clate constitutes a principal article of food, and, as such, it is considered both wholesome and nutritive. Its name is a word, formed of dacte or dactylus, implying a finger, from an imaginary resemblance which this firuit has to the end of the finger. Although dates, in general, are of yellowish colour, some are black, some white, and others brown: some also are sweet, and others bitter. The best are called royal dates, and are imported into this country from Tunis.

Each tree produces ten or twelve bunches of fruit, which, when gathered, are hung up in a dry place, until so much of their moisture is evaporated as to allow of their being packed in boxes for exportation.

Nearly all the parts of the date-tree are useful. The rood, though of spongy texture, is employed for the beams and rafters of houses, and for implements of husbandry, which are said to be very durable. The 
pith of the young trees is eaten, as well as the young and tender leaves. From the old leaves and their stalks the women and ehildren of Valencia make mats, baskets, and other ntensils; and from other filanentous parts, ropes and different kinds of eordage are manufactured. A considerable traffic is earried on in these leaves, which, under the name of palms, are sent to Italy, to be used in the grand religious ceremonies of Palm Sunday. In Persia an ardent spirit is distilled from the fruit; and, in many plaees, the stones are ground to make oil, and the paste that is left is given as food to cattle and sheep.

\section{PENTANDRIA.}

258. MASTIC is a resinous substance, obtained from a low tree or shrub (Pistacia lentiscus) which grows in the Levant.

It has alternate winged leuves, consisting of several pairs of spear-sliaped leaflets, and spities of very small flowers, which issue from the junction of the lenves with the branches.

The mode in which this resin is obtained is by mak. ing ineisions across the tree in different parts. From these the juice exudes in drops, that are suffered to run upon the ground, and there to remain until they are suffieiently hard to be collected for use. The season for this proeess eommenees in the dry weather at the beginning of August, and lasts until the end of September. The best mastie is that imported from the island of Seio. We receive it in semi-transparent grains of yellowish colour. These emit an agreeable smell when heated; and, when ehewed, they first erumble, and afterwards stick together, and become soft and white like wax.

With the Turkish women it is customary to chew this resin for the purpose of rendering their breath agreeable, and under a notion also that it tends to make their teeth white, and to strengthen the gums. They also nix it in firgrant waters, and burn it with other odoriferous sub- 
stances, by way of perfume. It was formerly much used in medicine, as a l'emedy against pain in the teetl and gums; and, dissolved in spirit of wine, as a relief in obstinate and long continued coughs : but it is now almost wholly disused for these purposes; and is chiefly employed in the composition of varnish, and by dentists, for filling up the cavities of decayed teeth.

The rood of the mastic-tree is imported in thick knotty pieces, covered externally with an ash-coloured bark. This wood is accounted a mild, balsamic, astringent; and a preparation of it, under the name of aurum portabile, is strongly recommended by some of the German writers in coughs, nausea, and weakness of the stomach.

859. HEMP is the fitrous part of the slalks of a plant (Cannabis sativa, Fig. 82) which grows wild in the East Indies, and is much cultivated in different parts of Europe.

It has the lower leaves in slender finger-like divisions; the male flowers in small loose spikes, at the end of the stem and branches; and the female flowers single, at the junction of the leaves and stent.

The principal country for hemp, as an article of commerce, is Russia, few other countries of Europe growing a quantity sufficient for their own consumption. It is cultivated in some parts of Britain, but particularly in the counties of Suffolk and Norfolk. The soil best adapted to it is a moist but loose sandy loam, or the black mould of low lands near water. The seed is sown in April or May; and the plants, which attain the height of five or six feet, are in a state to be pulled up in three or four months; the male plant, or fimble hemp, as it is called, being ready some time before the female plants, which have the name of larle or seed-hemp.

As soon as the hemp is pulled, it is tied in bundles and set up to dry; and, at the end of about ten days, the bundles are loosened at the top, and the lieads. are held upon a hurdle by one person, whilst another, with a small threshing-flail, beats out the seed. 
In the preparation of hemp for the manufacturer two modes are pursued. One of these is to spread it out on stubble or pasture ground, that the fibrous parts may be rendered separable by the gradual operation of the weather; the other is to immerse the bundles, for some days, in stagnant water. The next process consists in separating the bark, or hemp, from the stalks: this is effected either by pulling out the stalk with the hand, or by machinery similar to that adopted in the preparation of Hax (97). After some other operations the hemp is beaten in mills, and then combed or dressed by drawing it through instruments called hackles, which are somewhat similar to the conbs of wool-nianufacturers.

Thus prepared, the hemp is spun into thread, which is made into twine, ropes, and cordage of every description; and woven into canvas, and strong cloth of various kinds. Indeed so great is the importance of this production, particularly for the cordage, cables, and the rigging of ships, that, to encourage its growth, an act of parliament was passed in 1783, directing a bounty of three pence per stone to be paid on all hemp raised in Great Britain ; and imposing heavy duties on hemp imported from foreign countries.

From hemp-seed a valuable kind of oil is procured, by pressure, which is peculiarly adapted for burning, as it is perfectly limpid and without smell : it is also used for making the soap called green soap. The seeds themselves are sometines employed in the feeding of poultry, from a notion that they cause the hens to lay a greater number of eggs than they otherwise would do. They are also given as food to singing birds; but, if in great quantity, they are supposed to injure the plumage. 'The stallis, after the liemp is taken from them, afford an excellent fuel. The water in which hemp has been soaked is in a high degree poisonous.

200. HOPS S are the dried flower-buds of a climbing British plant (Humulus lupulus, Fig. 81), with a rough and angular 
stem, and leaves generally in three or five lobes or divisions, and serrated.

Although hops grow wild, in great abundance, on hedges in several parts of the south of England, there is reason to suppose that their use was first made known from the Continent in the reign of Henry the Eighth.

A hop plantation requires the growth of some years before it is in perfection. The plants begin to push up their young stems about the month of April. When these are three or four inches above the ground, poles about twenty feet high are driven in to support them during their growth. The season for picking hops usually commences about the middle of September. This work is performed by men, women, and children. Proper baskets, bins, or cribs being in readiness, the plants are cut off ,close to the ground, and the poles are drawn up. These are placed upon the bins, with the plants upon them, and three or more persons on each side, pick off the hops. After this they are clried in a kiln, and, when dry, are carried into, and kept, for five or six days, in an apartment called the stowageroom, until they are in a state to be put into bags. This is done through a round hole, or trap, cut in the floor of the stowage-room, exactly equal in dimensions to the mouth of the bag, and immediately under which this mouth is fastened. In each of the lower corners of the bag a small handful of hops is tied; and a person, called the packer, places himself in it, and, by a heavy leaden weight, which he. constantly moves round in the places where he is not treading, presses and forces the hops down, in a very close manner, into the bag, as fast as they are thrown to him by another labourer. The work thus proceeds till the bag is quite full, when each of the upper corners has a few hops tied in it, in the same manner as those at the bottom. These serve as handles for moving the bags. The bag is then taken away, and its mouth is properly sewed up and secured. 
The hops of finest colour and best sample are put into bags of finer manufacture than the others, under the denomination of pockets; and the inferior sorts are packed in canvas of coarser kind, called bags.

When the hop-picking is completed, the poles are cleared from the binds or plants which adhered to them, and are stacked or piled together. The binds, when perfectly dried, are either stacked or placed in sheds, to be used as fnel in ovens, or otherwise. Sometimes they are burnt upon the land, for the ashes to serve as manure, trodden in the farm-yard, or allowed to be taken away by the labourers for their own use.

As the hop-plants are liable to be injured in various ways during their growth, they are considered a very precarious crop. They suffer from the attacks of insects, from honey-dew, from blight, from hot sunny weather after rain, and by winds and storms.

'Ithe principal zuse of hops, in brewing, is for the preservation of malt liquor, and to conmunicate to it an agreeably aromatic bitter flavour. The best hops are used for ale and the finer kinds of malt liquor, and inferior linds are used for porter. The odour of hops hung over a bed, or a pillow stuffed with hops, has been said to promote sleep, after the application of opium has failed. The young shoots and tops are often gathered from the hedges, by poor people, andiboiled and eaten in the manner of asparagns. Of the woody part of the hop-binds, after having been steeped in water, and worked into a pulp, a coarse kind of paper may be made.

\section{HEXANDRIA.}

261. YAMS are an American and West Indian rool of vcry irregular shape, which possess properlies somewhat similar to those of the potatoe, but they are less mcaly, and, in a raw state, ure ver'y viscous.

- The plants (Dioscorea bulbifera) which produce lhese roots have heart-shaped lcaves, and a stem that crceps aloug the ground likc ivy. 
In some of the rich lands of South America, yams are said to grow to the weight of fifty or sixty pounds eaclı; and are so productive that an acre of ground planted with them has been known to produce roots to the weight of from 20,000 to 30,000 pounds. Yams are propagated by setting the eyes, in the same manner as we plant potatoes; and, in six or cight months, they arrive at maturity.

When they are dug out of the ground, they are, for a little while, exposed to the sun to dry; and if, after this, they be packed in casks full of dry sand, thcy may be nreserved, without injury, for many months. They are consequently often used as sea-store for vessels about to sail on long voyages, and are frequently brought into England. Several attempts have becn made to cultivate yams in this island; and these have been attended with a certain degree of success in the counties of Mid-Lothian, Perth, and Stirling in Scotland, where they are uscd for the feeding of cattle. There are two kinds, one red, and the other white. 'The former of these contain a more nutritive food than the latter, though their flavour is much less excellent.

With the negroes, in the West Indian islands, the yam is a very important article of food. When roastcd, it is so wholesome and nutritive that it is preferred by them even to bread. Like potatoes, yams may be converted into bread, by mixture with a portion of wheat or barley flour. They are sometimes made into soup, puddings, and other useful dishes.

\section{OCTANDRIA.}

262. The ABELE, or GREAT IVHITE POPLAR TREE (Populus alba, Fig. 74), is a British tree wohich grows in hadges and woods, near brooks, and is known by its leaves being nearly triangular, irregularly jagged ai the edges, and cottony underneath.

The quickness of growth of this tree is so great that it will sometimes make shoots from eighteen to twenty 
feet in length in one year; and the trees attain their full growth in the course of twenty years. The rood is white and soft, but tough and of close grain, and not subject to warp or shrink. Hence it has been found useful for the flooring of rooms, and for making laths and packing boxes. For turnery ware it is preferred to most other kinds of wood, on account of its peculiar whiteness, and the ease with which it is worked in the lathe. "Of this wood," says Evelyn, "people also made shields of defence, in sword and buckler days."

The bark of the abele-tree is said to be serviceable as a remedy in intermittent fevers; and Dioscorides informs us that if it be chopped small and sowed in rills, well and richly manured, it will yield a plentiful crop of mushrooms.

263. The ASPEN, or TREMBLING POPLAR (Populus tremula), is a tree which grows in moist woods; has nearly circular leaves, loolhed and angular at like edges, smoolh on both sides, and allached to foolstalls so long and slender as to te shaken by the slightest wind.

There is scarcely any situation in which the aspen will not flourish, but it succeeds best where the soil is moist and gravelly. Its rood is light, porous, soft, and of white colour; and, though inferior in excellence to that of the white poplar, is applicable to many useful purposes, particularly for field gates, the frames of pack-saddles, for milk-pails, clogs, and the wood-work of pattens. It is improper for bedsteads, as it is liable to be infested by bugs. In some countries the barls of the young trees is made into torches.

264. The BLACK POPPLAR (Populus nigra, Tig. 75)

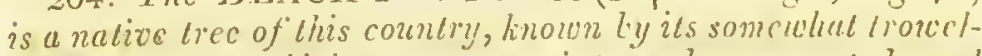
shaped leavcs, which laper lo " point, and are serralcd, and smooth on both sides.

This tree grows rapidly, and attains a considerable size. Its rood is soft and light, and in some respects useful to engravers; and is occasionally sawed into boards, though these are not in general much esteemed. 
The bark is so thick and light that it is not unfiequently used by fishermen as buoys or floats to support their nets. The inhabitants of Kamtschatka dry and pulverise the inner rind of the black poplar-tree, and use it as an ingredient in bread. The buds, when they first appear, are covered with and contain a viscous and fragrant juice, which may be advantageously used in plasters.

265. The LOMBARDY or ITALIAN POPLAR (Populus dilatata) grous wild in Lomburdy and the northern parts of Itcly, and is distinguished by its somewhat trowel-shaped and serraled leaves, lieing smoolh on bolh sides, and wider than they are loing.

From its slender and perpendicular growth the Lombardy poplar is found useful for hop-poles, and may be formed into masts for small vessels. The roood, which is soft and free from knots, is employed by joiners, carpenters, and cartwrights. It is recommended as peculiarly valuable for the floors of granaries, some persons believing it so obnoxious to insects that weevils will not continue in such granaries. It may be wrought into very flexible shafts for carriages, or felloes for wheels; and, not being liable to split, is peculiarly adapted for packing cases.

The growth of this tree is so rapid, and the space of ground which it occupies is so small, that it is in almost universal request as an ornamental tree, in places that are not sufficiently spacious to admit of trees of more spreading form.

\section{POLYANDRIA.}

260. SAGO is a granulated preparation from the pith of a species of palm-tree (Cycas circinalis) which grows in India and Africa.

This tree altains the height of thirly or forty feet; has " strait and somewhat slender stem, and winged leaves at the summit, each seven or eight feet long, with the leaftets long.
and narrow. 
The preparation of sago, under different forms, constitutes a principal source of employment to the inhabitants of many parts of the coast of Malabar, as well as those of several of the islands of the East Indies.

The trunk of the sago-tree contains a farinaceous pith, to obtain which it it sawn into pieces. After the pith is taken out it is beaten in mortars, and, water being poured upon the mass, this is allowed to stand for some hours to settle; after which it is strailied through a coarse cloth, and, the finest particles running through with the water, the grosser ones are left behind and thrown away, or washed over a hair sieve through which only the edible parts can pass. These are allowed to subside. The watcr is then poured off, and the flour, being properly dried, is made into cakes and baked for use, or is granulated in a manner somewhat similar to that adopted in the preparation of tapioca (251). It is in the latter state that sago is inported into Europe, where it is much used as a nourishing and agreeable diet for sick persons, in puddings and other culinary preparations.

267. The COMMON JUNIPER (Juniperus communis) is an evergrcen shrul, wilh slender and pointed lcaves, that grows on healhs in scveral parts of the south of England.

The leaves grow in thress; tach is tipped with a spine, and is longer than the ripe fruit, which is a lackish purple berry.

Juniper berries are at first green; and they continue upon the trees two years beforc they become ripe and assume their purple colour. When ripe they have a sweetish aromatic taste. The Swedes prepare, from these berries, a beveragc which they consider useful as a medicine; and in some parts of the Contincnt juniper berries are roasted, ground, and adopted as a substitute for coffee. In Sweden they are eatcn at breakfast, in the form of a conserve; and, in Germany, they are frequently used as a culinary spice, and especially for imparting their peculiar flavour to sour crout. Spirits impregnated with an essential oil distilled fiom them have the 
name of juniper water or gin. But it is a common practice to adopt spirit of turpentine (246) instead of this. Juniper-berries are imported into this country from Holland and Italy. Their smell is strong, but not disagreeable; and their flavour is warm, pungent, and sweetish, leaving a bitter taste in the moutl. 'The essential oil of these berries, if mixed with nut-oil (241), makes an excellent varnish for pictures, woodwork, and iron.

The wond of the juniper-tree is of reddish colour, very hard, and so durable that it will last more than a hundred years without decay. It is employed in veneering, for making cabinets, and for ornamental furniture. Charcoal formed from it affords a heat so lasting, that live embers are said to have been found in the ashes of juniper-trees after they have been covered up for more than twelve months. Such is the fibrous nature of the bark that it may be manufactured into ropes and other cordage.

From the crevices of the bark, or through perforations made in it by insects, a resinous gum exudes, which has the name of gum sandarach. This, which is of pale yellowish colour, very brittle, and inflammable, possesses a pungent aromatic taste, and emits a fragrant odour when burnt. It is imported from the Continent, in small pieces or tears, about the size of peas. When powdered and passed through a fine sieve, this is the substance called pounce, which is used for rubbing upon writing paper, in places where it has been scratched. Considerable quantities of this gum are consumed in the preparation of varnisl, and particularly of one kind, used by cabinet-makers and painters, called vernix.

268. The RED or COIMMON CEDAR is a specics of juni. per (Juniperus virginiana) which grows in North Amcrica und the IVest Indies.

It is distingruished by its lenves grouing in threes, and being fixed by their base, the younger oncs lying upon cach other, and the older ones spreading. 
The rood of this tree is in much request for the outsides of black-lead pencils. It is soft and incapable of high polish, but, on account of its powerful fragrance, and consequently resisting the attacks of insects, it is not unfrequently used for the bottoms of drawers, and the inside of cabinets. Some years ago it was in much request for wainscotting and cabinet work; but, since the introduction of mahogany, it has been in great measure neglected for these purposes.

269. The $Y E W$ is a well-known evergreen tree (Taxus baccata), which has dark, nurrow, pointed, and prickly leares, and red berries, in the hollow part of the extremity of which a green seed appears.

The cultivation of the yew was formerly very extensive throughout nearly the whole of the British dominions, since of the rood of this tree, which is peculiarly hard, smooth, and tough, our ancestors manufactured their bows. Hence, as well as on account of its gloomy and funereal aspect, it was usually planted in churchyards. But, when the introduction of fire-arms began to supersede the use of the bow, the yew was no longer cultivated than as an ornamental tree in parks and pleasure grounds.

In the formal style of gardening which was anciently prevalent, few trees were more the subject of admiration than this, from its bearing to be clipped, without injury, into almost any form. Yews were cut into the shape of men, quadrupeds, birds, ships, and other vegetable monsters, but such absurd fancies have of late years almost wholly disappeared. These trees are at present advantageously planted in hedges, as a fence for orchards and shrubberies, which nothing can injure.

'The rood of the yew-tree is hard, beautifully veined, and susceptible of high polish. Hence it is valuable as a wood for veneering, and is much used for card boxes, small cabinets, and other articles. It is frequently used by turners and cabinet-makers; and might perhaps be advantageously substituted for box 
(232) by engravers and other artists in that wood. From its hardness and durability, it may be made into cogs for mill-wheels, into axle-trees, and flood-gates for fish-ponds, which are scarcely susceptible of decay. The berries are sweet and clammy, and are often eaten by children without inconvenience; though when caten to excess, and particularly if the stones be swallowed, they are injurious. An ardent spirit might no doubt be obtained from them by distillation. The leaves of the yew-tree are extremely poisonous both to the human species and to cattle.

\section{CLASS XXIII.-POLYGAMIA.}

\section{MONCECIA.}

870. The PLANTAIN.TREE (Musa paradisiaca), which is much cultivated in the West Indies and South America, has a soft stem, fifteen or twenty feet high, with several leaves on the summit; and bears a fruit of pale yellow colour, somewhat shaped like " $\mathrm{cr}$ cumber, about a foot in length, and tico inches thick.

The leaves are frequently eight feet long, and nore than turo feet broud, and are so thin aud tender that they are often torn by the wind. The fruit is produced in bunches so large as each to weigh forty pounds and upvards.

To the negroes of the West Indian islands the plantain is an invaluable fruit, and, like bread to the Europeans, is with them denominated the staff of life. In Jamaica alone many thousand acres are planted with these trees. This fruit is usually gathered before it ic ripe, and, after the skin has been peeled off; is roasted for a little while in a clear fire; it is then scraped and eaten as bread, for which it is an excellent substitute. Plantains are sometimes boiled, and eaten with salt 
meat; they are also cut into slices and fried, pounded, and inade into puddings, and used in various other ways. Horses, cattle, swine, and other domestic animals, are fattened with them. When ripe they may be eaten raw, and, in this state, they have somewhat the taste of a ripe pear.

The leaves of the plantain-tree, being soft and sniooth, are sometimes employed as dressings after blisters; and, wheu green, are used as food for hogs.

The vegetation of this tree is so rapid that if a line or thread be drawn across, and on a level with the top of one of the leaves, when it begins to expand, it will be seen, in the course of an hour, to have grown nearly an inch.

271. The BANANA is a valuable plant (Musa sapientum) which grous in the West Indies and other tropical countries, and has leaves about six feet in length, and a foot broad in the middle; and fruit four or five inches long, and about the shape of a cucumber.

When ripe, the banana is an agreeable fruit, with a soft and luscious pulp; and is frequently introduced in desserts in the West Indies. The Spaniards have a superstitious dislike to cut this fruit across; they alvays slice it from end to end, because, in the former case, the section presents an imaginary resemblance to the instruments of our Saviour's crucifixion. The banana is sometimes fried in slices as fritters. If the pulp of this fruit be squeezed through a fine sieve, it may be formed into small loaves, which, after having been properly dried, may be kept for a great length of time.

272. MILLET is a small yellowish seed of a grussy plunt (Holcus sorghum), wilh large and compact stallis which rise to the height of scven or eight feet, and is much cultivated in several parts of India and Africa.

In some countries millet seed is ground into flour and converted into bread: but this is brown and heavy. It is, however, useful in other respects as food, and is 
an excellent seed for the fattening of poultry. A good vinegar has been madc from it, by fermentation; and, on distillation, it yields a strong spirit. Millet seed is imported into this country from the East Indies, for the purpose chicfly of puddings ; and, by many pcrsons, it is preferred to rice. The stalks of the millet plant, if subjected to the same process that is adopted with the sugar-cine, yield a sweet juice, from which an excellent kind of sugar may bc made.

273. GUM ARABIC is a well-known drug, obtained from a tree (llimosa nilotica) which grouts in Egypt.

This tree has leaves doubly winged, with spines at the base, and small flowers, of globular shape, growing four or five together on slender footslallis.

The principal supply of gum arabic in this country is obtained from larbary, Turkcy, and the Persian Gulf. The average quanticy imported from the Persian Gulf, betwixt 1804 and 1808, was about 7500 hundred weight per annum, and the pricc for which it was vended at the East India Company's sales was about 3l. per hundred weight. It used formcrly to be packed in skins, but it is now brought in large casks. The trecs which yield it grow abundantly in numerous parts of Africa and Asia, but the gum docs not fieely exude from them, except in tropical regions. It issues fiom clefts in the bark, in the samc manner as the gum of the cherry and pluni trees of our orchards and gardens: and, by exposure to the air, it soon becomes hard and solid. We arc informed that, in some parts of Egypt, thc inhabitants procure this gum, by boiling pieces of the roots of the tres, and afterwards scparating it from the water. We reccivc gum arabic in small irregular masses, or rough pieces, of pale yellowish colour, and roundish shape.

It is, however, to be remarked, that, by far the greatest part of the gum which is sold in the shops under this name is not such, but is the production of another species of tree (Mimosa senegal,) and is pro- 
perly called gum senegal. The latter is imported from Senegal, Guinea, and other parts of Africa. It is generally seen in largc rough pieccs, of roundish figurc, and brownish hue, more or less pure; possesses similar propcrties to the other, and is much cheaper.

On account of their mucilaginous qualities, these two kinds of gum, under the name of gum arabic, wcre formerly used for several purposes in medicine; and, in coughs and hoarsenesses, wcre considered of great service. They are now principally in request by the manufacturcrs of water-colours; by dyers, and artificers of different kinds. In Africa the latter eonstitutes a principal ingredient in the food of the inhabitants. They sometimes dissolve it in milk: and this solution of it is csteemed a favourite repast by some of thc tribes.

The dricd juice of the umripe fruit of Egyptian mimosa is called acacia, and is to this day much used in medicinc by the Egyptians. It is sometimes imported into this country in roundish masses, wrapped in thin bladders; and is externally of deep brown colour, and of a ycllowish or reddish brown within.

274. MYRRH is a gummy, resinous substunce, obtained from a tree which grous in Alnyssinia, Arabia, and other countries of the East, but resjocting which we are hitherto possessed of no certrin account. Mr. Bruce, houever, imagined it to be a species of mimosa.

This drug is generally imported in a kind of grains, of irregular form; of brownish, or reddish yellow eolour, and somewhat transparent. Its smell is aromatic; and its taste is pungent and bittcr. In its medieinal effects, myrrh, when taken into the stomach, is supposed to warm and strengthen it, and also to strengthen the other viscera. It is believed to resist putrefaetion in all parts of the body; and, lienee, lias been reeommended as a medicine in malignant, putrid, and pestilential fevers; and in small-pox.

At the East India Company's sales this drug is sold at the rate of about twenty pounds per hundred weight. 
It is, however, liable to great abuses. The larger masses, in particular, are frequently an artificial composition, skilfully incrusted with a coat of myrrh.

\section{DIOECIA.}

275. MANNA is a concrete or dried juice, procured from several species of ash.tree, but particulurly from the FLOWERING As (Fraxinus ornus, Fig. 76), which is much cultivuted in Calabria and Sicily.

This tree somewhat resembles the common ash. It has winged leaves, with an odd one at the end, the leaflets oblong, pointed, serrated, and veined, stunding on footstalks, and of bright green colout. The flowers are whitish, and appeur in close bunches, about the month of May or June.

The trees that are cultivated for the production of manna are chiefly planted on the eastern sides of hills. 'This substance exudes spontaneously from them; but as the supply thus obtained would be insufficient for the demand, incisions are made in the bark to obtain it more copiously. These incisions are formed, in the summer time, lengthwise in the tree, and each about a span long. They are begun at the lower part of the trunk, and repeated upward, at a little distance from each other, as high as the branches. One side of the tree is first cut; the other side being reserved until the ensuing year, when it undergoes a similar treatment. From the wounds thus made a thick whitish juice inmediately begins to flow, which gradually hardens on the bark, and in the course of a few days acquires a sufficient consistence to be taken off. It is collected in baskets, and afterwards packed in chests or boxes. Sometimes the manna flows in such abundance that it runs upon the ground, and thus becomes mixed with various impurities, unless it be prevented, as is sonietimes the case, by placing for its reception large leaves, stones, chips of wood, or straw. The collecting of manna generally terminates about the end of September.

This substance is known by druggists under dif- 
ferent names, according to its purity, rather than from any essential difference in the article itself. 'T'he best Calabrian manna is imported in oblong, light, and crumbly flakes or pieces of whitish no pale yellow, colour, and somewhat transparent appearance. 'The inferior solts are moist, unctuous, and of darker colour.

Manna is a mild and agreeable laxative medicine, particularly with the addition of a little cinmamon water, or other warm aronatic; and it is useful in astlumatic complaints, as well as in inflammatory affections of the breast. It is sometimes counterfeited by a composition of sugar and honey, mixed with a small portion of scammony.

The miraculous substance mentioned in the Old Testament by the name of manna, cannot, of course, be considered to have any alliance whatever with the manna thus produced. This remark would not have been made, did not young persons sometimes inconsiderately confound the two substances.

276. The ASH-TREE (Fraxinus cxcelsior, Fig. 79) is a well./6nou'n British tree, with winged leures; the leaflets in four or five pairs, with an odd one, serrated, and vithout footstalls; and the flowers without petals.

Of late years this valuable tree has been much planted in several parts of England. It is of hardy nature, and thrives even in barren soils. If planted in moist situations, the roots, spreading wide in every direction near the surface, have a tendency to render the ground dry and firm. 'The timber, which has the rare advantage of being nearly as good when young as when old, is white, and so hard and tough as generally to be esteemed next in value to oak. It is much used by coach-makers, wheel-wrights, ard cart-wrights : and is made into ploughs, axle-trees, felloes of wheels, harrows, ladders, and other implements of husbandry. It is likewise used by ship-builders for various purposes, and by coopers for the hoops of tubs and barrels. Where, by frequent cutting, the wood has become 
knotty, irregular, and veined, it is in much request for cabinet-work by mechanics on the Continent. The best season for felling ash-trees is from November to February. As fuel, this tree burns better whilst wet and green than other wood.

We are informed that, in the northern parts of Lancashire, when grass is scarce, the small farmers frequently cut off the tops of ash-trees to feed their cows with the leaves and tender branches; but these are said to spoil the taste of the milk. Mr. Pennant states that, in the reign of Queen Elizabeth, the inlabitants of Colton and Hawkshead-Fells remonstrated against the number of forges then lately erected in that part of the country, because they consumed the loppings of the trees, which formed the sole winter food for their cattle. The leaves of ash-trees were formerly much used in the adulteration of tea, under the name of smouch; but this practice has of late been prohibited by act of parliament.

The bark of the ash-tree is employed in the tanning of calf-skins, and sometimes in dyeing black and other colours. The innerbarli has been proposed as a substitute for Peruvian bark, in the cure of intermittent fevers.

277. EBONY is the wood of a species of pulm-tree (Diospiros ebenum), which grouts in the islund of Ceylon, and has smooth, leathery, oblong, and pointed leares, and ronghh-haired buds.

The black and valuable substance known to us by the name of ebony, is the centre part only of the trees. The outside wood is white and soft, and either decays soon, or is destroyed by insects, which leave the black part untouched. Ebony is imported into this country from the East Indies. It is exceedingly hard and heavy, admits of being highly polished, and is principally used by cabinet-makers and inlayers for the veneering of cabinets and otler ornamental work. The wood of the pear-tree, stained black, is frequently substituted for ebony.

VOL, II. 
The ripe fruit of the ebony tree is eaten by the natives of Ceylon; but it is astringent, and not very palatable.

Linnæus was of opinion that ebony was the wood of a shrub (ebenus cretica) which grows in the island of Crete, and has silky leaves and rose-coloured flowers.

278. The PAWPAW is a fruit ahout the size of a small melon, but of very rarious shape, the production of a species of palm-tree (carica papaya), which grows in tropical climates, loth of the eastern and western parts of the world.

The tree is twenty feet and upuards in height; nalied almost to the summit; and murlied, through its whole length, with the scars of fallen leures. Its leares ure on foot-stalls two feet in length, and decply dirided into seren, nine, or eleven large lobes. The flowers are axillary, white, and swect seented.

In shape the fruit of the pawpaw-tree is sometimes angular, and flattened at both ends; sometimes oval or round; and sometimes pyramidal. When ripe it is of yellow colour; and contains a yellow succulent pulp, of sweetish taste, and aromatic smell, with many black or brown and furrowed seeds. This fruit is seldom eaten raw, but when boiled it is esteemed a wholesome sauce for fresh meat. The inhabitants of the countries whele it is found sometimes preserve it in sugar, with oranges, and small cilrons. Thus prepared it may be kept a long time; and, in this state, it is not unfrequently brought into Europe. When about half grown, the pawpaw is sometimes pickled in vinegar with spices.

The fruit of the trifid-fruited custard apple (annona triloba) is called pawpaw in some parts of America.

The bark of the pawpaw-tree is manufactured by the Indians into cordage. 'The leaves are used in place of soap; and water-pipes are sometimes made of the stem of the tree. 


\section{TRICECIA.}

279. The FIG is the pulpy fruit of a shrub, or low tree (Ficus carica, Fig. 83), which is a nutive of the South of Europe, and soine parts of Asia.

Fig.trees are branched from the bottom, and the leaves are large, smooth, and irregularly divided into fiom three to five deep and rounded lobes. The fruit grows on shor't and thicks stalks, of purplish colour, und contuins a soft, sweet, and fiagrant pulp, intermixed with numerous small seeds.

It appears from history, both sacred and profane, that the fig-tree was an object of attention in the earliest times. This fruit was one of the most common and favourite aliments of the ancient Greeks, and constituted a very valuable food with the peasants of some parts of Italy. Fig-trees are now much cultivated in Turkey, Italy, and the Levant, as well as in Spain and some of the southern parts of France. All the islands of the Archipelago yield figs in abundance, but these are in general of very inferior quality.

The trees are propagated either by sucliers, by layers, or by cuttings; and the process of increasing and ripening the fruit is an art which requires much attention. This, as it is practised in the Levant, is called caprification, and is performed by wounding the buds of the figs, with a straw or feather dipped in sweet oil at a certain period of their growth.

Figs are dried either by a furnace or in the sun, afcer having been dipped in a scalding ley made of the ashes of the fig-tree. In this state they are used both in medicine, and as food; and are considered more wholesome and more easy of digestion than when fresh. They form a considerable branch of commerce, and are exported, in boxes of different size and shape, to nearly all the northern parts of Europe. When we receive them, their surface is usually covered with a saccharine matter which has exuded from the fruit. A small and cheap kind of fig is imported in small frails or baskets from Faro.

There are numerous varieties of the fig, but the w 2 
common purple kind is the hardiest of the whole. This is frequently cultivated in our gardens; and, if screened from the north-east winds, it ripens, even with us, in tolerable perfection.

The wood of the fig-tree is of spongy texture, and, when charged with oil and emery, is much used on the Continent by lock-smiths, gun-smiths, and other artificer's in iron and stecl, to polish their work. It is almost indestructible, and on this account was formerly employed in eastern countries as coffins for embalmed bodies.

\section{CLASS XXIV.-CRYPTOGAMIA.}

280. FERN, or BRAKE (Pteris aquilina), is a well-known cryplogamous plunt, which grows wild on keaths, in woods, and in barren places.

Though this plant is an extremely troublesome weed to the farmer, from the roots penetrating deep into the ground, it is applied to various uses in rural economy. When cut and properly dried, it serves as litter for horses and cattle; and it supplies the place of thatch for covering the roofs of cottages and stacks. Where coal is scarce, it is used for the heating of ovens and burning of lime-stone.

The ashes of fern, from their yielding a tolerably pure alkali, are frequently used by manufacturers of glass, particularly in France. And, in some parts of our own country, the poor people mix these ashes with water, and form them into round masses which they call fern balls. These are afterwards heated in a fire, and then, witl water, are made into a ley for the scouring of linen. They thus furnish a cheap substitute for soap.

Swine are fond of the roots of fern, and will feed 
freely upon them. We are even informed that, with the inhabitants of Palma, one of the Canary islands, they are sometimes made to supply the place of bread.

It is deserving of remark that, when the root of the fern is cut obliquely across, it presents a lind of figure of the Imperial or Russian eagle; from which circumstance Linnæus was induced to name it Pteris aquilina, or "Elagle brake."

281. The LICHENS constitute a very momerous family of plants, which grow on the bark of trees, on rocks, stoncs, and other snbstances; and harc an indistinct fructification, in scattercd wartlike tubercles, or excresccnces, and smooth saucors or shiclds, in which the sccds arc imbedded.

Some of them have a powdery appearance, and other's are crustaceous, lenf-like, shrub-like, herbaceous, or gelatinous.

282. The CALCAREOUS LICHEN (Lichen calcareus) consists of a white crust with black turbercles.

This plant, which is found on limestone rocks in Wales, and the north of England, is used in dyeing woollen and other cloths a scarlet colour.

283. CRAB'S-EYE LICHEN (Lichen parellus) is a crustaceous, whitish, and granulated vegetuble substance, with cups of the same colour, which have a thick and blunt border.

From this lichen, which is found on rocks and stones in mountainous countries, and sometimes on stones near the sea-shore, is prepared the bluish pigment called litmus. It is chiefly collected from rucks in the north of England, packed in casks, and sent to London for sale.

284. TARTAREOUS LICHEN (Lichen tartareus) is a whitish, crustaceons, vegetable production, with yellow cups or shields, which have a whitish border.

The inhabitants of the Highlands of Scotland gatler" this species of lichen from the rocks, and, after cleaning, and some further preparation, which is kept a secret by the manufacturer's, they form it into cakes. These, 
when dried, ale pulverized, and sold to dyers by the name of cudbear, which is a corruption of Cuthbert, the name of its inventor. In conjunction with alum, the powder of the tartareous lichen is used in dyeing scarlet, and also for striking a purple dye; but the colour produced by it is not very permanent.

285. ARCHELL, or PURPLE ROCK LICHEN (Lichen omphalodes), is a vegetable production, of somewhat crustaccous consistence, and leaf.like form; the segments with many lobes, and of dark purplish brown colvur, with dull purple sancers.

This kind of lichen grows upon rocks on the high stony moors of several parts of England, Wales, and Scotland. When properly prepared, it imparts to woollen cloth a reddish brown colour, or a dull but durable crimson. If wool that has been dyed with it be dipped into a blue vat, it will acquire a beautiful purple tinge. It is sometimes used as a styptic; and was formerly applied as a remedy in inflammatory fevers and other complaints; but, in the latter respect, it is now entirely neglected.

286. ORCHALL, or DYER'S LICHEN (Lichen rocella), is a somewhat crustaceons and shrub-like vegetable production, of nearly cylindrical form, solid, without leates, but little branched, and with blackish brown alternute tubercles.

In the Canary and Cape de Verd Islands, as well as in the Grecian Archipelago, orchall is found in great abundance. It likewise grows in Guernsey and in some parts of England, and is employed by dyers chiefly for giving a bloom to other colours. This is effected by passing the dyed cloth or silk through hot water slightly impregnated with it; but the bloom thus communicated soon decays after it has been exposed to the air. When prepared in a peculiar manner orchall yields a rich purple tincture, fugitive indeed, but very beautiful. Mixed with a solution of tin it is said to dye a permanent scarlet. Orchall is the 
substance generally adopted for colouring the spirits of thermometers. And it is a remarkable circumstance that, as exposure to the air destroys its colour upon cloth, so the exclusion of the air produces, in a few years, a like effect upon the fluid in those tubes; but on breaking the tubes the colour is restored.

287. ICELAND LICHEN (Lichen islandicus) is a leavy, membranous, vegetuble production, of brownish grcen colour, jugged at the edges, and fringed, hating large and purplish brown sancer's or shields.

The name of this lichen is derived from that of the island in which it chiefly grows. It is, however, also found in the Highlands of Scotland, and in some of the northern parts both of England and Wales.

It abounds with nutritious mucilage; and, after liaving been steeped in water to extract its bitter and laxative qualities, it is sometimes used as medicine in coughs and consumptions. One ounce of Iceland lichen, boiled in a pint of water, yields about seven ounces of mucilage. The inhabitants of Iceland prepare from it a kind of gruel, which they mix with milk. They also boil it in several waters, and then dry and make it into bread. In Germany a durable brown dye is made by means of it; and, under another mode of preparation, it imparts an excellent black tinge to white woollen yarn.

288. BLADDER FUCUS (Fucus resiculosus) is a sprecies of sea-weed, of flat shape, with a middle ril, the edges entire, forls. ed, and sometimes tumid at the ends, and furnished with sevcral air bludders inbedded in the substance of the plunt.

By far the most important application of this, one of the commonest of all our mariue plants, is for the making of kelp, which, in Scotland, affords employment to many industrious families. So lucrative and so highly estecmed is the bladder fucus, and some other plants nearly allied to it, that the natives of several parts of the Western Islands have rolled large masses of stone 
into the sea, with a view to promote and extend their growth.

For the preparation of kelp these plants are dried, by exposurc for some time to the sun and air. They arc then burnt by degrees in a kclp furnace, which is gerserally a round hole dug in the earth. When the furnace is nearly filled with the remains of the burnt seaweeds, the wholc is briskly agitated with a rake or hook, till it is compacted, or becomes of a shining glutinous consistence, in appearance not unlikc mclted iron. It is then allowed to cool, and is afterwards placed in storehouscs for exportation. In this state it is an impure kind of carbonat of soda. In the Orkney Islands every consideration is sacrificed to the making of kelp, ncarly 3,000 tons of which arc annually sent to markct and sold at Leith, Newcastlc, and other places, at the rate of from seven to ten pounds per ton of twenty-one hundred weiglit.

The inhabitants of Gothland boil this plant with coarse meal, as food for swine; and the poorer classes of Scania thatch their cottages with it, and also employ it as fuel. In the Hebrides it is customary to dry cheese, without using any salt, by covering it with the ashes of the bladder fucus, which abound in salinc particles. This and other sea-wecds serve as a winter food for cattle, which regularly fiequent the shores for them at the ebb of the tide: they are also used as manure for land.

A sonpy liquor which is found in the bladders of this plant is sometimes cxternally applied as a medicine for dispersing scrofulous and scorbutic swellings, by simply bruising them in the hand and rubbing them on the parts effected. When this plant is calcined or burnt in the open air, a black and saline powder is produced, which, under the name of vegetable cothiops, has been recommended as a dentrifice, and for other uses.

289. EATABLE IVINGED FUCUS, or BLADDERLOCKS (Fucus esculentus), is a simple, undivided, and 
sword-shaped sea-weed, which is olive-coloured, and sometimes several youds in length. Its stem is four.cornered, runs through the whole length of the leaf, and is winged at the base.

This plant, which is very common on some of the shores of Scotland, and also on thase of Cornwall, and several parts of North Wales, is a grateful food to cattle; and its stalk, when boiled, constitutes a very favourite dish in Scotland. 'The proper' season for' gathering it is the month of September, when it is in higher perfection that at any other time of the year.

290. SWEET FUCUS (Fucus saccharinus) is a simple, undivided, and su'm'd-shaped sea-weed, without any rib, of leathery consistence, and tawny green colour; and ficquacntly five or six feet in length. Its stalk is round and hord.

This plant abounds on all our sea-shores; and, if slightly washed from the sea-water, and dried in the air, it becomes covered with a sweet powdery efllorescence. It is edible either in a raw state, or boiled as a potherb. Sometimes it is hung up to serve the purpose of an hygrometer, which it does in some degree by becoming flaccid during a moist state of the atmosphere, and hard in dry weather.

291. DULSE, O1 RED. PALAIATE FUCUS (Flicus palmatus), is a flat, membranouts, and hand-shaped, ser-ueed, of brounish crinson colour, smooth on both sides, and without any mid-nib.

In the markets of Edinburgh, and other parts of Scotland, this plant, which is common on most of the Britisl shores, is exposed for sale as an article of food. After having been washed in fresh water, it is eaten law, by itself, in salad, or by poor people with other provisions. Sometimes it is boiled and used as a potherb. If gradually dried, it gives out a whitish powdery substance, which covers the whole plant, and has a sweet and agreeablc taste, somewhat resembling that of violets. In this state it is frequently packed in casks for exportation. Some persons chew it as to- 
bacco. In Scotland it is occasionally used as a medicine, and it is supposed to sweeten the breath and destroy worms.

292. GREEN or EDIBLE LAVER (Ulva lactuca) is a thin, membranous, pellucid, and green vegetable substance, which is found on rocks, stones, and shells, in the sea und salt-water ditches in nearly all parts of Great Britain.

Of late years this plant, stewed with lemon juice, las been introduced to the tables of the luxurious, as a sauce to be eaten with roast meat. Though in a recent state it has a salt and bitterish flavour, and even when thus prepared is not always relished at first, yet by habit most persons become partial to it. The laver which is consumed in London is chiefly prepared in the west of England, and packed in pots in a state ready for the table. Some persons use laver medicinally, and it is esteemed wholesome for scrofulous habits; but it can scarcely be taken in sufficient quantity to do much good, without having too strong an effect on the bowels.

293. The MORELL (Phallus esculentus, Fig. 84) is a kind of fungus with a naked and wrinkled stem, and an eggshaped head, full of cells on its external surface.

As an ingredient for thickening and heightening the flavour of sauces and soups, morells, which are chiefly found in woods and hedges in a loamy soil, are in great esteem. For this purpose, after they are gathered, they are strung upon pack-thread to be dried; and, when dry, they may be kept without injury for many months.

In Germany, the persons employed in gathering morells found that they always grew most abundantly in woods that had been burnt : and, with a view of promoting their increase, they were accustomed to set fire to the woods, until this practice was prohibited by the Government. Useful and palatable as these plants are, it has been ascertained that, if gathered after having 
been exposed for some days to wet weather, they are extremely pernicious.

294. The TRUFFLE (Tuber cibarium) is a globular, solid, and warty fungus, without root, wolich grows at the deplh of four or five inclies beneath the surface of the earth, and is from the size of a pea lo that of a potatoe.

This, one of the best of the edible funguses, is chiefly found in hilly woods and pastures, which have a sandy or clayey bottom; it occurs on the downs of Wiltshire, Hampshire, and Kent. Truffles are generally discovered by means of dogs, which are taught to liunt for them by scent; and wherever they sme!l one of them, they bark, and scratch it up. In Italy they are liunted, in somewhat similar manner, by pigs.

'Truffles are either served at table roasted in a fiesh state like potatoes, or they are cut into slices and dried, as an ingredient for sauces and soups. Those that are most delicious are internally of white colour, and have somewhat the odour of garlic.

In England truffles seldom exceed the weight of four or five ounces; whilst on the Continent they are known to weigh as much as fifteen or sixteen ounces each.

295. The PUFF-BALL (Lycoperdon bovista) is a round kind of .fungus, which is filled with a soft whitish flesh rohen young, and a fine brown powder when ripe.

The powder of the puff-ball is sometimes used as a styptic, to prevent the bleeding of recent wounds. This powder is extremely subtile, and is ver y injurious to the eyes. Instances have occurred of persons who, having had it blown into their face, have thereby been deprived of their sight for a considerable time; and have also been affected with violent pain and inflammation.

There is a curious experiment of taking a shilling from the bottom of a vessel of water, without wetting the hand. This is said to be effected by strewing a smalt quantity of. the dust of the puff-ball on the sur- 
face: it so strongly repels the fluid as to form a covering for the fingers, and defend them from the contact of the water.

The fumes of the puff-ball, when burnt, have a powerfully rarcotic quality ; and, on this account, they are sometimes used to take the combs from hives with. out destroying the bees.

296. The COMMON MUSHROOM (Agaricus canipestris) is a fungus consisting of a white cylindrical stalk and a convex cover of white or brownish colour, which has beneath an irregular arrangement of gills, pinkiy when young, but afterwards of dark liver colour.

When it first appears above ground the mushroom is smooth and nearly globnlar, and in this state it is calied " button.

In England muslirooms are in great demand for the table. 'They are found wild in parks, and other pastures where the turf has not been ploughed for many years; and the best time for gathering them is in the months of August and September.

They are eaten fresh, either stewed or broiled; and are preserved for use either by drying, by being pickled, or in powder. They are also employed in making the well-known sauce called mushroomketchup. As an article of food, however, mushrooms are by no means wholesone, being so tough, and haring so great a resemblance to soft leather, as to be almost indigestible. This is particularly the case when they are of large size.

Mushrooms may be raised artificially on berls constructed for the purpose, even in cellars; for if they have only warmit and moisture, the plants will vegetate without light; but the most proper situations for them are uncler sheds in the open air. The plants thus grown, however, have more toughress than such as grow wild in the fields; and, in other respects, are much inferior to them.

297. There is a kind of mushroon (Agraricus reorgii) which is yellowish, with yellowish white gills, and when 
full grown is sometimes so large as to measure eighteen inches across. This is occasionally eaten, but, in many instances, the use of it has been attended with injurious consequences.

295. In Covent Garden market a tall and spongy kind of mushroom (Agaricus procerus), with white gills, and a large horizontal ring round the stem, is frequently exposed for sale about the month of September.

299. On hedge-banks, in pastures, and in what are called fairy-rings, there is a species of mushroom ( $A \mathrm{ga}$ ricus orcades), with brownish or watery white gills, two or four in a set, a pale brown, convex, and irregular cover, and a whitish stem. These arc considered by many persons to be the champignons of the French cooks. They have a much higher flavour than the common mushroom: but fiom their leathery nature are indigestible, except in the form of powder, with sauces, or in ketchup, in all of which they are very admirable.

With respect to the plants of the mushroom tribe, it ought to be observed that, though several of them are edible, many are extremely poisonous. Instances of the fatal effects arising from an indiscriminate adoption of them are innumerable. Great caution, therefore, is requisite that strch only shail be used as are ascertained to be wholesome, particularly as, in many instances, the poisonous species can scarcely be distiriguished by the eye from such as are innoxious. In cases of injury arising from poisonous funguses, the best remedy that can be administered is an emetic.

300. SPUNK, or TOUCHWOOD (Boletus inniarius), is a fungus somerohat shaped like a horse's hoot, with pores on the under side, and the upper part very hard and smooth, but marked wilh circular bonds or ridges of different colours.

It arows horizontally on the trunks and large branches of seocral linds of trees, when old and decayed. 
In Germany, and in some parts of England, this fungus is used as tinder, for which, on account of its readily catching fire, it is well adapted. It is prepared by being boiled in a strong ley, dried, and again boiled in a solution of salt-petre. In Franconia pieces of the inner substance of the spunk are beaten so as to resemble leather, and are sewed together for making garments. 'The inlabitants of Lapland frequently burn it about their cottages, to keep off a species of gad-fly which is peculiarly injurious to the young rein-deer.

This fungus is often employed as a styptic for the stopping of blood. When intended for this use, the exterior hard substance is pared off, and the coat underneath is separated from the porous part, and well beaten with a hammer, until it becomes pliable. Thus prepared it is kept dry, in slices of convenient size, for use; and, although it is not so much esteemed in this country as it was some years ago, many of the coritinental surgeons have a very high opinion of its efficacy. 


\section{INDEX}

TO THE

\section{SECOND VOLUME.}

A BELE. Sec Poplar, great white.

\section{Acacia, 262}

Acorns, uses of, 223

Alder, wood, bark, branches, and leaves, uses of, 211

Alkanet, description, properlies, and uses of, 42

Alligator pear, description and uses of, 120

All-spice. See Pimento.

Alniond, common or sweet, description of, 140

-_., whence obtained, how imported, and uses of, 140

-_-, oil and milk of, how prepared, 141

-, bitter, description and uses of, 141

Aloe, American, description, culture, and uses of, 96, 97

Aloes, description of several kinds, 93, 94

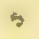

--, leaves, stems, and juice, uses of, 93,94

--, socotrine, description, culture, preparation, and uses of, 94

_-_, Barbadoes, common, or hepatic, 95

---, caballine, of horse, 96

Anise-seeds, description and uses of, 81

Apple, fruit and wood, uses of, 147, 148

Apricot, fruit, kernels, gum, and wood, uses of, 143

A rchell, description and use of, 270

Arcca, description and uses of, 231, 232

Arnatto, or annotta, description of, how prepared, and uses of, 157

Arrack, from what prepared, 106, 218

Arrow root, what it is, how prepared, and uses of, 9, 10

- -, how adulterated, 10

Artichoke, flowers, leaves, and stalks, uscs of, 197

- Jerusalcm, description, culture, and uses of, 201

Arum, common, description and uses of, 218, 219

Asafœtida, description and uses of, 77

- how obtained and exported, 77,78

Ash-tree, wood, leaves, and bark, uses of, 264 
Asparagus, description, cultivation, and uses of, 92,93

Aspen. See Poplar, trembling.

B.

Balsam, Frial's, or Turlington's, from what made, 130

Bamboo caues, description and uses of, 100,101

Banana, description and uses of, 269

Barberry, fruit, bark, and roots, uses of, 100

Barilla, description of, and how preparcd for use, 73

Barley, cultivation and uses of, 27

- pearl, how niade, and uses of, 28

-

Bay, common swect, description and uses of, 119,120

Bay plum. See Guava.

Beans, culture and uses of, 184

Beech-tree, wood, fruit, and leaves, uses of, 220

Beet, description and uses of, 71, 72

Benjamill, gum. Sec Benzoin.

Bent-grass, 32

Benzoin, description of, how prepared, and uses of, 129, 131

Bergamot, how prepared, 195

Betel, what it is, and use of, 15

Betel-nut. Sce Areca.

Bilberries, uses of, 113

Birch-tree, wood, bark, twigs, leaves, and sap, uses of, 210

Bird-lime, how made, uses and properties of, 4.1

Blackberries, uses of, 152

Bleaberries. Sce Bilberries.

Blend-corn, 28

Bonbab. Sce Sour gourd.

Borc cole, 176

Bottle gourd, description and uses of, 209

Box-1ree, value and uses of, 215

Brake, description and uses of, 268

Bran, uses of, 26

Brandy, whence obtained, and how made, 69

- distilled from potatoes and carrots, 55, 75

Brank. See Buck-whcat.

Bread prepared from turnips, arum roots, acorns, cassava, and sago, $175,219,224,259,256$

Bread.fruit, description and uses of, 203, 204 , tree, bark, juice, and flowers, uses of, 204, 205

Brocoli, 176

Broom, common, twigs, seeds, bark, \&c, uses of, 181

_- Spanish, description and uses of, 181

Buck-bean, or bog-bean, description and uses of, 43

Buck-thorm, syrup, and bark, uses of, 56 
Buck-wheat, description, cultivation and uses of, 114

Bullace plums, description and uses of, 144

clieese, from what prepared, 144

Bull-rush, uses of, 31

Burgundy winc, 64

Burgundy pitch, of what made, and uses of, 256

C.

Cabbage, eommon, culture and uses of, 176 tree, description and uses of, 230

Cacao. See Chocolatc.

- - , butter of, 192

Cajeput oil, what it is, and uses of, 195, 196

Calabash-trec, description and uses of, 170 African. See Sour gourd.

Calyx, or flower-cup, 1

Camomile, description and uses of, 199, 200

Canuphor, description, low obtained, and uses of, $117-119$

Canary wine 68 grass, 33

Canes, walking, description of, and whence obtained, 100

-_-, Trce cancs, description and uses, 100

--, bamboo, description and uses, 100-102

Caoutchonc. Sec Indian rubber.

Cape madeira wine, 68

Capers, description of, how prepared, and uses of, 153

$\longrightarrow$, suhstitutes for, 154, 181

Capsicum, differcnt linds and uses of, 56

Caraway, how cultivated, and uses of, 81

Cardamonis, description, culture, and uses of, 3,9

Cardoon, description and uses of, 198

Carriage-grease, of what made, 233

Carrot, cultivation and uses of, 74,75

Cashew-nut-trce and fruit, description and uses of, 121-123

Cassava, or cassada, description and uses of, 238

Cassia, and cassia buds, description and nses of, 117

- --, officinal, description and uscs of, 126, 127

Castor-oil, how prepared and uses of, 242

Cateclıu. Sce Areca.

Caulitlower, 176

Caycnne pepper, how made, and uses of, 56,57

Cedar, red or common, description and uses of, 257

Celery, uses of, 82

Champaigne wine, 66

Champignons, description and use of, 277

Charcoal, durability and uses of, 224

- -, vapour of, in what respect pernicious, 225 
Cherry-tree, fruit, wnod, and gum, uses of, 142

Chesnut, brandy, how macle, 142

Chesnut, horse, fruit, husks, wood, and bark, uses of, 106

China, broken, how to and fruit, properties and uses of, 220

Chives, description and usest, 89

Chocollate, description uses of, 91

Cider, and cider wine, how

made, 148

Cinnaluon, description, preparation, and uses of, 115,117

, oil of, 116

, wild. See Cassia.

Citron, description and uses of, 192

Claret, 66

Clover, cultivation and use of, 187

Cloves, description, culture, preparation, and uses of , 164

C--, oil of, 165

Cocoa-nut-tree and fruit, keruels, milk, husks, shells, \&c. uses of, 216

Coffee-tree, description of, and how cultivated, 47

listory of the use of, 48,49

, Mocha, West India, and Java, 49

, how roasted, and use of, 49

Co-, substitutes for, 181, 184

Cole-seed. See Rape-secd.

Colewort, 176

Constantia wine, 68

Copal, description, preparation, and use of, 83

Cornish, how made, 83

Coriander, cultivation and uses of, 79

Corinths. See Currants.

Cork, how collected and prepared for use, and uses of, 225

Cork cutting, how performed, 226

Corolla or blossom, 2

Cote rotie wine, 66

Cotton, description, culture, and preparation of, 179

C---, uses of, and trade in, 180

Court-plaster, how made, 130

Cowage, or cow-itch, description and uses of, 182, 183

Cowslip, use of, flowers, roots, and leaves, 43

Crab-tree fruit, uses of, 147

Cracow groats, 26

Cranberries, description and uses of, 112

Cuckoo fruit. See Arum.

Cucuniber, common, culture and uses of, 207

Currants, dried, what they are, and whence obtained, 70

--, how cultivated and prepared for use, 71

-- , red, juice and inner bark, use of, 60,61 
Currants, black, leaves and berries, uses of, 61

Curry powder, of what made, 9

Cypress powder, of what made, 219

Cypress-tree, description and uses of, 237

\section{D.}

Date-tree, description, cultivation, and management of, 346,34 ? Deals, yellow and red, 233

Dragon's-blood-trce, description and uses of, 98,99

Dulse, description, preparation, and use of, 273

Dutch pink, from what prepared, 136

E.

Ebony, description and uses of, 265

Eschalote. See Shallot.

Elder, common, wood, bark, leaves, flowers, berries, \&c, uses of, 63 Elm-trees, timber, bark, and leaves, uses of, 73

Endive, culture and uses of, 199

F.

Fan-palm, description and uses of, 98

Fennel leaves, stalks, seeds, and roots, uses of, 80

Fern, description and uses of, 268

Ferula, stalks of, how anciently used, 78

Fig-trees and figs, description, cultivation, and uses of,, 267

Filbert, 228

Fir, Scots, description of, timber and bark, uses of, 232, 233

-, turpentine, resin, tar and pitch, how obtained from, 232, 233

- spruce, description and uses of, 235

Flax, description of, cultivation, preparation, and uses of, 85

- - Oil made from the seeds of, 86

Flummery, what it is, and how made, 23

Fox-glove, description and uses of, 169

Frontignac wine, 66

Fructification of regetables, 1

Fucus, bladder, description and use of, 271

--, eatable winged, 272

-.-, sweet, and red palmate, 273

Furze, uses of, 182

Galls, use of, 223

G.

Gamboge, description of, how obtained, and uses of, 135

Garlic, description and uses of, 89

Gentian, description aud uses of, 74,75

Gerkins, 207 
Gilead, baln or balsam of, how obtained, and uses of, 108

$\mathrm{Gin}$, with what flavoured, 257

Ginger, cleseription, cultivation, preparation, and uses of, 7

Glass, broken, how to cemcnt, 89

Gooseberries, uses of, 61

Gorse, u-cs of, 182

Grafting of fruit-trees, how performed, and use of, 147

Grapes, uses of, 69, 70

Grass, swcet sccnted vernal, uscs of, 30

- eotton, meadow fox-tail, and Timothy or meadow eat'stail, 31

- Fiorin or Orcheston long, 32

- meadow soft, or Y'orkshire white eanary, purple melic, and recd meadow, 33

-, smooth-stalked meadow, and annual meadow, 34

fescuc, 35

- , ryc or ray, 37

- conch or squitch, 38

Grits or groats, what thcy arc, 23

Guava, description and uscs of, 137

Guiacum, gum, how obtained and uses of, 127

Gum arabic, low and whence obtained, and uscs of, 261

- Sencgal, 262

- Sandarach, 257

II.

Hazel nut tree and fruit, uscs of, 228

Heath, common, stalks, tops, flowcrs, leaves, and seeds, uses of, 113

Hemp, description of, how cultivated and prepared for use, 249

-, fimble, karle, or seed, 249

-

Heps, conserve of, 151

Hermitage winc, 66

Hickory nut, 227

Hock winc, 68

Holly-trec, wood, leaves, berries and bark, uses of, 14

Hops, description and mode of culture of, 250, 251

- how picked, dricd, and prepared for use, and uses of, 251

--, substitutcs for, in brewing, 43,135

Hornbeam, description and uscs of, 229

Horse-radish, description and uses of, 172

I. I.

Iecland lichen, deseription, preparation, and use of, 871

Indian corn. See Maize. 
Indian rubber-tree; deseription of, 240 241

Indigo, description, cultivation, preparation, and uses of, 188, 189 Ipecacuanlia, description, history, and use of, 62,63

Iris, common, description and uses of, 18

Jaek-fruit, description and uses of, 205, 206

Jalap, descrip tion of, whence obtained, and uses of, 43

Jasmine, oil of, how prepared, 12

Jesuit's bark. See Peruvian bark.

Jesuit's drops, from what made, 130

Juniper, berries, wood, bark, and gun, uses of, 256

K.

Kale, Dorsetshire, 176

----, Sea, description, eultivation, and uses of, 171

Kelp, preparation, value and uses of, 271

L.

Lachryma Christi wine, 67

Ladanum, or Labdanum, how eollected, and uses of, 166

Lamp-black, how made and uses of, 235

Larch, wood, bark, and sap, uses of, 236

Laudanum, how prepared and uses of, 156

Lavender, description and eulture of, 167

- flowers, oil, and spirit of, 168

— water, how prepared, 168

Laver, green or edible, deseription, preparation, and use of, 274

Leeks, deseription and uses of, 89

Lemon, description and uses of, 192

$\longrightarrow$, essential salt of, from what prepared, 193

Lettuce, culture and uses of, 198

Lichen, calcareous, deseription and uses of, 269

$\longrightarrow$, crab's eye, and tartareous, 269

- purple rock, and Dyer's, 270

- Iceland, 271

Lignum vitæ, wood, rcsin, bark, and flowers, uses of, 127

lime, a species of lemon, deseription and uses of, 194

Lime, or Linden-tree, flowers, wood, juiee, leaves, and seed, uses of, 153

Line-seeds, what they are, and uses of, 86

Linseed oil, how prepared, and use of, 86

Ling. See Heath.

Liquoriee, description, eultivation, and uses of, 186, 187

Lisbon wine, 65

Logwood, deseription of, how obtained, and uses of, 131, 182

Lords and Ladies. See Arum.

Lucern, description, cultivation, and uses of, 188 


\section{INDEX.}

\section{I.}

Macaroni, of what made, and uses of, 26

Mace, what it is, how prepared for use, and use of, 246

Maddcr, description, preparation, property, and uses of, 39

Madeira wine, 68

Mahogany, description of, and how obtained, 132

-

- when first introduced, and uses of, 134

Maize, description and culture of, 206

-

Malaga wine, 66

Malmsey Madeira, 66

Malt, how made, and used, 27

Mangel wurzel, description and uses of, 79

Mangoes, description and use of, 59

, imitations of, 59, 207

Manna, description of, how obtaincd, and uses of, 263

- seeds, what they are, and uses of, $\mathbf{S 6}$

Maple, common, description and uscs of, 110

-

Maslin, what it is, 28

Mastic, description of, mode of obtaining, and uses of, 948

- , wood and varnish, 249

Matweed, sea, uses of, 37

Medlar, description and uses of, 146

Melon, common or musk, description, culture, and uses of, 207

--, water, description and uses of, 209

Millct, description and use of, 260

Mint, common or spear, description and uses of, 168

-

Molasses, how made, 21

Morell, description and use of, 274

Moselle wine, 67

Mulberry-tree, fruit, juice, leaves, and bark, uses of, 214

cider, how made, 214

Mruscadel winc, 66

Mushroom, common, description of, how grown, and usc of, 976

--, description and uses of various kinds, 276, 277

Mustard, description and uses of, and how adulterated, 172

Myrrh, what it is, whence obtained, and uses of, 262

Myrtle, common, description and use of, 157

N.

Nankecn dye (Scot's), of what made, 157

Nectarinc, 140

Nettle, common, leaves, tops, stalks, roots, flowers, and seed, uses of, 213, 214 stings, description of, 214 
Nightshade, deadly, descriptinn, injurious eftects, and uses of, 53,54

Nutmeg tree, description of, 244

Nutmegs, how gathered and prepared for use, and uses of, 245

Nut-oil, from what prepared, 228

Nux vomica, description and uses of, 58

0 .

Oak tree, wood, bark, saw-dust, and acorns, uses of, $222-295$.

Oatmeal, uses of, 24

Oats, mode of cultivation and uses of, 24

Oil-cake, of what made, and uses of, 87,174

Olive trce, description and uses of, 11, 12

Oil, how prepared and uses of, 11

Olives, how prepared for use, and uses of, 11

Onion, Canadian or tree, description and uses of, 90

--, common, description and uses of, 91

_-, Portugal and Spanish, 91

Opium, how obtained, properties, and uses of, 154,155

Oping cultivated in England, 15.5

-.-., how adulterated, 154

Orange, flowers, juice, and peel, uscs of, 194, 195

, Seville or bittcr, 195

Orchall,-description, preparation, and use of, 270

Orders of plants, 4

Orenberg gum, of what made, 237

Orris root, description and uses of, 17

Osier, wood and bark, uses of, 243

Ottar of roses, from what made, and how adulterated, 150

Owler. See Alder.

Paddy. See Rice.

Paper made from vegetable productions of different kinds, 18, 28, 101, 185, 215, 243

Papyrus, description, preparation, and uses of, 18, 19

Parslcy, lcaves, roots, and seed, uses of, 82

Parsnips, how cultivated, and uses of, 79

Pawpaw, description and uses of, fruit, hark, leaves, and stem, 266

Peach, fruit, kernels, flowers, and leaves, uses of, 139

Pear, fruit, wood, and leaves, uses of, 146

Pearl barley, how made, and uses of, 23

Peas, cultivation and uses of, 185, 186

- everlasting, use of, 186

Pepper, black, how cultivated and prepared for use, 13

-, white, what it is, and low prepared, 13

- - uses of, and low adulterated, 14

- long, description and uses of, 14, 1.5

— Guinea, description and uses of, 57 
Perry, of what made, 147

Peruvian bark, whence obtained, how prepared for use, and uses of, 45

Petals, 2

Pimento, description and cultivation of, 138,139

, how collected and prepared for use, and uses of, 138

Pine, Weymouth, description and uses of, 235

Pines, fruit, description, history, cultivation, and uses of, 87

Pistil, 2

Pitch, how prepared, and uses of, 234, 235

Plane tree, description and uses of, 230

Plantain tree, description and uses of, 259

Plum, common, description and uses of, 143

- , French, 44

- bullace, frnit, flowers, and wood, uses of, 144

Pomegranate, description and uses of, 141, 142

Pontac wine, 66

Pontefract cakes, how made, and uses of, 187

Poplar, great white, description and uses of, 253,254

$\longrightarrow$, trembling, 25-1.

- black, 254

- Lombardy or Italian, 255

Poppy, white, description, cultivation, and uses of, 154, 155

Port-wine, 65

Potatoe, roots, stallis, and apples, uses of, $54-56$

Pounce, from what preparcd, 257

Prunes, 144.

Pulf-ball, description and use of, 275

Pumpkin or pompion, description and uses of, 208

Q.

Quassia, description, listory, and uses of, 134, 135

Quince, description and uses of, 149, 150

Quincy berries. See Currants, black.

R.

Rack or arrack, from what prepared, 218

Raisins, how prepared, and uses of, 70

Rape, culture and uses of, 173

Rasplecry, uses of, 152

brandy, how made, 152

Rattan, description and uses of, 100

Receptacle, 3

Reed, common, uses of, 36

Resin, common and yellow, how prepared, and uses of, 255

Rhenish wine, 67

Rhubarb, officinal or Turkey, how obtained, and uses of, 123 , how cultivated in England, 124 
Rlubarb, common, description and uses of, 12.5

Rice, description, culture, and preparation of, 104-106

- uscs of, 105

Rush, common, description, preparation, and uses of, $10 \%$

Ront of Scarcity. See Mangel Wurzel.

Rose, colmmon garden, uses of, 150

-

_. red officinal, uses of, 152

Roses, ottar or oil of, how made, 150

- -, conserve and syrup of, 150

- $\longrightarrow$, honey of, 152

Rose wood, description and uses of, 110

Rosin. See Resin.

Rotang. See Dragon's Blood-tree.

Rota wine, 66

Rum, how prepared, 23

Rye, uses of, 28

$\mathrm{S}$.

Saffron, description, culture, preparation, and uses of, 16, 17

Sago, description, preparation, and uses of, 255

Saint-foin, description, cultivation, and uses of, 187

Salad oil. See Olive oil.

Salep, what it is, how prepared, and uses of, 202

Sallow, common, 244

Saloop, what it is, 121

Samphire, rock, how obtaiued and uscs of, 76

- marsh, 76

Sandal wood, description and use of, 40

Sap-green, of what made, 57

Sassafras, description and uses of, 121

Saunders, yellow, description and use of, 40

Saxon blue and green, what made from, 189

Scammony, what, how obtainer, and uses of, 44

Sea Kale, description, mode of culture, and uses of, 171

Seed vessel, 2

Semolina, of what made, and use of, 26

Senna, description and uses of, 125

Shaddock, description and uses of, 195

Shalot, description and uses of, 90

Sherry wine, 66

Shoe-maker's wax, of what made, 235

Sloe, fruit, flowers, bark, leaves, and wood, uses of, 145.

Smouch, wliat it is, 164

Snuff, how made, 52

Soda. See Barilla.

Sour-crout, of what made, 176

Sour-goard, description and uses of, 178

VOL. II.

o. 
Sowins, 24

Soy, description, preparation, and usc of, 183

Spanish black, of what made, 226

Spart. See Broom.

Sprucc, essence of, from what prcpared, and uses of, 236

Spunk or Touclıwood, description and use of, yit

Squinancy bcries. Sce Currants, black.
Stamens, 2

Starch, preparcd from differcnt vcgetable productious, $2.5,55.5,107$

Stone blue, wliat made from, 189

Storax, description, mode of obtaining, and use of, 131

Stramoniun, description, properties, and uses of, 50
Strawberries, uses of, 1.53

Sugar, how manufactured, 19, 20

- , muscovado or raw, and claycd, 21

- , loaf or lump, 22

--, candy, how made, 22

-- , uses of, 22

--, canc, description and cultivation of, 19

Sunflowers, hode of obtaining sugar from, 20

Sycamore

Sycamore trec, description and uses of, 111, 112

T.

Tallow tree, description and uses of, 240

Tamarinds, description, preparation, and use of, 177

Tapioca, description, preparation, and use of, 239

Tar, how prepared, and uses of, 234

--- water, 234

Tarragon, description and use of, 200

, vinegar, how prepared, 200

Tea, tree, description and culture of, 159, 160

--, how collected, dried, and packed, 159

--, how used by the Chinese and Japanese, 160

-, difference between black and grecn, 160

--, grcen, how prepared, 162

--, bohea, why so callcd, and how preparcd, 160

--, congo, souchong, and Pekoe, 161, 169

--, Singlo, hyson, and gunpowder, 162, 163

--, history of tlic usc of in Europe, 163

-., trade and uses of, 163

--, how adulterated, 164

Teak tree, description and uses of, 59

Teasel, description and uscs of, 38

Tenerifie wine, 68 
T'ent wine, 67

'Iubacco, description, culture, preparation, and uscs' of, $50^{\circ}$

Toddy, from what prepared, 218

'lokay wine, how made, 67

Tolu, balsan, liow obtained, and uses of, 128

Touchwood, description and use of, 277

Treacle, low inade, 21

Truffles, description of, how procured, and use of, 275

Tulip tree, description and uses of, 167

'Turmeric, description and use of, 9

'Turnips, cultivation and uses of, 174,175

I'urpentine, common, how obtained, and uses of, 233

- , oil of, 233

-, Venice, of what preparcd, and use, of, 237

$\mathrm{V}$.

Tarnish, black, of Clina, what, 123

Vegetables, 1

Verjuice, from what prepared, and uses, 69,147

Vermicelli, low made, and use of, 27

Vernix, 256

Vetches, description, culture, and uses of, 185

Vin de Grave wine, 66

Vine, twigs, leaves, tendrils, and wood, uses of, 69

Vines and vineyards, account of, 63,64

Vonic nut. See Nux vomica.

W.

Walnut-tree, wood and fruit, uses of, 227

Water-flag, yellow, description and uses of, 18

Weld, description and uses of, 136

Wheat, cultivation and uses of, 24

-

$\longrightarrow$, bran and straw, uses of, 26

Will macaroni and semolina prepared from, 26

Willow. See Osier.

Wine, how nuade, 64

-_. Portuguese, 65

--, French and Spanish, 65

--, Italian and German, 67

-_-, Madeira and Teneriffe, 68

Writhye, 69

Withy. See Osicr.

Woad, description, culturc, preparation, and use of, 171

Wortleberries, use of, 113 
Yans, description and uses of, 252

Y-, cultivated in Scotland, 253

Yeast, how to prescrve for use, 228

Yew tree, description, uses, and poisonous qualities of, 257 .

END OF VOL. II. 


\section{3}




